\title{
Translating pain : assessing expressive pain behaviour of children with severe to profound intellectual disabilities
}

Citation for published version (APA):

van Dongen, K. A. J. (2004). Translating pain : assessing expressive pain behaviour of children with severe to profound intellectual disabilities. [Doctoral Thesis, Maastricht University]. Universiteit Maastricht. https://doi.org/10.26481/dis.20041110kd

Document status and date:

Published: 01/01/2004

DOI:

10.26481/dis.20041110kd

Document Version:

Publisher's PDF, also known as Version of record

Please check the document version of this publication:

- A submitted manuscript is the version of the article upon submission and before peer-review. There can be important differences between the submitted version and the official published version of record.

People interested in the research are advised to contact the author for the final version of the publication, or visit the DOI to the publisher's website.

- The final author version and the galley proof are versions of the publication after peer review.

- The final published version features the final layout of the paper including the volume, issue and page numbers.

Link to publication

\footnotetext{
General rights rights.

- You may freely distribute the URL identifying the publication in the public portal. please follow below link for the End User Agreement:

www.umlib.nl/taverne-license

Take down policy

If you believe that this document breaches copyright please contact us at:

repository@maastrichtuniversity.nl

providing details and we will investigate your claim.
}

Copyright and moral rights for the publications made accessible in the public portal are retained by the authors and/or other copyright owners and it is a condition of accessing publications that users recognise and abide by the legal requirements associated with these

- Users may download and print one copy of any publication from the public portal for the purpose of private study or research.

- You may not further distribute the material or use it for any profit-making activity or commercial gain

If the publication is distributed under the terms of Article 25fa of the Dutch Copyright Act, indicated by the "Taverne" license above, 


\section{TRANSLATING PAIN}

Assessing Expressive Pain Behaviour of

Children with Severe to Profound Intellectual Disabilities 
ISBN 90-9018784-7

(C) Katinka van Hastenberg - van Dongen, 2004

Vormgeving: Paul van Hastenberg

Druk: Febodruk BV, Enschede

Illustratie omslag: een kunstenares van Dagcentrum 'De Werf' in Boxtel 


\section{TRANSLATING PAIN}

Assessing Expressive Pain Behaviour of

Children with Severe to Profound Intellectual Disabilities

PROEFSCHRIFT

ter verkrijging van de graad van doctor

aan de Universiteit Maastricht,

op gezag van de Rector Magnificus

Prof. Mr. G.P.M.F. Mols,

volgens het besluit van het College van Decanen,

in het openbaar te verdedigen

op woensdag 10 november 2004 om 14.00 uur

door

Katinka Annette Jacqueline van Hastenberg - van Dongen 


\section{Promotoren:}

Prof. dr. H. Huijer Abu-Saad

Prof. dr. M.P.F. Berger

\section{Copromotor:}

Dr. J.P.H. Hamers

Beoordelingscommissie:

Prof. dr. L.M.G. Curfs (voorzitter)

Prof. dr. Th. van Achterberg (Katholieke Universiteit Nijmegen)

Prof. dr. M. van Kleef

Prof. dr. J. Passchier (Erasmus Universiteit, Rotterdam)

Prof. mr. F.C.B. van Wijmen

The studies presented in this dissertation have been supported by Grant number 940-031-044 of the Council for Medical and Health Research of the Netherlands (NWO-MW).

Printing of this dissertation was financially supported by the Maurits van Kattendijke Stichting and Fontys Hogeschool Verpleegkunde. 


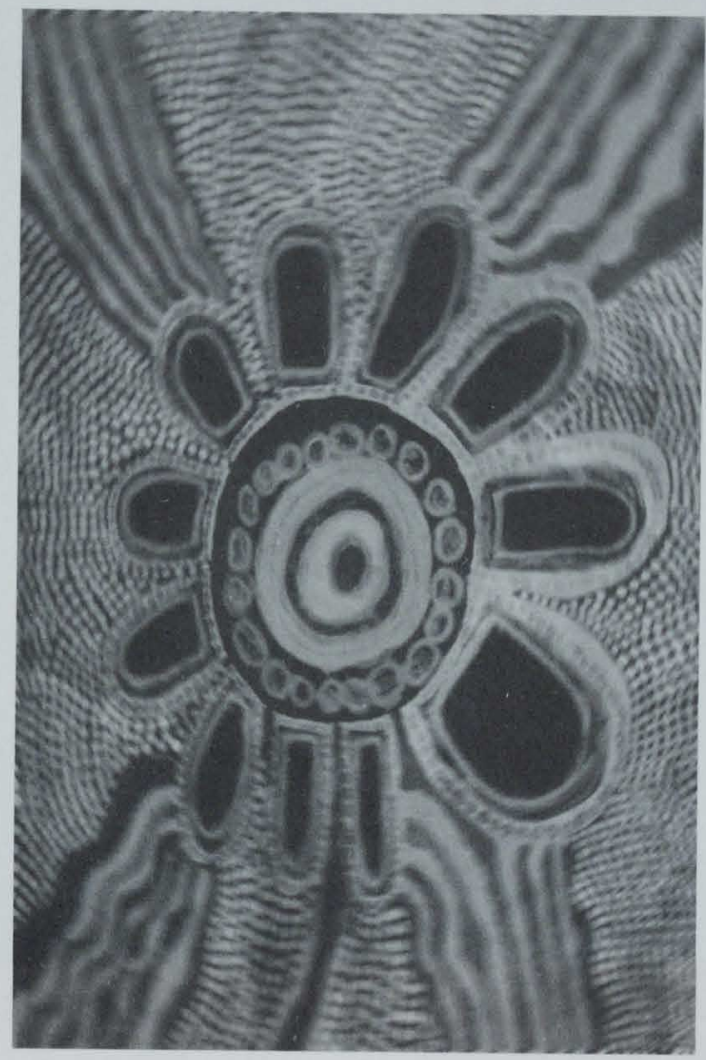

The heart is a bloom, shoots up through the stony ground (U2, Beautiful day) 



\section{Table of Contents}

CHAPTER 1

General introduction

CHAPTER 2

Non-verbal expressions of pain in children and young adults with severe to profound intellectual and communicative disabilities: an overview based on literature, caregivers' reports and observations

CHAPTER 3

Pain assessment in intellectually disabled people: non-verbal indicators used by nurses

CHAPTER 4

Behavioural repertoires of children with severe to profound intellectual disabilities in pain: a comparison based on parents' report

CHAPTER 5

Item selection and psychometric evaluation of KIDPAINS: an observational pain assessment instrument for children with profound intellectual and communicative disabilities

CHAPTER 6

Testing psychometric properties of KIDPAINS in children with profound multiple disabilities

CHAPTER 7

General discussion

APPENDICES

REFERENCES

SUMMARY

SAMENVATTING

DANKWOORD 



\section{Chapter 1}

\section{General introduction}

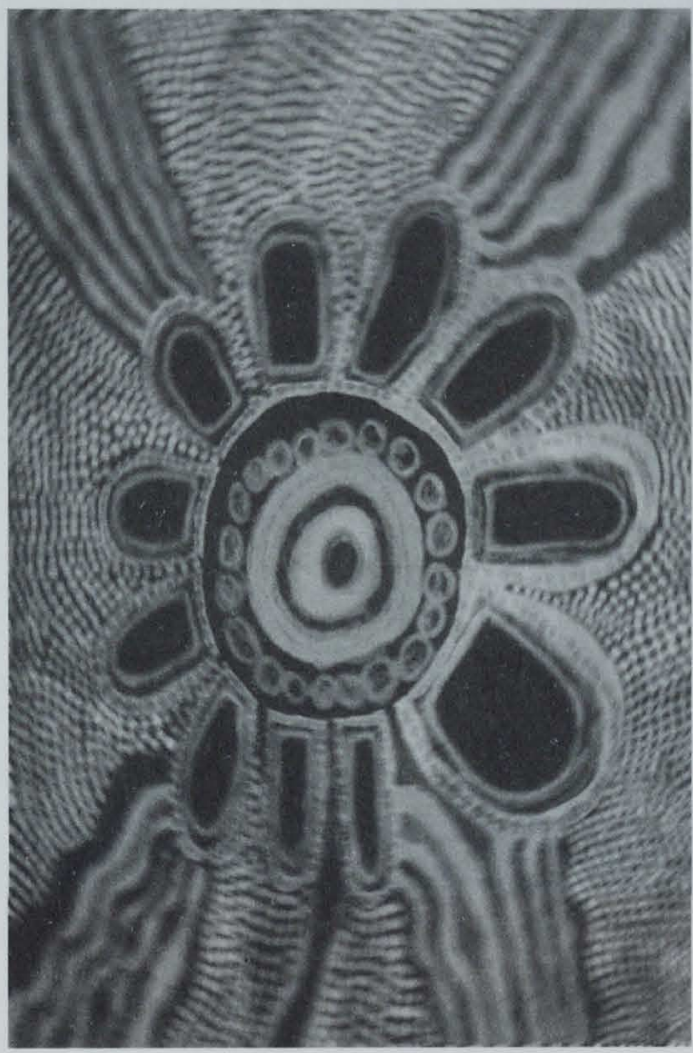

"I think you bave to know my son. It is hard to see when he is in pain, until you know where you have to look at. At that stage it is easier to translate his pain signals. When he is in the hospital nurses find it extremely difficult to observe when be is in pain. They don't interpret bis behaviour as pain behaviour."

(Interview with a mother of a child with profound multiple disabilities) 



\subsection{Introduction}

Pain is a topic everybody can relate to, and understanding the concept of pain has been the focus of much scientific research over decades. One key issue in this context is how to measure pain. Measurement is the basis of scientific research, and pain measurement enables clinicians to provide adequate treatment. As such, increased insights into the measurement of pain have helped improve the management of pain. Many challenging questions have been addressed along the way. For one thing, it was recognised that children as small as neonates do experience pain, and valid and reliable pain measures are now available for this paediatric population. However, many other questions still need to be answered. At the start of the research project discussed in the present dissertation, a new question had only just arisen, as it was finally noticed that pain in non-verbal children with severe to profound intellectual disabilities was still an underdeveloped area of investigation. In order to improve our understanding of pain in this paediatric population, insight had to be gained into the way children with severe or profound intellectual disabilities express pain. The findings were expected to allow the development of scales to measure and assess pain. The present dissertation tries to piece together some answers to these puzzling questions.

\subsection{Intellectual disability}

According to the International Classification of Functioning, Disability and Health (ICF) proposed by the World Health Organization, mental retardation is defined as impairment in intellectual functioning and as such related to one of the mental functions of the body (WHO, 2001). According to the ICF, the term disability serves as an umbrella term encompassing impairments, activity limitations and participation restrictions. One domain the ICF distinguishes as an area in which activity limitations or participations restrictions can occur, is that of communication. The current fourth edition of the Diagnostic and Statistical Manual of Mental Disorders of the American Psychiatric Association (APA, 1994) distinguishes four levels of mental retardation: mild (IQ 50-55 to 70), moderate (IQ 35-40 to 50-55), severe (IQ 20-25 to 35-40) and profound (IQ below 20 or 25). At the start of the present research project, our focus was on children with severe as well as those children with profound intellectual disabilities. Compared to a normally developing child, the developmental age of children with severe intellectual disability would be approximately 3 to 6 years, whereas children with profound intellectual disability display a developmental age up to 3 years (WHO, 1992). For the purposes of the Convention on the Right of the Child (UNHCHR, 1989), a child means "every buman being below the age of eigbteen years unless under the law applicable to the child, majority is attained earlier". In everyday practice, however, the distinction between children with severe or profound intellectual disability is not always easy to make, and the comparison with normally developing children is open to doubt. 
According to the new classification system (Luckasson, 2002) of the American Association on Mental Retardation (AAMR), children with severe or profound intellectual disability are those children who require extensive support, whereas children with profound intellectual disability are those in need of pervasive levels of support. Intellectual disability is currently defined by the AAMR as "a disability characterized by significant limitations in botb intellectual functioning and in adaptive bebaviour as expressed in conceptual, social and practical adaptive skills. This disability originates before age 18". Adaptive behaviour according to the AAMR is the collection of conceptual, social and practical skills people have learned so they can function in their everyday lives. Examples of conceptual skills comprise receptive and expressive language, while examples of social skills are the ability to follow rules and interpersonal skills, and practical skills comprise aspects like personal activities of daily living (AAMR, 2002a).

Using the AAMR definition means that aspects like the individual's communicative, sensory, motor and behavioural factors have to be taken into account. Because people with intellectual disabilities may vary in all these developmental areas and skills, they form a heterogeneous population, especially since individuals can also vary in secondary impairments such as cerebral palsy, autistiform disorders, gastric disorders, hearing impairments, visual impairments, motor impairments and epilepsy, which can co-exist with the intellectual disability. The more severe the intellectual disability, the more severe these secondary impairments usually are. In addition, health problems can lead to secondary and tertiary complications such as joint deformations and pressure sores. The health status of individuals with intellectual disabilities may thus be poor, and since all these conditions have to be treated and dealt with, people with intellectual disabilities are at greater risk of pain and suffering or even death than the general population. This is especially the case for those children who suffer from profound intellectual disabilities as well as possess profound neuromotor dysfunctions and presumably mostly sensory impairments, a group of children that is also referred to as children with profound multiple disabilities (Vlaskamp \& Nakken, 1999). The total population of the Netherlands includes approximately 111.750 individuals who are intellectually disabled, of whom $22 \%$ are younger than 22 years (Schrojenstein Lantman van - Valk de et al., 2002). Of all these people with intellectual disability, over 53.000 receive some sort of professional support, $26.6 \%$ of whom are severely intellectually disabled and $15.1 \%$ are profoundly intellectually disabled (Schrojenstein Lantman van - Valk de et al., 2002).

\subsection{Communication in children with severe to profound intellectual disabilities}

The development of a procedure that would allow the communicative meaning of behaviour by intellectually disabled children to be decoded is the key to professional caregiving (Cleland, 1979). Through communication, human beings 
are capable of interaction with each other and of sharing ideas, thoughts, needs and feelings. Communication takes place when one person (the receiver) gives meaning to the behaviour of another person (the sender), who can send a message intentionally or unintentionally (Maat van der, 1992). Granlund (1996) defines communication as "the mutual transfer of unintentional and/ or intentional messages between at least two persons". In addition, according to Granlund (1996), social and physical aspects of the context in which communication takes place are important. Willems (1996) defines communication as "every behavioural expression that leads to a change in the bebaviour of others: communication is the behaviour of one person that is perceived by another person and changes the behaviour, emotions and cognitions of that other person". The direction of communication can be either receptive (understanding the communication of others) or expressive (intentional or unintentional sending of a message).

Van der Maat (1992) proposed to distinguish three levels of pre-linguistic communication in the normally developing child. The first level comprises preintentional communication. In this phase, the child makes sounds without an intentional communicative meaning. This could be indicated as affective communication, and the communication in this phase can be regarded as strongly idiosyncratic. In the pre-intentional communication phase, the first communicative behaviours are reflexive, and important behaviours in this phase include reflexive reactions, watching, crying, sounds, levels of activity, temperature, smell and body posture. Every change in behaviour compared to a previous condition can have a signal function for the caregiver. Later on, communication becomes more reactive. Less reflexive and more intentional behaviours occur, such as body movements, turning the body away, vocalisations, smiling, and searching for eye contact. In the final stages of the pre-intentional phase, communication becomes pro-active. The child has more motor abilities, becomes fascinated by objects and starts to reach for objects, with the intention of putting them in its mouth. Egocentric babbling starts in this phase. According to Willems (1996), children normally remain in this phase until they are 9 to 12 months of age. Vlaskamp \& Oxener (2002) state that most people with profound multiple disabilities are in the pre-intentional phase of communication.

The second level of pre-linguistic communication comprises proto-symbolic communication (Maat van der, 1992). In this phase, motor and vocal behaviours of the child are more conscious and are used to influence the listener. These intentional communicative signals, however, are still strongly context-dependent. Expressive behaviours used in this phase are vocalisations, pulling the adult towards something, gesturing, using the total body. In this phase, only people who know the child well can interpret these gestures, making them context-dependent. According to Willems (1996), children remain in this phase from approximately 12 months until they start to speak their first words. 
The final level is that of symbolic communication (Maat van der, 1992). Communicative messages by the child are increasingly understood without a context and the child starts using signs. By the end of this phase, language is developing. Willems (1996) states that individuals with severe or profound intellectual disability generally never achieve symbolic communication by means of spoken language.

The limited ability to communicate is one of the most pervasive deficiencies demonstrated by individuals with intellectual disabilities (Lloyd, 1989). According to Brodin (1991), up to $70 \%$ of the total population of persons with intellectual disabilities and $100 \%$ of persons with profound intellectual disabilities experience interactive communication problems, while people with severe intellectual disabilities have trouble using spoken language. Those who cannot use spoken language have to use other means of communication to express themselves and to be able to understand each other. As such, e.g. it was found that people with profound multiple disabilities may display movements that can vary in frequency, intensity and direction, as well as sounds that can vary in intonation, pace and pitch. Furthermore, people with profound multiple disabilities display physiological reactions such as changes in muscle tone and breathing, as well as facial expressions and changes in alertness (Vlaskamp \& Oxener, 2002). Velthausz (1987) found that individuals with profound intellectual disability communicated by common behaviour (like body movements) on the one hand, but also by idiosyncratic behaviours that were typical of an individual person. Velthausz also found that facial expressions and glance were hardly used for interactions with others. Furthermore, interactions were short, and before people with profound intellectual disability can interact with others, they often screen themselves from other stimuli in their surroundings (e.g. by putting an arm before their face) in order to concentrate on the interaction. The 106 detailed, behavioural items used in the study by Velthausz (1987) were divided into 8 categories: facial expressions, positions of the head, head movements, glances, sounds, hand or arm movements, foot or leg movements, positions of the body and locomotion.

It is estimated that of all children with severe intellectual disabilities, $75 \%$ experience profound limitations in functional communicative skills (Willems, 1996). Furthermore, it must be remembered that such communicative abilities are more limited than would be expected on the basis of cognitive functioning only. Kiernan Reid \& Jones (1982) found that approximately 33\% of the pupils attending schools for children with severe intellectual disabilities were unable to use more than three words. In addition Yoder \& Feagans (in Willems, 1996) found that severely intellectually disabled children display fewer behavioural expressions that can be objectively coded as being communicative. Mothers of these children, however, did have a greater tendency to regard the behaviour of their child as being communicative, attributing meaning to subtle cues. People with profound intellectual disability are hampered by the additional impairments that coexist with 
the intellectual disability, both in expressive behaviour and in responsive behaviour (Campbell \& Wilcox, 1989). The expressive abilities of individuals with profound intellectual disability are influenced especially by motor impairments, while in responding to others, they are hampered by visual and auditory impairments. A difference in motor ability that seems insignificant at first can have rather big consequences. In everyday practice, it makes a major difference whether or not someone can point or gesture with his or her hand or not. Vlaskamp (1999) states that individual children with profound multiple disabilities often have a limited repertoire of signals available when communicating. Hence, one signal can communicate different messages. At the same time, children with profound multiple disabilities differ greatly from one another, so the range of different expressions within a group can be wide. A study on the way people with profound intellectual disability communicate towards others (Velthausz, 1987) found that it is not possible to interpret the meaning of their behaviour simply by observing it. Meaningful interpretation of behaviour is only possible by using the judgement of others. Another study by Velthausz (1987) found that interpretation by observers of the behaviour of individuals with profound intellectual disability was based on posture and movement of the upper limbs, as well as eye direction and facial expression. Overall, observers gave the same interpretation to only $51 \%$ of the observed behaviour.

\subsection{Pain assessment}

As Johnston (1998) states, the purpose of measuring pain is to assign a value to it for a particular child at a particular time. The purpose of assessing pain is to provide as complete a picture of the pain as possible, which will also include quantification. Stevens (1998) notes that "no one indicator is reliable, valid, sensitive, specific, practical or feasible for identifying the existence, intensity, location, and impact of the pain in any given population or situation". According to Stevens (1998), indicators from multiple dimensions that provide as much information as possible about individual pain responses and interactions should be included in any approach to pain assessment. Pain assessment encompasses not only the intensity of the pain, but also the quality and nature of the pain and the sensory, affective and evaluative response of the person experiencing it (McGrath \& Unruh, 1987). Often, however, the terms measurement and assessment are used simultaneously or even interchangeably.

Pain measurement methods roughly distinguish three types of measure: physiological, bebavioural and cognitive or self-report measures (McGrath, 1998). Pbysiological measures of pain include a variety of techniques that monitor the body's response to noxious stimuli, such as heart rate changes or increased respiration. Behavioural measures of pain include several observational procedures in which an independent observer records the type of behaviours that children exhibit when they are in pain, as well 
as the frequency of their occurrence (McGrath, 1990). Observational measures tend to focus upon non-verbal, overtly observable signs of pain that are often in the involuntary, non-deliberate domain (Hadjistavtopoulos \& Craig, 2002). Behaviours commonly associated with pain include facial expression, posture and vocalisation or verbalisation (Beyer \& Well, 1989). Finally, cognitive measures include projective methods, in which children's attitudes or perceptions of pain are inferred from their selection of colours, their drawings and their interpretations of cartoons. They also included several self-report methods, in which children directly describe their attitudes and perceptions of pain (McGrath, 1990) or the intensity of their pain by using instruments like Visual Analogue Scales (VAS) or facial expression scales such as the Faces Pain Scale (FPS) (Bieri et al., 1990).

According to Johnston (1998), it is important when measuring pain to chose a definition of pain that matches the operational definition, which essentially indicates how the concept is going to be measured. Pain is defined by the International Association for the Study of Pain (IASP) as "an unpleasant sensory and emotional experience associated with actual or potential tissue damage, or described in terms of such damage" (Mersky \& Bogduk, 1994). However, this currently most cited definition of pain still puts great emphasis on verbal expression and thus relies on the ability to use self-report measures. Therefore, a new definition of pain seems to be needed (Anand \& Craig, 1996), especially since over the years, a shift has occurred in the scientific investigation of pain from those individuals who are capable of using language in their expression of pain to those who are not able to do so, like infants and young children. Currently an additional note to the IASP definition is presented on its website describing that "the inability to communicate verbally does not negate the possibility that an individual is experiencing pain and is in need of appropriate pain-relieving treatment" (Merskey, 2003). The definition itself has not changed. Today, self-reports of pain are still regarded as the gold standard, since the suffering individual gives a direct indication of his or her pain. However, in view of the cognitive nature of self-reports, individuals who have a developmental age of approximately four years or younger are not able to provide this type of rating (Schechter, 1993). Young children have a relatively limited cognitive ability to understand what is being asked of them in pain measurement, and they have difficulty in articulating descriptions of their pain. Anand \& Craig (1996) state that the behavioural alterations caused by pain are the infantile forms of self-report and should therefore not be discounted as surrogate measures. Observational measures can be used and have clinical utility as indices of pain when self-reports are not available (Hadjistavropolous \& Craig, 2002). Until language becomes fully available, a process that may take the first four to seven years of life, non-verbal approaches therefore remain the primary mode of pain assessment according to Hadjistavropoulos \& Craig (2002). 
Loeser (1980) states that we can only know the subjective state of suffering through observation of pain behaviour. Such observation is thus a necessity in all people who are unable to communicate about pain in spoken language. Infants and young children take years to acquire the neurophysiological maturity and cognitive capabilities that enable them to encode pain messages in language. Therefore, numerous observational measures have been developed in the past decades to measure pain in these children. Table 1 (page 18-19) presents an overview of 138 detailed, behavioural items from a selection of observational paediatric pain measures, as identified at the onset of this research project.

As Table 1 shows, at that stage many behavioural items of pain were identified for non-verbal children. When comparing the behavioural items, we made a distinction between seven dimensions of pain behaviour: Facial, Motor, Injured Body Part, Social-Emotional, Vocal, Physiological and Activities of Daily Living. This distinction is based on a facet design as recommended by Shye (1978). A facet design is a scheme covering all the relevant dimensions of a construct that is going to be measured. The composition of the facet design used in this dissertation is presented in Table 2 (page 20).

The facet design created for this dissertation was based on common dimensions used in the literature on observational paediatric pain scales. In addition, we used scales for the assessment of communicative behaviour of individuals with profound intellectual disability. As Table 2 shows all selected scales comprise dimensions relating to Facial and Motor behaviour. Dimensions relating to SocialEmotional behaviour and Activities of Daily Living are only used in a limited number of pain assessment scales.

Although, as Table 1 shows, many behavioural items of pain have been identified for non-verbal children at the onset of the research project, we should not assume that because an instrument or procedure has been demonstrated to have good psychometric properties in one population, it can be applied to another population without a demonstration of the instrument's psychometric properties in the new population (Turk \& Melzack, 2001). In addition, it is questionable whether the behavioural responses of children with severe intellectual disabilities are comparable to those of normally developed children with the same developmental age. Many unique and complex features in this specific paediatric population distinguish intellectually disabled children from children without cognitive delay. It is especially because of the heterogeneity and diversity in the various developmental areas, the existence of secondary impairments and the idiosyncratic communicative behaviours that the population of children with severe to profound intellectual and communicative disabilities is not automatically comparable with normally developing children. 
Table 1

Items derived from the literature

\begin{tabular}{lll}
\hline Facial & & \\
\hline Facial expression & B M N & $3^{2}$ \\
Contorted face, cringing, flinching & E F G J O & 5 \\
Grimacing & D F G H I KOM & 8 \\
Facial tension, tight facial muscles & G H M & 3 \\
Change in eyes & O & 1 \\
Eyes tightly shut, eye squeeze & A E I K L M O & 7 \\
Eyes wide open & I O & 2 \\
Little eye movement, no blinking & E & 1 \\
Serious / sad & FO & 2 \\
Fear / widened eyes & F G & 2 \\
Open lips & A K & 2 \\
Stretch mouth vertically, 'O' mouth & A F K & 3 \\
Stretch mouth horizontally & A O & 2 \\
Lips tightly held & E & 1 \\
Turning down of mouth / not smiling & F O & 2 \\
Lips pouting, jutting lower lip & EO & 2 \\
Lip pursing & A O & 2 \\
Lips quivering & O & 1 \\
Tongue protrusion & A O & 2 \\
Taut tongue & A & 1 \\
Chin quivering & A E H & 3 \\
Clenched jaw, clenches teeth & F H O & 3 \\
Brow bulge (furrowed), frowning & A F E K L M OH & 8 \\
Naso-labial furrow (deepened) & A K L M & 4 \\
Nostrils flaring & E & 1 \\
& & \\
\hline Motor & &
\end{tabular}

Motor

Spontaneous motor activity, incessant
gros motor movement

Complex agitation, excitable movements,

jittery, vigorous movement

B DEGM

Mild kicking and wiggling

$\mathrm{F}$

Flailing and thrashing, wild hitting

F 1

movements

BEFHJM

Wriggling body movements, writhing, log $C F$

rolling

Spontaneous excitability

$B E$

Jerking / starting, jerky movements

$C F$

Increased involuntary movements

$\mathrm{N}$

Repetitive movements

Decreased movement, limited movement CEFMO

Arms / legs extended

EH

Arms / legs rapid extension / flexion

$\mathrm{H}$

Arms / legs (tightly) flexed

$\mathrm{EH} 2$ Not able to be satisfied or pacified

Fingers and toes in rapid extension /

c

Flexion of fingers / toes, flaring toes,

grasping fingers

\section{$B C E G J$}

CEJ

Spreading of fingers and toes

Twitching of fingers and toes

Wringing hands, making fists

$C$

EF J

$C M$

Hand / foot movements; rotation of wrist,

flexion, extension

Feet pointed downward and held stifly $E$

Feet turned upwards at sharp angle to leg $E$

Leg movements

Knees drawn up
CM

E

\section{Motor (continued)}

Head movements

Neck flexion / extension, chin down onto

chest

Head turn

Torso movements

Evaluation of muscle tone

Strong hypertonicity

Spastic

Tremors in hands / limbs

Floppy

Rigid / tense, rigidity of the limbs and

body

Frequent position change

Body in bowed position, arching

$\begin{array}{ll}\text { C } & 1 \\ \text { CE } & 2 \\ \text { C } & 1 \\ \text { CJM } & 3 \\ \text { BEGMN } & 5 \\ \text { DEG JM } & 5 \\ \text { NO } & 2 \\ \text { F } & 1 \\ \text { MO } & 2\end{array}$

\section{Injured Body Part}

Restricted movement, splinting $\quad$ CF 2

Position body part for comfort, favour $\mathrm{FNO}$

Withdrawing affected bodypart, flinching D J O 4

Protecting / guarding painful body part EN OP 4

Grabbing, holding painful body part FOP 3

Gesturing to painful body part $\quad O \quad 1$

Scratching / digging painful part $\quad F \quad 1$

Hunching body part

Indifference, resignation

$F$

N

Social-Emotional

State of arousal (sleeping / awake versus $\mathrm{H}$ fussy)

Interaction with surrounding, sociability

(eye contact), failing to pay attention

Attempting to withdraw, closing in on themselves

Interest in surroundings

Not do the things (s)he normally does

Decreased play

Less energy, no activity

Self-injuring

Self-biting

Self-pinching

Aggression

Fussy, jittery

Agitation, fidgety, restless, jumping

around

Not co-operating

Irritability, cranky

Consolability

Inconsolable, no consolability

BEFNO $\quad 5$

Seeking comfort or physical closeness

E O

2

$P$

FP

$O P$

N

$F$

$F$

FHM

EGHMO 5

NO 2

O

FIJO

BFKM

4

Panicky

Anxious

Whining, complaining

Difficult to distract

Acting more worried

Calm autistic manifestations

Self-consolation

Resistance, resisting movement and

handling
$O P$

G

G

0

P 1

$\mathrm{N} \quad 1$

F 1

CDFJM 5 
Table 1 continued

Items derived from the literature

\begin{tabular}{|c|c|c|c|c|c|}
\hline \multicolumn{3}{|l|}{ Vocal } & \multicolumn{3}{|l|}{ Physiological (continued) } \\
\hline \multirow{2}{*}{$\begin{array}{l}\text { Crying } \\
\text { Quality of cry (piercing, shrill, pitiable, } \\
\text { siren like cry, high pitched) }\end{array}$} & \multirow{2}{*}{$\begin{array}{l}\text { FNOK } \\
\text { BEJKMO }\end{array}$} & \multirow{2}{*}{$\begin{array}{l}4 \\
6\end{array}$} & Breathing patterns irregular (apnea / & HJMO & \multirow[t]{2}{*}{4} \\
\hline & & & $\begin{array}{l}\text { tachypnea) } \\
\text { Increased respiration rate }\end{array}$ & HIJM & \\
\hline Crying intensely, vigorously & $\mathrm{HJM}$ & 3 & Respiratory response & G & 1 \\
\hline Crying quantity, crying more easily & EIJ MP & 5 & Gasps, sharp intake of breath & EO & 2 \\
\hline Spontaneous crying, suddenly & JNE & 3 & Breath holding, indrawing & $\mathrm{EHO}$ & 3 \\
\hline Screaming, yelling & $\mathrm{BHJMO}$ & 5 & Decreased TCP / $\mathrm{O}_{2}$ SAT $10 \%$ TC; $5 \%$ & & \\
\hline Moans / groans, whimpering, grunting & FHIKMNOP & 8 & SAT & 1 & 1 \\
\hline Paintalk & $\mathrm{F}$ & 1 & Pallor / cyanosis & I 0 & 2 \\
\hline Specific sound or vocalisation for pain & 0 & 1 & Looking flushed & $P$ & 1 \\
\hline Quiet & OP & 2 & Grey pallor & E & 1 \\
\hline Chewing & 0 & 1 & Shivering & 0 & 1 \\
\hline Grinding teeth & 0 & 1 & & & \\
\hline Paradoxial laughter & NO & 2 & Activities of Daily Living & & \\
\hline \multirow[t]{2}{*}{ Sucking disorganised } & B & 1 & Refusing to eat & $\mathrm{P}$ & 1 \\
\hline & & & Altered appetite & FOP & 3 \\
\hline \multicolumn{3}{|l|}{ Physiological } & Increase in sleep, drowsy, naps & Go & 2 \\
\hline Tears & 0 & 1 & Sleeping (pattern, amount) & EFGKNO & 6 \\
\hline Diaphoresis, perspiring & Io & 2 & Decrease in sleep, sleepless, constantly & KO & 2 \\
\hline Gagging & $\mathrm{H}$ & 1 & awake & no & 2 \\
\hline Requires $\mathrm{O}_{2}$ for Sat $>95$ (oxygenation) & $K L M$ & 3 & Sleeping during preceding hour & BM & 2 \\
\hline \multirow{2}{*}{$\begin{array}{l}\text { Blood pressure (increase systolic), } \\
\text { increased MAP/ DBP }\end{array}$} & \multirow{2}{*}{ GIJKM } & \multirow{2}{*}{5} & Difficulty falling asleep & $\mathrm{N}$ & 1 \\
\hline & & & Nocturnal awakenings & N & 1 \\
\hline Heart rate & G J K L M & 5 & Take medication when (s)he normally & $\mathrm{P}$ & \\
\hline Tachycardia & I & 1 & refuses & P & 1 \\
\hline \multirow{2}{*}{\multicolumn{6}{|c|}{$\begin{array}{l}\text { (1) Scales literature } \\
\text { Unidimensional scales for assessing pain in young children (Bours et al., 1996) }\end{array}$}} \\
\hline & & & & & \\
\hline \multicolumn{6}{|c|}{$\begin{array}{l}\mathrm{A}=\text { Neontal Facial Coding System (Grunau \& Craig, 1987;1990) } \\
\mathrm{B}=\text { Clinical Scoring System (Barrier et al., 1989) }\end{array}$} \\
\hline \\
\hline \multicolumn{6}{|c|}{$\mathrm{D}=$ Behavioral Pain Score (Pokela, 1994) } \\
\hline \multirow{2}{*}{\multicolumn{6}{|c|}{$\begin{array}{l}E=\text { Liverpool Infant Distress Score (Horgan \& Choonarah, 1996) } \\
F=\text { Mills Infant/ Toddler Pain Index (Mills, 1996) }\end{array}$}} \\
\hline & & & & & \\
\hline \multicolumn{6}{|c|}{ Multidimensional scales for assessing pain in young children (Bours et al., 1996) } \\
\hline \multicolumn{6}{|c|}{$\begin{array}{l}\text { G= COMFORT SCale (Ambuel et al., 1992) } \\
H=\text { Neonatal Infant Pain Scale (Lawrence et al., 1993) }\end{array}$} \\
\hline \multirow{2}{*}{\multicolumn{6}{|c|}{$\begin{array}{l}\text { I= Infant of Non-Verbal Child Pain Evaluation Criteria (Lin \& Sentivany, 1994) } \\
\text { J= Wielenga Observatieschaal Pijn bij Pasgeborenen (Wielenga, 1994) }\end{array}$}} \\
\hline & & & & & \\
\hline \multirow{2}{*}{\multicolumn{6}{|c|}{$\begin{array}{l}K=\text { CRIES Neonatal Post-Op Pain Measurement Score (Krechel \& Bildner, 1995) } \\
\text { L= Premature Infant Pain Profile (Stevens et al., 1996) }\end{array}$}} \\
\hline & & & & & \\
\hline \multicolumn{6}{|c|}{$M=$ Neonatal Pain Assessement Scale (Bell, 1994) } \\
\hline \multicolumn{6}{|c|}{ Scales for assessing pain in people with intellectual disability } \\
\hline \multirow{2}{*}{\multicolumn{6}{|c|}{$\begin{array}{l}\mathrm{N}=\mathrm{Items} \text { proposed by physicians to assess pain in cerebral palsy (Giusiano et al., 1995) } \\
\mathrm{O}=\text { Items caregivers use to determine pain in non-verbal, cognitively impaired individuals (MCGrath et al., 1998) }\end{array}$}} \\
\hline Scales for assessing post operative paediatric $p$ & & & & & \\
\hline $\mathrm{P}=$ Post operative pain measure for parents $(\mathrm{Cl}$ & mbers et al., 1996) & & & & \\
\hline (2) Number of different scales the item was de & & & & & \\
\hline
\end{tabular}

Vlaskamp and Oxener (2002) discussed the communicative behaviour of individuals with profound multiple disabilities, and commented that one can question whether the behavioural repertoire of these people is not qualitatively and quantitatively different from that of normally developing children with the same developmental age, which would make the whole comparison itself questionable. Thus measurement systems have to be devised that are attuned to the unique expressive capabilities of children with severe and profound intellectual disabilities, in the area of pain as well as in other communicative areas. 


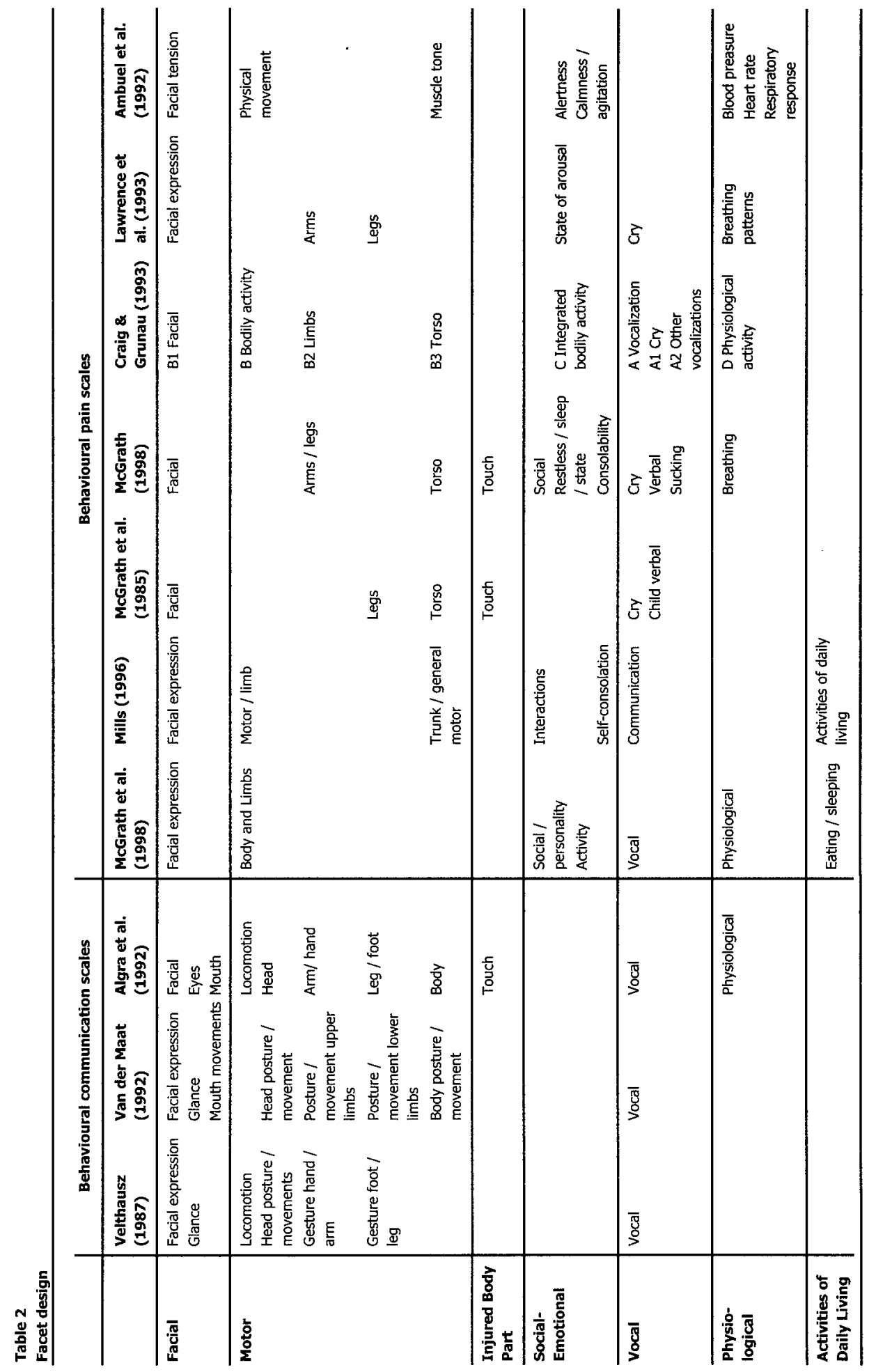


When we started the research project presented in this dissertation in 1998, very little was known about pain assessment in children with intellectual disabilities. The only literature reports on the observation of pain behaviour in the more severely intellectually disabled children available at that time were those on the work of Giusiano et al. (1995), followed shortly afterwards by the work of McGrath and colleagues (1998). Both scales had not been psychometrically tested at that stage.

Both studies identified a certain number of pain cues (see Table 1). In the General discussion to this thesis (Chapter 7) an overview of the behavioural expressions currently available in the literature on pain assessment in children with severe to profound intellectual disabilities will be provided. In 1998 the scales of Giusiano et al. (1995) and McGrath and colleagues (1998) did not seem to cover the full behavioural repertoire of intellectually disabled children, since the literature on the communicative behaviour of individuals with severe intellectual disabilities referred to earlier in this thesis suggested that a greater variety of non-verbal expressions of pain could be present. This difference might be explained by the fact that McGrath (1998) and Giusiano (1995) collected candidate items for their scales among one group of caregivers (parents versus physicians) rather than by approaching various types of caregivers. Furthermore, Giusiano and colleagues collected indicators in a hospital setting referring to a medical examination, thus limiting the dataset to a specific setting, while McGrath's dataset was based on retrospective reports relating to only 20 individuals, a sample that might not be representative in view of the heterogeneous nature of the population under investigation. In addition, Giusiano and colleagues focused primarily on individuals with cerebral palsy, thus limiting their scale to a group with a specific secondary impairment. Finally, these studies collected indicators by means of interviews only and not by a multi-method approach as recommended by Johnston (1998). In a comment on health measurement scales, Streiner \& Norman (1998) stated that no amount of statistical manipulation after the fact can compensate for items that are not present. Thus, a thorough basis for any observational pain scale must be created, prior to developing such a scale. In view of the limited investigation of psychometric properties in the two scales mentioned above, as well as their other limitations, it was deemed valuable to start a new study of expressive pain behaviour of nonverbal children with severe to profound intellectual disabilities.

\subsection{Objectives}

The research project described in this dissertation therefore aimed to:

- examine non-verbal expressions of pain in children with severe to profound intellectual disabilities;

- develop a pain assessment scale based on the expressions identified; and

- investigate the psychometric properties of this scale. 
The research project consisted of five studies: one qualitative study and four quantitative studies.

\subsection{Terminology}

The current literature employs a wide range of terms to refer to the population examined in the present dissertation. Terms such as mental retardation, learning disabilities, cognitive impairment, mental disabilities, mental handicap, neurological impairment and developmental disabilities are all used to describe the same population. However, there seems to be a growing preference for the term intellectual disability, both in the literature and among organisations. Recently, the board of directors of AAMR voted unanimously that the organisation's name be changed to the American Association on Intellectual Disabilities (AAMR, 2002b), however at present the name American Association on Mental Retardation is still being used (AAMR, 2004). Although every term that is used can be criticised in some way, we decided to define the research population in our studies using the terms intellectual and communicative disabilities, since the present dissertation focuses primarily on impairments of the intellect and the consequent inability to communicate effectively about pain in spoken language. Since that no existing standardised tests are applicable for a valid estimation of the intellectual capacity of children with severe to profound intellectual disability, and the (in-) ability to communicate about pain in spoken language plays an important role in pain assessment, communicative abilities will also be taken into account in the present dissertation.

\subsection{Overview of the dissertation}

The present dissertation comprises seven chapters. The present chapter (Chapter 1) presents the rationale for the research project, as well as an overview of nonverbal expressions of pain derived from the literature at the start of the research project discussed in the present dissertation.

Chapter 2 reports on a qualitative study, which created an item bank of candidate, items for pain assessment. The research questions addressed in this chapter are:

- What expressions do caregivers use to assess pain in children with severe intellectual and communicative disabilities?

- What expressions do children with severe intellectual and communicative disabilities display when undergoing interventions that may be painful?

- How do the expressions found compare with the items of existing scales for the measurement of pain in non-verbal populations?

Chapter 3 discusses a study among nurses to evaluate the items derived from the existing two pain checklists for people with intellectual disabilities. In addition, 
newly identified items from Chapter 2 as well as signs of nociception and symptoms of disease were presented to nurses caring for both severely and profoundly intellectually disabled people. The study was also used to check the face validity of the item bank presented in Chapter 2 . This cross-sectional study addressed the following research questions:

- What are the nature, frequencies and relative importance of the indicators nurses use to determine pain in people with severe to profound intellectual disability?

- What are the differences between nurses working only with severely intellectually disabled persons versus those working only with profoundly disabled persons in terms of the indicators the nurses consider important in determining pain?

Besides nurses, parents are a key source of information for children who are not able to express themselves verbally. Chapter 4 therefore presents a second crosssectional study, among parents of such children. Based on the results of Chapters 2 and 3 , and additional modifications of the items (Appendix $\mathrm{I}$ ), a questionnaire was developed to investigate whether different groups of children display different behavioural repertoires when they are in pain, according to their parents. The results of this study also allowed us to apply an initial item reduction to a draft pain assessment scale that was developed based on the same expressions as the questionnaire for parents. Research questions addressed were:

- Do children who cannot express pain verbally display different behavioural repertoires when in pain than children who have the ability to communicate by means of some verbal language?

- Do children with behavioural and emotional disturbances display different behavioural repertoires when in pain than children who do not suffer from these disturbances?

- Do children with severe multiple disabilities display different behavioural repertoires when in pain than children who do not suffer from multiple disabilities?

Although the investigation of pain behaviour on a detailed level is important, scales with vast numbers of items are not useful for everyday practice. It has rarely been reported however, how the elements of a pain measure are selected, particularly with regard to pain measurement among children (Johnston, 1998). Chapter 5 therefore presents the results of a third cross-sectional study, which primarily aimed at item reduction. It investigated what behaviour children with profound intellectual disability display following medical procedures in a children's hospital. The findings were then used to develop a more definitive pain assessment scale called Kids with Intellectual Disabilities Pain Assessment Instrument for Nonverbal Signals (KIDPAINS). 
Research questions addressed were:

- Is it possible to reduce the number of items in the draft checklist based on the observation of children with profound intellectual and communicative disabilities at several time points following medically induced pain?

- What are the psychometric properties of the pain assessment scale developed on the basis of these findings?

Although initial psychometric properties of the KIDPAINS seemed promising, more thorough testing and further item reduction were needed. In addition, the findings at that point made it likely that some items in the scale were applicable only to a limited number of participating children. Therefore in the fourth and final cross-sectional study as presented in Chapter 6 the research population was narrowed down to children with profound multiple disabilities. This study tested the KIDPAINS psychometrically in children with profound multiple disabilities, with the aim of achieving further item reduction. The research questions addressed in this chapter are:

- Is KIDPAINS reliable?

- Is KIDPAINS construct-valid in comparing extreme groups?

- Is KIDPAINS unidimensional or multidimensional?

- Is KIDPAINS valid examining sensitivity and specificity using a proxy 'silver' standard?

- Is KIDPAINS valid in investigating convergent relations with other (pain) measures?

Finally, Chapter 7 presents an overall conclusion and discussion, describing the project's main conclusions, methodological and theoretical reflections and implications for clinical practice. An update of the literature on pain assessment in children with severe to profound intellectual disabilities available at the end of the research project will be provided. A summary in English and Dutch concludes this dissertation.

Of importance to note is that the chapters in this dissertation have been published or submitted for publication in different journals. This had the advantage that chapters can be read separately, but a certain amount of overlap is inevitable. In addition, as a result of the evolving development of KIDPAINS, different number of items will be mentioned in different chapters. This might be confusing when reading this thesis. Table 2 in Chapter 7 provides the leading thread through the developmental process of KIDPAINS. 



\section{Chapter 2}

Non-verbal expressions of pain in children and young adults with severe to profound intellectual and communicative disabilities

An overview based on literature, caregivers' reports and observations

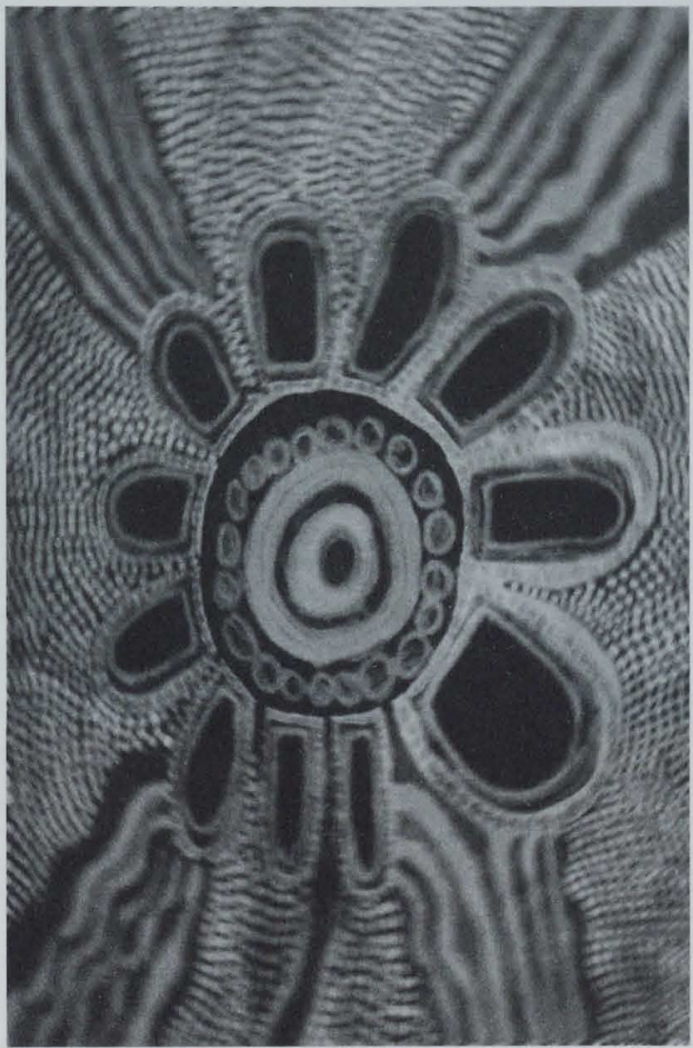

Katinka A.J. van Dongen, Huda Huijer Abu-Saad, \& Jan P.H. Hamers. Submitted for publication 


\section{Abstract}

The purpose of this study was to gain insight into non-verbal expressions of pain in children and young adults with severe to profound intellectual and communicative disabilities that are used by caregivers and practitioners. It was examined whether the expressions found in the present study are comparable with existing instruments used to measure pain in non-verbal children.

Data were collected by observing 32 children during possibly painful situations and by conducting unstructured interviews with parents and health care professionals $(\mathrm{N}=29)$. Expressions resulting from these observations and interviews were analysed by means of 7 checklist meta-matrices and compared with measurement scale items $(n=138)$ taken from the literature.

The observations led to the identification of 53 different expressions. The two pain expressions observed most often were 'High muscle tone, cramping' and 'Sounds, vocalisations'. In the interviews, 153 different expressions were mentioned, which partly overlapped with the 53 expressions derived from the observations. Only ten expressions were reported by at least $50 \%$ of the interviewees, including 'Crying', 'Self-injurious bebaviour' and 'Aggression'. In all, the interviews and observations yielded 167 different expressions. Forty-two measurement scale items taken from the literature were not found in our interviews or observations, whereas 71 new expressions were identified in addition to the 138 items found in the literature. These included Eyes whirling around', 'Humming, self-stimulating noises', Rumination', and 'Destructive behaviour'. The interviews, observations and literature study ultimately resulted in the compilation of an item bank of 209 expressions.

Non-verbal pain expressions are diverse and depend on the individuals' baseline behaviour, so functional abilities and behavioural repertoires have to be taken into account. There is a certain discrepancy between the measurement scale items found in the literature and those used in practice, suggesting both similarities and differences in the manner in which severely intellectually disabled children express pain in comparison with other non-verbal populations. 


\subsection{Introduction}

So far, measuring pain in people with severe intellectual disabilities has been a poorly developed area of research that has only been addressed by a few investigators (Collignon \& Giusiano, 2001; Breau et al., 2002a; Hunt et al., 1994; Stallard et al., 2002a). The inability to communicate about pain in words and the underlying conditions or symptoms related to the intellectual disability make the expression of pain in this population a complex issue. Pain assessment, however, must be designed to suit the communicative abilities of the suffering individual (Anand \& Craig, 1996). According to Granlund (1993) human beings unintentionally communicate needs and feelings through reflexes and innate reactions. Brodin (1991) conducted a longitudinal study of children with multiple disabilities and reported that interaction could be described in terms of gaze/ eye contact, facial expressions, gestures and body movements. Lack of response to these communicative signals from non-verbal, intellectually disabled children prevents them from communicating effectively about pain.

It has often been claimed that intellectually disabled persons are 'indifferent to pain' or 'insensitive to pain' or have an 'altered pain threshold' (Biersdorff, 1994). However, decreased pain intensity is difficult to be ascertained without adequate pain measures. Bio-behavioural tesponses may provide the necessary information that a child is in pain. Anand and Craig (1996) state that the behavioural alterations caused by pain are the infantile forms of self-report and therefore should not be discounted as surrogate measures of pain. However, it is questionable whether the bio-behavioural responses of children with severe intellectual disabilities are comparable with those of normally developed children with the same developmental age. Many unique and complex features in this specific paediatric population distinguish intellectually disabled children from children without cognitive delay (Bromley, 1998). This makes these children an extremely heterogeneous population, and the ways in which they express pain can also be expected to be heterogeneous.

Although previous studies of McGrath et al. (1998) and Giusiano et al. (1995) have found a certain number of pain cues, these cues might not completely cover the behavioural repertoire of intellectually disabled individuals. The literature on the communicative behaviour of individuals with severe intellectual disabilities suggests that a greater variety of non-verbal expressions of pain could be present (Granlund et al., 1995; Maat van der, 1992; Velthausz, 1987). This finding might be explained by the fact that McGrath (1998) and Giusiano (1995) collected candidate items for their scales in one group of caregivers (parents and physicians, respectively) rather than by approaching different types of caregivers. Furthermore Giusiano and colleagues collected indicators in the hospital setting, thus limiting the dataset to a specific setting, while McGrath's dataset was based on information relating to only 20 individuals, a sample that might not be representative in view of 
the heterogeneous nature of the population under investigation. Finally, these studies collected indicators by means of interviews only and not by a multi-method approach as recommended by Johnston (1998).

In a comment on health measurement scales, Streiner \& Norman (1998) state that no amount of statistical manipulation after the fact can compensate for items that are not present. This led us to conclude that previous studies might have overlooked some of the possible expressions of pain in children and young adults with severe intellectual and communicative disabilities, and that additional research was required. New measurement scale items can be derived from five different sources, which cannot always be clearly distinguished from each other: the patients themselves, clinical observation, theory, research, and expert opinion (Streinet \& Norman, 1998). The present study used three of these sources: theory, key informant interviews and clinical observations.

The aim of the present study was to examine non-verbal pain expressions used by caregivers and observed in practice to assess pain in children and young adults with severe intellectual and communicative disabilities. We investigated whether the expressions we were able to identify were comparable to existing tools for measuring pain in non-verbal children. We tried to achieve this by creating an item bank with non-verbal expressions of pain. Ultimately, this project should lead to the development of an instrument to assess pain in non-verbal children with severe intellectual disability. The item bank created can serve as a database from which the items for such an instrument can be selected.

Specifically, the present study tried to answer the following questions:

- What expressions do caregivers use to assess pain in children with severe intellectual and communicative disabilities?

- What expressions do children with severe intellectual and communicative disabilities display when undergoing interventions that may be painful?

- How do the expressions found in the present study compare with the items of existing scales for the measurement of pain in non-verbal populations?

\section{$\underline{2.2 \text { Methods }}$}

\subsubsection{Design}

The research questions of the present study were investigated using qualitative research methods, which have been advocated for exploring new areas of research (Miles \& Hubermann, 1994). As described above, there is hardly any empirical evidence available on this topic and a qualitative study is the appropriate method to build up a foundation of knowledge. In analysing the qualitative data, however, they were translated from words into numbers. Miles \& Hubermann (1994) see 
qualitative-quantitative linking at three levels. The level they call the 'quantizing' level is the level where qualitative information can be either counted directly or converted into ranks or scales. In the present study, expressions were quantified at this level to obtain some understanding of the occurrence of expressions in the vatious types of data sources.

\subsubsection{Defining the research population}

The literature employs a wide range of terms to refer to the population examined in the present study. Terms such as mental retardation, learning disabilities, cognitive impairment, mental disabilities, mentally handicapped, neurological impairment, developmental disabilities, are all used to describe the same population. The American Association on Mental Retardation (AAMR) currently defines mental retardation as: "a disability characterized by significant limitations in both intellectual functioning and conceptual, social, and practical adaptive skills. This disability originates before the age 18" (Luckasson et al., 2002). The definition of the AAMR is in line with the International Classification of Functioning, Disability and Health (ICF) of the World Health Organization (WHO). According to ICF mental retardation is classified as impairment in intellectual functioning (b117) and as such related to one off the mental functions of the body (WHO, 2002). The term disability according to ICF serves as an umbrella term encompassing impairments, activity limitations or participation restrictions. One domain ICF differentiates as an area in which activity limitations or participations restrictions can occur is the domain of communication (d3). Diagnostic and Statistical Manual - Fourth Edition (DSM-IV) distinguishes four levels of mental retardation based on intelligence quotient (IQ) scores: mild (IQ $50-55$ to 70), moderate (IQ 35-40 to 5055), severe (IQ 20-25 to 35-40) and profound (IQ below 20 or 25) (APA, 1994).

Since the present study focused primarily on the impairment of intellect and the inability to communicate effectively about pain in words or gestures, the term severe intellectual disability as used in this report refers to both individuals with severe and profound intellectual disabilities.

\subsubsection{Subjects}

The setting for both the observations and the interviews consisted of three residential institutions in the southern part of the Netherlands, specialising in the daily care of individuals with intellectual disabilities. Subjects were also sampled at a dental clinic specialising in dental health care for individuals with intellectual disabilities.

Two different types of participants can be distinguished in the present study: (1) a total of 29 caregivers who had at least one year of experience with caring for the target population were interviewed. In all, nine nurses, four physicians, five physiotherapists, six parents, a dentist, a dental hygienist, a psychologist, a 
neuropsychologist and a remedial educationalist were approached at the institutions.

(2) a total of 32 children and young adults were observed during possibly painful situations. With respect to cognition participants were included based on the information provided by caregivers who were familiar with the medical record of participants. As such both children and young adults with a severe and a profound intellectual disability were included. Participants' biological age ranged from three up to 25 years of age. The inability of the population under investigation to verbalize pain was a key issue in the present study. Subjects were included on the basis of the minimum Dutch speech norms proposed by Goorhuis \& Scharlaekens (1994), which could be easily assessed during the observations. Subjects were included if they could produce at best three-word sentences, representing the speech level of a 2\%/2-year-old child.

\subsubsection{Data collection}

Data were collected over a period of six months. During this period, the researcher approached the head nurses of three groups including children and young adults with severe intellectual and communicative disabilities. In one of the institutions, the caregivers used a programme specifically developed for children with multiple disabilities (Vlaskamp, 1993) and these caregivers seemed particularly familiar with children's behaviour. This institution was chosen for the researcher to participate in the daily care of the children, in order to get to know the children and observe their communicative signals. All three residential groups served as a starting point for approaching caregivers to take part in the interviews. In addition observations took place during care giving of some of the participating healthcare professionals (e.g. physiotherapist and dentist). The observer did not intervene with the intervention of the healthcare professional. Children were observed in an open manner, meaning that only behaviour which struck the observer as aberrant was recorded.

Interviews were based on a topic list, drawn up on the basis of the literature and the researchers' own reflections as well as those of other researchers. Topics addressed included pain, expressions of pain, diagnosing pain, communication, pain behaviour in relation to attendant disabilities and differences between pain behaviour and behaviour related to other emotions. All of these topics were addressed in each of the interviews, although specific questions could vary. Related questions included: What are the behavioural expressions that tell you when a child is in pain?; How do you know that a child experiences pain rather than other emotions like anxiety?; What makes you sure that it is actually pain you observe?

\subsubsection{Data analysis}

Miles \& Hubermann (1994) state that data analysis in qualitative research starts even before the data are collected. In the present study, measurement scale items 
from the literature on pain measurement in non-verbal populations served as the starting point for data analysis. However, expressions resulting from observations and interviews were first analysed separately. Data from both observations and interviews were for this purpose accommodated in within-subject matrices (Miles \& Hubermann, 1994) in order to identify possible expressions of pain per interview or observation. Additionally resulting expressions were accommodated in cross-case displays. Regarding the interviews meta-matrices were used with roleordered columns and conceptually ordered rows. An example of such a metamatrix is provided in Table 1 (page 34). Data resulting from the observations were analysed using meta-matrices with intervention-ordered columns and, like the interviews, conceptually-ordered rows.

Before comparisons could be made with items reported in the literature, measurement scale items from 16 scales had first been compared for similarities and differences (Giusiano et al., 1995; McGrath et al., 1998; Gruneau \& Craig, 1990; Barrier et al., 1989; Craig et al., 1993; Pokela, 1994; Ambuel et al., 1992; Lawrence et al., 1993; Lin \& Sentivany, 1994; Wielenga, 1994; Krechel \& Bildner, 1995; Steven et al., 1996; Horgan \& Choonara, 1996; Mills, 1996; Bell, 1996; Chambers et al., 1996a). The state of the art study of Bours and colleagues (1996) was used to collect most of these scales. A close look at the scales revealed that far more measurement scale items could be identified than had been expected, with large numbers of detailed items reported especially in the appendices to scales. Hence the analysis came to focus on these detailed measurement scale items in order to make the comparison with the expressions found in interviews and observations possible. For example, the item Crying from the CRIES scale (Krechel \& Bildner, 1995) was divided into 'High-pitched crying' and Inconsolable' to allow comparison with Mills' Infant/Toddler Pain Index (Mills, 1996), since the latter scale includes 'Crying' in the category of Communication and Inconsolable' in the category of Interactions. Furthermore, items like 'Crying during manipulations' (Giusiano et al., 1995) were interpreted as the behavioural expression of 'Crying'. This procedure resulted in a total of 138 different measurement scale items being identified within these 16 scales (see Table 1 of Chapter 1, pages 18-19). These items were adapted and categorised into seven checklist meta-matrices (Miles \& Hubermann, 1994) with data source-ordered columns and conceptually- ordered rows. Matrices were based on the facet design as presented in the General Intoduction (Chapter 1) and represented the categories Facial $(\mathrm{N}=25)$, Motor $(\mathrm{N}=37)$, Injured Body Part ( $=9$ ), Social-Emotional $(\mathrm{N}=27)$, Vocal $(\mathrm{N}=14)$, Physiological $(\mathrm{N}=17)$ and Activities of Daily Living $(\mathrm{N}=9)$. As such the 138 measurement scale items taken from the literature were accommodated in the upper rows of the matrices, additional expressions resulting from observations and interviews were accommodated in the lower rows. 


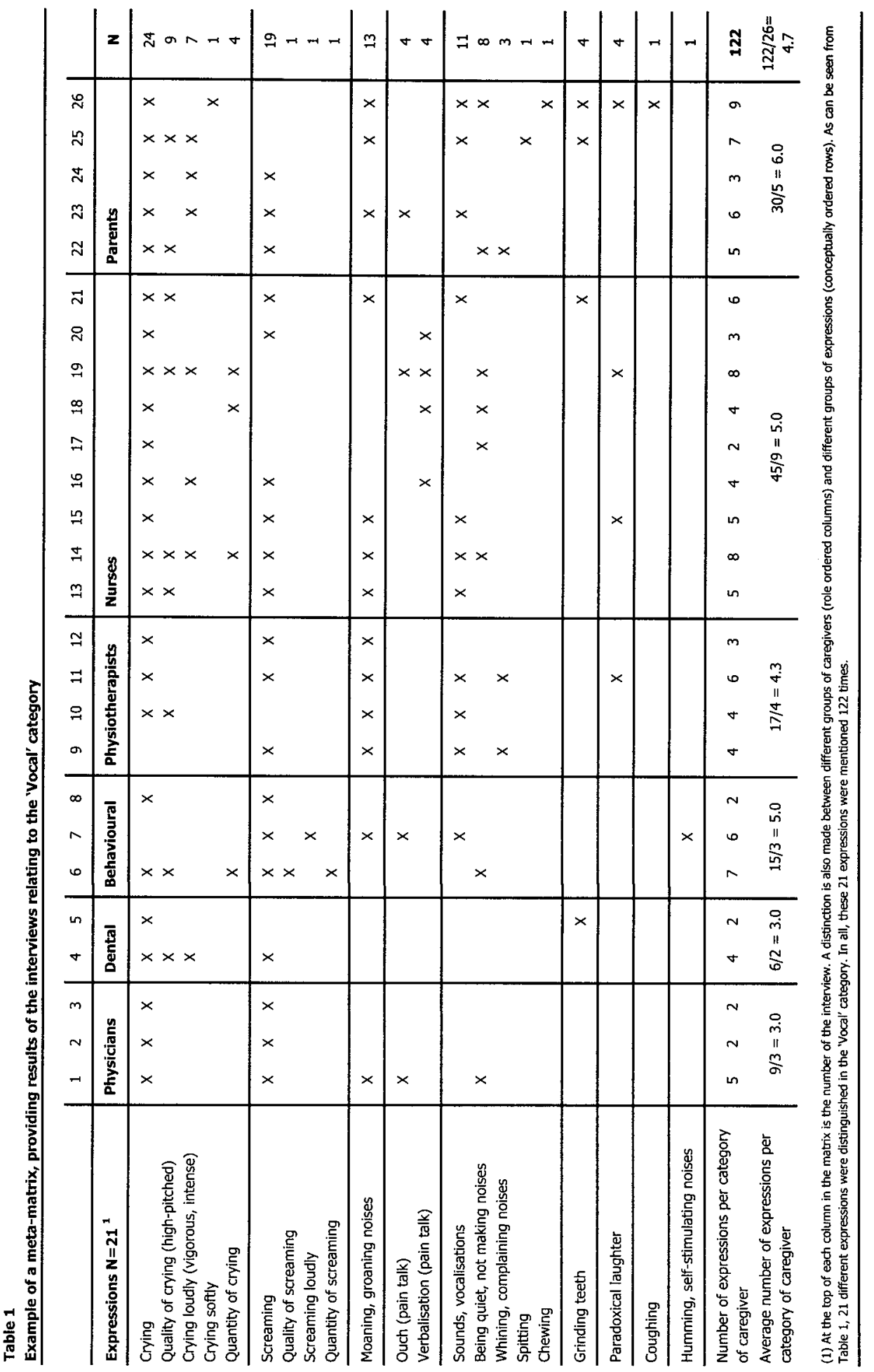


Only two measurement scale items were not incorporated into the matrices: 'Capacity to react to painful care' and 'Capacity to interact with adult' (Giusiano et al., 1995) were regarded as abilities to react to pain, rather than pain behaviour. Therefore those items were omitted from further analysis. Although Indifference to painful care' (Giusiano et al., 1995) was not regarded as an expression of pain, at this stage it was kept in the analyses since researchers were interested whether or not it would occur in the data collection.

Finally, it should be kept in mind that measurement scale items were initially translated from English into Dutch. After analysis, a back-translation procedure was used and the translated items were compared with their original description.

\subsubsection{Validity and reliability}

In order to increase the internal reliability, the audio taped data of the interviews were partly transcribed by an independent researcher. Furthermore another independent researcher coded half of the interviews. The resulting raw codes were compared and differences resolved by discussion. Four researchers then independently examined the raw codes for ambiguity, overlap and conceptual clarity. Children undergoing vaccination against influenza were observed not only by the main researcher but also by an independent observer, in order to increase the reliability of the results. Finally, we used between-methods triangulation, a type of triangulation that combines dissimilar methods to measure the same unit (Denzin, 1978), since the present study combined data resulting from observations and from interviews.

In order to achieve internal validity, interviews were recorded and notes were made. Furthermore in the present study, observations took place at different locations, while different children were observed and different types of caregivers, with different backgrounds, were approached for the interviews. This procedure can be described as data triangulation, a procedure to search explicitly for as many different data sources as possible that bear upon the events under analysis (Denzin, 1978).

In order to achieve external validity, caregivers were purposively sampled with the aim of collecting an item bank as complete as possible and thus to provide a general picture of the area of investigation. Therefore caregivers with a wide variety of knowledge, skills and experience were interviewed. For example, one behavioural caregiver was selected because of her knowledge of children with autism. Finally we compared the pain expressions we collected with measurement scale items reported in the literature to further increase the external validity. 


\subsection{Results}

\subsubsection{Subjects}

(1) Nine male and 20 female caregivers were interviewed. However, only 26 interviews are represented in the matrices, since two physicians, two physiotherapists and a mother and father took part simultaneously in an interview. On average, the professional caregivers had 17 years of experience in caring for the target population.

(2) A total of 14 boys and 18 girls with severe or profound intellectual and communicative disabilities were observed. Of these, $34 \%$ were observed while undergoing vaccination against influenza, $19 \%$ at the dentist, $25 \%$ at the dental hygienist, and finally $29 \%$ during physiotherapy. Thirty-two subjects met the minimum Dutch speech standards, indicating they could produce at best threeword sentences. (Goorhuis \& Schaerlaekens, 1994). Five children were able to use at least five words (one at a time), six children were able to babble and 21 children did not produce any language sounds and as such performed as would be expected from an infant. In this sample, $16 \%$ of the children were regarded as severely intellectually disabled, and $84 \%$ of the children were profoundly intellectually disabled, of whom $56 \%$ had severe multiple disabilities.

\subsubsection{Expressions caregivers use to assess pain}

The 29 interviewees used a great variety of expressions to identify pain in children with severe intellectual and communicative disabilities, spontaneously mentioning a total of 153 different expressions. In all, these expressions were mentioned 658 times, meaning that each interview resulted in an average of over 25 possible pain cues. A selective overview of expressions frequently mentioned by the participants is presented in Table 2 (page 37).

The expressions in Table 2 represent all indicators mentioned in at least eight interviews. Only 28 of the 153 expressions met this criterion. Additionally, no more than ten expressions were spontaneously mentioned in $50 \%$ or more of the interviews. These included 'Self-injurious behaviour' and 'Aggressive behaviour'. Expressions relating to the Facial, Vocal and Social-Emotional categories were most often mentioned spontaneously by a substantial number of the interviewees. The expressions included in the Vocal expression meta-matrix, however, were most frequently mentioned. The density of the 21 expressions of the Vocal matrix is 5.8, meaning that each expression in this category was mentioned by an average of almost six participants. In absolute numbers, however, the Social-Emotional category includes ten expressions mentioned in eight or more interviews and as such is the category with the greatest absolute number of expressions. The Motor category only includes two expressions mentioned in eight or more interviews. On average, however, each expression relating to the Motor matrix was mentioned four times, which is not much different from the density per expression in 
categories like Facial (4.1) and Social-Emotional (4.4). The only category in this respect that has a significantly lower score is the Physiological category. Each expression relating to this matrix was only mentioned by an average of 2.6 participants.

Table 2

Overview of expressions reported in eight or more interviews

\begin{tabular}{|c|c|c|c|c|}
\hline & $\begin{array}{c}\text { Number of } \\
\text { different mentions }\end{array}$ & $\begin{array}{l}\text { Overall number of } \\
\text { mentions }\end{array}$ & $\begin{array}{l}\text { Percentage of } \\
\text { mentions }\end{array}$ & $\begin{array}{l}\text { Density of } \\
\text { category }\end{array}$ \\
\hline FACIAL & 31 & 128 & & 4.1 \\
\hline Facial expression & & 22 & $85 \%$ & \\
\hline Eyes & & 15 & $58 \%$ & \\
\hline Looking serious, sad & & 11 & $42 \%$ & \\
\hline Grimacing & & 10 & $38 \%$ & \\
\hline Mouth & & 10 & $38 \%$ & \\
\hline MOTOR & 22 & 88 & & 4.0 \\
\hline High muscle tone, cramping & & 14 & $54 \%$ & \\
\hline Evaluation of muscle tone & & 8 & $31 \%$ & \\
\hline INJURED BODY PART & 10 & 47 & & 4.7 \\
\hline Avoiding touch or treatment & & 12 & $46 \%$ & \\
\hline Withdrawing & & 8 & $31 \%$ & \\
\hline SOCIAL-EMOTIONAL & 44 & 198 & & 4.5 \\
\hline Self-injurious behaviour & & 20 & $77 \%$ & \\
\hline Restless, fidgety & & 13 & $50 \%$ & \\
\hline Aggression & & 13 & $50 \%$ & \\
\hline Irritability, cranky & & 11 & $42 \%$ & \\
\hline Attempting to withdraw, retiring & & 9 & $35 \%$ & \\
\hline Head banging & & 9 & $35 \%$ & \\
\hline Seeking comfort, closeness & & 9 & $35 \%$ & \\
\hline Self hitting & & 8 & $31 \%$ & \\
\hline Hitting someone else & & 8 & $31 \%$ & \\
\hline Problem behaviour & & 8 & $31 \%$ & \\
\hline VOCAL & 21 & 122 & & 5.8 \\
\hline Crying & & 24 & $92 \%$ & \\
\hline Screaming & & 19 & $73 \%$ & \\
\hline Moaning & & 13 & $50 \%$ & \\
\hline Sounds, vocalisations & & 11 & $42 \%$ & \\
\hline Quality of crying & & 9 & $35 \%$ & \\
\hline Quiet, not making any noises & & 8 & $31 \%$ & \\
\hline PHYSIOLOGICAL & 13 & 34 & & 2.6 \\
\hline Tears & & 9 & $35 \%$ & \\
\hline ACTIVITIES OF DAILY LIVING & 11 & 41 & & 3.7 \\
\hline Refusing to eat & & 13 & $50 \%$ & \\
\hline Increased sleep, tired & & 8 & $31 \%$ & \\
\hline
\end{tabular}


The findings not only show the prevalence of expressions of pain, but also show that different types of caregivers reported different types of pain cues. Parents in particular mentioned a great variety of pain cues, and reported the highest average number of expressions, especially in the Facial and Motor categories. Each parent used an average of 10.6 expressions in the Facial category as indications that their child was in pain. However, dental caregivers also tended to pay great attention to changes in facial expression, especially referring to expressions relating to the eyes.

Nurses and parents paid more than average attention to physiological indications that a child was in pain. It is remarkable that physicians did not report a single physiological expression of pain. By contrast, physicians did report a large number of symptoms and diagnostic procedures as indications that a child was in pain, such as swelling, vomiting, temperature, $\mathrm{x}$-ray and records of constipation. In all, participants to 14 interviews reported symptoms as signs of pain and 13 interviewees referred to diagnostic procedures as pain cues. We feel, however, that symptoms of disease and diagnostic procedures cannot be regarded as expressions of pain. As could be expected, behavioural therapists reported the greatest average number of expressions (15.7) in the Social-Emotional category. The difference between behavioural therapists and other caregivers in this category is remarkable. Surprisingly, parents had the lowest mean score in the Social-Emotional category, mentioning an average of only four social-emotional expressions.

\subsubsection{Expressions observed during possibly painful situations}

The observations revealed a total of 53 different expressions. On average, 4.8 expressions per child were recorded. One child did not display a single expression when the intervention took place, while four children had the maximum of nine expressions. The 16 expressions listed in Table 3 (page 39) represent all indicators that were recorded in four or more children.

As Table 3 shows, only two of the 16 expressions were observed in $25 \%$ or more of the children: 'High muscle tone' and 'Sounds, vocalisations'. In the category Activities of Daily Living, not a single observation was made, whereas in the categories Physiological, Social-Emotional and Injured Body Part, only one expression was found in four or more children. Together with the Facial matrix, these matrices also comprise the categories with the lowest density per expression, with the average densities with which the expressions were observed ranging from 2.0 to 2.7 in these four matrices. The Motor matrix was the category with the highest density per expression, each expression in the Motor category being observed an average of 3.5 times, followed closely by the Vocal category, with an average density of 3.4. In terms of absolute numbers, seven expressions in the Motor category were observed in four or more children, making the Motor matrix the category with the most frequently observed expressions in absolute numbers. 
Another comparison that can be made involves the type of intervention. The two categories with the largest average numbers of expressions were the Facial and Motor categories. In the Facial category, numbers were especially large during physiotherapy, while in the Motor category the largest numbers of expressions were recorded at the dentist.

Table 3

Overview of expressions observed in four or more children

\begin{tabular}{|c|c|c|c|c|}
\hline & $\begin{array}{c}\text { Number of } \\
\text { different observed } \\
\text { expressions }\end{array}$ & $\begin{array}{l}\text { Overall number of } \\
\text { observed } \\
\text { expressions }\end{array}$ & $\begin{array}{c}\text { Percentage of } \\
\text { observed } \\
\text { expressions }\end{array}$ & $\begin{array}{l}\text { Density of } \\
\text { category }\end{array}$ \\
\hline FACIAL & 19 & 52 & & 2.7 \\
\hline Brow bulge furrowed, frowning & & 8 & $22 \%$ & \\
\hline Wrinkle above nose & & 6 & $19 \%$ & \\
\hline Eyes tightly shut & & 6 & $19 \%$ & \\
\hline MOTOR & 15 & 55 & & 3.7 \\
\hline High muscle tone, cramping & & 11 & $34 \%$ & \\
\hline Pulling up legs & & 6 & $19 \%$ & \\
\hline Spastic & & 5 & $16 \%$ & \\
\hline Restless motion & & 5 & $16 \%$ & \\
\hline Neck extending & & 5 & $16 \%$ & \\
\hline Head movements & & 4 & $13 \%$ & \\
\hline Feet wiggling & & 4 & $13 \%$ & \\
\hline INJURED BODY PART & 2 & 5 & & 2.5 \\
\hline Withdrawing & & 4 & $13 \%$ & \\
\hline SOCIAL-EMOTIONAL & 7 & 14 & & 2.0 \\
\hline Fright reaction & & 4 & $13 \%$ & \\
\hline VOCAL & 7 & 24 & & 3.4 \\
\hline Sounds, vocalisations & & 8 & $25 \%$ & \\
\hline Moaning & & 5 & $16 \%$ & \\
\hline Crying & & 4 & $13 \%$ & \\
\hline PHYSIOLOGICAL & 3 & 7 & & 2.3 \\
\hline Holding breath & & 4 & $13 \%$ & \\
\hline
\end{tabular}

Children did not display a single expression relating to the Activities of Daily Living meta-matrix. Furthermore, children showed few expressions from either the Physiological or the Injured Body Part matrix. Physiotherapy was the intervention with the largest average number of recorded expressions per child per matrix, while immunisation was the intervention with the smallest average number of recorded expressions per child. 


\subsubsection{Comparison with the literature}

The item bank comprising all the pain cues from the literature, the interviews and observations, contained 209 different expressions. Of these 209 possible expressions of pain, 167 were either observed or referred to in the interviews, while 42 measurement scale items taken from the literature were not found in the present qualitative study. Furthermore, of the 209 expressions in the item bank, 71 candidate pain cues resulting from the observations and interviews were not among the 138 measurement scale items derived from the literature. These 71 indicators were added to the checklist meta-matrices. Examples of the 42 expressions not found in observations and interviews, as well as examples of the 71 additional expressions, are listed in Table 4.

Table 4

Examples of measurement scale items taken from the literature but not identified in observations and interviews, and additional expressions collected in observations and interviews but not identified as items in the literature

\begin{tabular}{|c|c|c|}
\hline & Measurement scale items not identified & Additional expressions \\
\hline Facial & $\begin{array}{l}\text { Naso-labial furrow deepened } \\
\text { Open lips } \\
\text { Nostrils flaring }\end{array}$ & $\begin{array}{l}\text { Eyes whirling around } \\
\text { Raising upper lip } \\
\text { Contorted mouth }\end{array}$ \\
\hline Motor & $\begin{array}{l}\text { Wriggling body movements } \\
\text { Mild kicking and wiggling } \\
\text { Spreading of fingers and toes }\end{array}$ & $\begin{array}{l}\text { Shrugging shoulders } \\
\text { Putting fingers in mouth } \\
\text { Toes wiggling }\end{array}$ \\
\hline Injured Body Part & Scratching, picking painful part & $\begin{array}{l}\text { Not wanting to use body part } \\
\text { Ignoring, repelling body part } \\
\text { Letting someone else feel body part }\end{array}$ \\
\hline Social-Emotional & $\begin{array}{l}\text { Whining, complaining } \\
\text { State of arousal } \\
\text { Difficult to distract }\end{array}$ & $\begin{array}{l}\text { Destructive behaviour } \\
\text { Self-restrained behaviour } \\
\text { Self-hitting }\end{array}$ \\
\hline Vocal & Disorganised sucking & $\begin{array}{l}\text { Humming, self-stimulating noises } \\
\text { Spitting } \\
\text { Grumbling, angry shrieks }\end{array}$ \\
\hline Physiological & $\begin{array}{l}\text { Blood pressure } \\
\text { Shivering } \\
\text { Increased respiration rate }\end{array}$ & $\begin{array}{l}\text { Rumination } \\
\text { Absence of rumination } \\
\text { Incontinence }\end{array}$ \\
\hline $\begin{array}{l}\text { Activities of Daily } \\
\text { Living }\end{array}$ & $\begin{array}{l}\text { Taking medications when (s)he normally refuses } \\
\text { Sleeping pattern } \\
\text { Sleeping during preceding hour }\end{array}$ & $\begin{array}{l}\text { Developmental reversion } \\
\text { Refusing to drink } \\
\text { Drinking a lot }\end{array}$ \\
\hline
\end{tabular}

Table 5 (page 41) summarises the results of the comparison with the literature for each matrix. As Table 5 illustrates, it was especially the interviewees who reported the measurement scale items taken from the literature, as well as some additional expressions. Items from the literature relating to the Vocal category were mentioned particularly often. Thirteen of the 14 vocal items found in the literature $(93 \%)$ were reported by the interviewees, with an average of 8.6 times per expression. Other measurement scale items from the literature that were frequently 
mentioned by the interviewees were those from the Facial (80\%) and Injured Body Part matrices $(88 \%)$. The category with the lowest percentage in this respect was the Physiological matrix, although the interviewees did spontaneously mention $41 \%$ of all physiological items taken from the literature. The Social-Emotional matrix accounts for the second highest density of measurement scale items from the literature reported by the interviewees. These 19 expressions were mentioned an average of 6.5 times each.

\begin{tabular}{|c|c|c|c|c|c|c|c|}
\hline & Facial & Motor & $\begin{array}{l}\text { Injured } \\
\text { Body Part }\end{array}$ & $\begin{array}{l}\text { Social- } \\
\text { Emotional }\end{array}$ & Vocal & $\begin{array}{l}\text { Physio* } \\
\text { logical }\end{array}$ & $\begin{array}{l}\text { Activities } \\
\text { of Daily } \\
\text { Living }\end{array}$ \\
\hline $\begin{array}{l}\text { Number of measurement scale items } \\
\text { taken from the literature }\end{array}$ & $25(2.8)$ & $37(2.4)$ & $9(2.2)$ & $27(2.0)$ & $14(3.1)$ & $17(2.2)$ & $9(2,2)$ \\
\hline $\begin{array}{l}\text { Number of measurement scale items } \\
\text { from literature observed in children } \\
\text { present study }\end{array}$ & $9(3.2)$ & $12(4)$ & $2(2.5)$ & $4(2.0)$ & $6(3.6)$ & $3(2.3)$ & $0(---)$ \\
\hline $\begin{array}{l}\text { Number of measurement scale items } \\
\text { from literature reported in interviews } \\
\text { present study }\end{array}$ & $20(5.1)$ & $18(4.5)$ & $7(5.7)$ & $18(6.8)$ & $13(8.6)$ & $7(3.7)$ & $6(4.7)$ \\
\hline $\begin{array}{l}\text { Number of measurement scale items } \\
\text { from literature not observed or } \\
\text { reported in present study }\end{array}$ & $4(2.0)$ & $15(2.1)$ & $1(1.0)$ & $9(1.8)$ & $1(1.0)$ & $9(2.1)$ & $3(3.0)$ \\
\hline $\begin{array}{l}\text { Number of additional expressions } \\
\text { observed in children present study }\end{array}$ & $10(2.3)$ & $3(2.3)$ & $0(---)$ & $3(2.0)$ & $1(2.0)$ & $0(-\cdots)$ & $0(---)$ \\
\hline $\begin{array}{l}\text { Number of additional expressions } \\
\text { reported in interviews present study }\end{array}$ & $11(2.4)$ & $4(1.8)$ & $3(2.3)$ & $26(2.9)$ & $8(1.3)$ & $6(1.3)$ & $5(2.6)$ \\
\hline
\end{tabular}

(1) The $\mathbf{2 5}$ different measurement scale items taken from the literature in the 'Facial' category were overall mentioned 71 times in the 16 selected scales with an average of 2.8 times per expression. The number between brackets thus represents the density per expression per source

In terms of absolute numbers, the greatest number of additional expressions found in the interviews but not identified in the literature belonged to the Social-

Emotional category. No less than 26 different additional expressions were reported in this category. With a density of 2.9, meaning that each additional expression was referred to in an average of three different interviews, the Social-Emotional matrix had the highest average frequency of additional expressions.

The observations yielded fewer expressions than those reported in the literature, and fewer 'new' expressions were found. An exception in this respect is the Facial matrix. No less than 10 'new' expressions were observed in this category, each of which was observed in at least two children. By contrast, no new expressions were added in the Physiological, Injured Body Part and Activities of Daily Living 
matrices. Of the expressions that were observed and were also mentioned in the literature, the highest percentage belonged to the Vocal matrix. In addition, $36 \%$ of the measurement scale items from the literature relating to the Facial category were also recorded during the observations. In the Social-Emotional category, however, only four of the 27 items were observed. The Activities of Daily Living category did not yield any observed expressions, neither those mentioned in the literature, nor additional ones.

Finally, Table 5 shows that the Motor matrix was the category with the largest number of measurement scale items found in the literature but not in observations and interviews. Sixteen of the 38 items taken from the literature in this category were neither observed, nor reported. Both the Vocal and the Injured Body Part matrices yielded only one item that was not identified in the observations and interviews.

\subsection{Discussion}

The present study used complementary research methods to establish a sound foundation for the measurement of pain in non-verbal children with severe to profound intellectual disabilities. The results of the present study show that the use of inductive research methods leads to a database with a huge number of potential expressions of pain. Although Streiner \& Norman (1998) state that item generation ideally leaves the researcher with far more items than ultimately end up on the scale, the size of the item bank we created was overwhelming. Although the large number of expressions can be partly attributed to the analysis at a detailed level, it seems that a simple but complete picture of pain behaviour cannot be provided, especially in the population we examined. Nevertheless, some behavioural expressions of pain, like 'Crying' or 'Grimacing', have proved to be of great importance for the assessment of pain in populations for whom there simply is no other information available. The results of the present study show that these 'common' expressions also seem to be important in children with severe intellectual disabilities.

However, there also seem to be differences between such children and nondisabled children regarding the expression of pain. Normal behaviour in children with severe intellectual disability simply is not the same as that in children without cognitive delay. Individuals with severe intellectual disabilities form an extremely heterogeneous group in terms of functional abilities and behavioural repertoires. In their study of risk factors for behavioural problems, Chadwick and colleagues (2000), for one, underline the importance of independent mobility as a prerequisite for the manifestation of many of the behaviours characterised as problematic. Children with multiple disabilities simply are unable to bang their heads against the wall when in pain. In view of such differences in abilities, not all of the expressions 
of pain we collected are applicable to all children, which underlines the importance of baseline measurements in this population. If self-injurious behaviour is a part of a child's behavioural repertoire, this has to be taken into account when diagnosing pain.

\subsubsection{Interviews and observations}

The interviews resulted in more expressions than the observations. The average number of over 25 expressions mentioned per interview is remarkable, especially since the interviewees spontaneously mentioned all the recorded expressions. This can be explained by the fact that the professional caregivers based their answers on their general knowledge of pain assessment in all children with severe to profound intellectual disabilities, and did not refer to one specific child. Furthermore, the interviewees referred to the expression of pain in general, without distinguishing between different types of pain, which might also account for the large number of expressions mentioned.

Different types of caregivers mentioned different types of expressions. This finding supports our decision to include a range of caregivers involved in the daily care of children with intellectual disabilities in the interviews. This effect was most obvious with respect to the expressions belonging to the Social-Emotional category. Behavioural therapists mentioned a huge number of expressions in this category that in their view could be indicative of pain. In view of the greater prevalence of behavioural and emotional disturbance in children with intellectual disabilities (Einfeld \& Tonge, 1995) it seems useful to assess these kinds of expressions in greater detail in future research.

Our own observations of individual children resulted in a smaller range of expressions, which could be regarded as a limitation of the present study. Only 32 children were observed during possibly painful situations, most having profound multiple disabilities. Children were observed in an open manner, meaning that only behaviour which struck the observer as aberrant was recorded. Since the observer did not use a checklist of expressions from the literature when observing the children, other behavioural indications could have been present. Furthermore, there is the possibility that the children did not display changes in behaviour because they did not experience any pain. Another point is whether a change in behaviour actually occurs at the time when an intervention takes place. Several caregivers reported that children might not display behavioural changes straight away, but might respond to painful stimuli after a certain delay. This may have influenced especially the immunisation observations, since the observer followed the nurse on immunisation rounds and did not stay with the children. Finally expressions included in the Activities of Daily Living matrix are not likely to show up during the possibly painful situations chosen in the present study. For example, there was simply no food offered to children while they were undergoing 
immunisation. It is thus obvious that no such expressions were recorded during immunisation. Hence, the Activity of Daily Living matrix is also one of the matrices that did not yield any new expressions during the observations.

According to the interviewees, facial, vocal and social-emotional expressions seem to be most important when diagnosing pain in children with severe intellectual and communicative disabilities. The large number of expressions mentioned by the behavioural therapists, however, might have biased this finding. On the basis of the results of the observations, the Facial, Motor and Vocal categories seem to be the most valuable. Overall, the Physiological category did not account for many expressions, which would seem to contradict the large number of signs and symptoms of disease reported as pain expressions. Caregivers may have focused on signs of nociception rather than on the physiological expression of pain itself. The risk of diagnosing pain in such a manner is that pain may be regarded as absent if no tissue damage is found.

\subsubsection{Additional expressions}

Some of the expressions that were identified in the present study and were not mentioned in the literature are conceptually not all that different from existing ones, so some of them might not really be 'new'. For example, some of the additional expressions we found in the Facial category are known to be indicators in the Child Facial Coding System (Chambers et al., 1996b). This was the case for the expression 'Cheek raiser', 'Nose wrinkle', 'Upper lip raise' and Blink'. Some of the other additional expressions identified in the present study may also have been included in some published or unpublished pain scales not included among the 16 scales we selected from the literature. Thus, although the range of possible pain expressions we found was much wider, and some expressions were more specific, their nature was generally not greatly different from those found in other nonverbal populations.

One major exception however is the Social-Emotional category. This category did result in a large number of new candidate items for pain expression, such as 'Destructive behaviour', 'Self-restrained behaviour', 'Stereotypic behaviour', 'Compulsive behaviour', Tearing clothes apart', Problem behaviour' and 'Enjoying'. This finding can be attributed to the greater prevalence of behavioural and psychiatric disorders in individuals with intellectual disability. Dosen (1990) indicates that the prevalence of these disorders as a cross section of the literature ranges from 30 to $50 \%$ and that their prevalence increases in proportion to intellectual impairment. In their study on the assessment of psychopathology in intellectually disabled children, Einfeld \& Tonge (1995) reported that these children have about 2-4 times as many emotional and behavioural disturbances as other children. This could account for the various types of self-injurious behaviour that were identified in the present study. 'Selfslapping', 'Head banging', 'Hair pulling', Ear rapping' and 'Self-scratching', for example, 
can all be regarded as detailed descriptions of the concept of self-injurious behaviour.

Self-injuring was also identified as a measurement scale item in the study by Giusiano et al. (1995) although self-injurious behaviour was not described in further detail. In the study by McGrath and colleagues(1998), caregivers did not refer to self-injurious behaviour. Bosch and colleagues (1997), however, found that some forms of self-injurious behaviour might indeed reflect an individual's attempt to respond to or communicate pain or discomfort. Twenty-eight percent of the subjects in their research were found to have at least one active untreated medical problem potentially associated with pain. After medical intervention, all but one of these patients demonstrated a decrease in self-injurious behaviour.

In our study, while the professional caregivers interviewed mentioned self-injurious behaviour often, only one participating parent did so. Remarkably, Self-injurious bebaviour' was among the 10 expressions mentioned by over $50 \%$ of the interviewees. Of the seven expressions relating to self-injury, 'Head banging' and 'Self-bitting' were among the 28 expressions mentioned by a significant part of the interviewees (Table 2). In the observations, however, only the 'Self-slapping'item was observed. Another explanation for the many reports of self-injury could be the great impact of self-injury on caregivers. They have a hard time understanding why the children inflict such shocking behaviour on themselves and therefore might tend to report self-injury often in the interviews. Furthermore, although selfinjurious behaviour is regarded as typical of individuals with intellectual disabilities, it is remarkable that 'Self-biting' and 'Self-pinching' were also incorporated in one of the 16 scales derived from the literature on pain in normally developed children (Mills, 1996).

Facial and vocal information seem to be particularly important as expressions of pain in children with profound multiple disabilities. This is underlined by the fact that both the observations and the interviews yielded new expressions in this category. Parents in particular seem to pay a great deal of attention to facial expressions and they provided a vast amount of detailed information. A comparison of these results with the literature on communication by individuals with profound intellectual disabilities shows that, for example, movements of the mouth (Maat van der, 1992) and eyes (Velthausz, 1987) are recognised as important aspects of communication with such individuals. The present study identified six additional expressions involving the eyes and another six involving the mouth, underlining the importance of both items.

\subsubsection{Expressions not found}

Several measurement scale items mentioned in the literature were not identified in the present study. Sometimes there is an obvious explanation for this. Thus, an 
important factor is the setting in which the scales selected from the literature were developed. It is hardly surprising that an expression like 'Requires $\mathrm{O}_{2}$ for saturation' was not identified in the present study, since it is very much related to an ICU environment. Another explanation for not finding some of these items is the use of professional language. 'State of arousal', for example, is a term not easily used by caregivers and seems too general for the observations. Furthermore, some items taken from the literature are very specific, which might explain why the caregivers did not report them. An example would be Feet turned upwards at sharp angle to leg'. And since 'Grimacing' was extensively reported, this might explain the absence of Naso-labial furrow deepened' from the interviews. As the observations were not made in a 'top-down' fashion (i.e., using a checklist), it is likely that some of these expressions, though present, may not have been observed. Another reason for not finding certain measurement scale items in the dataset is the probability that items are not appropriate for the population under study. Takes medication when be/ she normally refuses'might only be applicable in individuals with more cognitive capabilities. McGrath and co-workers (1998) report a similar result regarding this measurement scale item taken from the tool of Chambers and colleagues (1996). Finally, there are some expressions for which there seems to be no obvious reason why they should not be present in the dataset.

\subsubsection{Comparison with current literature on pain assessment in individuals with intellectual disability}

We compared our data with those reported in recent publications on pain in individuals with intellectual disability. The comparison with recent work by Breau and colleagues(2001) shows that four of the seven core items of their initial checklist (McGrath et al., 1998), were (partially) reported in 8 or more interviews of our study (Table 2, page 37). These are the indicators 'Eyes', Tears', 'Seeking comfort, closeness', and 'Trritable, cranky'. From the measurement scale item 'Change in eyes' of Breau's checklist, the component 'Eyes closed tight' was mentioned seven times and the component Eyes wide open' was mentioned two times. The item Not cooperating', that is related to 'Tritable, cranky' in the checklist of Breau and colleagues, was mentioned seven times in the present study. Furthermore it can be reported that another eleven items of our Table 2 were also included in their initial 31-item checklist based on the work of McGrath and co-workers (1998). Not all the expressions in the original McGrath checklist however were found in our study. 'Sharp intake of breath' was not observed or reported, although 'Holding or drawing breatb', which comes rather close, was observed four times, so this might be explained as a translation issue. Another part of a measurement scale item that was neither observed nor reported in our dataset was 'Difficult to distract'. However the other part of this item Not able to satisfy or pacify' was mentioned four times in the interviews. Finally the measurement scale item 'Shivering' was not observed or reported in the present study. 
Of the ten currently used measurement scale items of Collignon and colleagues (2001), six items seem to be among the 28 expressions included in our Table 2. These are 'Facial expression', 'Crying', Moaning', High muscle tone, cramping', 'Attempting to witbdraw' and 'Avoiding touch or treatment'. From their 22 initially proposed measurement scale items (Giusiano et al., 1995), another 8 items seem to be present in our data, e.g. 'Self-injurious behaviour', 'Self-conjuring bebaviour', Increased involuntary movements', and Paradoxical laughter'.

\subsubsection{Recommendations}

The present study managed to compile a considerable item bank. It was concluded that non-verbal pain expressions in children with severe intellectual and communicative disabilities are diverse and depend on the individuals' baseline behaviour. Future research should examine the importance and prevalence of the different expressions. At present, there seems to be a discrepancy between those behavioural expressions of pain that children might have in common, and those that might be unique to specific children. Standard scientific method would require the elimination of those items that are not representative of a considerable number of children. It may be questioned, however, whether this specific paediatric population would benefit most from such an approach. Before items can be selected for a pain assessment scale and its content validity can be established, further insight should be gained into the nature of the expressions collected. Only then can the best items be selected from the item bank and can reduction take place. In several studies we are currently trying to answer these questions and we expect to report these findings soon. It seems essential to develop scales focusing on more 'homogeneous' subgroups, such as children with profound multiple disabilities. Furthermore it should be investigated whether it would be possible to create an Individual Pain Profile. In any case, the ultimate aim of developing a generic pain assessment tool remains a challenging task. 



\section{Chapter 3}

Pain assessment in intellectually disabled people: nonverbal indicators used by nurses

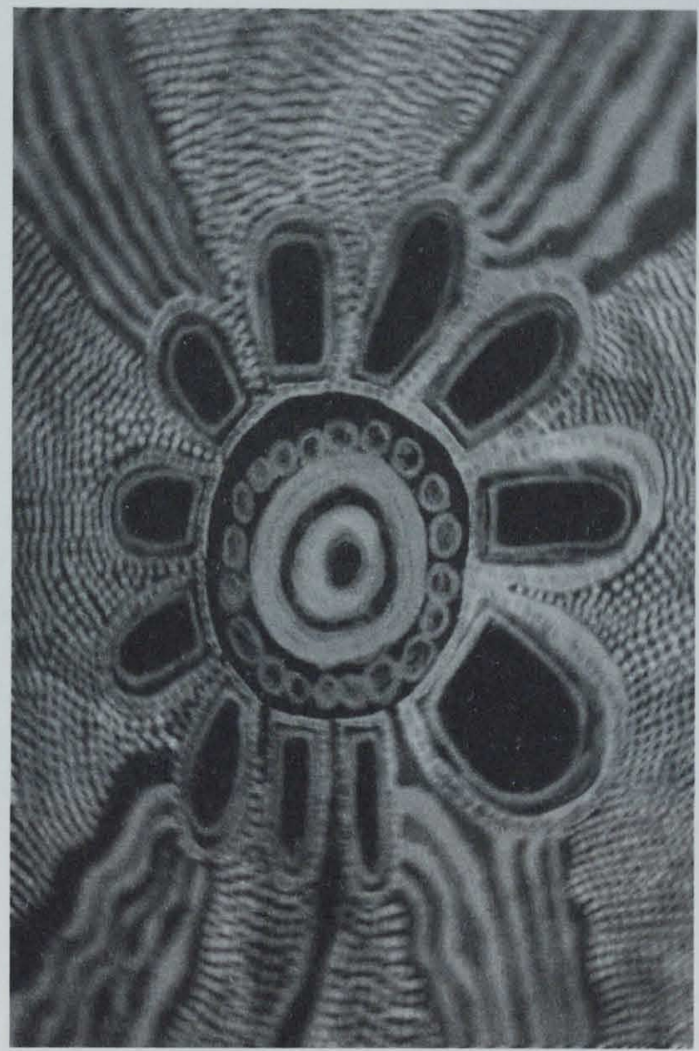

Sandra M.G. Zwakhalen, Katinka A.J. van Dongen, Jan P.H. Hamers, Huda Huijer Abu-Saad. Based on paper published in: Journal of Advanced Nursing (2004) 


\section{Abstract}

The aim of this cross-sectional study was to investigate the nature and relative importance of non-verbal indicators used by nurses to assess pain in people with a severe or profound intellectual disability.

A questionnaire comprising a variety of pain indicators was used. Indicators were adopted verbatim from the studies by Giusiano et al. (1995) and McGrath et al. (1998). In addition, the questionnaire included the newly identified expressions from the item bank created in the study reported in Chapter 2 as well as signs of nociception and symptoms of disease, resulting in a total of 158 indicators used in the present study. A facet design distinguishing seven dimensions of pain behaviour was used. One hundred and thirty-five nurses from nine institutions specialising in the care of people with intellectual disability were asked to rate each indicator on a scale of 1 to 10 to show which non-verbal expressions they considered important in diagnosing pain.

One hundred and nine nurses responded. All 158 indicators were mentioned at least once as being important to indicate pain. All except four had a range of 9 . Seven indicators ('Moaning during manipulation', 'Crying during manipulation', Painful facial expression during manipulation', 'Swelling', 'Screaming during manipulation', Not using (affected) body part', and 'Moving the body in a specific way') were reported as 'very important' by more than $50 \%$ of the nurses. The lowest score (median 5.5 ) was given to the indicator 'Waving arm movements'. Pain in people with severe intellectual disability appeared to be assessed differently from that in people with profound intellectual disability. Indicators of the Physiological dimension were given higher scores by the group of nurses specialising in profound disability. By contrast, indicators belonging to the Social-Emotional dimension received higher scores from nurses specialising in severe disability. Two additional expressions of pain were identified in this study. Thus, the item bank developed in Chapter 2 now comprised 211 expressions.

Nurses used a wide range of indicators to assess pain in people with intellectual disability. Functional abilities and level of disability seemed to influence the indicators nurses regarded as important. Indicators referring to the context as well as those referring to nociception were regarded as most important. These data, however, could not be used to reduce the number of items in the item bank. 


\subsection{Introduction}

Pain is always a subjective and complex response, and different people may react in different ways to the same stimulus, or the same person may react differently in different situations or at different moments (Pigeon et al., 1989). Assessing pain can be extremely difficult if the person has a severe or profound intellectual disability and lacks the ability to communicate verbally. Gathering more information about pain in people with intellectual disabilities is of major importance and relevance for nursing, and adds to the developing body of knowledge. Discovering what nurses, health care workers, and parents consider important is the first step in understanding pain in people with an intellectually disability. Having a clear insight into pain is necessary for the development of a valid and reliable assessment scale for use with people with an intellectual disability.

Assessment of pain allows nurses to detect and relieve it in clients. Without objective assessment, pain could be misinterpreted or underestimated, which might lead to inadequate management and undermine quality of life (Malviya et al., 2001). The preliminary findings of a recent study suggest that everyday pain in people with severe intellectual disability is common, yet is rarely actively treated (Stallard et al., 2001). Concurrent health problems, directly or indirectly linked to the disability, often lead to painful situations. An example is gastroscopy, a medical procedure performed in suspected gastro-oesophageal reflux, which is a common condition in people with severe or profound intellectual disability (Tracy \& Wallace, 2001). People with this level of intellectual disability are more likely to have other disabling conditions, or to have multiple complex medical problems coupled with communication difficulties. Recent studies showed that people with intellectual disability appeared to have 2.5 times more health problems than people without intellectual disability (Schrojenstein Lantman van - Valk de et al., 2000).

Few studies on pain among people with intellectual disability have been published. There are several reasons why pain assessment in this group of people has lagged behind. To begin with, many have neurological problems that may alter the neurological system and affect their ability to comprehend and communicate pain (Oberlander, et al., 1999a). In view of an inability to communicate pain verbally and a relative lack of intellectual ability, the gold standard of pain measurement, i.e. selfreport, cannot be used. Furthermore, people with severe or profound intellectual disability often have multiple handicaps and form an extremely heterogeneous group in terms of functional and behavioural repertoires. Behaviour that is typically associated with pain may well appear at times when they are not in pain, or behavioural limitations may mask expressions of pain (McGrath et al., 1998). Although, recently, more information about expressive behaviour related to pain in people with intellectual disabilities has been gathered (Fanurik et al., 1999a; Oberlander \& O'Donnel, 2001; Donovan, 2002; Carter et al., 2002; Stallard et al., 2001; Stallard et al., 2002b; Hadden \& Bayer von, 2002), research on this topic is 
still scarce. Only a few tools for assessing pain in this specific population have been developed, most of which have been psychometrically tested in a paediatric population (Collignon \& Giusiano, 2001; Breau et al., 2001; Breau et al., 2002a; Breau et al., 2002b; Hunt et al., 2002; Stallard et al., 2002a; Dongen van et al., 1999; Dongen van et al., 2002b).

Guisiano et al. (1995) developed a scale consisting of 22 items that physicians felt were indicative of pain. Results provide evidence of a common set of pain behaviours in people with cerebral palsy and severe intellectual disabilities. Different items were found to be important in determining pain, depending on the person's level of development. Collignon et al. (1997), members of the same research group as Guisiano, later developed a 10 -item observational scale to evaluate pain and facilitate therapeutic decisions in children with severe handicap and adults with cerebral palsy. This study built on their earlier work. Recently, Collignon \& Giusiano (2001) concluded that this tool seems to be sensitive and reliable enough to assess pain in this population.

McGrath et al. (1998) created a checklist of 31 behaviours that caregivers could use to assess pain in people with intellectual disability who lack verbal communication. Breau et al. (2002a) report that a revised version of the Non-Communicating Children's Pain Checklist is internally consistent, sensitive and specific to pain, and produces results that are significantly related to pain intensity ratings provided by caregivers and consistent over time. In addition, Stallard et al. (2002a) conducted a study that extends the work of McGrath et al. (1998) and explores the expression of chronic pain in non-communicating children with a significant intellectual disability. As a result of this study, six core items were identified and the Pain Indicator for Communicatively Impaired Children (PICIC) was produced. In a further study, Stallard et al. (2002b) demonstrated a significant relationship between five out of the six core items and the presence and severity of pain.

In an ongoing programme of research in the Netherlands, Van Dongen and colleagues (1999) have conducted several studies to gain insight into non-verbal pain expressions in children and young adults with severe intellectual and communicative disabilities. This ongoing programme should, ultimately, lead to the development of an instrument to assess pain in children with profound intellectual and verbal disability. In addition to a review of the literature, these researchers used qualitative methods as a first step in creating an item bank that consists of 209 expressions of pain. In view of this overwhelming number, the study presented in this paper was designed to evaluate the importance of a number of these nonverbal expressions, by investigating which indicators nurses consider important in diagnosing pain in people with severe or profound intellectual disability. In particular, the study aimed to investigate: (1) the nature, frequency and relative importance of the indicators that nurses use to determine pain in people with 
severe to profound intellectual disability, and (2) the differences between two groups of nurses (those working only with people with severe intellectual disability versus those working only with people with profound intellectual disability) in terms of the indicators considered important.

\subsection{Methods}

\subsubsection{Objective}

The objective of the study was to investigate the nature and relative importance of non-verbal indicators used by nurses to assess pain in people with a severe to profound intellectual disability.

\subsubsection{Defining the research population: 'severe to profound intellectual disability'} According to the American Association on Mental Retardation (AAMR) 'Mental retardation is a disability characterized by significant limitations in botb intellectual functioning and conceptual, social, and practical adaptive skills. This disability originates before the age 18." (AAMR, 2002a).

Furthermore, the Diagnostic and Statistical Manual of Mental Disorders - Fourth Edition (DSM-IV) distinguishes four levels of 'mental retardation', based on intelligence quotient (IQ) scores, namely: mild (IQ 50-55 to 70), moderate (IQ 3540 to $50-55$ ), severe (IQ 20-25 to 35-40) and profound (IQ below 20 or 25) (American Psychiatric Association, 1994). Although the term 'mental retardation' is still valuable in terms of diagnostic use, it had been replaced by several other terms. 'Cognitive impairment', 'neurological impairment', 'developmental disability' and 'intellectual disability' are often used in the literature, usually to describe the same condition. The term 'intellectual disability' is preferred for several reasons. The World Health Organization (2002) and the International Association for the Scientific Study of Intellectual Disabilities (IASSID), which is a sister organization of the AAMR, also use the term 'intellectual disability'. Furthermore, the term is used in a number of journal names all with clear links to 'mental retardation'.

\subsubsection{Participants}

As self-reports cannot be obtained, acquiring information on behaviour related to pain requires informants who are expert at observing and interpreting pain. Because of their expertise, nurses and other healthcare workers were expected to be able to provide pain-relevant information about the people they cared for on a regular basis. They were expected to know which behaviours were indicative of pain and to be sensitive to clients' ability to communicate without expressive language. Therefore, in our study, nurses specializing in nursing people with intellectual disabilities (children and/ or adults) were asked to complete a questionnaire. While this article focuses on nurses, parents are another important 
source of information about pain. In an ongoing study (Dongen van et al., 2002b), information from parents is being gathered on indicators that they use to determine pain in children with severe to profound intellectual disability who are living at home.

\subsubsection{Methods}

A cross-sectional design was used to answer the research questions. Nurses were selected from nine residential homes throughout the Netherlands, specializing in the daily care of people with severe and/ or profound intellectual disability. More than one year of experience in this specific field of nursing was required. In each institution, a contact person was designated who was responsible for distributing and collecting questionnaires. A covering letter, detailing aims and procedures, was sent with the questionnaire and nurses were asked to respond within two weeks. Of the 135 nurses that were invited, 109 eventually participated, 96 women and 13 men.

\subsubsection{Questionnaire}

The questionnaire was developed especially for this study. A total of 158 possible indicators of pain was included, based on existing pain measurement scales for people with intellectual disability (Giusiano et al., 1995; McGrath et al., 1998) and on the results of an ongoing project (Dongen van et al., 1999). Newly identified items resulting from this ongoing project as well as signs of nociception and symptoms of disease were used as indicators in the present questionnaire. The first part of the questionnaire sought demographic information, including gender, educational level and years of experience working with people with intellectual disability. The second part listed the 158 indicators. A 10-point scale was used for responses, with 1 indicating that an item was 'completely unimportant' as an indicator of pain and 10 indicating that it was 'very important' (see Table 1).

\section{Table 1}

Pain indicator section from the questionnaire (for the 'Vocal' category)

How important are the following indicators for identifying pain in severely or profoundly intellectually disabled individuals?

\begin{tabular}{l|llllllllll} 
indicator & \multicolumn{3}{l}{$\begin{array}{l}\text { completely } \\
\text { unimportant }\end{array}$} & & & & & & & $\begin{array}{r}\text { r } \\
\text { very } \\
\text { important }\end{array}$ \\
\hline (1) Verbal expressions & 1 & 2 & 3 & 4 & 5 & 6 & 7 & 8 & 9 & 10 \\
(2) Moaning / groaning & 1 & 2 & 3 & 4 & 5 & 6 & 7 & 8 & 9 & 10 \\
(3) Moaning during manipulation & 1 & 2 & 3 & 4 & 5 & 6 & 7 & 8 & 9 & 10 \\
(4) Moaning more than usually & 1 & 2 & 3 & 4 & 5 & 6 & 7 & 8 & 9 & 10 \\
(5) Crying & 1 & 2 & 3 & 4 & 5 & 6 & 7 & 8 & 9 & 10 \\
\hline
\end{tabular}

The 158 indicators were divided into seven categories: Facial $(\mathrm{N}=26$ items), Motor $(\mathrm{N}=32)$, Injured Body Part $(\mathrm{N}=11)$, Social-Emotional $(\mathrm{N}=28)$, Vocal $(\mathrm{N}=24)$, Physiological $(\mathrm{N}=22)$ and Activities of Daily Living $(\mathrm{N}=15)$. The categories were based on a facet design, in order to improve face and content validity, and related to the ways in which pain can be expressed non-verbally. A facet design is a scheme 
covering all the relevant dimensions of a construct that is going to be measured (Shye, 1978). Categories, as well as indicators, were based on comparison of common categories of existing scales for the measurement of pain in non-verbal populations and scales developed for the assessment of communication in people with profound intellectual disabilities (McGrath et al., 1998a; McGrath et al., 1998b; McGrath et al., 1985; Mills, 1996; Craig \& Gruneau, 1993; Lawrence, 1993; Ambuel, 1992; Van der Maat, 1992; Velthausz, 1987; Algra, 1992). The facet design used for this study was presented in Chapter 1 . Nurses were asked whether or not the questionnaire was comprehensive and could suggest additional indicators. Content validity was further tested by consulting 11 experts in the field of intellectual disabilities. Data on reliability will be presented in the results section.

\subsubsection{Ethical considerations}

Permission to conduct the study was obtained from the managing directors of the institutions by giving permission to consult nurses. Each institution was asked to provide the names of 15 nurses who might be willing to participate in the study. Nurses were approached through the contact person and participated on a voluntary basis.

\subsubsection{Data analysis}

All data were analyzed using SPSS 10.0. Descriptive statistics were generated for the characteristics of the participants. The indicators that nurses used to identify pain were examined using frequency tables. Both medians and trimmed means were computed and are reported in the paper. The 5\% trimmed means were computed by ranking the values within each group from the smallest to largest, trimming 5\% from the top and 5\% from the bottom of each group, and then computing the usual means for the remaining observations. This procedure ensures that unusual values in the tails of the distribution do not affect the value of the mean. However, emphasis is placed on the median, as data are not normally distributed and, strictly speaking, trimmed means should be regarded as parametric statistics. Current literature, however, shows a growing interest in trimmed means taking into account outliers while still information on distribution can be provided (Wilcox, 2001). Ranking is based on valid percentage scores. Nonparametric MannWhitney $U$ tests were used to investigate whether there was a significant difference between the ways in which nurses in the two study groups assessed pain. Because of the risk of Type-I errors, $\alpha$ was set at 0.001 in order to correct for multiple testing.

Internal consistency analyses were carried out for all seven categories. Table 2 (page 56) shows high Cronbach's $\alpha$ values for all categories, ranging from 0.95 to 0.97 . Furthermore, it can be reported that all item-total correlations were over 0.40 . 
Table 2

Comparison of mean scores from 3 groups of nurses (overall; subgroup severe only; subgroup profound only) over the 7 categories of indicators including internal consistency

\begin{tabular}{ll|ccc|cc} 
Category & Description of the category & $\begin{array}{c}\text { Number of } \\
\text { indicators }\end{array}$ & Cronbach's a $\begin{array}{c}\text { Mean overall } \\
\text { group N=109 }\end{array}$ & $\begin{array}{c}\text { Mean severe } \\
\text { group N=14 }\end{array}$ & $\begin{array}{c}\text { Mean profound } \\
\text { group N=42 }\end{array}$ \\
\hline Category 1 & Facial & 26 & 0.97 & 7.3 & 6.9 & 7.2 \\
Category 2 & Motor & 32 & 0.97 & 7.0 & 6.5 & 6.9 \\
Category 3 & Injured Body Part & 15 & 0.96 & 7.6 & 7.3 & 7.3 \\
Category 4 & Social-Emotional & 28 & 0.96 & 6.8 & 6.8 & 6.6 \\
Category 5 & Vocal & 24 & 0.96 & 7.5 & 7.2 & 7.4 \\
Category 6 & Physiological & 22 & 0.97 & 7.9 & 7.0 & 7.9 \\
Category 7 & Activities of Daily Living & 11 & 0.95 & 7.4 & 7.8 & 7.3 \\
\hline
\end{tabular}

\section{$\underline{3.3 \text { Results }}$}

\subsubsection{Participants}

Questionnaires were returned by $89.6 \%$ of nurses $(N=121)$. Twelve questionnaires were excluded: 5 were incomplete, 4 were not related to pain in people with severe to profound intellectual disability, and 3 because nurses had less experience than was required.

Nurses ranged in age from 21 to 50 years (mean $=32.2 ; \mathrm{SD}=6.6$ years). With regard to nurses' education, the vast majority $(94.5 \%, \mathrm{~N}=103)$ had completed in-service education provided by the institution (diploma nurse), but only two had completed Middle level Professional Education in Nursing and four a Higher Professional Education in Nursing. The mean number of years of experience in nursing was 8.8 (SD 6.7 years) and the mean number of years of experience with the client group was also 8.8 (SD 6.0 years). Many nurses (43\%, N=47) worked full-time and only three were employed for less then 15 hours a week. Thirty-eight per cent of nurses were working primarily with people with profound intellectual disabilities, $13 \%$ with people with severe intellectual disabilities, and $49 \%$ were involved with both.

\subsubsection{Pain indicators used by nurses}

The first research question related to the nature, frequency and relative importance of the indicators that nurses used to determine pain in people with severe to profound intellectual disabilities. To assess which of the 7 categories nurses considered most important in determining pain, means were computed using the summed scores of the indicators in each category. Table 2 shows that the Physiological category achieved the highest overall mean score (7.9), while the Social-Emotional category (mean $=6.8$ ) was less frequently classed as being important. The 109 participants scored a wide variety of indicators as important for assessing pain in people with severe to profound intellectual disability. All 158 indicators were selected at least once as being very important, and $94.5 \%$ of respondents thought that combinations of indicators were important in assessing pain. The list of 158 indicators seemed to be content valid, as only two relevant 
additional items were mentioned as being possibly indicative of pain ('Looking angry' and 'Taking of clothes, shoes').

All indicators had a range of 9 (minimum 1, maximum 10), except for 'Mood changes' (3-10), Reacting differently to nursing staff (5-10), Facial expressions' (4-10) and Paleness' (3-10). Furthermore, it can be reported that the lowest score, was given to the indicator 'Making waving arm movements' (median 5.5; minimum 1, maximum 10; trimmed mean 5.39; SD 2.48). Based on calculated medians, the highest item scores, for the overall sample were given to the indicators Moaning during manipulation (of the affected body part)', 'Crying during manipulation', Painful facial expression during manipulation', 'Swelling', 'Screaming during manipulation', Not using (affected) body part', and 'Moving the body in a specific way of behaving'. These seven indicators were reported as 'very important' (10 on a 10-point scale) by more than $50 \%$ of nurses and are presented in Table 3. Ranking is based on valid percentage of nurses scoring a 10 .

\section{Table 3}

The highest scoring indicators based on the medians which scores 10 in the overall group $(N=109)$

\begin{tabular}{|c|c|c|c|c|}
\hline Indicator & Min / Max & $\begin{array}{l}\text { Valid percentage } \\
\text { Median }=10\end{array}$ & Trimmed mean & $\begin{array}{l}\text { Standard } \\
\text { deviation }\end{array}$ \\
\hline Moaning during manipulation & $1 / 10$ & $60 \%$ & 9.3 & 1.8 \\
\hline Crying during manipulation & $1 / 10$ & $59 \%$ & 9.3 & 2.1 \\
\hline Painful facial expression during manipulation & $1 / 10$ & $56 \%$ & 9.4 & 1.8 \\
\hline Swelling & $1 / 10$ & $54 \%$ & 9.2 & 2.0 \\
\hline Screaming during manipulation & $1 / 10$ & $53 \%$ & 9.0 & 2.4 \\
\hline Not using (affected) body part & $1 / 10$ & $52 \%$ & 9.2 & 2.0 \\
\hline Moving the body in a specific way of behaving & $1 / 10$ & $51 \%$ & 8.8 & 2.4 \\
\hline
\end{tabular}

\subsubsection{Severely versus profoundly disabled clients}

The second research question referred to the difference between nurses caring only for people with severe intellectual disability $(N=14)$ and those caring only for people with profound intellectual disability $(\mathrm{N}=42)$. A comparison was made in terms of the indicators that they considered important in determining pain in their clients. The remaining nurses $(N=53)$ were taking care of both groups. In the group of nurses working with people with severe disabilities the indicator Unusual way of crying' received the highest score (median 10; minimum 1, maximum 10; trimmed mean 8.6; SD 3.0). In this group only this single indicator received such a high score. All other computed medians were lower than 10. Several indicators, all referring to eating and drinking, also scored high in this group, Refusing to drink' (median 9; minimum 5, maximum 10; trimmed mean 9.1; SD 1.7), Refusing to eat' (median 9; minimum 4, maximum 10; trimmed mean 9.0; SD 1.6), and Eating little' (median 9; minimum 7, maximum 10; trimmed mean 8.8; SD 1.1). These indicators were of less importance in determining pain for nurses working with clients with profound intellectual disability. 
The scores of nurses caring for those with profound disabilities $(N=42)$ were more similat to those of the total group $(\mathrm{N}=109)$. Within this group, the following indicators were considered most important (median for all indicators $=10$ ): 'Screaming during manipulation' (minimum 1, maximum 10; trimmed mean 8.7; SD 2.8); Painful facial expression during manipulation' (minimum 1, maximum 10; trimmed mean 9.5; SD 1.5); Moaning during manipulation' (minimum 2, maximum 10; trimmed mean 9.4; SD 1.7); 'Crying during manipulation' (minimum 1, maximum 10; trimmed mean 9.3; SD 2.4); 'Swelling' (minimum 1, maximum 10; trimmed mean 9.2; SD 1.8); Not using affected body part' (minimum 2, maximum 10; trimmed mean 9.2; SD 1.7), and 'Moaning more than usually' (minimum 1, maximum 10; trimmed mean 9.0; SD 2.1). Six of the seven indicators mentioned by nurses working with people with profound disabilities as being most important also occurred in the highest scoring indicators for respondents as a whole (Table 3).

Although the group of nurses working with people with severe disabilities was not very large $(\mathrm{N}=14)$, there seemed to be some differences between the way they assessed pain and the way it was assessed by nurses working with people with profound disabilities $(\mathrm{N}=42$ ). Using an $\alpha$ of 0.001 , a Mann-Whitney $U$ test indicated that, strictly speaking, only the indicator 'Moaning during manipulation' showed a clear significant difference.

\section{Table 4}

Indicators with largest relative differences in medians between nurses working with severely intellectually disabled individuals $(\mathrm{N}=14)$ and those working with profoundly disabled individuals $(\mathrm{N}=42)$

\begin{tabular}{ll|cccc|c} 
Indicator & Category & $\begin{array}{c}\text { Median } \\
\text { severe } \\
(\mathrm{N}=14)\end{array}$ & Min / Max & $\begin{array}{c}\text { Median } \\
\text { profound } \\
(\mathrm{N}=42)\end{array}$ & Min / Max & $p$-value \\
\hline Moaning during manipulation & Vocal & 8.0 & $1 / 10$ & 10.0 & $2 / 10$ & 0.000 \\
Crying during manipulation & Vocal & 9.0 & $1 / 10$ & 10.0 & $1 / 10$ & 0.014 \\
Turning red in the face & Physiological & 6.0 & $1 / 10$ & 8.0 & $1 / 10$ & 0.034 \\
Seeking comfort & Social-Emotional & 8.0 & $1 / 10$ & 6.0 & $1 / 10$ & 0.036 \\
Vomiting & Physiological & 7.0 & $1 / 10$ & 9.0 & $1 / 10$ & 0.040 \\
Being grouchy & Social-Emotional & 7.0 & $5 / 10$ & 6.0 & $1 / 10$ & 0.042 \\
Gasping for breath & Physiological & 8.0 & $1 / 10$ & 9.0 & $1 / 10$ & 0.048 \\
Change in breathing & Physiological & 8.0 & $1 / 10$ & 9.0 & $1 / 10$ & 0.051 \\
Slaw heart rate & Physiological & 7.0 & $1 / 10$ & 8.0 & $1 / 10$ & 0.051 \\
Moaning & Vocal & 8.0 & $1 / 10$ & 9.0 & $3 / 10$ & 0.059 \\
Eating little & Activities of Daily Living & 9.0 & $7 / 10$ & 8.0 & $1 / 10$ & 0.062 \\
Increasing hart rate & Physiological & 6.5 & $1 / 10$ & 8.0 & $1 / 10$ & 0.067 \\
Breath holding & Physiological & 7.0 & $1 / 10$ & 8.0 & $1 / 10$ & 0.079 \\
Being angry & Social-Emotional & 7.5 & $1 / 10$ & 6.5 & $1 / 10$ & 0.086 \\
Increasing grimacing & Facial & 8.0 & $5 / 10$ & 9.0 & $1 / 10$ & 0.088 \\
Being irritated & Social-Emotional & 7.0 & $5 / 10$ & 6.0 & $1 / 10$ & 0.091 \\
Stretching the body & Motor & 6.0 & $1 / 10$ & 8.0 & $1 / 10$ & 0.100 \\
Refusing to eat & Activities of Daily Living & 9.0 & $5 / 10$ & 8.5 & $1 / 10$ & 0.103 \\
(1) A non-parametric test (Mann-Whitney U test) was used to test whether differences between groups were significant & & \\
(2) After Bonferroni correction only the first item differs significantly (Bonferroni corrected o 50.00032$)$ & & & \\
\hline
\end{tabular}

Table 4, however, presents the 18 indicators with the largest relative differences in medians. Since a plot of the $p$-values did not show a clear cut-off point, this 
absolute line was drawn because the $19^{\text {th }}$ indicator was the first indicator not to show an absolute difference in median between the groups of nurses.

Table 4 presents relative differences in the median scores for indicators, which show a trend that is relevant to comparing the two groups of nurses. It shows that indicators belonging to the Physiological and Vocal category scored relatively higher in the group of nurses specializing in profound disability. In contrast, indicators belonging to the Social-Emotional and Activities of Daily Living category scored relatively higher by nurses specializing in severe disability people.

\section{$\underline{3.4 \text { Discussion }}$}

We used a cross-sectional design and questionnaires focusing on the non-verbal indicators that nurses consider important in assessing pain in people with severe to profound intellectual disability. Some limitations need to be addressed before conclusions can be drawn.

First, the results must be interpreted with caution, given the limited number of respondents $(N=109)$, and the large number of indicators $(N=158)$ included in the questionnaire. Respondents were selected from nine institutions, a factor which limits generalizability. Second, there is the problem that the people cared for by respondents were very heterogeneous in terms of age, abilities and disabilities, behaviour and health status, and this poses the question of whether it is feasible to answer questions in relation to such a broad spectrum of people. This may explain the large number of indicators that were regarded as important. Furthermore, the nurses in this study provided information based on their estimation of the severity of disability. Although it is not uncommon to use the judgments of respondents to assess the severity of disability (Fanurik et al., 1999a), it might have been better to verify the correctness of this judgment by using a more objective assessment method. Third it can also be questioned whether nurses are able to provide painrelevant information in a situation that does not allow self-assessment. So far, however, there is no hard evidence that nurses working on a daily basis with people with severe to profound intellectual disability are insensitive to changes in pain behaviour.

The aim of the study was to examine the nature and relative importance of the indicators that nurses use to determine pain in people with severe to profound intellectual disability. The analysis showed that all indicators were rated as important by at least one respondent. This suggests that nurses used a multitude of indicators in assessing pain in this client population. Several explanations for these results can be proposed. First, nurses working with people with severe to profound intellectual disability in a residential setting may use all possible pain-relevant information and, therefore, choose a broad range of pain indicators. Our findings 
suggest that many behaviours and signs that occur during painful events are used to identify pain.

Another explanation for our findings might be that the numerous pain indicators included in the questionnaire showed some overlap and sometimes only differed from another slightly. The indicators may have been too specific, reducing their power of discrimination as is underlined by the high internal consistency ratings. Furthermore, nurses were asked what indicators seemed to be important in determining pain. This question might be one of the reasons why almost all indicators had a range of 9 . More relevant information might have been gathered by means of a more specific question, such as: "Imagine a painful situation. What indicators occur when a client is exposed to this situation?" A third explanation might relate to individual pain responses. It is conceivable that specific indicators would have to be selected for specific people. The wide range found for almost every indicator might underline the importance of individual pain response. Pain is a complex response, in that the same person may react differently in different situations and at different times, and in that different people may react differently to the same stimulus. This complexity, and the heterogeneity of clients, may well explain why such a large number of possible cues was selected by nurses. This might suggest that nurses do not want to discriminate between possible pain indicators in these people, as is also suggested by the wide range found for almost all indicators.

However, seven indicators were considered as being very important by more than half of the 109 participants, namely: Moaning during manipulation', 'Crying during manipulation', Painful facial expression during manipulation', 'Swelling', 'Screaming during manipulation', Not using affected body part' and 'Moving the body in a specific way of bebaving'.

For the most part, these indicators were derived from 22 items described in a study by Giusiano and colleagues (1995) and refer to medical examination. Thus, in diagnosing pain, nurses seem to rely mostly on behaviours relating to the situation in which they occur. In this context 'Moaning during manipulation' is regarded as more important (median 10; minimum 1, maximum 10; trimmed mean 9.3; SD 1.8) than Moaning more than usually' (median 9.5; minimum 1, maximum 10; trimmed mean 8.9; SD 1.9), which on its own is regarded as more important than just Moaning' (median 9.0; minimum 1, maximum 10; trimmed mean 8.6; SD 1.9). In addition to items relating to a context of medical examination, signs of nociception and symptoms of disease are also regarded as being important in labeling behaviour as pain behaviour. These findings are underlined by the result that, in respondents as a whole, the Physiological category had the highest mean score (mean $=7.9$ ) of all the categories, although many of the items belonging to this category are, in fact, symptoms rather than pain indicators. 
Three out of the seven indicators rated as most important by respondents as a whole are in the Vocal category. These findings are in line with those of other researchers who have stressed the importance of vocal information when diagnosing pain in people with profound intellectual disabilities. Donovan (2002), for example, found that nurses caring for a mostly preverbal population of people with intellectual disability reported that crying was often the only indication of pain. This finding is supported by Carter et al., (2002) who also report that, according to parents, vocalizations such as crying and moaning are often key means of pain expression in children with profound special needs. In their study, facial expression was another important indication that a child was in pain. Other authors have stressed the importance of both facial and vocal expressions of pain in people with severe intellectual disabilities (Stallard et al., 2002a; Breau et al., 2002b; Dongen van et al., 2002a; Oberlander et al., 2003). In our study several items relating to facial expression of pain were also rated as being important, although the Facial category was not among the most highly rated. The high number of detailed indicators within this category might explain this finding.

Another aim of our study was to examine differences in pain indicators used by nurses for people with severe versus profound intellectual disability. Although the group of nurses specializing in severe disability was small $(N=14)$, the results suggest that there are differences in this respect, as nurses in the two groups referred to different indicators as being important. Medians calculated were generally higher in the 'profound disability' group. Significantly different scores were found for the indicator 'Moaning during manipulation'. Although not statistically significant, the indicator 'Crying during manipulation' showed a relatively higher score in the group of nurses working with people with profound disability. Both these indicators belong to the Vocal category. This finding might indicate that nurses working with people with profound disabilities search for pain-relevant information more actively. This client group often has very limited verbal communication, leading to greater difficulties in identifying and assessing pain. Several of the Physiological indicators, such as 'Gasping for breatb', 'Vomiting' and 'Turning red in the face' were also given relatively higher scores by those specializing in profound disability. By contrast, relatively higher scores on the indicators 'Seeking comfort' and 'Being groucby' show the importance of Social-Emotional indicators to nurses caring for people with severe disability.

Furthermore, verbal expression was important for nurses diagnosing pain in clients with severe intellectual disability. The differences between nurses specializing in severe disability versus those specializing in profound disability seem to relate to the functional abilities of clients as well as their levels of intellectual disability. Although not resulting in significantly different scores, three indicators relating to eating and drinking aspects of the Activities of Daily Living category seemed to be 
rated differently by nurses working with clients with severe disabilities, as shown by higher median scores.

Studies contributing further to the understanding of pain in people with severe to profound intellectual disability would expand the knowledge base of nursing science. Research in this area of pain has important implications for nursing practice and patient care. Nurses play a unique role in pain assessment and management. They are at the bedside for long periods of time and have major responsibilities during the whole process. Without objective assessment, pain could be misinterpreted or underestimated, which might lead to inadequate pain management and undermine quality of life. Therefore, nurses need a set of valid and reliable 'pain indicators' to identify pain. The more specific and accurate the pain assessment, the more adequate nursing interventions could become, which would obviously be in patients' and nurses' best interests. It is hoped that the findings of our study will stimulate further research in this highly specific area, which could contribute to more effective assessment and management of pain by nurses. 




\section{Chapter 4}

Behavioural repertoires of children with severe to profound intellectual disabilities in pain: a comparison based on parents' report

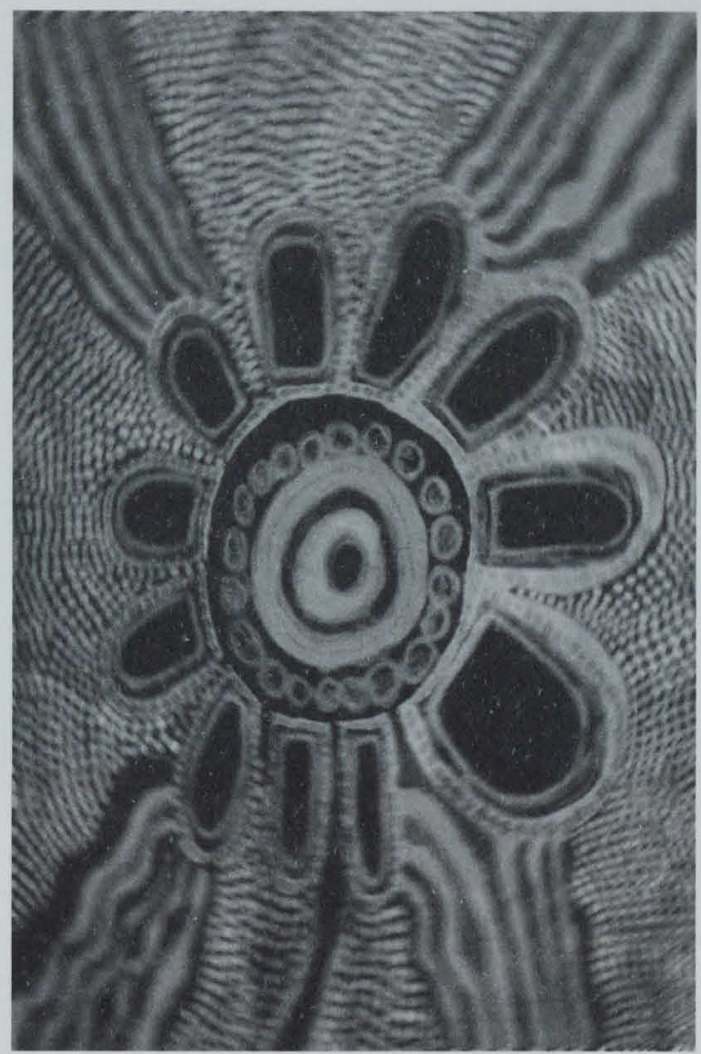

Katinka A. J. van Dongen, Jan P.H. Hamers, Sandra M.G. Zwakhalen, Huda Huijer Abu-Saad, Martijn G. van Lobenstein, Martijn P.F. Berger. 


\section{Abstract}

This study investigated the differences in pain behaviour between severely and profoundly intellectually disabled children with or without the ability to express themselves verbally, children with or without behavioural and emotional disturbances, and children with or without severe multiple disabilities, based on their parents' opinions. We used a questionnaire comprising 145 questions, relating to the prevalence of the various pain expressions retained in the item bank after testing for content as well as face validity and interpretability (see Chapters 2, 3, and Appendix I). Answers were given on five-point adjective scales. Other questions related to items parents considered the most important indicators of pain. We also investigated general aspects of the observation of pain behaviour. In all, data from 183 parents were used to answer the research questions.

Data from parents of non-verbal children suggested it is harder to discriminate between pain behaviour and behaviour related to other emotions than for parents of verbal children. Items relating to the Injured Body Part dimension, such as Pointing to, gesturing to injured body part', were more often reported in children who were able to express themselves verbally. According to their parents, the item 'Crying loudly' was the most important indicator of pain in all participating children. In addition, the item 'Using a word for pain'was regarded as one of the most important expressions for children with some verbal language, whereas the item 'High muscle tone, cramping' was important for diagnosing pain in non-verbal children. Parents of children with behavioural and emotional disturbances reported that they themselves, as well as others, generally had more difficulty ascertaining whether their child was in pain than parents of children without such disturbances. Parents of these children gave higher ratings to items related to the Vocal and SocialEmotional dimensions such as 'Self-biting'. These children, however, less often displayed the item 'Seeking comfort or physical closeness'. In addition the items 'Screaming, yelling' was regarded as being very important by parents of children with behavioural and emotional disturbances. When comparing children with and without severe multiple disabilities, it was found that children with these disabilities more often displayed items relating to the Motor, Vocal, and Physiological dimensions. In addition, these children less often displayed items relating to the Injured Body Part dimension. The items with the greatest mean difference between the two groups was 'Stiffness, rigidity' (-1.31). In addition the item 'Moaning, groaning' was considered to be very important.

Overall, a comparison of common pain behaviours showed that several items occurred frequently in all groups of children. In addition, every group we had distinguished showed differences in pain behaviour in terms of the most frequently displayed items. Thus according to their parents, groups of children displayed both similarities and differences in their behavioural repertoires. Data of this study were later used to reduce the number of items for KIDPAINS. 


\subsection{Introduction}

Most children with intellectual disabilities live at home with their families. Valuing parents' views and their knowledge of their children is crucial to the effective provision of health care. Among many other things, parents of children with severe or profound intellectual disabilities face the daily challenge of diagnosing pain in their child. Using the parents' knowledge in further exploring this relatively new area of investigation is therefore essential. Since nurses and physicians specialising in the care of children with profound intellectual disability tend to base their pain assessment on parent reports (Fanurik, 1999a) and parents themselves indicate they are mostly correct in both the assessment of pain and judging its location, intensity and possible causes (Carter et al, 2002) the present study focussed on parental judgements about the occurrence of possible expressions of pain. To this end, some of the behavioural items related to pain collected in a previous study (Dongen van et al., 2002b) were presented to parents of children with severe to profound intellectual disabilities.

The literature shows that a great variety of behavioural items can be related to pain in this special paediatric population (Stallard et al., 2001; Hunt et al., 2003, Dongen van et al., 1999). However, not all of these behavioural items might be relevant to all children. Stallard and colleagues (2001) found that parents are indeed sensitive to minor changes in the behaviour of their child that might indicate pain. So far, however, little is known about the prevalence of specific pain indicators in relation to the ability (or inability) to express pain verbally, or about the influence of additional disabilities such as severe limitations in motor functions and behavioural problems on pain behaviour in children with severe intellectual disabilities. In their study of pain behaviour in children with cerebral palsy, Hadden \& Bayer von (2002) found that parents of children who were able to communicate their pain verbally reported a significantly greater frequency of items relating to touching, protecting, favouring or gesturing to a sore body part. In addition, parents of children who were able to move voluntarily reported observing a greater frequency of touching a sore body part as well as becoming agitated.

In their study of the assessment of psychopathology in intellectually disabled children, Einfeld \& Tonge (1991) reported that these children have about two to four times as many emotional and behavioural disturbances as other children. Items relating to these types of disturbance might be relevant in the expression of pain. In a qualitative study, we found that pain items relating to self-injury and aggression seemed particularly important in children with behavioural and emotional disturbances (Dongen van et al., 1999). Thus it seems likely that children differ from each other in their pain expression, not only because every child is a unique person, but also because of different 'normal' behavioural repertoires. Therefore, we asked parents of children with severe intellectual disabilities to complete a questionnaire, to enable us to answer the following research questions: 
- do children who cannot express pain verbally display different behavioural repertoires when in pain than children who have the ability to communicate by means of some verbal language?

- do children with behavioural and emotional disturbances display different behavioural repertoires when in pain than children who do not suffer from these disturbances?

- do children with severe multiple disabilities display different behavioural repertoires when in pain than children who do not suffer from multiple disabilities?

We investigated whether the above groups of children differed in terms of general aspects of the observation of pain behaviour, the prevalence of certain behavioural dimensions, the prevalence of individual items within these dimensions, common behaviours related to pain and the items parents considered most important in diagnosing pain.

\subsection{Methods}

\subsubsection{Design}

A cross-sectional study was conducted. Parents of children with severe to profound intellectual disabilities were recruited via 12 medical childcare services, mostly concentrated in the northern part of the Netherlands. In the Netherlands, medical childcare services provide care for children with intellectual disabilities with a maximum IQ of 70 who live at home with their parents. There is a growing trend for these services to provide care mostly to children with severe to profound intellectual disabilities (Willems, 1997). Parents in the present study were asked to participate by the professional caregivers involved in the daily care of their children. At every service, one professional caregiver served as the contact person. $\mathrm{He}$ or she was asked to distribute questionnaires among parents of children with severe to profound intellectual disabilities. Parents who were willing to participate received a questionnaire with a return envelope and a consent form. No reminders were sent to the medical childcare services.

\subsubsection{Subjects}

Since the literature defines adults with a developmental age up to three years as profoundly intellectually disabled (WHO, 1992), it was decided that only parents of children with a biological age of three years or older were eligible for inclusion, especially since the development of language in individuals with intellectual disabilities usually lags behind and the ability to produce language was an important variable in the present study. The maximum age for inclusion was defined as eighteen years. 
In order to answer the three research questions the study population was divided into different groups.

- In order to answer the first research question, the study population was divided into two groups on the basis of language. The first group, that of children without the ability to produce verbal language, included children who were not able to produce any language sounds and children who were able to babble. The other groups consisted of children who could produce threeword or longer sentences according to the Dutch speech standards (Goorhuis \& Schaerlaekens, 2000);

- We attempted to answer the second research question by comparing children having behavioural and emotional disturbances with a selected group of children without these disturbances. The group of children with behavioural and emotional disturbances comprised those children with reported autistiform, automutilative and/ or aggressive behaviours. Children who also suffered from severe multiple disabilities were excluded from this group in order to avoid bias. The group of children that served as a comparison group comprised children without behavioural and emotional disturbances, without profound motor, hearing and visual impairments and children who were reported not to be spastic;

- Attempts to answer the third research question used this same comparison group, comparing it with a group of children with severe multiple disabilities, that is, children with profound motor impairment and/ or profound visual and/ or hearing impairment. Children who were also reported to have behavioural and emotional disturbances were excluded from this group.

\subsubsection{Measure}

The standardised questionnaire used in the present study first asked parents to provide general information. The present study used the AAMR classification system (Luckasson, 1992) to classify the cause of the intellectual disability. In addition, the questionnaire addressed specific questions regarding the child's ability to understand and produce language. Questions relating to the production of verbal language were based on the minimum Dutch speech standards (Goorhuis \& Schaerlaekens, 2000). Parents were also asked to answer five general questions relating to the observation of pain in their child: whether they were generally able to infer from their child's behaviour that it is in pain; whether others were generally able to infer from their child's behaviour that it is in pain; whether they felt there is an obvious difference between pain behaviour and behaviour related to other emotions like being sad, angry or anxious; whether their child sometimes seemed to be insensitive to pain; and whether their child sometimes seemed to display a delayed response to a painful stimulus? Answers were given on a five-point adjective scale with the following answering options for the presence of each behavioural item: never-sometimes-regularly-usually-always. The terminology was 
adapted from a paper on semi-quantitative language for general practitioners in the Nethetlands (Eekhof et al., 1992) in order to cover in words a range of 0 to $100 \%$.

The body of the questionnaire comprised questions relating to the frequency of occurrence of 145 behavioural items related to pain, such as Facial tension', 'Moaning, groaning' and Restlessness'. These standardized questions were derived from an item bank created in previous research on pain in non-verbal children with severe intellectual disabilities (Chapter 2). When developing this item bank, seven dimensions of pain behaviour were originally postulated, based on a facet design (Chapter 1): Facial, Motor, Injured Body Part, Social-Emotional, Vocal, Physiological and Activities of Daily Living. Content validity of the items was confirmed by a study among nurses (Chapter 3 ) and the candidate items were checked for interpretability by experts (Appendix I). In addition a draft scale was developed to facilitate further item development. This first version of the scale was checked for applicability in a hospital environment. This led, for instance, to all items referring to Activities of Daily Living being removed from the scale (Appendix 1). The remaining items were presented to a group of professionals (nurses $(\mathrm{N}=44)$, physicians $(\mathrm{N}=35)$, and psychologists $(\mathrm{N}=26)$ ) attending a conference on pain assessment in individuals with intellectual disabilities. The participants on average had 7.4 years of professional experience with severely intellectually disabled children. (Koot et al., 2000). On the whole, they confirmed face validity and the remaining 144 items were included in a questionnaire. One further question has since been added, regarding the occurrence of the item 'epileptic attack', which is strictly speaking a symptom of disease rather than a pain indicator but was mentioned as such in the study referred to above. Thus altogether 145 items were included in the questionnaire (see Appendix I).

Parents were asked, for each of the 145 expressions, how often the item was present in their child at times when they thought he or she was in pain. Answers were given on the same five-point (0-4) adjective scale mentioned above. Parents were also given the opportunity to indicate that they did not know whether or not an item was present when their child was in pain. These ratings were labelled as missing values. Finally, at the end of the questionnaire, parents were asked to select from the 145 items those five items they considered most important for diagnosing pain in their child. Four parents of children with severe intellectual disabilities participating in an ongoing research project then piloted the questionnaire prior to it being distributed to the entire sample. As a result of their comments, some minor changes to the layout of the questionnaire were made. Parents indicated that it took them at least 30 minutes to complete the questionnaire.

\subsubsection{Analysis}

Since the present study used a newly developed questionnaire, several psychometric properties of the questions relating to the prevalence of 145 pain 
items were examined before further analysis of the data took place. It was decided not to eliminate items on the basis of frequency of endorsement ratings, since items might have been endorsed, for instance, only by parents of children with severe multiple disabilities. Within each of the six dimensions, internal consistency ratings were carried out in order to eliminate irrelevant items. Items were discarded based on the following criteria: (1) negative item-total correlation, (2) item-total correlations $<0.20$, and (3) improvement of Cronbach's $\alpha$ (Streiner \& Norman, 1998; Breukelen van \& Candel, 2000; Norman \& Streiner, 2002). These criteria were used for stepwise elimination of items. In addition to Cronbach's $\alpha$, Gutman split half statistics were also computed.

Principal Components Analysis (PCA) was then used to assess the underlying factor structure of the questionnaire. Eigenvalues and scree tests were examined to determine the number of components using the sum-scores for the six dimensions, including all items left in the scale at that point. When two or more components were identified as a result of PCA, data were rotated using Oblimin, meaning that different components were allowed to correlate.

Overall descriptive information as well as questions relating to language were analysed using descriptive statistics. Items describing common pain behaviours were ranked on the basis of descending means and standard deviations. Descriptive statistics were also used to analyse the five items parents considered most important in diagnosing pain. Differences between groups regarding the prevalence of items were analysed using independent sample $t$-tests. To adjust for the increased chance of type 1 errors for repeated testing, a Bonferroni correction was used. A Bonferroni corrected $\alpha$ was calculated for every research question by dividing $\alpha 0.05$ by the number of analyses used to answer the research question. The $95 \%$ confidence interval of the mean difference was used for further examination of the data. We concluded that there was a difference between the groups if the zero was not included in the $95 \%$ confidence interval of the mean difference. In order to avoid using too many statistical tests, we first examined whether there was a difference between groups in sum-scores regarding the six dimensions of pain behaviour distinguished in the present study. In order to being able to calculate such sum-scores, missing values were recoded as not present $(0-$ score). Only when there was a difference did we test for individual pain items within a dimension.

\subsection{Results}

\subsubsection{Response}

In all, the caregivers returned 195 of the 460 questionnaires handed out, a response rate of $42.4 \%$. Five of the questionnaires were excluded on the basis of the age 
criterion: four children were younger than three years and one individual was older than 18 years. In addition, one questionnaire was ignored since it provided no descriptive information. In all, therefore, 189 questionnaires were initially used for data analysis. All questionnaires were encoded and computerized by an independent researcher. Missing value analysis revealed that six respondents were indicated as outliers, having answered 'Don't know' to over $25 \%$ of the questions. These respondents were omitted from further data analysis. Thus, 183 questionnaires were used to answer the research questions.

\subsubsection{Psychometric properties}

An overview of the psychometric properties of the questionnaire is presented in Table 1.

Table 1

Psychometric properties of the questionnaire on pain items

\begin{tabular}{|c|c|c|c|c|c|c|c|c|}
\hline \multirow{2}{*}{$\begin{array}{l}\text { Dimensions } \\
\text { Facial }\end{array}$} & \multirow{2}{*}{$\begin{array}{c}\begin{array}{c}\text { Number of } \\
\text { items removed } \\
\text { based on MVA }\end{array} \\
2\end{array}$} & $\begin{array}{l}\text { Number of } \\
\text { items removed } \\
\text { based on ICA }{ }^{2}\end{array}$ & \multirow{2}{*}{$\begin{array}{c}\begin{array}{c}\text { Number of } \\
\text { items left in } \\
\text { scale }\end{array} \\
28\end{array}$} & \multicolumn{2}{|c|}{$\begin{array}{l}\text { Cronbach's a } \\
\text { (N cases) }\end{array}$} & $\begin{array}{l}\text { Gutman split } \\
\text { half } \\
\text { (correlation) }\end{array}$ & \multicolumn{2}{|c|}{$\begin{array}{l}\text { Pattern Matrix }{ }^{3} \\
\text { Comp. } 1 \text { Comp. } 2\end{array}$} \\
\hline & & 3 & & 0.87 & (74) & $0.91(0.83)$ & 0.71 & \\
\hline Motor & 2 & 9 & 26 & 0.91 & $(90)$ & $0.87(0.78)$ & 0.83 & \\
\hline Social-Emotional & 0 & 6 & 20 & 0.89 & (121) & $0.75(0.61)$ & 0.38 & 0.70 \\
\hline Injured Body Part & 1 & 0 & 14 & 0.80 & (127) & $0.70(0.60)$ & & 0.89 \\
\hline Vocal & 0 & 5 & 14 & 0.75 & (143) & $0.60(0.46)$ & 0.68 & \\
\hline Physiological & 0 & 3 & 14 & 0.80 & (127) & $0.66(0.52)$ & 0.79 & \\
\hline Total scale & 5 & 26 & 114 & 0.95 & $(42)$ & $0.77(0.64)$ & $\begin{array}{c}43 \% \\
\text { variance }\end{array}$ & $\begin{array}{c}21 \% \\
\text { variance }\end{array}$ \\
\hline $\begin{array}{l}\text { (1) MVA = Missing val } \\
\text { (2) ICA = Internal con } \\
\text { (3) Factor loading ove }\end{array}$ & $\begin{array}{l}\text { lysis } \\
\text { cy analysis } \\
\text { is presented, Comp. }\end{array}$ & = Component & & & & & & \\
\hline
\end{tabular}

To begin with, five items were discarded because they led to missing values in over $25 \%$ of the questionnaires. In all, 26 of the 140 remaining items were dropped based on internal consistency analyses, including items such as 'Crying softly' (item total correlation 0.17) and 'Crying loudly' (item total correlation 0.17) within the Vocal dimension and 'Tears' (item total correlation 0.11) in the Physiological dimension. Although the mean scores of these items ranged from 0.75 to 0.96 for 'Crying softly', from 1.50 to 2.02 for 'Crying loudly', and 1.64 to 2.13 for 'Tears'. Regrouping of items and additional analysis however confirmed the removal of these items.

Most of the 114 remaining items had a range of four, whereas 14 items had a range of three. As Table 1 shows, Cronbach's $\alpha$ 's were mostly high. The Vocal dimension showed the least coherence among items in this respect. Facial, Motor and Social-Emotional items showed the best psychometric properties. The pattern matrix of exploratory PCA with Oblimin rotation, of the sum-scores for the six dimensions is presented in Table 1. Although the Kaiser-Meyer-Olkin measure of 
sampling adequacy (MSA) was mediocre (0.68), it was acceptable in view of the nature of the research question, focussing on a variety of children. A total of $64.8 \%$ of the variance was explained, and all MSA values of individual items and communalities exceeded 0.4 .

\subsubsection{Sample}

Table 2 presents characteristics of parents and children in the study population.

Table 2

Descriptive information $(\mathrm{N}=\mathbf{1 8 3})$

\begin{tabular}{l|lrr}
\hline \multicolumn{5}{l}{} & $\mathrm{N}$ Valid \\
\hline \multicolumn{2}{l}{ Descriptive information } & & \\
\hline Questionnaire & Mother & 148 & $81 \%$ \\
completed by & Father & 11 & $6 \%$ \\
& Mother and father & 9 & $5 \%$ \\
& Others & 15 & $8 \%$
\end{tabular}

\section{Characteristics of child}

\begin{tabular}{l|lrr}
\hline Age & Mean 8.1 (SD 4.1) & & \\
Gender & Male & 105 & $57 \%$ \\
Intellectual disability & Female & 78 & $43 \%$ \\
according to parents & Mild & 11 & $6 \%$ \\
& Moderate & 34 & $19 \%$ \\
& Severe & 108 & $59 \%$ \\
& Profound & 30 & $17 \%$
\end{tabular}

\section{Communication}

Producing spoken
language communication (alternative) communication Understanding

\begin{tabular}{|lrr}
\hline Does not use any language sounds & 53 & $29 \%$ \\
Babbles & 48 & $26 \%$ \\
Speaks less than 5 single words & 24 & $13 \%$ \\
Speaks at least 5 single words & 19 & $10 \%$ \\
Speaks in 2 word sentences & 10 & $5 \%$ \\
Speaks in 3 to 5 word sentences & 15 & $8 \%$ \\
Speaks simple, short sentences & 14 & $8 \%$ \\
Uses gestures & 20 & $11 \%$ \\
Uses symbols & 26 & $14 \%$ \\
Understands meaning of simple & 124 & $68 \%$ \\
words & 59 & $32 \%$ \\
Understands gestures & 54 & $30 \%$ \\
Understands symbols &
\end{tabular}

Pain

\begin{tabular}{l|lrr}
\hline Child does & & 180 & $98 \%$ \\
experience pain & & 59 & $35 \%$ \\
Frequency of pain & Hardly ever & 37 & $22 \%$ \\
experience $(\mathrm{N}=170)$ & At least once a month & 43 & $25 \%$ \\
& At least once a week & 28 & $16 \%$ \\
& At least once a day & 3 & $2 \%$ \\
& Almost continously & 138 & $76 \%$ \\
Different pain & Yes, higher & 10 & $5 \%$ \\
threshold $(\mathrm{N}=182)$ & Yes, lower & & \\
\hline
\end{tabular}

$N$ Valid

AAMR classification system cause

\section{of I.D.}

\begin{tabular}{lll}
\hline Unknown & 60 & $33 \%$
\end{tabular}

Prenatal, unknown $\quad 7 \quad 4 \%$

Prenatal, chromosomal disorder $\quad 31 \quad 17 \%$

Prenatal, syndrome disorders $\quad 12 \quad 7 \%$

Prenatal, inborn errors of metabolism $2 \quad 1 \%$

Prenatal, developmental disorders $\quad 10 \quad 5 \%$

brain formation

Prenatal, environmental influences $\quad 2 \quad 1 \%$

Perinatal, unknown $\quad 1 \quad 1 \%$

Perinatal, intrauterine disorders $\quad 8 \quad 4 \%$

Perinatal, neonatal disorders $\quad 25 \quad 14 \%$

Postnatal, unknown $\quad 32 \%$

$\begin{array}{lll}\text { Postnatal, head injury } & 2 & 1 \%\end{array}$

Postnatal, infections $\quad 7 \quad 4 \%$

Postnatal, degenerative disorders $\quad 3 \quad 2 \%$

Postnatal, seizure disorders $\quad 5 \quad 3 \%$

Postnatal, toxic-metabolic disorders $\quad 5 \quad 3 \%$

\section{Other disabilities}

Profound impairment upper limbs $\quad 42 \quad 23 \%$

Profound impairment lower limbs $\quad 58 \quad 32 \%$

Spasticity $\quad 42 \quad 23 \%$

Profound hearing impairment $\quad 19 \quad 10 \%$

Profound visual impairment $\quad 43 \quad 24 \%$

Severe multiple disabilities $\quad 50 \quad 27 \%$

Self-injurious behaviour $\quad 34 \quad 19 \%$

Autistiform behaviour $\quad 32 \quad 17 \%$

Behavioural and emotional $\quad 56 \quad 31 \%$

disturbances

$7642 \%$

As Table 2 shows, the children in the present study comprised a heterogeneous sample, which is in line with the nature of the population under investigation. Children were on average eight years old (SD 4.09). According to the parents, over $75 \%$ of the children had severe to profound intellectual disability $(\mathrm{N}=138)$. In all, 
101 children did not have the ability to produce any verbal language. Only $8 \%$ of the children were able to speak in sentences comprising more than three words. This cause of the intellectual disability was unknown in $39 \%$ of the children. In addition, children were reported to suffer from a variety of other disabilities, those most frequently reported being epilepsy $(42 \%)$ and profound impairment of the lower limbs (32\%). A total of 74 children were reported to experience pain once a week or more, while the parents of 138 children believed their child to have a higher pain threshold than others in their social environment.

\subsubsection{Children with versus those without verbal language}

The first research question we addressed was whether children who do not express pain verbally display different behavioural repertoires when in pain than children who have the ability to communicate by means of some verbal language.

\section{General questions on the observation of pain behaviour}

We first examined whether parents of children with verbal language differed from those of children without the ability to express themselves verbally, in terms of five general questions on the observation of pain. Table 3 (page 75) shows that no statistically significant differences were found at $\alpha 0.01$.

However, the $95 \%$ confidence interval (CI) shows there was a trend that parents of children without verbal language more often failed to make a clear distinction between pain behaviour and behaviour related to other emotions.

\section{Prevalence of dimensions}

As regards the prevalence of sum-scores of items within dimensions, when looking at Table 3, only the Injured Body Part dimension showed a statistically significant difference between children with and without verbal language at Bonferronicorrected $\alpha$ of 0.008 . Items relating to this dimension were more frequently observed in children who were able to express themselves verbally. The $95 \% \mathrm{CI}$ shows there was a trend that parents of children without verbal language reported items relating to the Motor dimension to be more often present in their children.

\section{Prevalence of individual items}

Since there was a difference between children with and without verbal language for both the Motor and Injured Body Part dimensions, items of these two dimensions were investigated for individual differences. As Table 3 shows, five of the 40 items showed a significant difference, at a Bonferroni-corrected $\alpha$ of 0.001 . The highest mean differences were found for the item Pointing to, gesturing to injured body part', in the sense that children who expressed themselves verbally more frequently displayed this item when in pain. The one item displayed more often by children without verbal language was Restless movements'. The $95 \%$ CI values of seven items show that only the item Not using injured body part' is represented in Table 3, since it 
showed a mean difference $\geq 0.5$. Children with some verbal language more frequently displayed this item when in pain.

Table 3

Difference between children with $(\mathrm{N}=82)$ and without verbal language $(\mathrm{N}=101)$

General questions on the observation of pain behaviour

\begin{tabular}{|c|c|c|c|c|c|c|}
\hline \multirow[t]{2}{*}{ Independent Sampies Test } & \multicolumn{3}{|c|}{$\begin{array}{l}\text { Bonferroni corrected } a \text { : } \\
0.05 / 5=0.02\end{array}$} & \multicolumn{3}{|c|}{ Uncorrected interva! } \\
\hline & $t$ & $\begin{array}{l}\text { 2-tailed } \\
\text { significance }\end{array}$ & $\begin{array}{c}\text { mean } \\
\text { difference }^{1}\end{array}$ & $\begin{array}{l}\text { standard } \\
\text { error diff. }\end{array}$ & $\begin{array}{l}95 \% \text { conf } \\
\text { Lower }\end{array}$ & $\begin{array}{l}\text { Ce interval } \\
\text { Upper }\end{array}$ \\
\hline Pain behaviour visible to parents & -0.41 & 0.684 & -0.07 & 0.17 & -0.40 & 0.27 \\
\hline Pain behaviour visible to others & -0.04 & 0.969 & -0.01 & 0.17 & -0.34 & 0.33 \\
\hline Discrimination between pain and other emotions & -2.36 & 0.019 & -0.45 & 0.19 & -0.82 & -0.07 \\
\hline Degree of indifference to pain & 0.88 & 0.380 & 0.11 & 0.13 & -0.14 & 0.36 \\
\hline Slow response to pain & -0.82 & 0.414 & -0.12 & 0.15 & -0.43 & 0.18 \\
\hline
\end{tabular}

Prevalence of sum-scores items dimensions

\begin{tabular}{|c|c|c|c|c|c|c|}
\hline \multirow{4}{*}{ Independent Samples Test } & \multicolumn{6}{|c|}{$t$-test for Equality of Means } \\
\hline & \multicolumn{3}{|c|}{$\begin{array}{l}\text { Bonferroni corrected } a: \\
0.05 / 6=0.0084\end{array}$} & \multicolumn{3}{|c|}{ Uncorrected interval } \\
\hline & \multirow{2}{*}{$t$} & \multirow{2}{*}{$\begin{array}{l}\text { 2-tailed } \\
\text { significance }\end{array}$} & \multirow{2}{*}{$\begin{array}{c}\text { mean } \\
\text { difference }\end{array}$} & \multirow{2}{*}{$\begin{array}{l}\text { standard } \\
\text { error diff. }\end{array}$} & \multicolumn{2}{|c|}{$95 \%$ confidence interval } \\
\hline & & & & & Lower & Upper \\
\hline Sum Facial & 0.23 & 0.820 & 0.42 & 1.86 & -3.24 & 4.08 \\
\hline Sum Motor & 2.09 & 0.038 & 4.70 & 2.25 & 0.26 & 9.15 \\
\hline Sum Injured Body Part * & -5.04 & 0.000 & -4.05 & 0.80 & -5.64 & -2.46 \\
\hline Sum Social-Emotional & 0.33 & 0.739 & 0.57 & 1.72 & -2.82 & 3.97 \\
\hline Sum Vocal & 1.41 & 0.160 & 1.25 & 0.89 & -0.50 & 3.00 \\
\hline Sum Physiological & 0.83 & 0.406 & 0.71 & 0.85 & -0.97 & 2.39 \\
\hline
\end{tabular}

Prevalence of significant individual items of significanty different dimensions

\begin{tabular}{|c|c|c|c|c|c|c|}
\hline \multirow[t]{3}{*}{ Independent Samples Test } & \multicolumn{3}{|c|}{$\begin{array}{c}\text { Bonferroni corrected } a \text { : } \\
0.05 / 40=0.00126\end{array}$} & \multicolumn{3}{|c|}{ Uncorrected interval } \\
\hline & \multirow{2}{*}{$t$} & \multirow{2}{*}{$\begin{array}{l}\text { 2-tailed } \\
\text { significance }\end{array}$} & \multirow{2}{*}{$\begin{array}{c}\text { mean } \\
\text { difference }\end{array}$} & \multirow{2}{*}{$\begin{array}{l}\text { standard } \\
\text { error diff. }\end{array}$} & \multicolumn{2}{|c|}{$95 \%$ confidence interval } \\
\hline & & & & & Lower & Upper \\
\hline Protecting injured body part * & -4.08 & 0.000 & -0.62 & 0.15 & -0.93 & -0.32 \\
\hline Pointing to, gesturing to injured body part * & -6.03 & 0.000 & -0.90 & 0.15 & -1.20 & -0.61 \\
\hline Holding injured body part * & -5.11 & 0.000 & -0.72 & 0.14 & -1.00 & -0.44 \\
\hline Rubbing injured body part * & -4.39 & 0.000 & -0.60 & 0.14 & -0.87 & -0.33 \\
\hline Not using injured body part & -3.04 & 0.002 & -0.51 & 0.17 & -0.84 & -0.18 \\
\hline Restess movements * & 3.27 & 0.001 & 0.61 & 0.18 & 0.24 & 0.97 \\
\hline \multicolumn{7}{|c|}{$\begin{array}{l}\text { (1) A negative number reflects a lower mean difference for children without verbal language, a positive number reflects a higher mean difference for } \\
\text { children without verbal language } \\
\text { * Significance based on Bonferroni corrected a } \\
\sim \text { Significance based on } 95 \% \text { confidence interval difference }\end{array}$} \\
\hline
\end{tabular}

\section{Common pain behaviours}

The descending means of items reported to be most common in children show that, of the 15 items with highest mean scores included in Table 4 (page 76), the two groups had 12 items in common. 
Table 4

Descending means of common pain behaviours in children with and without verbal language

\begin{tabular}{|c|c|c|c|c|c|}
\hline Without language $(\mathrm{N}=101)$ & Mean & SD & With language $(\mathrm{N}=82)$ & Mean & SD \\
\hline Facial tension & 2.41 & 1.2 & Facial tension & 2.17 & 1.3 \\
\hline Restless movements & 2.41 & 1.2 & Facial restiessness & 2.16 & 1.4 \\
\hline Seeking comfort or physical closeness & 2.32 & 1.4 & Seeking comfort or physical cioseness & 2.11 & 1.4 \\
\hline Facial restlessness & 2.30 & 1.3 & Looking anxious & 2.10 & 1.3 \\
\hline Restlessness & 2.30 & 1.2 & Looking sad & 2.03 & 1.2 \\
\hline Looking sad & 2.06 & 1.3 & Restless movements & 1.80 & 1.2 \\
\hline Looking anxious & 2.05 & 1.3 & Restlessness & 1.77 & 1.3 \\
\hline High muscle tone, cramping & 1.93 & 1.3 & Irritable, cranky & 1.75 & 1.3 \\
\hline Grimacing & 1.87 & 1.4 & High muscle tone, cramping & 1.62 & 1.2 \\
\hline Irritable, cranky & 1.71 & 1.4 & Grimacing & 1.59 & 1.4 \\
\hline Not cooperating & 1.64 & 1.3 & Looking serious, dejected & 1.55 & 1.2 \\
\hline Stiffness, rigidity ${ }^{1}$ & 1.60 & 1.3 & Not cooperating & 1.42 & 1.1 \\
\hline Restless head movements & 1.47 & 1.2 & Panicky & 1.34 & 1.2 \\
\hline Moaning, groaning & 1.40 & 1.2 & Jutting lower lip, pouting & 1.33 & 1.3 \\
\hline Stretching torso & 1.39 & 1.3 & Restless head movements & 1.28 & 1.1 \\
\hline
\end{tabular}

For both groups, Facial tension' was the item with the highest mean score, although parents of children without any language gave higher average scores. As regards the differences between the two groups, the items 'Stiffness, rigidity', 'Moaning, groaning', and 'Stretching torso' were among the 15 most frequently occurring items in the group of children without verbal language. Children with some verbal language more often displayed the items 'Looking serious, dejected', 'Panicky', and 'Jutting lower lip, pouting'.

\section{Most important items}

Finally, a comparison of the answers given by the two groups of parents to the request to select the five most important items for diagnosing pain in their child shows that 'Crying loudly, intensely' was regarded as the most important item for children with or without verbal language. As Table 5 (page 77) shows, both groups also shared the items 'Seeking comfort or physical closeness' and 'Tears' in terms of the five items parents considered most important.

For those children who were able to express themselves verbally, Using a word for pain' was considered to be one of the most important items, whereas 'High muscle tone, cramping' and 'Moaning, groaning' were more important in non-verbal children. The Social-Emotional dimension (with 26 items in all) provided the highest percentage of items mentioned among the five most important ones. Twenty-three items from this dimension were mentioned for non-verbal children, against 20 for children with some verbal language. For both groups of children, however, the items from the Vocal dimension (13 and 11, respectively) were most frequently noted overall, and as such had the highest density. Each item used was reported by an average of approximately eight parents. 
Table 5

Most important pain behaviours or categories of pain behaviours in children with and without verbal language

\begin{tabular}{|c|c|c|c|c|c|c|c|c|c|}
\hline \multirow{3}{*}{$\begin{array}{l}\text { Dimensions } \\
\text { Facial }\end{array}$} & \multirow{3}{*}{$\begin{array}{c}\text { Items } \\
\mathrm{N}=145 \\
33\end{array}$} & \multicolumn{4}{|c|}{ Without language $(\mathrm{N}=101)$} & \multicolumn{4}{|c|}{ With language $(\mathrm{N}=82)$} \\
\hline & & \multicolumn{2}{|c|}{ Different items } & \multicolumn{2}{|c|}{ Density items } & \multicolumn{2}{|c|}{ Different items } & \multicolumn{2}{|c|}{ Density items } \\
\hline & & 15 & $45 \%{ }^{1}$ & 66 & $4.4^{2}$ & 22 & $67 \%$ & 68 & 3.1 \\
\hline Motor & 37 & 26 & $70 \%$ & 97 & 3.7 & 19 & $51 \%$ & 45 & 2.4 \\
\hline Injured Body Part & 13 & 6 & $46 \%$ & 13 & 2.2 & 7 & $54 \%$ & 25 & 3.6 \\
\hline Social-Emotional & 26 & 23 & $88 \%$ & 90 & 3.9 & 20 & $77 \%$ & 85 & 4.3 \\
\hline Vocal & 19 & 13 & $68 \%$ & 101 & 7.8 & 11 & $58 \%$ & 88 & 8.0 \\
\hline Physiological & 17 & 8 & $47 \%$ & 42 & 5.3 & 7 & $41 \%$ & 30 & 4.3 \\
\hline \multirow{5}{*}{$\begin{array}{l}\text { Five most important items } \\
\text { noted }(N)\end{array}$} & 1 & \multicolumn{3}{|c|}{ Crying loudly, intensely } & 43 & \multicolumn{3}{|c|}{ Crying loudly, intensely } & 36 \\
\hline & 2 & \multicolumn{3}{|c|}{ High muscle tone, cramping } & 18 & \multicolumn{3}{|c|}{ Using a word for pain } & 18 \\
\hline & 3 & \multicolumn{3}{|l|}{ Tears } & 18 & \multicolumn{3}{|c|}{$\begin{array}{l}\text { Seeking comfort or physical } \\
\text { closeness }\end{array}$} & 16 \\
\hline & 4 & \multicolumn{3}{|c|}{$\begin{array}{l}\text { Seeking comfort or physical } \\
\text { closeness }\end{array}$} & 16 & \multicolumn{2}{|l|}{ Tears } & & 13 \\
\hline & 5 & \multicolumn{3}{|c|}{ Moaning, groaning } & 14 & \multicolumn{3}{|c|}{ Facial tension } & 12 \\
\hline
\end{tabular}

(1) Forty-five percent of the items $(N=33)$ within the Facial dimension were used by parents

(2) The 15 different items used by parents within the Facial dimension were used 66 times, resulting in an average density of 4.4 per item

Overall, answering the first research question children who do not express pain verbally display different behavioural repertoires when in pain than children who have the ability to communicate by means of some verbal language. However there are also similarities between both groups of children.

\subsubsection{Children with versus those without behavioural and emotional disturbances}

The second research question addressed in the present study was whether children with behavioural and emotional disturbances display different behavioural repertoires when in pain than children who do not suffer from these disturbances.

\section{General questions on the observation of pain behaviour}

Of the five general questions on the observation of pain described above, two differences had a statistically significant $p$-value, as Table 6 (page 78) shows. Parents of children with behavioural and emotional disturbances reported that they generally had more difficulty ascertaining whether or not their child was in pain and they also believed that others found it more difficult to ascertain whether their child was in pain.

\section{Prevalence of dimensions}

A comparison between the two groups in terms of sum-scores of the six dimensions shows that, at a Bonferroni corrected $\alpha$ of 0.008 , two dimensions were statistically significantly different for the two groups. Parents of children with behavioural and emotional disturbances gave significantly higher ratings to items within the Social-Emotional as well as the Vocal dimension as Table 6 shows. 
Table 6

Difference between children with $(\mathrm{N}=50)$ and without behavioural and emotional disturbances $(\mathrm{N}=56$ )

General questions on the observation of pain behaviour

\begin{tabular}{|c|c|c|c|c|c|c|}
\hline \multirow{4}{*}{ Independent Samples Test } & \multicolumn{6}{|c|}{$t$-test for Equality of Means } \\
\hline & \multicolumn{3}{|c|}{$\begin{array}{l}\text { Bonferroni corrected } a \text { : } \\
0.05 / 5=0.02\end{array}$} & \multicolumn{3}{|c|}{ Uncorrected interval } \\
\hline & \multirow{2}{*}{$t$} & \multirow{2}{*}{$\begin{array}{c}\text { 2-tailed } \\
\text { significance }\end{array}$} & \multirow{2}{*}{$\begin{array}{c}\text { mean } \\
\text { difference }{ }^{1}\end{array}$} & \multirow{2}{*}{$\begin{array}{l}\text { standard } \\
\text { error diff. }\end{array}$} & \multicolumn{2}{|c|}{$95 \%$ confidence interva! } \\
\hline & & & & & Lower & Upper \\
\hline Pain behaviour visible to parents * & 2.84 & 0.005 & 0.61 & 0.21 & 0.18 & 1.04 \\
\hline Pain behaviour visible to others * & 3.07 & 0.003 & 0.66 & 0.22 & 0.23 & 1.09 \\
\hline Discrimination between pain and other emotions & 1.77 & 0.080 & 0.45 & 0.26 & -0.05 & 0.96 \\
\hline Degree of indifference to pain & -1.61 & 0.110 & -0.27 & 0.17 & -0.60 & 0.06 \\
\hline Slow response to pain & -0.74 & 0.462 & -0.16 & 0.22 & -0.60 & 0.27 \\
\hline
\end{tabular}

Prevalence of sum-scores items dimensions

\begin{tabular}{|c|c|c|c|c|c|c|}
\hline \multirow[t]{3}{*}{ Independent Samples Test } & \multicolumn{3}{|c|}{$\begin{array}{l}\text { Bonferroni corrected } a \text { : } \\
0.05 / 6=0.0084\end{array}$} & \multicolumn{3}{|c|}{ Uncorrected interval } \\
\hline & \multirow{2}{*}{$t$} & \multirow{2}{*}{$\begin{array}{l}\text { 2-tailed } \\
\text { significance }\end{array}$} & \multirow{2}{*}{$\begin{array}{c}\text { mean } \\
\text { difference }\end{array}$} & \multirow{2}{*}{$\begin{array}{l}\text { standard } \\
\text { error diff. }\end{array}$} & \multicolumn{2}{|c|}{$95 \%$ confidence interval } \\
\hline & & & & & Lower & Upper \\
\hline Sum Facial & 0.59 & 0.558 & 1.32 & 2.24 & -3.12 & 5.75 \\
\hline Sum Motor & -1.91 & 0.058 & -4.90 & 2.56 & -9.98 & 0.17 \\
\hline Sum Injured Body Part & -0.38 & 0.706 & -0.41 & 1.07 & -2.54 & 1.72 \\
\hline Sum Social-Emotional * & -3.93 & 0.000 & -8.88 & 2.26 & -13.37 & -4.39 \\
\hline Sum Vocal * & -3.09 & 0.003 & -3.27 & 1.06 & -5.37 & -1.17 \\
\hline Sum Physiological & 0.64 & 0.521 & 0.58 & 0.90 & -1.21 & 2.37 \\
\hline
\end{tabular}

Prevalence of significant individual items of significantly different dimensions

\begin{tabular}{|c|c|c|c|c|c|c|}
\hline \multirow{4}{*}{ Independent Samples Test } & \multicolumn{6}{|c|}{$t$-test for Equality of Means } \\
\hline & \multicolumn{3}{|c|}{$\begin{array}{l}\text { Bonferroni corrected } a: \\
0.05 / 40=0.00126\end{array}$} & \multicolumn{3}{|c|}{ Uncorrected interval } \\
\hline & \multirow{2}{*}{$t$} & \multirow{2}{*}{$\begin{array}{l}\text { 2-tailed } \\
\text { significance }\end{array}$} & \multirow{2}{*}{$\begin{array}{c}\text { mean } \\
\text { difference }\end{array}$} & \multirow{2}{*}{$\begin{array}{l}\text { standard } \\
\text { error diff. }\end{array}$} & \multicolumn{2}{|c|}{$95 \%$ confidence interval } \\
\hline & & & & & Lower & Upper \\
\hline Restlessness & -2.21 & 0.030 & -0.51 & 0.23 & -0.97 & -0.05 \\
\hline Panicky & -2.31 & 0.023 & -0.55 & 0.24 & -1.03 & -0.08 \\
\hline Agitation & -2.50 & 0.013 & -0.62 & 0.24 & -1.10 & -0.14 \\
\hline Hitting (and other aggressive behaviours) * & -3.40 & 0.001 & -0.75 & 0.22 & -1.20 & -0.31 \\
\hline Head banging * & -3.95 & 0.000 & -0.64 & 0.16 & -0.97 & -0.32 \\
\hline Self biting * & -4.52 & 0.000 & -0.91 & 0.20 & -1.31 & -0.51 \\
\hline Self slapping $\sim$ & -3.17 & 0.002 & -0.61 & 0.19 & -0.99 & -0.22 \\
\hline Self-injuring in other manner * & -3.76 & 0.000 & -0.56 & 0.15 & -0.86 & -0.26 \\
\hline Stereotypic, repetitive behaviour * & -3.93 & 0.000 & -0.86 & 0.22 & -1.29 & -0.43 \\
\hline Penetrating, restless sounds & -3.11 & 0.003 & -0.63 & 0.20 & -1.04 & -0.23 \\
\hline Stereotypical, repetetive sounds * & -3.79 & 0.000 & -0.72 & 0.19 & -1.10 & -0.34 \\
\hline Seeking comfort or physical closeness & 2.00 & 0.048 & 0.51 & 0.25 & 0.01 & 1.02 \\
\hline \multicolumn{7}{|c|}{$\begin{array}{l}\text { (1) A negative number reflects a lower mean difference for children without behavioural and emotional disturbances, a positive number reflects a higher } \\
\text { mean difference for children without behavioural and emotional disturbances } \\
\text { * Significance based on Bonferroni corrected a } \\
\sim \text { Significance based on } 95 \% \text { confidence interval difference }\end{array}$} \\
\hline
\end{tabular}

\section{Prevalence of individual items}

Individual items of the Social-Emotional and Vocal dimensions were then tested for differences between the two groups. Independent sample $t$-tests were carried 
out for a total of 34 items. At a Bonferroni-corrected $\alpha$ of 0.001 , six items were found to be statistically significantly different between the two groups, as shown in Table 6. All six items occurred more frequently among children with behavioural and emotional disturbances than among the children without such disturbances.

Table 7

Descending means of common pain behaviours in children with behavioural and emotional disturbances, severe multiple disabilities, or neither

\begin{tabular}{|c|c|c|c|c|c|c|c|c|}
\hline $\begin{array}{l}\text { No additional disabilities } \\
(\mathrm{N}=56)\end{array}$ & Mean & SD & $\begin{array}{l}\text { Behavioural and } \\
\text { emotional disturbances } \\
(\mathrm{N}=50)\end{array}$ & Mean & SD & $\begin{array}{l}\text { Severe multiple } \\
\text { disabilities }(N=44)\end{array}$ & Mean & SD \\
\hline $\begin{array}{l}\text { Seeking comfort or } \\
\text { physical closeness }\end{array}$ & 2.33 & 1.2 & Restlessness & 2.42 & 1.1 & Restless movements & 2.60 & 1.4 \\
\hline Facial tension & 2.31 & 1.4 & Facial tension & 2.39 & 1.1 & $\begin{array}{l}\text { Seeking comfort or } \\
\text { physical closeness }\end{array}$ & 2.55 & 1.5 \\
\hline Looking sad & 2.20 & 1.3 & Restless movements & 2.12 & 1.3 & Facial restlessness & 2.51 & 1.3 \\
\hline Facial restlessness & 2.20 & 1.4 & Facial restlessness & 2.10 & 1.3 & $\begin{array}{l}\text { High muscle tone, } \\
\text { cramping }\end{array}$ & 2.42 & 1.3 \\
\hline Looking anxious & 2.04 & 1.3 & Irritable, cranky & 2.04 & 1.3 & Looking anxious & 2.30 & 1.3 \\
\hline Restless movements & 1.93 & 1.2 & Not cooperating & 1.94 & 1.2 & Facial tension & 2.29 & 1.3 \\
\hline Restlessness & 1.91 & 1.2 & Looking sad & 1.94 & 1.2 & Restlessness & 2.20 & 1.3 \\
\hline Grimacing & 1.84 & 1.5 & Looking anxious & 1.90 & 1.3 & Stiffness, rigidity & 2.18 & 1.4 \\
\hline Irritable, cranky & 1.74 & 1.2 & $\begin{array}{l}\text { Seeking comfort or } \\
\text { physical closeness }\end{array}$ & 1.82 & 1.4 & Looking sad & 2.14 & 1.3 \\
\hline Not cooperating & 1.53 & 1.1 & Shifting head away & 1.79 & 1.2 & Grimacing & 2.00 & 1.5 \\
\hline $\begin{array}{l}\text { Eyes suddenly wide } \\
\text { open }\end{array}$ & 1.44 & 1.3 & Panicky & 1.77 & 1.3 & Moaning, groaning & 1.75 & 1.2 \\
\hline $\begin{array}{l}\text { Jutting lower lip, } \\
\text { pouting }{ }^{1}\end{array}$ & 1.42 & 1.4 & $\begin{array}{l}\text { High muscle tone, } \\
\text { cramping }\end{array}$ & 1.69 & 1.3 & $\begin{array}{l}\text { Stretching neck, } \\
\text { pulling neck }\end{array}$ & 1.70 & 1.4 \\
\hline $\begin{array}{l}\text { Independent, } \\
\text { frequent position }\end{array}$ & 1.42 & 1.2 & $\begin{array}{l}\text { Stereotypic, } \\
\text { repetitive behaviour }\end{array}$ & 1.65 & 1.2 & Stretching torso & 1.67 & 1.5 \\
\hline $\begin{array}{l}\text { Looking serious, } \\
\text { dejected }\end{array}$ & 1.36 & 1.1 & $\begin{array}{l}\text { Other stereotypic } \\
\text { movements }\end{array}$ & 1.60 & 1.4 & $\begin{array}{l}\text { Restless head } \\
\text { movements }\end{array}$ & 1.61 & 1.3 \\
\hline $\begin{array}{l}\text { High muscle tone, } \\
\text { cramping }\end{array}$ & 1.30 & 1.1 & Grimacing & 1.59 & 1.2 & Stretching leg & 1.50 & 1.3 \\
\hline Pallor & 1.27 & 1.0 & Fussy, lively & 1.59 & 1.5 & $\begin{array}{l}\text { Eyes suddenly wide } \\
\text { open }\end{array}$ & 1.48 & 1.2 \\
\hline $\begin{array}{l}\text { Withdrawing injured } \\
\text { body part }\end{array}$ & 1.23 & 1.2 & $\begin{array}{l}\text { Looking serious, } \\
\text { dejected }\end{array}$ & 1.55 & 1.2 & $\begin{array}{l}\text { Involuntary } \\
\text { movements }\end{array}$ & 1.47 & 1.3 \\
\hline Eyes wide open & 1.22 & 1.2 & Anger & 1.53 & 1.2 & $\begin{array}{l}\text { Looking serious, } \\
\text { dejected }\end{array}$ & 1.44 & 1.3 \\
\hline Panicky & 1.22 & 1.1 & $\begin{array}{l}\text { Restless head } \\
\text { movements }\end{array}$ & 1.50 & 1.1 & $\begin{array}{l}\text { Penetrating, restless } \\
\text { sounds }\end{array}$ & 1.41 & 1.2 \\
\hline $\begin{array}{l}\text { Restless head } \\
\text { movements }\end{array}$ & 1.20 & 1.1 & $\begin{array}{l}\text { Resistance, mutinous } \\
\text { behaviour }\end{array}$ & 1.47 & 1.1 & Irritable, cranky & 1.38 & 1.4 \\
\hline
\end{tabular}

'The items Biting self' and 'Stereotypic, repetitive bebaviour' had the highest mean differences. The $95 \%$ CI values yielded another 11 items that differed between the two groups. Only items with a mean difference $\geq 0.5$ are presented in Table 6 . The 
only item that was significantly less common in children with behavioural and emotional disturbances was 'Seeking comfort or physical closeness'.

\section{Common pain behaviours}

The descending means of items reported to be most frequent show that of the 20 most frequently occurring items, the two groups shared 14 items, as shown in Table 7 (page 79).

For children with behavioural and emotional disturbances, items such as 'Anger', 'Stereotypic, and repetitive behaviour', 'Other stereotypic movements' and Fussy, lively' were among the 20 most prevalent items. By contrast, parents of children without these disturbances reported items such as 'Pallor' and 'Jutting lower lip, pouting' among the 20 most frequently occurring items.

\section{Most important items}

Finally, we examined what items were most important for diagnosing pain according to parents of children with and without behavioural and emotional disturbances. Data are presented in Table 8.

Table 8

Most important pain behaviours or categories of pain behaviours in children with behavioural and emotional disturbances, severe multiple disabilities, or neither

\begin{tabular}{|c|c|c|c|c|c|c|c|c|c|c|c|}
\hline \multirow[b]{2}{*}{ Dimensions } & \multirow{2}{*}{$\frac{\text { Items }}{N=145}$} & \multicolumn{3}{|c|}{$\begin{array}{l}\text { No additional disabilities } \\
\qquad(N=56)\end{array}$} & \multicolumn{3}{|c|}{$\begin{array}{l}\text { Behavioural and emotional } \\
\text { disturbances }(\mathrm{N}=50)\end{array}$} & \multicolumn{4}{|c|}{$\begin{array}{l}\text { Severe multiple disabilities } \\
\qquad(N=44)\end{array}$} \\
\hline & & \multicolumn{3}{|c|}{ Different items Density items } & \multicolumn{3}{|c|}{ Different items Density items } & \multicolumn{4}{|c|}{ Different items Density items } \\
\hline Facial & 33 & $1545 \%^{1}$ & 46 & $3.1^{2}$ & $1133 \%$ & 30 & 2.7 & 12 & $36 \%$ & 32 & 2.7 \\
\hline Motor & 37 & $1643 \%$ & 31 & 1.9 & $1643 \%$ & 37 & 2.3 & 16 & $43 \%$ & 45 & 2.8 \\
\hline Injured Body Part & 13 & $754 \%$ & 19 & 2.7 & $862 \%$ & 11 & 1.4 & 3 & $23 \%$ & 3 & 1.0 \\
\hline Social-Emotional & 26 & $1662 \%$ & 53 & 3.3 & $2285 \%$ & 70 & 3.2 & 11 & $42 \%$ & 26 & 2.4 \\
\hline Vocal & 19 & $947 \%$ & 54 & 6.0 & $1263 \%$ & 48 & 4.0 & 11 & $58 \%$ & 50 & 4.6 \\
\hline \multirow[t]{3}{*}{ Physiological } & 17 & $635 \%$ & 21 & 3.5 & $5 \quad 29 \%$ & 14 & 2.8 & 7 & $41 \%$ & 24 & 3.4 \\
\hline & 1 & $\begin{array}{l}\text { Crying loudly, } \\
\text { intensely }\end{array}$ & & 25 & $\begin{array}{l}\text { Crying loudly, } \\
\text { intensely }\end{array}$ & & 17 & $\begin{array}{l}\text { Crying } \\
\text { intense }\end{array}$ & $\begin{array}{l}\text { loudly, } \\
\text { ely }\end{array}$ & & 19 \\
\hline & 2 & $\begin{array}{l}\text { Seeking comfort } \\
\text { physical closene }\end{array}$ & & 13 & $\begin{array}{l}\text { Seeking comfo } \\
\text { physical closer }\end{array}$ & & 8 & $\begin{array}{l}\text { High } m \\
\text { crampir }\end{array}$ & $\begin{array}{l}\text { luscle to } \\
\text { ng }\end{array}$ & & 12 \\
\hline \multirow[t]{3}{*}{$\begin{array}{l}\text { Five most important } \\
\text { items noted }(N)\end{array}$} & 3 & Using a word fo & r pain & 11 & Grimacing & & 7 & Moanin & g, groar & ing & 10 \\
\hline & 4 & Tears & & 10 & Irritable, cranl & & 7 & Tears & & & 10 \\
\hline & 5 & $\begin{array}{l}\text { Pointing/gesturi } \\
\text { injured body par }\end{array}$ & $\begin{array}{l}\text { ng to } \\
\text { it }\end{array}$ & 9 & Screaming, ye & & 6 & Grimac & ing & & 9 \\
\hline
\end{tabular}

(1) Forty-five percent of the items $(\mathrm{N}=33$ ) within the Facial dimension were used by parents

(2) The 15 different items used by parents within the Facial dimension were used 46 times, resulting in an average density of 3.1 per item

As Table 8 shows, 'Crying loudly, intensely' was the most important item for both groups of children, followed by 'Seeking comfort or physical closeness'. For children with emotional and behavioural disturbances, Irritable, cranky' and 'Screaming, yelling' were also among the five most important items. The parents of this group of children used 22 of the 26 items within the Social-Emotional dimension when selecting the 
five most important items. The density of items from this dimension was also relatively high for children with disturbances. For both groups of children, however, it was the Vocal dimension that comprised the items with the highest density.

Overall, answering the second research question, children with behavioural and emotional disturbances display different behavioural repertoires when in pain than children who do not suffer from these disturbances. However there are also similarities between both groups of children.

\subsubsection{Children with versus those without severe multiple disabilities}

The final research question to be addressed was whether children with severe multiple disabilities display different behavioural repertoires when in pain than children who do not suffer from multiple disabilities?

\section{General questions on the observation of pain behaviour}

Table 9 (page 82-83) shows that the five general questions on observing pain in children with severe multiple disabilities yielded no statistically significant differences between these two groups.

\section{Prevalence of dimensions}

At an $\alpha$ of 0.008 , sum-scores of four of the six dimensions were found to be statistically significantly different between the groups, as shown by Table 9 . The sum-scores for the Motor, Vocal and Physiological dimensions where higher for children with severe multiple disabilities, whereas children without multiple disabilities had higher ratings for the Injured Body Part dimension. The 95\% CI of the Social-Emotional dimension shows a trend that children without severe multiple disabilities had higher ratings for this dimension.

\section{Prevalence of individual items}

Since children with and without severe multiple disabilities differed in five of the six dimensions, 86 items had to be tested. A Bonferroni-corrected $\alpha$ of 0.001 had to be used for the comparisons on these items. Ten items were found to differ statistically significantly between the two groups. Five items of the Motor dimension were found to be more prevalent in children with severe multiple disabilities, while five items of the Injured Body Part dimension were found to be more prevalent in children without these additional disabilities. The items with the greatest mean differences in this respect were 'Stifness, rigidity' (-1.31), 'High muscle tone, cramping' (-1.12) and Rubbing injured body part' (1.01). The 95\% CI showed a trend for 34 items to differ between the two groups. Items with a mean difference $\geq 0.5$ are presented in Table 9. Thirteen of the 17 items reported on the basis of the $95 \% \mathrm{CI}$ were more often present in children with severe multiple disabilities, most of them relating to the Motor dimension. 
Table 9

Difference between children with $(\mathrm{N}=44)$ and without severe multiple disabilities $(\mathrm{N}=56)$

General questions on the observation of pain behaviour

\begin{tabular}{|c|c|c|c|c|c|c|}
\hline \multirow{4}{*}{ Independent Samples Test } & \multicolumn{6}{|c|}{$t$-test for Equality of Means } \\
\hline & \multicolumn{3}{|c|}{$\begin{array}{l}\text { Bonferroni corrected } a \text { : } \\
\qquad 5=0.01\end{array}$} & \multicolumn{3}{|c|}{ Uncorrected interval } \\
\hline & \multirow{2}{*}{$t$} & \multirow{2}{*}{$\begin{array}{c}\text { 2-tailed } \\
\text { significance }\end{array}$} & \multirow{2}{*}{$\begin{array}{c}\text { mean } \\
\text { difference }\end{array}$} & \multirow{2}{*}{$\begin{array}{l}\text { standard } \\
\text { error diff. }\end{array}$} & \multicolumn{2}{|c|}{$95 \%$ confidence interval } \\
\hline & & & & & Lower & Upper \\
\hline Pain behaviour visible to parents & -1.17 & 0.245 & -0.25 & 0.21 & -0.67 & 0.17 \\
\hline Pain behaviour visible to others & 0.41 & 0.680 & 0.10 & 0.23 & -0.36 & 0.55 \\
\hline Discrimination between pain and other emotions & -0.60 & 0.552 & -0.15 & 0.25 & -0.65 & 0.35 \\
\hline Degree of indifference to pain & -0.24 & 0.809 & -0.04 & 0.17 & -0.38 & 0.29 \\
\hline Slow response to pain & 1.77 & 0.079 & 0.35 & 0.19 & -0.04 & 0.73 \\
\hline
\end{tabular}

Prevalence of sum-scores items dimensions

\begin{tabular}{|c|c|c|c|c|c|c|}
\hline \multirow{4}{*}{ Independent Samples Test } & \multicolumn{6}{|c|}{$t$-test for Equality of Means } \\
\hline & \multicolumn{3}{|c|}{$\begin{array}{c}\text { Bonferroni corrected } a: \\
0.05 / 6=0.0084\end{array}$} & \multicolumn{3}{|c|}{ Uncorrected interval } \\
\hline & \multirow{2}{*}{$t$} & \multirow{2}{*}{$\begin{array}{l}\text { 2-tailed } \\
\text { significance }\end{array}$} & \multirow{2}{*}{$\begin{array}{c}\text { mean } \\
\text { difference }\end{array}$} & \multirow{2}{*}{$\begin{array}{l}\text { standard } \\
\text { error diff. }\end{array}$} & \multicolumn{2}{|c|}{$95 \%$ confidence interva } \\
\hline & & & & & Lower & Upper \\
\hline Sum Facial & -0.77 & 0.444 & -1.99 & 2.59 & -7.12 & 3.14 \\
\hline Sum Motor * & -3.72 & 0.000 & -10.96 & 2.95 & -16.81 & -5.12 \\
\hline Sum Injured Body Part * & 7.57 & 0.000 & 5.85 & 0.77 & 4.32 & 7.38 \\
\hline Sum Social-Emotional & 2.04 & 0.044 & 3.56 & 1.74 & 0.10 & 7.01 \\
\hline Sum Vocal * & -3.02 & 0.003 & -3.32 & 1.10 & -5.50 & -1.14 \\
\hline Sum Physiological * & -2.81 & 0.006 & -3.57 & 1.27 & -6.09 & -1.04 \\
\hline
\end{tabular}

Prevalence of significant individual items of significantly different dimensions

\begin{tabular}{|c|c|c|c|c|c|c|}
\hline \multirow{4}{*}{ Independent Samples Test } & \multicolumn{6}{|c|}{$\underline{t}$-test for Equality of Means } \\
\hline & \multicolumn{3}{|c|}{$\begin{array}{c}\text { Bonferroni corrected } a \text { : } \\
0.05 / 40=0.00126\end{array}$} & \multicolumn{3}{|c|}{ Uncorrected interval } \\
\hline & \multirow{2}{*}{$t$} & \multirow{2}{*}{$\begin{array}{l}\text { 2-tailed } \\
\text { significance }\end{array}$} & \multirow{2}{*}{$\begin{array}{c}\text { mean } \\
\text { difference }\end{array}$} & \multirow{2}{*}{$\begin{array}{l}\text { standard } \\
\text { error diff. }\end{array}$} & \multicolumn{2}{|c|}{$95 \%$ confidence interval } \\
\hline & & & & & Lower & Upper \\
\hline Restless movements & -2.66 & 0.010 & -0.68 & 0.25 & -1.18 & -0.17 \\
\hline Involuntary movements & -2.95 & 0.004 & -0.71 & 0.24 & -1.19 & -0.23 \\
\hline Jerky movements & -2.33 & 0.023 & -0.61 & 0.26 & -1.12 & -0.09 \\
\hline High muscle tone, cramping * & -4.43 & 0.000 & -1.12 & 0.25 & -1.62 & -0.61 \\
\hline Stiffness, rigidity * & -5.14 & 0.000 & -1.31 & 0.25 & -1.82 & -0.80 \\
\hline Tremor leg, foot* & -3.95 & 0.000 & -0.75 & 0.19 & -1.13 & -0.37 \\
\hline Stretching torso and back & -2.93 & 0.004 & -0.80 & 0.27 & -1.35 & -0.26 \\
\hline Stretching arm * & -3.97 & 0.000 & -0.92 & 0.23 & -1.38 & -0.46 \\
\hline Spreading fingers & -2.01 & 0.049 & -0.50 & 0.25 & -0.99 & -0.002 \\
\hline Stretching leg * & -3.67 & 0.000 & -0.87 & 0.24 & -1.33 & -0.40 \\
\hline Stretching neck, pulling neck backwards & -3.26 & 0.002 & -0.86 & 0.26 & -1.39 & -0.34 \\
\hline Clenching fists, wringing hands & -2.49 & 0.015 & -0.59 & 0.24 & -1.07 & -0.12 \\
\hline Pulling up legs, knees & -2.54 & 0.013 & -0.54 & 0.21 & -0.96 & -0.12 \\
\hline Moaning, groaning & -2.97 & 0.004 & -0.68 & 0.23 & -1.13 & -0.22 \\
\hline Guttural sounds & -2.27 & 0.026 & -0.54 & 0.24 & -1.02 & -0.07 \\
\hline Penetrating, restless sounds $\sim$ & -2.56 & 0.012 & -0.58 & 0.23 & -1.03 & -0.13 \\
\hline Grinding teeth $\sim$ & -2.46 & 0.016 & -0.53 & 0.22 & -0.96 & -0.10 \\
\hline Spotted body & -3.22 & 0.002 & -0.58 & 0.18 & -0.95 & -0.22 \\
\hline Independent frequent position change $\sim$ & 2.00 & 0.049 & 0.51 & 0.25 & 0.00 & 1.01 \\
\hline Protecting injured body part * & 5.59 & 0.000 & 0.98 & 0.17 & 0.63 & 1.32 \\
\hline Pointing to, gesturing to injured body part * & 4.84 & 0.000 & 0.90 & 0.18 & 0.53 & 1.26 \\
\hline Withdrawing injured body part $\sim$ & 2.78 & 0.007 & 0.62 & 0.22 & 0.18 & 1.07 \\
\hline
\end{tabular}


Table 9 continued

Difference between children with $(N=44)$ and without severe multiple disabilities $(N=56)$

\begin{tabular}{|c|c|c|c|c|c|c|}
\hline \multirow{4}{*}{ Independent Samples Test } & \multicolumn{6}{|c|}{$t$-test for Equality of Means } \\
\hline & \multicolumn{3}{|c|}{$\begin{array}{l}\text { Bonferroni corrected } a: \\
0.05 / 40=0.00126\end{array}$} & \multicolumn{3}{|c|}{ Uncorrected interval } \\
\hline & \multirow{2}{*}{$t$} & \multirow{2}{*}{$\begin{array}{c}\text { 2-tailed } \\
\text { significance }\end{array}$} & \multirow{2}{*}{$\begin{array}{c}\text { mean } \\
\text { difference }\end{array}$} & \multirow{2}{*}{$\begin{array}{l}\text { standard } \\
\text { error diff. }\end{array}$} & \multicolumn{2}{|c|}{$95 \%$ confidence interval } \\
\hline & & & & & Lower & Upper \\
\hline Holding injured body part * & 4.66 & 0.000 & 0.79 & 0.17 & 0.45 & 1.12 \\
\hline Rubbing injured body part * & 6.73 & 0.000 & 1.01 & 0.15 & 0.71 & 1.30 \\
\hline Scratching, digging injured body part * & 3.88 & 0.000 & 0.44 & 0.11 & 0.21 & 0.66 \\
\hline Not using injured body part & 2.81 & 0.006 & 0.61 & 0.22 & 0.18 & 1.05 \\
\hline Fussy, lively $\sim$ & 2.18 & 0.032 & 0.50 & 0.23 & 0.04 & 0.95 \\
\hline \multicolumn{7}{|c|}{$\begin{array}{l}\text { (1) A negative number reflects a lower mean difference for children without severe multiple disabilities, a positive number reflects a higher mean difference } \\
\text { for children without severe multiple disabilities } \\
\text { * Significance based on Bonferroni corrected a } \\
\sim \text { Significance based on } 95 \% \text { confidence interval difference }\end{array}$} \\
\hline
\end{tabular}

Other items reported to be more often present in children with severe multiple disabilities were e.g. 'Guttural sounds', Penetrating, restless sounds', and 'Grinding teeth'. Of the four items more often present in children without multiple disabilities, two are related to the Injured Body Part dimension. The other two items were 'Independent, frequent position change' and Fussy, lively'.

\section{Common pain behaviours}

The comparison based on descending means showed that the two groups of children had 13 of the 20 items in common (Table 7, page 79). Items such as 'Stiffness rigidity', Involuntary movements', Penetrating, restless sounds' as well as several items relating to stretching were most frequently present in children with severe multiple disabilities. By contrast, children who did not suffer from additional disabilities were reported to show 'Witbdrawing injured body part' and Independent, frequent position change' as the most prevalent items.

\section{Most important items}

The final comparison related to the items indicated as most important by parents of children with and without multiple disabilities. As Table 8 (page 80) shows, 'Crying loudly, intensely' was the most important item for children with severe multiple disabilities. In addition, 'High muscle tone, cramping' and 'Moaning, groaning' were also regarded as very important for these children, whereas for children without multiple disabilities Pointing to, gesturing to injured body part' and 'Using a word for pain' were regarded as most important. Furthermore, the parents of children with severe multiple disabilities selected the greatest variety of items from the Motor and Vocal dimension, while selecting a relatively low percentage of items from the Social-Emotional dimension. The total number of selected items was relatively small. The Vocal dimension was the dimension with the highest density of items. The same was found for the parents of children without multiple 
disabilities. Overall, answering the third research question children with severe multiple disabilities display different behavioural repertoires when in pain than children who do not suffer from multiple disabilities. However there are also similarities between both groups of children.

\subsection{Discussion}

The present study investigated possible differences in pain-related behavioural repertoires in severely to profoundly intellectually disabled children. Children differed in their ability to express themselves verbally, in behavioural and emotional disturbances and in severe multiple disabilities. Overall, it can be concluded that there are differences in behavioural repertoires between different groups of children. This was found for the frequency of occurrence of items as well as for common behaviours and behaviours indicated by the parents as the most important pain indicators. Differences were most evident between children with severe multiple disabilities and those with behavioural and emotional disturbances on the one hand, and children without these additional disabilities on the other. This suggests that future studies should further examine the influence of these additional disabilities, especially since many questions were relevant to individual children in terms of both prevalence and importance of items.

We also found similarities between children in their expression of pain. Behaviours that were common to all children were mostly related to the facial expression of pain as well as items related to restlessness. These items are comparable to those identified in other paediatric populations. In the present study, 'Crying loudly, intensely' and 'Tears' were removed as a result of our internal consistency analysis, which means they seemed to be unrelated to other pain items. Nevertheless, 'Crying loudly, intensely' in particular was an important item according to the parents of children with severe intellectual disabilities in the present study, since this item was found to be the most important in all groups of children. These findings thus seem to be contradictory. Crying may be a more general indication of distress, rather than being specific for pain. Stallard and colleagues (2002a) showed that 'Crying with or without tears' was not related to pain severity and therefore might be a general indicator of distress in a population of non-verbal children with cognitive impairment. Other authors have generally reported that crying functions as a warning signal (Craig \& Gruneau, 1994). More research on this topic is obviously needed.

One of the limitations of the present study was the artificial creation of groups. It might be questioned whether it is wise to create subgroups in such a heterogeneous population. One could also object to the way in which the subgroups were defined. It might have been better to make a distinction between children with and without self-injurious behaviour within the group of children 
with emotional and behavioural disturbances. Or we should perhaps have been more strict regarding the intellectual disabilities of the group of children with severe multiple disabilities. However, it would be simply impossible to correct for all confounding variables, as it would have meant even smaller sample sizes, already a limitation of the present study. In view of the findings the artificial creation of groups did lead to significant differences between children. This provided a deeper understanding of pain behaviour in children with various (dis-) abilities.

\subsubsection{Children with versus those without verbal language}

The first comparison made in the present study was between the pain behaviour of children who were able to express some verbal language and that of children who were not able to do so. It was found that children seemed to differ especially regarding the frequency of occurrence of items related to the Injured Body Part dimension. Children who had the ability to communicate verbally more often displayed items such as Pointing to, gesturing to injured body part'. These findings are in line with the study by Hadden \& Bayer von (2002), who found that parents of children who were able to communicate their pain verbally reported a significantly greater frequency of items relating to touching, protecting, favouring or gesturing to a sore body part. Our finding in this respect might be explained by the fact that children who were able to communicate verbaliy were generally less severely intellectually disabled than those who could not communicate verbally. As McGrath (1990) pointed out, children's cognitive levels may be more predictive of their perception, expression and behavioural responses to pain than their actual chronological ages. A study focusing on pain expression and stimulus localisation in individuals with Down Syndrome (Hennequin et al., 2000) found that participants with Down Syndrome had more difficulties in localising a cold stimulus than the control group. It is imaginable that localising pain is even more difficult for children with more severe intellectual disabilities. In addition, children without verbal language are also more likely to be hampered by a severe motor disability, which in itself makes it more difficult to actually hold or rub an injured body part (Vlaskamp \& Oxener, 2002). Seibert and colleagues (1982) found that the development of language is highly correlated with the level of motor development in children with intellectual disabilities. Our findings in terms of the most frequently occurring and most important pain behaviours further highlight the role of the Motor dimension for non-verbal children. The item High muscle tone, cramping' e.g. was found to be the second most important item for these children. Among the children who were able to communicate verbally, 'Using a word for pain' was a key source of information for the parents. This may also account for the fact that parents of children who are not able to communicate pain through words find it more difficult to differentiate between pain and other emotions. When a child is not able to express itself verbally parents are dependent on other communicative expressions. When selecting the five most important items e.g., parents of non- 
verbal children used over $70 \%$ of the Motor items, whereas parents of children who were able to express themselves verbally selected just over half of the Motor items. Furthermore, of all the items noted for children without verbal communication, almost $24 \%$ belong to the Motor dimension.

When looking at the similarities between the two groups of children it is remarkable that the top ten among the most frequently occurring items are conceptually the same, although rankings may differ. Of these ten items, five belong to the Facial dimension. Furthermore, three of the five items parents noted as most important are the same for both groups of children. Although children differ in the frequency with which they display particularly the Injured Body Part items, the two groups are therefore reasonably comparable in terms of the most common and important items.

\subsubsection{Children with versus those without behavioural and emotional disturbances}

In the present study, the parents of children with behavioural and emotional disturbances indicated that they found it harder to decide whether or not their child is in pain than the parents of children without these disturbances. The parents felt the same to be true about other people dealing with the child. This seems to indicate that diagnosing pain in this group of children might require different methods. A similar finding was reported by Oberlander and colleagues (2000), who found it very difficult to separate pain experience from more generalised distress in children with autism. The present study found no significant difference between these two groups regarding the degree of indifference to pain as perceived by parents, which is remarkable in that it has been recognized that some individuals suffering from autism and related pervasive developmental disorders may show reduced responses to presumably painful stimuli (Symons, 1999).

In our study, the children with behavioural and emotional disturbances differed mostly from those without these types of disturbance in items from the SocialEmotional dimension. Several items relating to self-injury, stereotypic and aggressive behaviour were more often present in the children with behavioural and emotional disturbances. In their work on self-injurious behaviour, Gardner \& Sovner (1994) state that in many instances maladaptive behaviour may be the major means available to a person to indicate localised discomfort such as headaches and cramps and more general conditions such as malaise. Furthermore, the present study found that the children with these types of disturbance sought comfort or physical closeness less often and became agitated, panicky or restless more often. Of the items parents considered most important in diagnosing pain, over 33\% belong to the Social-Emotional dimension, and of the 26 items within this dimension, almost $85 \%$ were reported at least once as being among the five most important items for diagnosing pain in a child. By contrast, the Facial 
dimension seems less important for children with behavioural and emotional disturbances, since fewer items were reported as being most important and a relatively small proportion of all items mentioned belong to the Facial dimension compared to our findings among children without additional disabilities.

Nevertheless, six of the 20 most common behaviours in children with behavioural and emotional disturbances belong to the Facial dimension. It is also remarkable that of these 20 most common items, 10 are part of the Social-Emotional dimension. However, 5 of these 10 items were shared by children with and those without any additional disabilities. Other similarities between the two groups of children include the fact that 'Crying loudly, intensely' and 'Seeking comfort or physical closeness' were reported to be the most important items. It can be concluded that behavioural repertoires do seem to be different for children with and those without behavioural and emotional disturbances, in terms of the frequency of occurrence of items as well as in terms of common and most important behaviours. At the same time, however, there were also clear similarities between the groups.

\subsubsection{Children with versus those without severe multiple disabilities}

The final comparison made in the present study was that between children with and those without severe multiple disabilities. As the IASSID website (IASSID, 2001) confirms, individuals with profound multiple disabilities form a heterogeneous group. The 'core group' consists of individuals who have such profound mental disabilities that no existing standardized tests are applicable for a valid estimation of their level of intellectual capacity and who often have profound neuromotor disabilities as well. Apart from profound intellectual and physical disabilities, it is presumed that these individuals frequently have sensory impairments. The 'core group' described by IASSID overlaps to some extent with two other 'groups', that comprising persons who also have physical impairments and that comprising persons with 'only' severe mental disabilities in addition to neuromotor disabilities. The study population of children with severe multiple disabilities in the present study most likely comprised all three of the above groups.

We found that children with severe multiple disabilities seemed to differ from those without these disabilities on most dimensions, the only dimension that yielded no differences being the Facial dimension. However, in terms of the difference in prevalence of individual items, most items rated as significant belong to the Motor and Injured Body Part dimensions. Children with severe multiple disabilities more frequently displayed especially the items 'Stiffness, rigidity' and 'High muscle tone, cramping'. The latter was also reported to be one of the five most important items for diagnosing pain in this group of children. These findings are in line with a study by Hunt et al. (2003), who found that a change in tone is a significant cue that a child with severe neurologic impairment is in pain. In addition to motor items, the two groups of children also differed significantly on 
several items of the Vocal dimension, in the sense that children with severe multiple disabilities more often displayed items such as 'Grinding teeth' when in pain. This finding is in line with a study by Giusiano et al. (1995), who described the grinding of teeth as an indication that children with cerebral palsy are in pain. Furthermore, children with severe multiple disabilities more often displayed items such as 'Guttural sounds', 'Moaning and groaning' and Penetrating, restless sounds'. The last two items were also rated as belonging to the 20 most common pain behaviours in this group of children, while 'Moaning and groaning' was also regarded as one of the most important items. The same can be said for the Vocal dimension as a whole, since this dimension had the highest valid percentage of all items mentioned as most important.

Another point that has to be made is that children with severe multiple disabilities less frequently displayed items from the Injured Body Part dimension. Furthermore, these children less often showed Independent frequent position changes'. The study by Hadden \& Bayer von (2002) on pain in cerebral palsied children also found that parents of children who were able to move voluntarily reported a higher frequency of the behaviour 'Touches part of the body that burts'. As Fanurik (1999b) puts it, the presence of motor impairments poses special challenges to the accurate assessment of pain, because pain may be masked by the child's limited physical response to discomfort.

As regards similarities in the expression of pain between children with severe multiple disabilities and those without, the groups were found to share eight of the ten most common behaviours. And among the items parents considered most important as expressions of pain, 'Crying loudly, intensely' and 'Tears' were shared by the two groups. We thus conclude that, although there were many differences between the behavioural repertoires of children with and without severe multiple disabilities in terms of the prevalence of items, some similarities were also found.

Overall it can be concluded that the abilities and normal behavioural repertoires of children with severe to profound intellectual disabilities seem to influence their expression of pain in. This finding should be taken into account when assessing pain in these children. Not all items identified in our scale are applicable to all children. When developing pain measures for the total range of children with severe to profound intellectual disabilities, focussing on shared expressions between children seems important. However since there seem to be differences in the frequency in which shared expressions are observed in different groups of children, even when using shared pain expressions one has to be cautious with considering all children with severe to profound intellectual disabilities as being the same. 



\section{Chapter 5}

\section{Item selection and psychometric evaluation of KIDPAINS}

An observational pain assessment instrument for children with profound intellectual and communicative disabilities

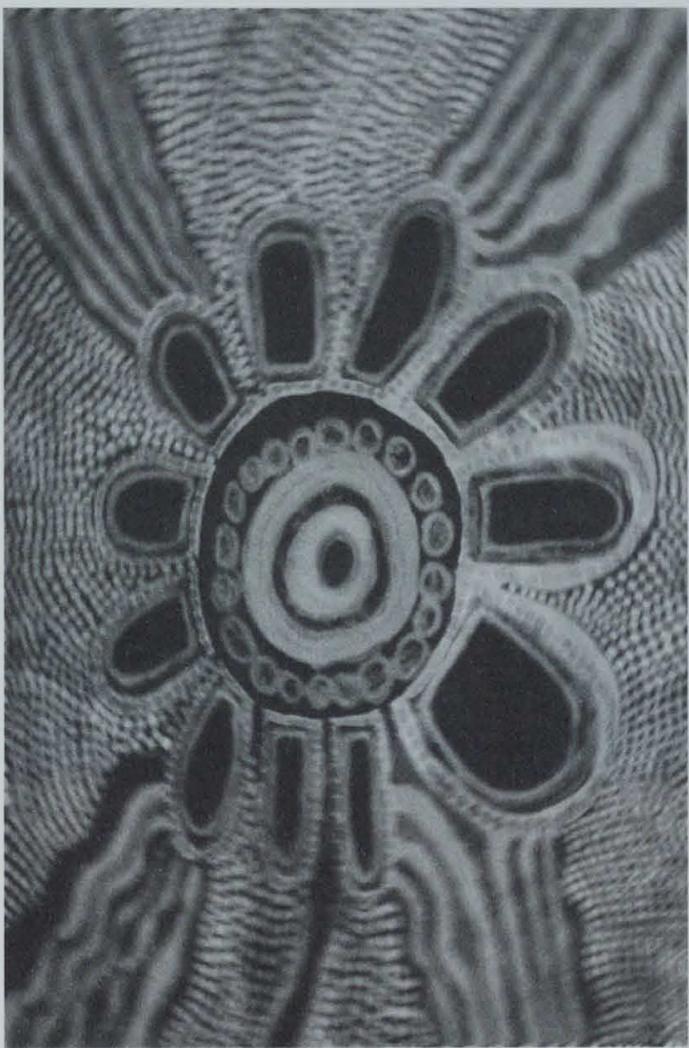

Katinka A.J. van Dongen, Jan P.H. Hamers, Huda Huijer Abu-Saad, Sandra M.G. Zwakhalen, Martijn P.F. Berger 


\begin{abstract}
Complementary research methods have established a solid foundation for the Kids with Intellectual Disabilities Pain Assessment Instrument for Non-verbal Signals (KIDPAINS). This chapter discusses a further item selection process, as well as an evaluation of the preliminary psychometric properties of the KIDPAINS instrument in non-verbal children with profound intellectual disabilities.
\end{abstract}

Part of the item selection process was based on parental judgements about the frequency of occurrence of items in their non-verbal child with profound intellectual disability. Items that never occurred according to these parents were removed, limiting the number to 114 items. The 114 retained items were used to rate video recordings derived from the clinical observations of 52 children with profound intellectual disabilities at standardised episodes before and after a medical procedure under general anaesthesia. Two episodes were selected for presumed absence of pain, while three episodes were selected for presumed presence of medically induced pain. One additional episode was selected as an intervention-specific moment presumed to reflect acute pain. The item selection process was applied separately to each time episode in order to cross-validate the selection process. Items were discarded based on frequencies of endorsement, internal consistency and PCA per dimension for each time episode, as well as based on a negative coherence between dimensions, resulting in 42 items that were present in the item selections for at least one of the four time episodes. Each dimension yielded adequate ( 0.643$)$ to good (0.893) Cronbach's $\alpha$ values, indicating homogeneity between items. During the item selection process the original facet design was partially abandoned.

The cross-validation of the item selection process for the episodes recorded at standardised episodes after extubation resulted in similar item selections for the various episodes. The item selection process for the intervention-specific episode (i.e., the situation of presumed acute pain) resulted in a number of items that were present only at this particular time episode. It remained unclear whether this finding was caused by this episode being conceptually different than the postoperative episodes or by the higher average VAS scores for the interventionspecific episode. After subtraction of the 'normal' behaviour, as scored one day before and one month after the procedure, from the behaviour at the moments of presumed pain, correlations with VAS were especially significant for the components in the Facial, Vocal and Social-Emotional dimension, identified by Principal Components Analysis. A comparison of the results for different time episodes identified a total of 11 of these possible components. Since clear convergent relationships with pain could not be identified for all of these components, further investigation was needed. At the end of this study, the KIDPAINS comprised 42 items. 


\subsection{Introduction}

People with profound intellectual disability suffer from serious neurological deficits and severe associated disorders (Schrojenstein Lantman van - Valk de et al., 1997), causing a decreased life expectancy in all age groups (Patja et al., 2000) Hence, people with profound intellectual disability are at risk of experiencing pain (Engel et al., 2000; Hadden \& Bayer von, 2002). Fanurik and colleagues (1999a) found that $90 \%$ of the parents of children with severe to profound intellectual disability reported to be able to determine the presence of pain from their child's indirect behaviours. Many of these parents felt, however, that health care providers had difficulty in identifying pain and were likely to underestimate and undertreat their children's pain. A similar finding was reported by Malviya and colleagues (2001), who studied pain management following spinal surgery and found that children with intellectual disability underwent pain assessment less frequently, received lower total doses of opiates and had analgesics administrated less frequently than children without intellectual disability. Stallard and colleagues (2001) reported that although $67.7 \%$ of the children in the sample they examined experienced moderate to severe pain over a two-week period, the pain was rarely actively treated. All this underlines the importance of adequate pain assessment tools for this population. Valid and reliable pain scales would enable professional caregivers to systematically recognise communicative behaviours indicating pain and would enable them to respond to these signals by providing adequate pain relief.

Research into pain measurement in children with intellectual disabilities has started only recently. Several research groups are currently testing the psychometric properties of scales evaluating pain in a diversity of samples derived from this specific paediatric population (Collignon \& Giusiano, 2001; Breau et al., 2001; Breau et al., 2002a; Breau et al., 2002b; Stallard et al., 2002a; Terstegen et al., 2003). However, these groups have worked from different perspectives: some focused on children with specific conditions such as cerebral palsy (Collignon \& Giusiano, 2001), while others focused on children with both severe and profound intellectual disabilities (Breau et al., 2001, 2002ab) or on chronic pain (Stallard et al., 2002a). The present study addressed the development of a pain assessment scale for nonverbal children with profound intellectual disabilities: the Kids with Intellectual Disabilities Pain Assessment Instrument for Non-verbal Signals (KIDPAINS).

\subsubsection{Designing KIDPAINS}

The process of designing the KIDPAINS started with candidate items for the scale being devised by observing 32 children and young adults with severe to profound intellectual and communicative disabilities during potentially painful situations and by conducting unstructured interviews with 29 parents and health care professionals. Expressions resulting from these observations and interviews were compared with measurement scale items taken from the literature on pain 
assessment in non-verbal paediatric populations (Dongen van et al., 1999). In all, 209 items were collected in this way (Chapter 2). After data extraction based on a facet design, seven dimensions of pain were postulated, distinguishing items relating to the Facial, Motor, Injured Body Part, Social-Emotional, Vocal, Physiological and Activities of Daily Living dimensions (Chapter 1).

The next step involved a study among nurses caring for individuals with severe or profound intellectual disabilities (Zwakhalen et al., 2004). The nurses seemed to value all presented expressions as important indicators of pain. Two additional items were devised (Chapter 3). Four experts on pain measurement in children then checked the items for interpretability, ambiguity and overlaps in the wording (Appendix I). Based on the results at that point, a draft scale was developed to facilitate further item development. Items were checked for their applicability in a hospital environment and the draft scale was pilot-tested by two researchers and a research student, who watched videos of children undergoing a medical procedure. It turned out that several items were not applicable, mostly since they did not fit the context in which the observations were made. Hence, for instance, all items referring to the Activities of Daily Living dimension were removed from the scale (Appendix D). To find out whether the remaining items were easy to understand for health care professionals working with people with intellectual disabilities, items were presented to a group of 105 of these professionals attending a conference on pain assessment in individuals with intellectual disabilities (Koot et al., 2000). Based on these findings, 145 items remained in the scale. A final check of the draft scale led to the removal of another seven items (Appendix I).

After testing for content validity, interpretability and face validity, 138 items were retained. In order to make the scale useful for daily practice, item reduction was then required. At that point it was decided to limit our population for psychometric testing to non-verbal profoundly intellectually disabled children. The first item selection study focussed on parental judgements about the occurrence of the behavioural items collected (Chapter 4). Parents of non-verbal children with profound intellectual disability $(\mathrm{N}=99)$ were asked to complete a standardized questionnaire. Parents were asked how often they noticed the various behavioural items in their child at moments when they felt he or she was in pain. For this purpose the 138 items adapted in the scale described above were used. All items that were never present according to $75 \%$ of these parents were discarded from the scale. This resulted mostly in the removal of expressions relating to the Injured Body Part dimension and items relating to self-injurious and aggressive behaviour. After this item selection process, 114 items were retained (Appendix II).

The present paper describes a further item selection process for KIDPAINS, based on observations of children with profound intellectual and communicative disabilities experiencing medically induced procedural/ postoperative pain at 
different moments in time. The study also examined the basic psychometric properties of KIDPAINS items resulting from these observations. Items were selected on the basis of the guidelines for scale development given by Streiner \& Norman (1998).

Specifically, the present study attempted to answer the following questions:

- What expressions of pain can be discarded from the original selection based on the frequency of endorsement of items for each episode?

- What expressions can be discarded based on the degree of homogeneity of the items within the dimensions of the scale for each episode?

- What components can be identified within the dimensions of the scale and what expressions can be discarded based on this dimensional structure for each episode?

- What can be said about the coherence of the dimensions of the draft scale?

- What can be said about the adequacy of item reduction by comparing item selections for different episodes?

- What can be said about the indications for construct and convergent validity of the KIDPAINS items retained after item reduction?

\section{$\underline{5.2 \text { Methods }}$}

\subsubsection{Design}

The 114 items originally selected for KIDPAINS had to be further reduced and tested for psychometric properties in a hospital setting. To this end, children with profound intellectual and communicative disabilities were observed and videotaped at various moments relating to various medical procedures in a children's hospital.

\subsubsection{Participants}

Children with a biological age of three years or older were considered suitable for inclusion in view of the possible overlap between biological and developmental age. The children's medical records as well as a parental questionnaire were used to extract information about the level of intellectual impairment. Since most people with profound intellectual disability remain in the pre-intentional phase of communication (Vlaskamp \& Oxener, 2002), we decided to include in the sample only children who performed at a developmental age up to one year in terms of language. The minimal Dutch speech standards (Goorhuis \& Schaerlaekens, 2000) were used for inclusion. The children were not able to produce any verbal language. No maximum age was set for inclusion since data were collected in a children's hospital. Children with abnormal renal or liver functions were excluded, since they might respond differently to pain relieving medication. This criterion led to the exclusion of two children. It was also decided to exclude any children who had undergone major changes in their daily environment, as this might influence 
their behaviour; in fact, however, no children were excluded on the basis of this criterion.

\subsubsection{Procedure}

Children who were scheduled for surgery or a medical procedure under general anaesthesia were recruited before admission to hospital. Parents of the children were invited to participate in the study at least one month prior to the procedure. Information about diagnoses was obtained from the children's medical records. Six-minute video recordings were made. Each recording comprised two minutes showing the whole body, two minutes showing the torso with upper limbs and two minutes showing the child's face.

Children were observed at the hospital one day before the procedure in order to examine their behaviour during hospitalisation but prior to the procedure (referred to below as ' $24 \mathrm{~h}$ pre'). Children were also observed at 30 minutes after extubation ( ${ }^{1} / 2 \mathrm{~h}$ post'), as well as at three hours (' $3 \mathrm{~h}$ post'), 24 hours (' $24 \mathrm{~h}$ post') and 48 hours (' $48 \mathrm{~h}$ post') after extubation, and during an intervention-specific moment ('ISM') that was hypothesized to be most likely to cause brief spells of acute pain. For example, children who had undergone adductor tenotomy were observed during the removal of the plaster cast when the leg was being moved for the first time by the orthopaedic surgeon. Finally, children were videotaped one month after the procedure in order to record their behaviour in their daily environment (" $1 \mathrm{mth}$ post'). Five of the seven episodes were chosen because they had a possible relationship with the occurrence of pain, while two were chosen to show the children's 'normal' behaviour at the hospital and at home. Participating children received standard medication.

\subsubsection{Measures}

The 114 original KIDPAINS items were used to rate the video recordings. Two researchers carried out the ratings separately, after a kappa $(0.67)$ had been calculated over 30 video scenes and had been found to be satisfactory. Answers were given on a five-point adjective scale with discrete response using 'no, not present' and 'yes, continuously present' as the anchors of the scale. Researchers also used a $100 \mathrm{~mm}$ mechanical Visual Analogue Scale (Price et al., 1994) for pain assessments, both directly, that is, while the video recordings were being made in the clinical situation (VAS-D), and while watching the videos (VAS-V). The VAS was anchored by the extremes 'no pain sensation' (left) and 'the most intense pain sensation imaginable' (right). When present in the clinical situation parents provided such a VAS score as well (VAS-P).

\subsubsection{Analysis}

Data were analysed using SPSS for Windows. All analyses aiming at item reduction were carried out separately for five different episodes $(1 / 2 \mathrm{~h}$ post, $3 \mathrm{~h}$ post, $24 \mathrm{~h}$ post, 
$48 \mathrm{~h}$ post and the ISM) in order to cross-validate the item selection process. Ideally, each episode should yield the same item selection. Furthermore, as a result of the large number of items in the draft scale, all data within each episode were analysed separately for the dimensions of pain that had initially been conceptually distinguished (Facial, Motor, Injured Body Part, Social-Emotional, Vocal and Physiological). Thus, six different analyses were done for all five pain related episodes. Hence, different items could be retained in the scale for different episodes. A comparison of the remaining items was made in order to cross-validate the item selection process. Descriptive statistics were used to describe the population under investigation, as well as VAS-V, VAS-D and VAS-P scores. For item selection several steps were taken.

\section{Item selection}

- We started by examining frequency of endorsement (Streiner \& Norman, 1998). Items endorsed as 'no - not present' in over $90 \%$ of the scenes were regarded as candidates for being dropped;

- Internal consistency ratings were carried out within each dimension and for each episode, in order to eliminate irrelevant items. Items were discarded based on the following criteria: (1) negative item-total correlation (2) itemtotal correlations $<0.20$ (3) item-total correlations $<0.40$ with a significant improvement of Cronbach's coefficient $\alpha$ (Streiner \& Norman, 1998), (Breukelen van \& Candel, 2000), (Norman \& Streiner, 2002). Using these criteria, items were removed in a stepwise procedure;

- Principal Components Analysis (PCA) was used to assess the underlying factor structure for the dimensions of the scale, in order to identify possible sub-dimensions for each of the various episodes. We decided to use PCA in view of the exploratory nature of the study and since PCA is used mostly as the first step in factor analysis (Hair, 1998). Eigenvalues and scree tests were examined in order to determine the number of components. Items were removed from a dimension at a particular episode based on the following criteria: (1) items with Measure of Sampling Adequacy $<0.50$, (2) communality of an item $<0.50$, (3) items with loadings in the component or pattern matrix $<0.50$. When two or more components were identified as a result of PCA, data were rotated using direct Oblimin, meaning that different components were allowed to correlate (Breukelen van, 2000; Norman \& Streiner, 2002; Hair, 1998). In view of the small sample size in the present study, loadings of the component or pattern matrix had to be between 0.70 and 0.75 to be considered significant (Hair, 1998);

- In order to investigate whether the dimensions and the identified components represented aspects of the same phenomena, the coherence of the dimensions and components was investigated. As an indication of the coherence, sumscores of the remaining items of the subscales or components were correlated with each other for each episode, using Pearson's correlation coefficient. 
Bonferroni correction was used to correct for the large number of correlations. A Bonerroni corrected $\alpha$ of 0.0001 was found to be acceptable per episode, however $p$-values $<0.005$ are marked as well. Dimensions or component that were negatively correlated with all other dimensions or components were dropped;

- After item reduction analysis, the sum-scores of the remaining items were calculated for the episodes $1 / 2 \mathrm{~h}$ post, $3 \mathrm{~h}$ post, $24 \mathrm{~h}$ post, $48 \mathrm{~h}$ post and ISM and correlated with the sum-score of the 114 items in the original scale used at the start of the present study, using Pearson's correlation coefficient (Norman \& Streiner, 2002). A Bonferroni corrected $\alpha$ of 0.0001 was used, however $p$ values $<0.005$ are marked as well.

\section{Validation}

In order to investigate convergent relations with the VAS-V, VAS-D and VAS-P scores, intra class correlations (ICC) for these measures were calculated for each episode (two-way random, absolute agreement).

To examine indications for construct and convergent validity, VAS-V, VAS-D, and VAS-P were correlated with differential scores using Pearson's correlation coefficient (Streiner \& Norman, 1998; Norman \& Streiner, 2002; Breukelen van \& Candel, 2000). Differential scores were calculated by subtracting the ratings of the remaining items within each of the dimensions for the baseline episodes, that is, $24 \mathrm{~h}$ pre and $1 \mathrm{mth}$ post intervention, from the ratings for the episodes reflecting possible pain, that is, $1 / 2 \mathrm{~h}$ post, $3 \mathrm{~h}$ post, $24 \mathrm{~h}$ post and $48 \mathrm{~h}$ post and ISM. The large number of correlations was corrected for by means of Bonferroni correction. A Bonerroni corrected $\alpha$ of 0.0001 was found to be acceptable per episode.

\section{$\underline{5.3 \text { Results }}$}

\subsubsection{Participants}

Altogether, 52 children with profound intellectual and communicative disabilities were enrolled in the study. The children had an average age of 8.6 years (SD 4.5; Range 3-19) and 25 were female. A significant number of the children (41) were unable to produce any language sounds; eleven children were able to babble. Additional descriptive information on the children is presented in Table 1 (page 99). In all, 364 episodes were supposed to be videotaped, but 25 episodes were missing, including $24 \mathrm{~h}$ pre $(\mathrm{N}=3), 1 / 2 \mathrm{~h}$ post $(\mathrm{N}=2), 3 \mathrm{~h}$ post $(\mathrm{N}=2), 24 \mathrm{~h}$ post $(\mathrm{N}=2), 48 \mathrm{~h}$ post $(\mathrm{N}=7), \mathrm{ISM}(\mathrm{N}=13)$ and 1 month post $(\mathrm{N}=3)$. Data for the ISM were missing for instance because researchers were not notified that a plaster cast was being removed or there was no typical ISM for a procedure, such as after the placement of middle ear tubes. 
Table 1

Demographic information hospitalised children $(N=52)$

AAMR classification system cause intellectual disabillity

Unknown

Prenatal, chromosomal disorder

Prenatal, syndrome disorders

Prenatal, inborn errors of metabolism

Prenatal, developmental disorders brain formation

Prenatal, environmental influences

Perinatal, intrauterine disorders

Perinatal, neonatal disorders

Postnatal, head injury

Postnatal, infections

Postnatal, degenerative disorders

Postnatal, seizure disorders

Postnatal, toxic-metabolic disorders

Additional impairments

Impairment upper limbs

Impairment lower limbs

Spasticity

Hearing impairment

Visual impairment

Both hearing and visual impairment

Self-injurious behaviour

Autistiform behaviour

Epilepsy
Type of intervention N

Gastroscopy, ph-monitoring

Gastroscopy, change of PEG

Gastroscopy, gastrostomy

Nissen fundoplication

Nissen fundoplication and gastrostomy

Oesofagectomy

Hernia umbilicalis

Adductor tenotomy

Tooth extractions

Release feet

Recanulation tracheostomy

Adenotonsillectomy

Middle ear tubes

Placement endonasal drains

Scoliosis correction

Amputation finger

Enucleation os

Cystoscopy, bilateral ureteral reimplantation
7

10

2

3

1

1

1

1

2

2

1

3

\subsubsection{VAS}

Descriptive results on the basis of the Visual Analogue Scales used in this study are presented in Table 2.

Table 2

Descriptive information VAS

\begin{tabular}{|c|c|c|c|c|c|c|}
\hline & VAS video $^{1}$ & $\mathbf{N}$ & VAS direct & $\mathbf{N}$ & VAS parent & $\mathbf{N}$ \\
\hline $\begin{array}{l}1 / 2 h \text { post } \\
\text { Mean (SD) }\end{array}$ & $17(22)$ & 50 & $25(27)$ & 50 & $23(31)$ & 31 \\
\hline $\begin{array}{l}\text { 3h post } \\
\text { Mean (SD) }\end{array}$ & $12(19)$ & 50 & $16(22)$ & 47 & $14(18)$ & 29 \\
\hline $\begin{array}{l}\text { 24h post } \\
\text { Mean (SD) }\end{array}$ & $9(14)$ & 50 & $14(17)$ & 50 & $11(16)$ & 32 \\
\hline $\begin{array}{l}\text { 48h post } \\
\text { Mean (SD) }\end{array}$ & $7(16)$ & 45 & $14(21)$ & 44 & $12(18)$ & 27 \\
\hline $\begin{array}{l}\text { intervention } \\
\text { specific moment } \\
\text { Mean (SD) }\end{array}$ & $30(21)$ & 39 & $42(25)$ & 37 & $36(24)$ & 21 \\
\hline
\end{tabular}

As this table shows, mean VAS ratings were not high. As a result of these findings it was decided to omit the $48 \mathrm{~h}$ post intervention episode from further data analysis. Since the intervention-specific moment (ISM) resulted in the highest average VAS 
ratings, it was decided to retain this episode for analyses, although the number of missing values was relatively high, as shown above.

\subsubsection{Item reduction based on frequency of endorsement}

In view of the low VAS scores, the frequency of endorsement rate for a particular item in children with a VAS-V rating $\geq 0.20$ was examined before items were actually removed based on frequency of endorsement. Only items that had also been endorsed as 'not present' in over $80 \%$ of these children, were permanently removed from the scale for that particular episode. This resulted in 4 items at $1 / 2 \mathrm{~h}$ post that would otherwise have been removed but were now retained in the item selection. Similarly, five items at $3 \mathrm{~h}$ post and seven items at $24 \mathrm{~h}$ post were retained in this manner. The item 'Hyperactive bebaviour' was scored separately since it had accidentally been omitted when the scoring sheets of KIDPAINS were printed.

Overall, 27 items were removed for all four episodes based on frequencies of endorsement; these items are presented in Table 3 (pages 101-103). Most items, however, were removed for only one, two or three episodes. In addition, results showed that the largest number of items had to be discarded for the $1 / 2 \mathrm{~h}$ post episode. In all, 54 items were removed based on the recordings made 30 minutes after extubation, indicating that these items were not endorsed at all by the researchers in $90 \%$ of the children at this time. For the $3 \mathrm{~h}$ post episode, that is, three hours after extubation, 48 items were removed. A total of 44 items were endorsed in less than $10 \%$ of the children one day after extubation ( $24 \mathrm{~h}$ post). Finally, the results for the acute pain episode (ISM) showed that 37 items were endorsed as 'no, not present' in over $90 \%$ of the children. At the end of these item reduction analyses, there were 60 items left in the scale at $1 / 2 \mathrm{~h}$ post extubation, 66 items at $3 \mathrm{~h}$ post and 70 items at $24 \mathrm{~h}$ post, while 77 items were left in the scale for the ISM.

\subsubsection{Item reduction based on internal consistency}

In view of the limited number of items that had remained in the Injured Body Part dimension after the frequency of endorsement analyses, and in view of the reduced number of items resulting in low internal consistency ratings within the Physiological domain, dimensions had to be redefined prior to, and during internal consistency ratings. Cronbach's $\alpha$ for the Physiological dimension at $1 / 2 \mathrm{~h}$ post was 0.23 , while that at $3 \mathrm{~h}$ post was 0.26 ; there was only one physiological item left in the scale at $24 \mathrm{~h}$ post, and $\alpha$ at the ISM was 0.54 . We therefore merged the Physiological dimension with the Vocal dimension, since several physiological items, such as expressions relating to breathing and an expression like 'Tears', seemed to fit best in the Vocal dimension. Correlations for these items were higher with the Vocal dimension than with other subscales. All items relating to the Injured Body Part dimension were placed within the Motor dimension. Correlations with this subscale were higher than with other subscales. 
Table 3

Overview of the 114 KIDPAINS items and item reduction

\begin{tabular}{|c|c|c|c|c|c|}
\hline Individual items & $\begin{array}{l}\text { Frequency of } \\
\text { endorsement }\end{array}$ & $\begin{array}{r}\text { Internal } \\
\text { consistency }\end{array}$ & $\begin{array}{r}\text { Principal } \\
\text { components } \\
\text { analysis }\end{array}$ & $\begin{array}{r}\text { Coherence } \\
\text { dimensions } \\
\text { negative }\end{array}$ & Selection ${ }^{1}$ \\
\hline
\end{tabular}

FACIAL.

Facial tension

Facial restlessness

Grimacing

Nasio-labial furrow deepened

Lips quivering

Jutting lower lip, pouting

Holding lips tightly

Turning down of mouth

Stretching mouth vertically, ' $O$ ' shaped mouth

Taut tongue

Clenching jaws

Eyes suddenly wide open

Widened eyes

Eyes slit

Squeezing eyes

Blinking continuously

Eyes whirling around

Looking sad

Looking serious, dejected

Looking angry

Looking anxious

Nostril flaring

Frowning chin

Trembling chin

Raising eyebrows, forehead furrowed

Frowning eyebrows, forehead

\begin{tabular}{|c|c|c|c|}
\hline & & & ++ \\
\hline & & $3^{2,3}$ & ++ \\
\hline & & & ++ \\
\hline & & & ++ \\
\hline $2,3,4$ & & & --- \\
\hline 2 & 1,3 & 4 & --- \\
\hline 1,2 & 3,4 & & --- \\
\hline & $1,2,3$ & 4 & -..-- \\
\hline 1 & $2,3,4$ & & --- \\
\hline$, 2,3,4$ & & & -- \\
\hline 1,3 & 2,4 & & -- \\
\hline 1,3 & 2 & & ++ \\
\hline & $1,2,3,4$ & & --- \\
\hline & $1,2,3$ & 4 & --- \\
\hline & $1,2,3$ & 4 & --- \\
\hline 1 & $2,3,4$ & & ---- \\
\hline & $1,2,3,4$ & & --- \\
\hline & 1 & 3 & ++ \\
\hline & $1,2,4$ & 3 & $-\cdots-$ \\
\hline $1,2,4$ & 3 & & $-\cdots-$ \\
\hline & & 3 & ++ \\
\hline 1,4 & 2,3 & & - \\
\hline & 1 & 2,4 & ++ \\
\hline 3,4 & 1 & 2 & $\ldots$ \\
\hline 1 & & & ++ \\
\hline & & & ++ \\
\hline
\end{tabular}

\section{MOTOR - TONUS}

Involuntary movements

Jerky movements

High muscle tone, cramping, spastic

Stiffness, rigidity

Floppy

Stretching torso and back

Streching arm

Streching leg

Spreading fingers

Stretching neck, pulling neck backwards

Tremor arm, hand

Tremor leg, foot

\begin{tabular}{rrrr} 
& & 4 & ++ \\
& & 4 & ++ \\
4 & $1,2,3$ & $1,2,3$ & ++ \\
2 & 4 & 1,3 & ++ \\
$1,2,3$ & 2 & 3 & +- \\
& $1,2,3,4$ & & ++ \\
& $1,3,4$ & 2 & -- \\
$1,2,3,4$ & & & -- \\
$1,2,3,4$ & & & -- \\
\hline
\end{tabular}

\section{MOTOR - MOVEMENT}

Wild hitting movements

Restless movements

Slow movements

$1 \quad 2,3,4$

Body in bowed position, arching

$1,2,3,4$

Body rocking

$1,2,3,4$

Fluttering, repetitive movements with the hands

$1,2,3,4$

Other stereotypical movements

$1,2,3,4$

Limited movements, hardly any movements

Independent frequent position change

Putting fingers in mouth

Clenching fists, wringing hands

1,2

Raising shoulders

$1,2,3,4$

Flexion of toes

$1,2,3,4$ 
Table 3 continued

Overview of the 114 KIDPAINS items and item reduction

\begin{tabular}{|c|c|c|c|c|c|}
\hline Individual items & $\begin{array}{l}\text { Frequency of } \\
\text { endorsement }\end{array}$ & $\begin{array}{r}\text { Internal } \\
\text { consistency }\end{array}$ & $\begin{array}{r}\text { Principal } \\
\text { components } \\
\text { analysis }\end{array}$ & $\begin{array}{r}\text { Coherence } \\
\text { dimensions } \\
\text { negative }\end{array}$ & Selection ${ }^{1}$ \\
\hline \multicolumn{6}{|l|}{ MOTOR - MOVEMENT (continued) } \\
\hline Rubbing hands against face & & 2,3 & 1,4 & & --- \\
\hline Moving hand (no tremor or stretching) & & & & & ++ \\
\hline Moving arm (no tremor or stretching) & & & & & ++ \\
\hline Moving foot (no tremor or stretching) & 1 & 4 & & & ++ \\
\hline Moving leg (no tremor or stretching) & & 1,4 & & & ++ \\
\hline Moving torso and back (no stretching) & & & & & ++ \\
\hline Restless movements with head & & & & & ++ \\
\hline Moving head (no stretching of neck) & & & 4 & & ++ \\
\hline Pulling up legs, knees & & 1,4 & & & ++ \\
\hline
\end{tabular}

\section{INJURED BODY PART - MOVEMENT}

\begin{tabular}{lrrr}
\hline Protecting injured body part & $1,2,3$ & & \\
Shifting head away & & $2,3,4$ & ++ \\
Shifting body away to avoid touch & 1,2 & 3 & - \\
Withdrawing injured body part & $1,2,3,4$ & & ++ \\
Holding injured body part & $1,2,3,4$ & & $+\cdots$ \\
Rubbing injured body part & $1,2,4$ & 3 & - \\
\hline
\end{tabular}

\section{SOCIAL-EMOTIONAL}

\begin{tabular}{|c|c|c|c|c|c|}
\hline Restlessness & & 2,3 & & & ++ \\
\hline Agitation & 1,2 & 3 & & & ++ \\
\hline Fussy, lively & $1,2,4$ & 3 & & & $\cdots$ \\
\hline Irritable, cranky & & $1,2,3$ & 4 & & $\cdots$ \\
\hline Panicky & & 2,3 & & & ++ \\
\hline Listless, insensible to psychological stimuli & & 4 & 1 & 2,3 & --- \\
\hline Being very calm & & 4 & & $1,2,3$ & --- \\
\hline Hardly any interaction with surrounding & & 4 & 2 & 1,3 & --- \\
\hline Not cooperating & $1,2,3$ & & 4 & & --- \\
\hline Sleepy, drowsy & 4 & & & $1,2,3$ & -- \\
\hline Dozing & 4 & & & $1,2,3$ & -- \\
\hline Inconsolable & 2,3 & 1 & & & ++ \\
\hline Refusing physical contact & $1,2,3,4$ & & & & $\cdots$ \\
\hline Accepting comfort, consolable & 2,3 & 1,4 & & & $-\cdots$ \\
\hline Seeking comfort or physical closeness & $1,2,3,4$ & & & & $\cdots$ \\
\hline Resistance, mutinous behaviour & 1,2 & 3 & & & ++ \\
\hline Anger & 1,2 & 3 & & & ++ \\
\hline Hitting (and other aggressive behaviours) & $1,2,3,4$ & & & & $\cdots$ \\
\hline Hyperactive behaviour & $1,2,3,4$ & & & & $\cdots$ \\
\hline Stereotypic, repetitive behaviour & $1,2,3,4$ & & & & --- \\
\hline
\end{tabular}

\section{VOCAL}

Crying softly

Moaning, groaning, whimpering

Crying loudly, intensely

Screaming, yelling

Stereotypical, repetetive sounds

$1,2,3,4$

Angry shrieks

$1,2,3,4$

Grinding teeth

Smacking sounds

$1,2,3,4$

Coughing

Paradoxical laughing

Being quiet, not making any sounds

Guttural sounds

Penetrating, restless sounds

Babbling

\begin{tabular}{|c|c|c|}
\hline \multirow{2}{*}{1} & $2,3,4$ & $\ldots$ \\
\hline & $1,2,3,4$ & $\cdots$ \\
\hline \multirow[t]{2}{*}{$1,2,3$} & 4 & - \\
\hline & $1,2,3,4$ & \\
\hline \multirow[t]{2}{*}{1} & $2,3,4$ & - \\
\hline & 4 & $T$ \\
\hline 2,3, & & \\
\hline
\end{tabular}


Table 3 continued

Overview of the 114 KIDPAINS items and item reduction

\begin{tabular}{|c|c|c|c|c|c|}
\hline Individual items & $\begin{array}{l}\text { Frequency of } \\
\text { endorsement }\end{array}$ & $\begin{array}{r}\text { Internal } \\
\text { consistency }\end{array}$ & $\begin{array}{r}\text { Principal } \\
\text { components } \\
\text { analysis }\end{array}$ & $\begin{array}{r}\text { Coherence } \\
\text { dimensions } \\
\text { negative }\end{array}$ & Selection ${ }^{1}$ \\
\hline \multicolumn{6}{|l|}{ PHYSIOLOGICAL } \\
\hline Holding or drawing in breath & $1,2,3$ & & & & ++ \\
\hline Increased respiration rate & $1,2,3,4$ & & & & -- \\
\hline Irregular jerky respiration & 3 & & & & ++ \\
\hline Sharp intake of breath & 3 & $1,2,4$ & & & $\cdots$ \\
\hline Gasping & $1,3,4$ & 2 & & & $\ldots$ \\
\hline Perspiring & $1,2,3,4$ & & & & $-\ldots$ \\
\hline Shivering & $1,2,3,4$ & & & & - \\
\hline Grey pallor & $1,2,3,4$ & & & & $\ldots$ \\
\hline Snoring respiration & & $1,2,3,4$ & & & $\cdots$ \\
\hline Pallor & $2,3,4$ & 1 & & & $\cdots$ \\
\hline Looking flushed & 3 & $1,2,4$ & & & --- \\
\hline Blue lips & $1,2,3,4$ & & & & -- \\
\hline Spotted body & $1,2,3,4$ & & & & --- \\
\hline Tears & 2,3 & 1 & & & ++ \\
\hline \multicolumn{6}{|c|}{$\begin{array}{l}\text { (1) }++=\text { Items present in selection for at least one episode after item reduction analyses } \\
---=\text { Items not present in selection after item reduction analyses } \\
\text { (2) } 1=1 / 2 \mathrm{~h} \text { post, } 2=3 \mathrm{~h} \text { post, } 3=24 \mathrm{~h} \text { post, } 4=\text { interventon specific moment } \\
\text { (3) Number specifies that the item Facial restlessness was removed based on principal components analysis } 24 \mathrm{~h} \text { post extubation }\end{array}$} \\
\hline
\end{tabular}

The Motor dimension was then split into two new dimensions, since all items relating to muscle tone showed item-total correlations $<0.20$ within the Motor dimension as a whole. Rather than discarding all these items at once, it was decided to distinguish between items relating to movement and those relating to muscle tone. The entire process resulted in a new set of five dimensions of pain behaviour: Facial, Movement, Tonus, Social-Emotional and Vocal/ Physiological.

Table 4

Improvement in Cronbach's a resulting from elimination of items that did not meet the set criteria

\begin{tabular}{|c|c|c|c|c|}
\hline & $\begin{array}{c}1 / 2 h \text { post } \\
N=49\end{array}$ & $\begin{array}{c}3 \mathrm{~h} \text { post } \\
\mathrm{N}=50\end{array}$ & $\begin{array}{c}24 h \text { post } \\
N=50\end{array}$ & $\begin{array}{c}\text { ISM } \\
N=39\end{array}$ \\
\hline \multicolumn{5}{|l|}{ FACIAL } \\
\hline Cronbach's a improved from & 0.61 to 0.88 & 0.74 to 0.88 & 0.81 to 0.89 & 0.82 to 0.87 \\
\hline \multicolumn{5}{|l|}{ MOVEMENT } \\
\hline Cronbach's a improved from & 0.69 to 0.89 & 0.71 to 0.89 & 0.76 to 0.89 & 0.70 to 0.83 \\
\hline \multicolumn{5}{|l|}{ TONUS } \\
\hline Cronbach's a improved from & 0.56 to 0.78 & 0.66 to 0.81 & 0.75 to 0.80 & 0.72 to 0.73 \\
\hline \multicolumn{5}{|l|}{ SOCIAL-EMOTIONAL } \\
\hline Cronbach's a improved from & 0.52 to 0.64 & 0.68 to 0.89 & 0.43 to 0.78 & 0.63 to 0.86 \\
\hline \multicolumn{5}{|l|}{ VOCAL / PHYSIOLOGICAL } \\
\hline Cronbach's a improved from & 0.39 to 0.87 & 0.26 to 0.86 & 0.63 to 0.85 & 0.63 to 0.85 \\
\hline
\end{tabular}

In all, 27 items were dropped as a result of the internal consistency ratings at $1 / 2 \mathrm{~h}$ post. The analysis at the other three episodes resulted in the removal of 31 items at $3 \mathrm{~h}$ post, 36 items at $24 \mathrm{~h}$ post and 31 items at the ISM. Table 4 shows the improvement in Cronbach's $\alpha$ resulting from the elimination of all the items that did not meet the above criteria. 
Overall, the largest number of items was discarded from the Facial dimension, resulting in high Cronbach's $\alpha$ values for all episodes. Cronbach's $\alpha$ values were also consistently high for the Vocal/ Physiological dimension. The homogeneity of the dimensions was then examined and improved with the help of Principal Components Analysis (PCA).

\subsubsection{Item reduction based on Principal Components Analysis}

As a result of PCA, six items were removed for the $1 / 2 \mathrm{~h}$ post episode, four of which had communalities smaller than 0.50 . Five items were discarded for $3 \mathrm{~h}$ post, based on low communalities. Seven items were dropped in the factor solution for $24 \mathrm{~h}$ post, due to insufficient communalities. Finally, two items were removed for the ISM, because they had low loadings for both components. Furthermore, ten items were dropped because of low communalities. The results of all 48 items remaining after Principal Components Analysis are presented in Table 5 (page 105106).

In view of the small sample size of the present study, loadings of the component or pattern matrix had to be between 0.70 and 0.75 to be considered significant. As Table 5 shows, 10 loadings were below this cut-off point. Loadings below 0.70 were mostly related to the Movements dimension. Furthermore, Table 3 shows that almost all Kaiser-Meyer-Olkin Measure of Sampling Adequacy summary values were over 0.70. Norman \& Streiner (2002) reported that Kaiser describes values in the $0.60 \mathrm{~s}$ as mediocre, values in the $0.50 \mathrm{~s}$ as miserable and lower ones as unacceptable. Most summary values of MSA exceeded 0.70 (Table 5). Those that were below 0.70 were mostly related to the Social-Emotional and Tonus dimensions. Both the Facial and the Vocal/ Physiological dimensions had summary values of 0.70 or higher for each episode. Table 5 also shows that most components explained a considerable proportion of the variance.

\subsubsection{Investigating coherence of dimensions}

As an indication of the coherence between dimensions, sum-scores of the remaining items of the subscales were correlated with each other for each episode, using Pearson's correlation coefficient. Data are presented in Table 6 (page 107). The data in Table 6 show that correlations tended to be significant between the Vocal and Facial and Social-Emotional components for all episodes. Table 6 also shows that when items relating to lower activity levels were selected from the Social-Emotional dimension, the sum-scores of these components correlated negatively with all other sum-scores. The second Social-Emotional component was therefore discarded at $1 / 2 \mathrm{~h}$ post. Similarly, Social-Emotional components were discarded at $3 \mathrm{~h}$ post and $24 \mathrm{~h}$ post (Table 3 , page 102). 
Table 5

Results of principal components analysis within the various dimensions

1/2h post 3h post 24h post $\begin{array}{r}\text { intervention- } \\ \text { specific moment }\end{array}$

\section{FACIAL}

\begin{tabular}{lllll}
\hline Facial tension & 0.78 & $0.80^{1}$ & 0.80 & $0.74^{1}$ \\
Grimacing & 0.89 & $0.75^{1}$ & 0.80 & $0.89^{1}$ \\
Looking sad & & $0.91^{1}$ & & $0.82^{1}$ \\
Nasio-labial furrow deepened & 0.81 & $0.85^{1}$ & 0.84 & $0.87^{1}$ \\
Frowning eyebrows, forehead & 0.74 & $0.81^{1}$ & 0.74 & $0.64^{1}$ \\
Facial restlessness & 0.73 & $0.81^{2}$ & $0.80^{2}$ \\
Looking anxious & 0.83 & $0.94^{2}$ & & $0.92^{2}$ \\
Raising eyebrows, forehead furrowed & & $0.75^{2}$ & 0.73 & $0.67^{2}$ \\
Eyes suddenly wide open & & & $0.80^{2}$ \\
Frowning chin & & & 0.77 & $50 \%^{1}$ \\
\hline Percentage explained variance & $64 \%$ & $59 \%^{1}$ & $60 \%$ & $23 \% \%^{2}$ \\
& & $16 \%^{2}$ & & 0.82
\end{tabular}

\section{MOVEMENT}

Restless movements

Wild hitting movements

Restiess movements with head

Moving hand (no tremor or stretching)

Moving arm (no tremor or stretching)

Moving head (no stretching of neck)

Moving torso (no stretching)

Independent frequent position change

Moving foot (no tremor or strectching)

Moving leg (no tremor or stretching)

Pulling up legs, knees

Protecting injured body part

Shifting body away to avoid touch

Percentage explained variance

Kaiser-Meyer-Olkin MSA summary

\subsection{6}

0.71

0.78

0.82

0.76

0.85

0.77
$0.61^{2}$

$0.92^{2}$

$0.81^{2}$

$0.79^{1}$

$0.86^{1}$

$0.90^{\prime}$

$0.64^{1}$

$-0.72^{3}$

$-0.73^{3}$

$-0.94^{3}$

\section{$0.65^{2}$}

$0.89^{2}$

$0.86^{2}$

$-0.85$

$-0.88^{3}$

$-0.75^{3}$

$0.59^{1}$

$0.75^{1}$

$0.75^{1}$

$0.86^{1}$
$0.73^{1}$

$0.65^{1}$

$0.67^{1}$

$0.81^{1}$

$0.83^{1}$

$0.87^{3}$

$0.90^{3}$

$0.94^{2}$

$0.97^{2}$

$61 \%$

0.76
$54 \%$

$13 \%{ }^{2}$

$12 \%{ }^{3}$

0.83
$52 \% 1$

$13 \%{ }^{2}$

$11 \%{ }^{3}$

0.79

\section{TONUS}

Involuntary movements

0.84

0.78

0.73

High muscle tone, cramping, spastic

Stiffness, rigidity

Stretching arm

Percentage explained variance

Kaiser-Meyer-Olkin MSA summary
0.73

$60 \%$

0.71
0.90

0.90

0.77

0.85

0.89

0.81

0.64
$73 \%$

0.67
$72 \%$

0.69
0.78

$64 \%$

0.75

86

8

\section{SOCIAL-EMOTIONAL}

Restlessness

Panicky

Being very calm

Sleepy, drowsy

Dozing

Hardly any interacting with surroundings

Listless, insensitive to psychological stimuli

\section{$-0.89^{1}$}

$-0.86^{1}$

$0.82^{1}$

$0.91^{2}$

$0.95^{2}$

$0.63^{2}$ 
Table 5 continued

Results of principal components analysis within the various dimensions

\begin{tabular}{|c|c|c|c|c|}
\hline & $1 / 2 h$ post & 3h post & $24 h$ post & $\begin{array}{l}\text { intervention- } \\
\text { specific moment }\end{array}$ \\
\hline \multicolumn{5}{|l|}{ SOCIAL-EMOTIONAL (continued) } \\
\hline Agitation & & & & 0.77 \\
\hline Inconsolable & & & & 0.79 \\
\hline Resistance, mutinuous behaviour & & & & 0.78 \\
\hline Anger & & & & 0.72 \\
\hline \multirow[t]{2}{*}{ Percentage explained variance } & $61 \%^{1}$ & $78 \%$ & $55 \% 1$ & $59 \%$ \\
\hline & $18 \%^{2}$ & & $25 \%{ }^{2}$ & \\
\hline Kaiser-Meyer-Olkin MSA summary & 0.74 & 0.74 & 0.62 & 0.68 \\
\hline \multicolumn{5}{|l|}{ VOCAL / PHYSIOLOGICAL } \\
\hline Crying softly & 0.91 & 0.86 & 0.88 & $0.94^{ \pm}$ \\
\hline Moaning, groaning, whimpering & 0.86 & 0.83 & 0.88 & $0.82^{1}$ \\
\hline Penetrating, restless sounds & 0.79 & 0.89 & 0.86 & \\
\hline Holding or drawing in breath & & & & $0.75^{1}$ \\
\hline Irregular jerky respiration & 0.91 & 0.75 & & $0.63^{1}$ \\
\hline Crying loudly, intensely & & 0.84 & & $0.75^{2}$ \\
\hline Screaming, yelling & & & & $0.93^{2}$ \\
\hline Tears & & & & $0.83^{2}$ \\
\hline \multirow[t]{2}{*}{ Percentage explained variance } & $76 \%$ & $69 \%$ & $76 \%$ & $55 \%{ }^{1}$ \\
\hline & & & & $16 \%^{2}$ \\
\hline Kaiser-Meyer-Olkin MSA summary & 0.72 & 0.82 & 0.73 & 0.77 \\
\hline $\begin{array}{l}\text { (1) Loading on first identified component } \\
\text { (2) Loading on second identified component }\end{array}$ & & & & \\
\hline
\end{tabular}

Components comprised the items 'Being very calm', 'Sleepy, drowsy', Dozing', Hardly interacting with surroundings', and the item 'Listless, insensitive to physical stimuli' from Table 5. As regards the items relating to Movements and Tonus, it can be noted that most of these components were highly correlated with each other, except for the ISM. When items relating to emotional arousal were included in the item selection, however, correlations with some Motor components tended to be significant as well.

\subsubsection{Item selection}

After the item reduction analyses had been finalised for each of the four episodes, the sum-score of all remaining items within that particular episode was calculated and correlated with the sum-score of the original 114 scale items used at the start of the present study, using Pearson's correlation coefficient (Norman \& Streiner, 2002). Correlations were all highly significant when comparing with a Bonferroni corrected $\alpha$ of 0.0001 . Correlations were 0.87 for $1 / 2 \mathrm{~h}$ post, 0.84 for $3 \mathrm{~h}$ post, 0.84 for $24 \mathrm{~h}$ post and 0.88 for the ISM, indicating that the item selections after item reduction correlated with the initial item selection of 114 items. Item selections for each episode can be found in Table 3. 
Table 6

Pearson correlations between sum-scores of the different dimensions / components

\begin{tabular}{|c|c|c|c|c|c|c|c|c|}
\hline $1 / 2 h$ post & Move & Tonus & Vocal & Soc. Em. $\mathrm{C1}^{1}$ & Soc.Em.C2 & & & \\
\hline Face & 0.29 & 0.26 & $0.66^{2}$ & $0.61^{2}$ & $-0.40^{3}$ & & & \\
\hline Movement & & $0.60^{2}$ & 0.72 & $0.55^{2}$ & $-0.63^{2}$ & & & \\
\hline Tonus & & & 0.32 & $0.40^{3}$ & -0.35 & & & \\
\hline Vocal & & & & $0.50^{2}$ & -0.23 & & & \\
\hline Soc.Em.C1 & & & & & $-0.51^{2}$ & & & \\
\hline $3 \mathrm{~h}$ post & Face $\mathrm{C} 2$ & Move $\mathrm{C} 1$ & Move C2 & Move $\mathrm{C} 3$ & Tonus & Vocal & Soc. Em. & \\
\hline Face $\mathrm{C} 1$ & $0.56^{2}$ & 0.25 & 0.20 & 0.14 & 0.35 & $0.76^{2}$ & $-0.46^{2}$ & \\
\hline Face $\mathrm{C} 2$ & & 0.14 & 0.31 & 0.07 & 0.26 & $0.77^{2}$ & $-0.40^{3}$ & \\
\hline Movement $\mathrm{Cl}$ & & & $0.56^{2}$ & $0.57^{2}$ & $0.50^{2}$ & 0.17 & $-0.74^{2}$ & \\
\hline Movement $\mathrm{C} 2$ & & & & $0.58^{2}$ & $0.72^{2}$ & 0.20 & $-0.52^{2}$ & \\
\hline Movement $\mathrm{C} 3$ & & & & & $0.50^{2}$ & 0.02 & $-0.49^{2}$ & \\
\hline Tonus & & & & & & 0.24 & $-0.52^{2}$ & \\
\hline Vocal & & & & & & & $-0.47^{2}$ & \\
\hline $24 h$ post & Move $\mathrm{C} 1$ & Move C2 & Move C3 & Tonus & Vocal C1 & Soc.Em. C1 & Soc.Em.C2 & \\
\hline Face & 0.16 & 0.09 & -0.07 & $0.47^{2}$ & $0.73^{2}$ & -0.10 & -0.34 & \\
\hline Movement $\mathrm{Cl}$ & & $0.54^{2}$ & $0.59^{2}$ & 0.33 & 0.13 & -0.14 & -0.34 & \\
\hline Movement $\mathrm{C} 2$ & & & $0.54^{2}$ & $0.54^{2}$ & 0.15 & -0.05 & $-0.47^{2}$ & \\
\hline Movement $\mathrm{C} 3$ & & & & 0.34 & -0.10 & -0.19 & $-0.48^{2}$ & \\
\hline Tonus & & & & & $0.48^{2}$ & -0.10 & $-0.46^{2}$ & \\
\hline Vocal & & & & & & -0.06 & -0.36 & \\
\hline Soc.Em.C1 & & & & & & & $-0.39^{3}$ & \\
\hline ISM & Face $\mathrm{C} 2$ & Move C1 & Move $\mathrm{C} 2$ & Move C3 & Tonus & Vocal C1 & Vocal C2 & Soc.Em. \\
\hline Face $\mathrm{Cl}$ & $0.44^{2}$ & 0.09 & 0.19 & 0.11 & -0.11 & $-0.66^{2}$ & $0.64^{2}$ & $0.54^{2}$ \\
\hline Face $\mathrm{C} 2$ & & 0.17 & -0.17 & -0.20 & $0.48^{3}$ & $0.56^{2}$ & 0.47 & 0.18 \\
\hline Movement $\mathrm{Cl}$ & & & 0.31 & 0.38 & 0.27 & -0.04 & 0.05 & $0.52^{2}$ \\
\hline Movement $\mathrm{C} 2$ & & & & 0.25 & -0.16 & -0.12 & -0.05 & 0.21 \\
\hline Movement $\mathrm{C} 3$ & & & & & -0.35 & -0.14 & 0.14 & $0.68^{2}$ \\
\hline Tonus & & & & & & -0.10 & -0.07 & -0.13 \\
\hline Vocal C1 & & & & & & & $0.55^{2}$ & 0.28 \\
\hline Vocal C2 & & & & & & & & $0.43^{3}$ \\
\hline $\begin{array}{l}\text { (1) Soc. Em. = So } \\
\text { (2) Pearson corre } \\
\text { (3) Pearson corre }\end{array}$ & $\begin{array}{l}\text { tional, } C 1=C \\
\text { mificant at the } \\
\text { gnificant at the }\end{array}$ & $\begin{array}{l}\text { mponent } 1 \\
0.0001 \text { level } \\
0.005 \text { level }\end{array}$ & & & & & & \\
\hline
\end{tabular}

As Table 3 shows, most items were not present in all item selections. Selecting the items for KIDPAINS at four different episodes resulted in 42 items that were retained in the scale for at least one of the four episodes. An overview of these items is presented in Table 7 (page 108). Twelve items were present after all four item-selection procedures, while nine items were part of the item selection for three episodes. Twelve of the 42 items were present in just one item selection, eleven of which were included for the intervention-specific moment (ISM) only.

\subsubsection{Construct and convergent validity}

Before examining convergent relations with the VAS scores, we calculated an intra class correlation for each episode. The ICC was 0.80 for $1 / 2 \mathrm{~h}$ post, 0.57 for $3 \mathrm{~h}$ post, 0.25 for $24 \mathrm{~h}$ post and 0.57 for the ISM. Based on these results, the $24 \mathrm{~h}$ post episode was omitted from further analyses. 
Table 7

Overview 42 items KIDPAINS

\section{FACIAL}

Facial tension

Facial restlessness

Grimacing

Nasio-labial furrow deepened

Eyes suddenly wide open

Looking sad

Looking anxious

Frowning chin

Raising eyebrows, forehead furrowed

Frowning eyebrows, forehead

\section{MOVEMENT}

Wild hitting movements

Restless movements

Independent frequent position change

Moving hand (no tremor or stretching)

Moving arm (no tremor or stretching)

Moving foot (no tremor or stretching)

Moving leg (no tremor or stretching)

Moving torso and back (no stretching)

Restless movements with head

Moving head (no stretching of neck)

Pulling up legs, knies

Protecting injured body part

Shifting body away to avoid touch

\section{TONUS}

Involuntary movements

Jerky movements

High muscle tone, cramping, spastic

Stiffness, rigidity

Streching arm

\section{SOCIAL-EMOTIONAL}

\section{Restlessness}

Agitation

Panicky

Inconsolable

Resistance, mutinious behaviour

Anger

\section{VOCAL / PHYSIOLOGICAL}

\section{Crying softly}

Moaning, groaning, whimper

Crying loudly, intensely

Screaming, yelling

Penetrating, restless sounds

Breath holding, indrawing

Irregular jerking respiration

Tears

The scores of the items at the selected 'painful' moments, that is, $1 / 2 \mathrm{~h}$ post, $3 \mathrm{~h}$ post and ISM, minus the scores at $24 \mathrm{~h}$ pre (baseline at hospital) or at $1 \mathrm{mth}$ post (baseline at home) show that correlations with VAS-V and VAS-D were mostly significant for the (first) Facial and Vocal components. It should be noted, however, that at the ISM, that is, the moment hypothesized to be most likely to produce brief acute pain, as well as at 1/2h post, the differential scores of the SocialEmotional dimension also correlated significantly with VAS-V.

As Table 8 (page 109) shows, observations 3 h post resulted in the largest number of significant correlations of the selected components with both VAS-V and VAS$D$. For VAS-P, however, this episode did not result in any significant correlations. Overall, VAS-V correlations were higher than VAS-D correlations. Furthermore, the number of significant correlations was slightly lower for the differential scores after subtraction of the behaviour 1 month after the procedure than for those after subtraction of the behaviour within the hospital, 24 hours prior to the procedure.

\subsection{Discussion}

The purpose of the present study was to select items for KIDPAINS and to test the initial psychometric properties of the resulting item selection. Overall, it can be concluded that a significant reduction of the number of items was achieved, resulting in five subscales with high internal consistency ratings. 
Table 8

Pearson correlations between differential scores and VAS video, VAS parent and VAS direct

\begin{tabular}{|c|c|c|c|c|c|c|c|}
\hline $1 / 2 h$ post $-/-24 h$ pre & VAS-V & VAS-P & VAS-D & $1 / 2 \mathrm{~h}$ post $-1-1 \mathrm{~m}$ th post & VAS-V & VAS-P & VAS-D \\
\hline Face & $0.76^{2}$ & $0.51^{1}$ & $0.57^{2}$ & Face & $0.78^{2}$ & $0.57^{1}$ & $0.62^{2}$ \\
\hline Movement & 0.16 & 0.05 & 0.08 & Movement & 0.22 & 0.26 & 0.22 \\
\hline Tonus & 0.06 & 0.04 & 0.04 & Tonus & 0.18 & 0.12 & 0.18 \\
\hline Vocal & $0.69^{2}$ & 0.44 & $0.61^{2}$ & Vocal & $0.70^{2}$ & $0.59^{1}$ & $0.67^{2}$ \\
\hline Social-Emotional C1 & $0.61^{2}$ & $0.51^{1}$ & $0.45^{1}$ & Social-Emotional C1 & $0.61^{2}$ & 0.50 & $0.47^{1}$ \\
\hline $3 h$ post $\% 24 h$ pre & VAS-V & VAS-P & VAS-D & 3h post -1 - 1mth post & VAS-V & VAS-P & VAS-D \\
\hline Face $\mathrm{Cl}$ & $0.73^{2}$ & 0.31 & $0.63^{2}$ & Face $\mathrm{C} 1$ & $0.69^{2}$ & 0.22 & $0.51^{2}$ \\
\hline Face $\mathrm{C} 2$ & $0.45^{1}$ & 0.26 & $0.53^{2}$ & Face $\mathrm{C} 2$ & 0.40 & 0.14 & 0.37 \\
\hline Movement $\mathrm{C} 1$ & $0.50^{2}$ & 0.37 & 0.33 & Movement $\mathrm{C} 1$ & $0.41^{1}$ & 0.44 & 0.33 \\
\hline Movement $\mathrm{C} 2$ & $0.39^{1}$ & 0.23 & 0.23 & Movement $\mathrm{C} 2$ & 0.36 & 0.34 & 0.29 \\
\hline Movement $\mathrm{C} 3$ & 0.26 & 0.06 & 0.02 & Movement $\mathrm{C} 3$ & 0.11 & 0.40 & -0.05 \\
\hline Tonus & $0.46^{2}$ & 0.30 & 0.30 & Tonus & $0.48^{2}$ & 0.29 & 0.26 \\
\hline Vocal & $0.67^{2}$ & 0.16 & $0.60^{2}$ & Vocal & $0.78^{2}$ & 0.26 & $0.65^{2}$ \\
\hline ISM $\%-24 h$ pre & VAS-V & VAS-P & VAS-D & ISM -/- 24h pre & VAS-V & VAS-P & VAS-D \\
\hline Face $\mathrm{C} 1$ & $0.69^{2}$ & 0.28 & 0.38 & Face C1 & $0.76^{2}$ & 0.23 & 0.35 \\
\hline Face $\mathrm{C} 2$ & 0.26 & 0.15 & 0.36 & Face $\mathrm{C} 2$ & 0.26 & 0.06 & $0.42^{1}$ \\
\hline Movement $\mathrm{Cl}$ & 0.32 & 0.50 & 0.24 & Movement C1 & 0.16 & 0.40 & 0.03 \\
\hline Movement $\mathrm{C} 2$ & 0.02 & 0.33 & 0.43 & Movement $\mathrm{C} 2$ & 0.01 & 0.33 & 0.07 \\
\hline Movement $\mathrm{C} 3$ & 0.25 & 0.28 & 0.02 & Movement $\mathrm{C} 3$ & 0.18 & 0.09 & 0.01 \\
\hline Tonus & 0.13 & 0.23 & 0.25 & Tonus & -0.18 & -0.29 & 0.23 \\
\hline Vocal C1 & $0.58^{2}$ & 0.22 & $0.52^{1}$ & Vocal C1 & $0.60^{2}$ & 0.23 & $0.50^{1}$ \\
\hline Vocal C2 & $0.55^{2}$ & 0.36 & 0.34 & Vocal C2 & $0.56^{2}$ & 0.38 & 0.28 \\
\hline Social-Emotional & $0.67^{2}$ & $0.66^{2}$ & 0.16 & Social-Emotional & $0.68^{2}$ & $0.60^{1}$ & 0.09 \\
\hline
\end{tabular}

Within these subscales, a number of components were identified, some of which seemed to show more construct and convergent validity than others.

\subsubsection{Items discarded based on frequency of endorsement}

Twenty-seven items were removed from the selections for all four episodes based on their frequencies of endorsement (Table 3). This means that, although these items could have been present according to parents of children with profound intellectual disability (see introduction), they were hardly observed in the present study. They included items such as Body rocking', Fluttering, repetitive movements with the band', 'Withdrawing injured body part', Holding injured body part', Blue lips', and 'Shivering'. While this absence might be partially explained by the use of video recording instead of real life observations, another possible explanation is that children in the present study often suffered from profound multiple disabilities, making them unable to show certain expressions included in the original item selection. In addition, only four children were reported to display autistiform and self-injurious behaviour. It thus seems likely that the present study population only partially reflects the group of children with profound intellectual and communicative disabilities. Five items were removed (on the basis of their frequency of endorsement) only for the three postoperative episodes, these 
included Not cooperating' and 'Protecting injured body part'. Those items might not be relevant for medically induced/ postoperative pain.

\subsubsection{Items discarded based on homogeneity within dimensions}

Overall internal consistency analyses led to the removal of a significant number of items for each episode (Table 3 ) indicating that the mostly moderate Cronbach's $\alpha$ values at the start of the analyses reflected the large number of items rather than their homogeneity. The internal consistency analyses led to seven items being removed for all four episodes, including Limited movement, bardly any movement', Being quiet, not making any sounds', and Widened eyes'. Although some of these items reflect expressions contradicting other behaviours (e.g. not moving versus moving) all of them had item-total correlations below 0.4 and thus were not removed based on negative item-total correlations. The internal consistency analyses led to six items being removed for the three postoperative episodes only, including Floppy', 'Squeezing eyes' and Trritable, cranky'. After the removal of items based on internal consistency, Cronbach's $\alpha$ values ranged from 0.64 to 0.89 . The lowest value was found for the Social-Emotional dimension $1 / 2 \mathrm{~h}$ post. At that stage, however, the Social-Emotional dimension still comprised both items relating to 'Dozing' as well as items relating to Restlessness'.

\subsubsection{Components identified within dimensions}

Although no items were removed from the original item selection based on PCA only (i.e., removed for all four episodes), there were twelve items for which PCA was the analysis that eventually led to their removal from the final item selection (Table 3). These included Looking serious, dejected', Irritable, cranky', and Not cooperating'. Although the use of PCA can be criticised in view of the limited sample size, criteria were stringent and, as Table 5 shows, results made sense. This is exemplified by the identification by PCA of two components in the Facial dimension, both at three hours after surgery ( $3 \mathrm{~h}$ post) and during the acute episode (ISM). These two Facial components together accounted for a large percentage of explained variance at $3 \mathrm{~h}$ post and during the ISM. The first component identified seems to be closely related to pain, while the second seems to be less closely related to pain, in view of its smaller correlations with VAS and the smaller-thanexpected correlations between the two facial components. Since the second component at both episodes incorporates expressions relating to anxiety or stress, like 'Eyes suddenly wide open' and Facial restlessness', component 2 may measure aspects of the broader concept of behavioural distress, comprising e.g. anxiety, fear and depression (Stevens, 1998), rather than pain only. However, these findings require closer examination.

As regards the Vocal/ Physiological dimension, the analysis for the ISM was found to result in two components. Table 5 shows that one of these components relates to soft noises, while the other relates to louder noises and tears. Social-Emotional 
items were also divided into two components at $1 / 2 \mathrm{~h}$ post, one component relating to emotional arousal, expressing unrest, the other relating to the absence of arousal. An overview of components possibly underlying the results of the present study is provided in Table 9.

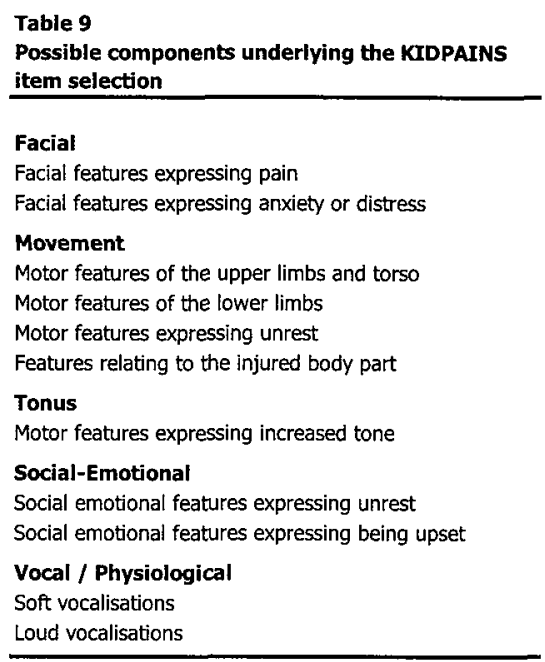

\subsubsection{Coherence between dimensions}

Based on the coherence between dimensions, five Social-Emotional items were discarded. Table 8 shows significant negative correlations especially between Being very calm', Being listless, insensitive to physical stimuli', Dozing' or 'Sleepy, dronsy' and other dimensions, indicating that the absence rather than the presence of these items reflected pain in the present study. Significant correlations were especially found between Facial, Social-Emotional and Vocal items/ components on the one hand, and those relating to Tonus and Movement on the other.

However, there seems to be a link between Movement and Social-Emotional items and between Facial and Tonus items. Thus, although not all dimensions/ components were significantly related to each other, certainly similar patterns were found for all episodes. This might e.g. be explained by the fact that both in the Movement as in the Social-Emotional dimension a component relating to unrest was identified.

\subsubsection{Comparing item selections}

We concluded that adequate item reduction had been achieved at each of the episodes since the high correlations with the sum-score of the original 114 scale items used at the start of the present study. Selecting the items for KIDPAINS at four different episodes resulted in 42 items that were retained in the scale for at least one of the four episodes. 
The fact that eleven items were included for the intervention-specific moment (ISM) only may have been the result of the higher average VAS ratings for the ISM, but the ISM may also be a conceptually different episode, involving more acute pain and thus inducing different types of behaviour. The item selection for the ISM included Social-Emotional expressions relating to being upset. Items such as 'Resistance, mutinous behaviour' and 'Anger' seem more likely to be present when a child is actually being subjected to an acute pain stimulus. The same can be said about the items Protecting injured body part', and 'Shifting body part away to avoid touch'. The ISM was the only episode where these behaviours were not removed on the basis of frequencies of endorsement. By contrast, Breau and colleagues (2002b) report that four items relating to the injured body part were observed after surgery in a significant percentage of children, both by caregivers and parents.

The reason why these behaviours were observed less often in our study may be that a larger percentage of the children in the study suffered from impairments of the upper limbs and functioned at a lower developmental age, causing difficulties in the ability to localise pain. Collignon \& Giusiano (2001) reported similar findings for their final scale for the assessment of pain in children with multiple disabilities that was most evident in items such as 'Coordinated defensive reaction or equivalent on examination of an area supposed painful' and Protection of painful areas'.

\subsubsection{Construct and convergent validity}

As regards construct validity, while the difference score of pain behaviour minus baseline behaviour at home tended to correlate somewhat less with VAS, there are no clear indications that the hospital setting influenced pain behaviour. In analysing these convergent relations with VAS, we did not use VAS ratings for the $24 \mathrm{~h}$ post episode, because of the low intra-class correlation between the various observers. One day after the medical intervention under general anaesthesia, observers did not agree on the amount of pain a child suffered as recorded on VAS.

It is difficult to explain why correlations with VAS-V and VAS-D were more comparable for the episodes $1 / 2 \mathrm{~h}$ post and $3 \mathrm{~h}$ post than for the ISM. Although researchers rated the ISM as the episode with the most intense pain levels, the only correlations $(\alpha 0.005)$ found in the direct observations were those between VAS-D and the sum score of the first component of the Vocal/ Physiological dimension and the second component of the Facial dimension. By contrast, VAS-P showed a significant correlation with the Social-Emotional component. Although the first identified component relating to Movement seemed to correlate with VAS-P, this was not a significant correlation. 
High correlations of Facial and Vocal/ Physiological dimensions with both VAS-V and VAS-D indicate that the researchers who were present when the video was taped and those who rated the video recordings both based their judgement of pain on Facial and Vocal/ Physiological information. Correlations with VAS-P, however, suggest that parents' indications about their child's pain were not consistently correlated with Facial and Vocal/ Physiological information. The data suggest that parents' indications about pain seem to be correlated with SocialEmotional items as well as items related to Movement. However, parents' VAS ratings were not always provided, so no conclusive statements can be made about these findings.

Limitations of the present study, such as the relatively low VAS scores for the various postoperative episodes, the use of video recordings instead of real life observations and the relatively large number of children with profound multiple disabilities, may have influenced the results. More information is needed on the correlations between the present item selection and more general ratings of distress, especially for the Facial dimension. Another finding that remains to be further explored is that of the different item selections found for different episodes, relating to postoperative and more acute procedural pain. Further study is also needed regarding the Movement and Tonus dimensions, since researchers in the present study did not seem to base their judgement about the presence of pain on items relating to motor behaviour, even though the literature on communicative behaviour of individuals with profound intellectual disability underlines the importance of motor behaviour in communication (Ogletree et al., 1992; McLean \& Sneider-McLean, 1987; Downing \& Siegel, 1988).

Future research is also needed to examine the psychometric properties of a scale called the Individual Pain Profile (Dongen van et al., 2000), a scale developed for the individual child. Parents feel that health professionals will not recognise their child's pain cues and would prefer to base their subjective assessments of pain intensity on expected pain-related behaviours (Carter, 2002), which might be beyond those expressed by children who are cognitively impaired. We feel that further research exploring parental input in pain assessment within this unique population is worthwhile, especially considering the heterogeneous nature of pain expressions, a fact that, in a sense, seems to be underlined by the results of the present study. Based on the results of the present study, we decided to proceed with the 42 items listed in Table 7 . These items will have to be checked for reliability and for extreme-groups validity. The results of such analyses may then be used to develop a clinically useful pain assessment scale. In all, it may be said that we have come a long way, but there is still a great deal of work to be done. 
. 


\section{Chapter 6}

Testing psychometric properties of KIDPAINS in children with profound multiple disabilities

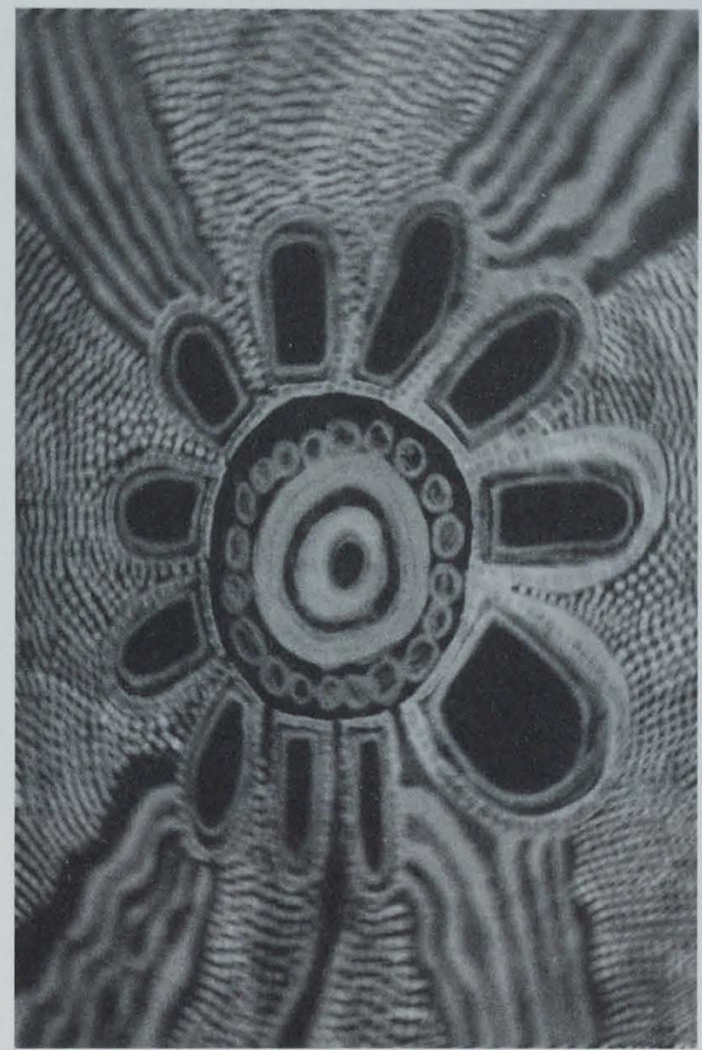

Katinka A. J. van Dongen, Sandra M.G. Zwakhalen, Huda Huijer Abu-Saad, Martijn P.F. Berger, Jan P.H. Hamers

Submitted for publication 


\section{Abstract}

This study tested the 42 items of KIDPAINS for reliability, criterion validity and construct validity, using a known-groups design of 39 children with profound multiple disabilities in presumed painful and non-painful situations.

Video recordings of 20 children with profound multiple disabilities undergoing medically induced procedural/ postoperative pain (previous VAS score $>30 \mathrm{~mm}$ on $100 \mathrm{~mm}$ scale) were presented to four raters, two of whom were nurses unfamiliar with the children. Video recordings of 19 children who had been previously judged not to be in pain (VAS score $<2 \mathrm{~mm}$ ) were observed by one of the two participating researchers. This researcher watched the 20 pain scenes twice. To establish convergent relations with other measures, this study used VAS pain, VAS anxiety, VAS stress and the NCCPC-PV instrument, as well as KIDPAINS. In addition, VAS pain tatings by four previous raters were used, including parents.

The results led to three items being removed because of frequencies of endorsement, whereas five items were removed because of low item-total correlations $(<0.2)$. Assessment of inter-rater agreement showed that seven of the KIDPAINS items did not result in adequate intra-class correlations between raters who were familiar and those (i.e. nurses) who were unfamiliar with the children. Another seven items did not differentiate significantly between pain scenes and nopain scenes. These were mostly items related to the Movement dimension. Four items were retained based on their ability to differentiate between moderate and severe pain. The PCA did not cause additional items to be removed. Two components were identified, one relating somewhat more to the VAS for pain, the other to the VAS for stress. Altogether, the 18 remaining items that were included in the reduced KIDPAINS showed good psychometric properties: high internal consistency ratings (Cronbach's $\alpha 0.90-0.96$ ), high intra-class correlations for inter-rater (0.84-0.87) and intra-rater (0.90) agreement, high sensitivity $(0.94-1.00)$ and specificity $(0.91-0.95)$ using a proxy silver standard based on nine VAS pain ratings, and an identified cut-off point of 10 points (21 for severe pain). High convergent relations with other pain measures were found. However, significant correlations were also found with the VAS for stress, raising the question whether a distinction between pain and stress can be made. Finally, the reduced KIDPAINS showed construct validity by differentiating significantly between pain and no-pain situations.

Overall, it can be concluded that a psychometrically sound scale was developed comprising 18 different items. In addition, it should be noted that a scale developed for a broader population of children with severe to profound intellectual disabilities might lead to underestimation of pain in children with profound multiple disabilities. 


\subsection{Introduction}

Scientists are increasingly investigating expressive pain behaviour in children with intellectual disabilities. Recently, several scales were published for diagnosing pain in severely to profoundly intellectually disabled children (Breau et al., 2001; Stallard et al., 2002a; Terstegen et al., 2003; Hunt et al., 2004). In developing these scales, researchers have focused mostly on either the intellectual and co-existing communicative disability, or on secondary impairments caused by, e.g., cerebral palsy (Giusiano et al., 1995; Hadden \& Bayer von, 2002). When investigating this specific paediatric population, however, it should be recognised that individual children can vary greatly in their abilities in various developmental areas and skills. These abilities are likely to influence the expression of pain. In view of the diversity of children's behaviour, it seems important when developing pain measures to focus on groups of children that are as homogeneous as possible.

Children with profound multiple disabilities are a special group within the diverse population of children with special needs. In addition to their profound intellectual and motor impairments, their disability means they are at high risk of healthrelated problems. These children encounter various diseases and complications, and consequently painful procedures and painful moments in their lives. Parents of children with profound multiple disabilities report that their children behave differently when in pain and motor disabilities are now known to influence these children's (pain) behaviour (Hadden \& Bayer von, 2002; Vlaskamp \& Oxener, 2002).

The KIDPAINS (Kids with Intellectual Disabilities Pain Assessment Instrument for Non-verbal Signals) was developed to assess medically induced pain in children with profound intellectual and communicative disabilities (Dongen van et al., 2002a; Oberlander et al., 2003). To this end, items were initially collected among professional caregivers as well as parents and observations (Chapter 1). These items were compared with items resulting from research into the expressive pain behaviour of other paediatric populations. The remaining items $(\mathrm{N}=209)$ were thoroughly tested for face and content validity (Appendix I). Based on parents' opinions, the number of items was reduced from 138 to 114 (Appendix II). After item reduction for profoundly intellectually and communicatively disabled children undergoing medical procedures in a children's hospital, 42 items were left in the scale and five dimensions of expressive pain behaviour were distinguished (Chapter 5). Within these dimensions, 11 sub-clusters were identified. Although initial psychometric properties of the KIDPAINS seemed promising, more thorough testing and further item reduction were needed. In addition, the findings at that point made it likely that some items in the scale were applicable only to a limited number of participating children. The authors therefore felt that the research population had to be narrowed down further. 
The current study tested the KIDPAINS psychometrically in children with profound multiple disabilities, with the aim of achieving further item reduction. Specifically, we investigated whether:

- KIDPAINS is reliable;

- KIDPAINS is construct-valid in comparing extreme groups;

- KIDPAINS is unidimensional or multidimensional;

- KIDPAINS is valid in examining sensitivity and specificity using a proxy 'silver' standard;

- KIDPAINS is valid in investigating convergent relations with other (pain) measures.

\subsection{Methods}

\subsubsection{Design}

In order to test the psychometric properties of the KIDPAINS, data collected as part of an ongoing research process were presented to new observers. To this end, video recordings of children with profound multiple disabilities were presented to four raters participating in the present study in order to test for reliability and validity. Several scores were compared with those of raters participating in a previous cross-sectional study. The contents of the video scenes, the participants to the present study and those who had provided ratings in the past are described below.

\section{Video scenes}

Six-minute video recordings of 39 children with profound multiple disabilities were presented to the four raters participating in the present study. All children involved were profoundly intellectually disabled according to their medical records. They were not able to produce any verbal language and were all wheel chair dependent, receiving complete care. Each video recording comprised two minutes showing the whole body, two minutes showing the torso with upper limbs and two minutes showing the child's face. The children had been videotaped at standardised moments in relation to their admission to hospital undergoing surgery or a medical procedure under general anaesthesia. Based on ratings from a previous study, 20 scenes were selected for the present study, on the assumption that they were most likely to represent children in pain, while 19 scenes were selected as representing children who were presumably not in pain. For all 20 pain scenes, an independent rater had previously given a VAS rating of over $30 \mathrm{~mm}$ on a $100 \mathrm{~mm}$ scale. A cutoff point of $30 \mathrm{~mm}$ has also been used in a similar study (Breau et al., 2002b), as well as in children without intellectual disability (Berde et al., 1991) and in adults (Collins et al., 1997). The 19 scenes of children labelled as not being in pain had been given a VAS rating of less than $2 \mathrm{~mm}$ by the same rater. This yielded extreme groups. Some of the pain scenes presented children in hospital who had just 
undergone surgery or a medical procedure under general anaesthesia. Other scenes involved children undergoing an intervention-specific moment that was hypothesised to be most likely to cause brief spells of acute pain. No pain scenes were videotaped in the children's everyday living environment.

\section{Current raters}

Video scenes of children with profound multiple disabilities were presented to four raters. Two nurses were asked to participate as raters because of their nursing experience. One nurse specialised in caring for people with multiple disabilities (rater 1), while the other nurse was experienced in paediatric nursing (rater 2). Rater 1 had nine years of experience, rater 2 seven. Both (female) nurses were unfamiliar with the KIDPAINS. The other two raters who participated were familiar with the research project: one was familiar with the research project but had not been involved in rating the videos for the item selection of KIDPAINS previously (rater 3) while the fourth rater had been involved in rating videos for the KIDPAINS (rater 4).

\section{Previous raters}

The ratings provided by the above four raters were compared with several global pain ratings that had been provided by raters participating in the previous study. These previous ratings included global pain ratings with a VAS reported on the spot by a rater who had been present when the videos were being recorded (rater 5 ), as well ratings given on the spot by the parents of a child who had been present at the recording (rater 6). In addition, we used the scores of two further past raters, who had watched the videos (raters 7 and 8 ).

\subsubsection{Measures}

Several measures were used to rate the video recordings, although not all measures were used by all participants. An overview of raters and measures is provided in Table 1.

\section{Table 1}

Overview ratings

\begin{tabular}{|c|c|c|c|c|c|c|c|c|c|}
\hline \multirow[b]{3}{*}{ Measures } & \multicolumn{5}{|c|}{ Current raters } & \multicolumn{4}{|c|}{ Previous raters } \\
\hline & \multirow{2}{*}{$\begin{array}{c}1 \\
\text { Nurse } \\
N=20\end{array}$} & \multirow{2}{*}{$\begin{array}{c}2 \\
\text { Nurse } \\
N=20\end{array}$} & $\begin{array}{l}3 a^{1} \\
\operatorname{Re}\end{array}$ & erb & $\begin{array}{c}4 \\
\text { Researcher }\end{array}$ & $\begin{array}{c}5 \\
\text { Researcher }\end{array}$ & $\begin{array}{c}6 \\
\text { Parent }\end{array}$ & $\begin{array}{c}7 \\
\text { Researcher }\end{array}$ & $\begin{array}{c}8 \\
\text { Researcher }\end{array}$ \\
\hline & & & $N=20$ & $N=39$ & $\mathrm{~N}=20$ & $N=39$ & $\mathrm{~N}=26$ & $N=39$ & $N=39$ \\
\hline KIDPAINS & $x$ & $\mathrm{x}$ & $x$ & $\mathrm{x}$ & & & & $x$ & \\
\hline VAS pain & $x$ & $\mathrm{x}$ & $x$ & $x$ & $x$ & $x$ & $x$ & $x$ & $x$ \\
\hline VAS anxiety & $x$ & $x$ & $x$ & $x$ & $x$ & & & & \\
\hline VAS stress & $x$ & $x$ & $\mathrm{x}$ & $x$ & $x$ & & & & \\
\hline NCCPC-PV ${ }^{2}$ & & & & $x$ & $x$ & & & & \\
\hline
\end{tabular}


As Table 1 shows, five different measures were used in the present study:

- KIDPAINS. After item reduction, KIDPAINS (Chapter 5) comprised 42 items, and distinguished five dimensions of expressive pain behaviour, the Facial, Movement, Tonus, Social-Emotional and Vocal/ Physiological dimensions. Within these dimensions, 11 sub-clusters were identified, labelled as 'Facial features expressing pain', 'Facial features expressing anxiety or distress', 'Soft vocalisations', 'Loud vocalisations', 'Social-emotional features expressing unrest, 'Social-emotional features expressing being upset, 'Motor features expressing increased tone', 'Features relating tot the injured body part', 'Motor features of the upper limbs and torso', 'Motor features of the lower limbs' and finally 'Motor features expressing unrest'. In the present study, all 42 items were presented to raters 1,2 and 3 as they observed the 20 selected pain scenes. In addition, rater 3 used this version of KIDPAINS when observing the 19 scenes of children who were presumably not in pain. Answers were given on a five-point adjective scale with discrete response ranging from zero to four, with 'no, not present' and 'yes, continuously present' as the anchors of the scale. Previous ratings by rater 7 had used a longer, 114-item version of the draft scale that was used to develop KIDPAINS (Chapter 5). These ratings were also included in some of the analyses, using only items that were relevant to the present study (that is 42 items);

- VAS pain. All raters applied a $100 \mathrm{~mm}$ Visual Analogue Scale (Streiner \& Norman, 1998). 'The VAS was anchored by the endpoints 'no pain sensation' (left) and 'the most intense pain sensation imaginable' (right). A mean VAS pain score was calculated, based on all VAS pain ratings;

- VAS anxiety. Raters 1 to 4 applied a $100 \mathrm{~mm}$ Visual Analogue Scale with 'no anxiety' (left) and 'the most intense anxiety imaginable' (right) as the anchors;

- VAS stress. Raters 1 to 4 also applied a $100 \mathrm{~mm}$ Visual Analogue Scale with 'no stress' (left) and 'the most intense stress imaginable' (right) as the anchors;

- NCCPC-PV. This pain scale was developed by Breau and colleagues (2002b) for 'non-communicating' children with intellectual disabilities and was used in the present study by raters 3 and 4 when observing the 20 selected pain scenes. The NCCPC-PV contains six subscales comprising 27 items for which observers indicate how often each item is observed during observation $0=$ not at all, $1=$ just al little, $2=$ fairly often, $3=$ very often).

\subsubsection{Procedure}

Raters 1, 2 and 3 met on two occasions to observe the 20 selected pain scenes. The nurses (raters 1 and 2) were unaware that the observed children had been indicated to be in pain by a previous rater. Nurses were able to ask questions about the scoring schemes they had to use. They had received a copy of the schemes several days prior to the first rating session, to enable them to familiarise themselves with the measures. Approximately 10 minutes per child were needed to complete the 
procedure, including watching the video. The first page of the scoring scheme presented the 42 items of KIDPAINS, while the second page showed the other measures, in the following order: VAS pain, VAS anxiety and VAS stress. The nurses (raters 1 and 2) were instructed not to look back and not to turn pages while scoring. In addition, raters 3 and 4 completed the NCCPC-PV while watching the videos separately. Rater 3 on this occasion also provided KIDPAINS and VAS ratings for both the pain and no-pain scenes. This allowed the ratings of rater 3 (b) to be used for intra-rater reliability.

\subsubsection{Analysis}

Data were analysed using SPSS, using descriptive statistics for the population under investigation.

First, frequencies of endorsement were examined using descriptive statistics. Items marked as not being present in over $75 \%$ of the pain scenes were not retained. Subsequently, internal consistency analyses were carried out to assess reliability. Items with an item total correlation smaller than 0.2 were not retained. Intra- and inter-rater reliability were assessed by calculating intra-class correlations (ICC) for the individual items of KIDPAINS. A two-way mixed consistency ICC was calculated for both the intra-rater reliability and the inter-rater reliability within rater 3 and between raters 3 and 4, since their ratings focused on results within the research project. The inter-rater reliability between the scores of raters 1,2 and 3 was analysed using a two-way random absolute agreement ICC, since this ICC takes into account an extra source of variance, allowing results to be generalised. Cut-off points of $0.6 / 0.5$ for single items were used for intra- and inter-rater reliability, indicating which items with lower scores had to be removed. In order to obtain a better understanding of the measures used to assess convergent validity, we also analysed the reliability of VAS pain, VAS anxiety and VAS stress, as well as the sum score of the NCCPC-PV, using the same analyses as for KIDPAINS.

To investigate construct validity, extreme groups were created. To this end, pain scenes and no-pain scenes were compared using independent samples $t$-tests. Nonsignificant items were removed from the item selection, since these items did not seem to differentiate between pain scenes and no-pain scenes. Items with a significant $p$-value, using a Bonferroni corrected $\alpha$ of 0.002 , were retained. Items that did not have a significant $p$-value but were significantly different based on the $95 \%$ confidence interval were tested further. Items with a mean difference of over 1 point between moderate (mean VAS $\geq 30 \mathrm{~mm}$ ) and severe pain (mean VAS $\geq 60$ $\mathrm{mm}$ ) (Berde et al, 1991) were retained. Principal Components Analysis (PCA) was then used to assess the underlying factor structure of KIDPAINS. Both eigenvalues and scree tests were examined to determine the number of components using all items left in the scale at that point. Items were removed by means of the following criteria: (1) measure of sampling adequacy (MSA) for a 
specific item $<0.50$; (2) communality of an item $<0.40$; (3) items with loadings in the component or pattern matrix $<0.50$. When two or more components were identified as a result of PCA, data were rotated using Oblimin, meaning that different components were allowed to correlate.

After item reduction, the 'final' version of KIDPAINS was tested for reliability using the same techniques mentioned above. In order to shed some light on the reproducibility of the reduced KIDPAINS, standard errors of measurement (SEM) were calculated. To examine whether the reduced KIDPAINS scores varied with demographic statistics, correlational analyses were conducted using eta and Pearson correlations. Receivers operating characteristic (ROC) curves were created and sensitivity and specificity were calculated for the reduced KIDPAINS. By way of external criterion (proxy 'silver' standard), we used the calculated mean score for the nine VAS ratings provided by the four current and four previous raters. A mean VAS score $\geq 30 \mathrm{~mm}$ was classified as a pain case, a score $<30 \mathrm{~mm}$ was defined as a non-pain case. In addition, a mean VAS score $\geq 60 \mathrm{~mm}$ was classified as severe pain, in order to explore the distinction between severe pain and moderate or no pain. Finally, to investigate convergent validity, the reduced KIDPAINS was correlated with other measures by calculating Pearson correlations.

\section{$\underline{6.3 \text { Results }}$}

\subsubsection{Participants}

Two nurses completed the ratings of the 20 pain scenes (mean age 32.5 years). Two researchers completed the ratings of the 20 pain scenes (mean age 30.5 years), one of those researchers provided ratings a second time for all 39 scenes. Children were on average 8.5 years old (SD 4.3; range 3-19) as Table 2 (page 123) shows. In addition to their profound motor impairment, almost all children were epileptic and most children had been diagnosed with visual or hearing impairments. Children were not able to communicate verbally, although ten children were able to produce some language sounds.

\subsubsection{Reliability}

The analysis started by examining frequencies of endorsements, with 42 items in the scale. Three items, 'Shifting body away to avoid toucb', 'Wild bitting movements' and, Independent, frequent position change', were removed from the scale because endorsements of 'not present' were made for over $75 \%$ of the pain scenes $(\mathrm{N}=20)$. All of these items related to the Movement dimension. Subsequently, internal consistency analyses were carried out. Five items of the KIDPAINS had item total correlations smaller than 0.2 when analysed for all 39 children. 
Table 2

Descriptive information

$\begin{array}{cc}\text { Pain } & \text { No pain } \\ (\mathrm{N}=20) & (\mathrm{N}=19)\end{array}$

\section{Child's characteristics}

\begin{tabular}{lcc}
\hline Mean age & 8 & 9 \\
Male & 12 & 12 \\
Female & 8 & 7 \\
Communication & & \\
Does not use any language sounds & 14 & 15 \\
Babbles & 6 & 4
\end{tabular}

AAMR classification system cause I.D.

Unknown

Prenatal, unknown

Prenatal, chromosomal disorder

Prenatal, syndrome disorders

Prenatal, inborn errors of metabolism

Prenatal, developmental disorders brain

formation

Prenatal, environmental influences

Perinatal, intrauterine disorders

Perinatal, neonatal disorders

Postnatal, head injury

Postnatal, infections

Postnatal, degenerative disorders

Postnatal, seizure disorders

Postnatal, toxic-metabolic disorders
Pain No pain

$(N=20) \quad(N=19)$

Other impairments

$\begin{array}{lll}\text { Spasticity } & 14 & 12\end{array}$

Profound hearing impairment

Profound visual impairment

Both hearing and visual impairment

Behavioural and emotional disturbances

Epilepsy

Medical procedure

Gastroscopy, ph-monitoring

Gastroscopy, change of PEG

Gastroscopy, gastrostomy

Nissen fundoplication

Nissen fundoplication and gastrostomy

Adductor tenotomy

Tooth extractions

Recanulation tracheostomy

Release feet

Placement endonasal drains

Adenotonsillectomy

Hernia umbilicalis ok

Scoliosis correction

$\begin{array}{cc}2 & 1 \\ 7 & 9 \\ 2 & 1 \\ 4 & 4 \\ 18 & 16\end{array}$

Hence, these items, viz., Involuntary movements', Jerky movements', 'Stretching arm', 'Stiffness', and Eyes suddenly wide open', were removed from the item selection. Four of these items related to the Tonus dimension. Removal of these items resulted in an increase in Cronbach's $\alpha$ from 0.944 to 0.951 . Since this $\alpha$ might have been the result of the inclusion of children without pain $(\mathrm{N}=19)$, the same analysis was carried out for the scenes with children in pain only. In the analysis of these 20 scenes, Cronbach's $\alpha$ increased from 0.903 to 0.929 when the five items were removed.

To investigate intra- and inter-rater reliability, intra-class correlations (ICCs) were calculated for the remaining 34 items, using a lower limit of 0.6 for intra-rater reliability. Three items in the KIDPAINS scale failed to meet this criterion, as Table 3 (page 124) shows. These three items, viz., Facial tension', Looking anxious' and 'Moving head, not stretcbing neck' were also found not to be reliable between raters (1,2 and 3). The analysis of inter-rater reliability yielded another four items of KIDPAINS that were not reliable: Frowning chin', Raising eyebrows, forehead', 'Holding or drawing in breath' and 'High muscle tone, cramping, spastic'. Thus, a total of seven items were removed from the scale based on intra- and inter-rater reliability analyses. 
Table 3

Reliability of 34 items version of KIDPAINS

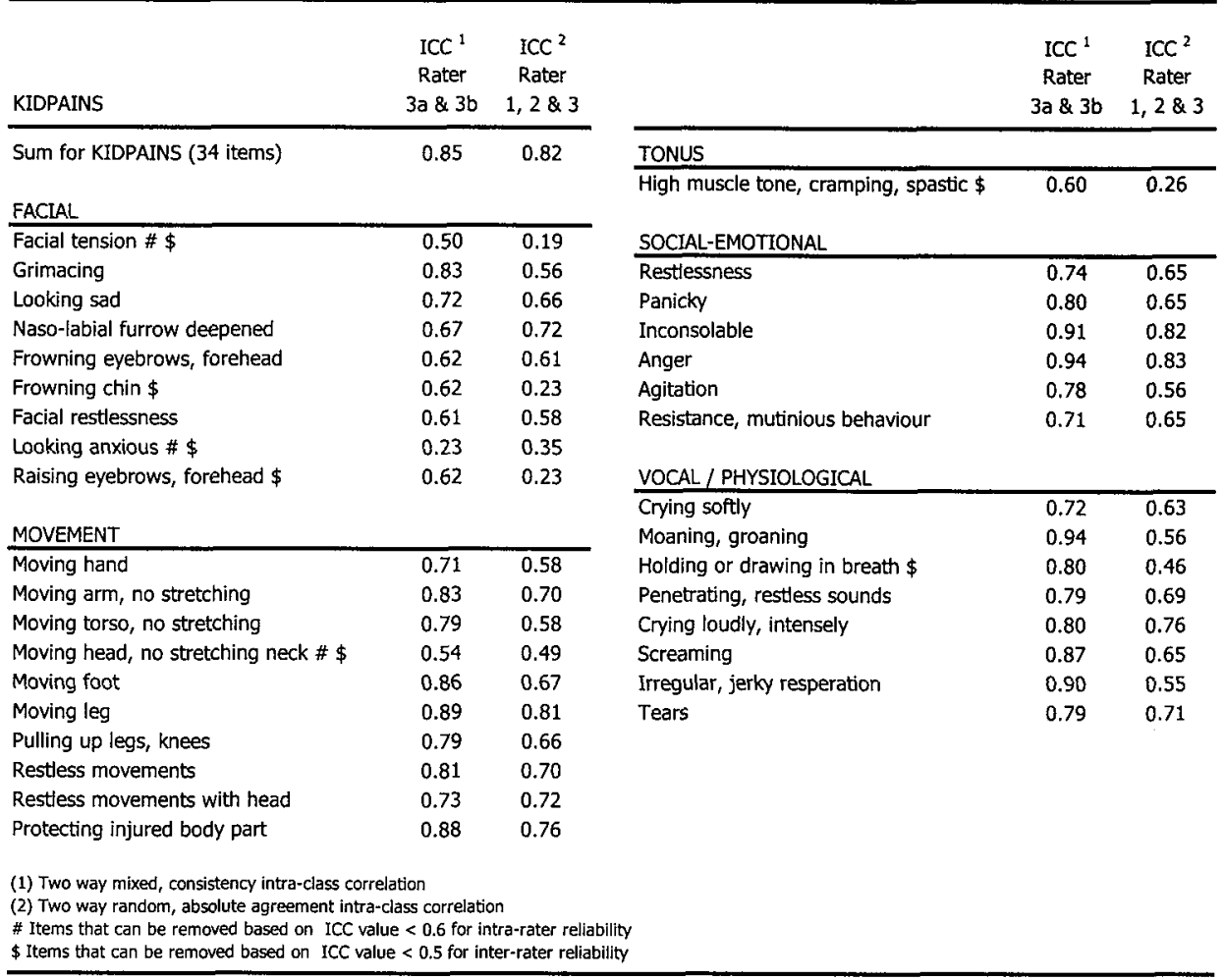

We then examined the reliability of all other measures used, in order to gain more insight into the convergent relations between KIDPAINS and the other measures. The results are shown in Table 4.

Table 4

Reliability of the other measures used

\begin{tabular}{l|ccc}
\hline & $\begin{array}{c}\text { ICC }^{1} \\
\text { Rater 3a \& 3b }\end{array}$ & $\begin{array}{c}\text { ICC }^{2} \\
\text { Rater 1, 2 \& } 3\end{array}$ & $\begin{array}{c}\text { ICC }^{1} \\
\text { Rater 3 \& 4 }\end{array}$ \\
\hline VAS for pain & 0.80 & 0.63 & 0.76 \\
VAS for stress & 0.72 & 0.58 & 0.51 \\
VAS for anxiety \$ & 0.69 & 0.33 & 0.45 \\
NCCPC-PV & & & 0.78 \\
& & & \\
(1) Two way mixed, consistency intra-class correlation & \\
(2) Two way random, absolute agreement intra-class correlation \\
(3) NCCPC-PV = Non-Communicating Children's Pain Checklist - Postoperative Version, Breau \\
et al., 2002b \\
\$ Items that can be removed based on ICC value < 0.5 for inter-rater reliability \\
\hline
\end{tabular}

Although intra-rater reliability was found to be satisfactory for all additional measures, an analysis of the inter-rater ICCs showed that the VAS anxiety was unreliable both between raters 1,2 and 3 and between raters 3 and 4 . The VAS 
anxiety was therefore not used in further analyses. The inter-rater reliability for the NCCPC-PV was satisfactory, at 0.78 .

\subsubsection{Construct validity; comparison of extreme groups}

The comparison of pain scenes versus no-pain scenes showed that of the twentyseven items left in the scale at that stage, fourteen differed significantly, based on a Bonferroni corrected $\alpha$ of 0.002 . Most of these items were completely or almost absent in children without pain (Table 5).

Table 5

Extreme groups comparison 27 items from KIDPAINS; difference between no pain scenes $(\mathrm{N}=19)$ and pain scenes $(\mathbf{N}=\mathbf{2 0})$

\begin{tabular}{|c|c|c|c|c|c|c|c|c|c|c|}
\hline \multirow[b]{2}{*}{ KIDPAINS } & \multicolumn{2}{|c|}{$\underline{\text { Pain }}$} & \multicolumn{2}{|c|}{ No pain } & \multicolumn{6}{|c|}{$t$-test for Equality of Means } \\
\hline & Mean & SD & Mean & SD & $t$ & $p^{1}$ & $\begin{array}{c}\text { Mean } \\
\text { Diff. }\end{array}$ & SE Diff. & $95 \% \mathrm{C}$ & Diff. \\
\hline \multicolumn{11}{|l|}{ Facial } \\
\hline Grimacing * & 1.50 & 1.24 & 0.05 & 0.23 & -5.15 & 0.000 & -1.45 & 0.28 & -2.03 & -0.86 \\
\hline Looking sad * & 2.20 & 1.61 & 0.05 & 0.23 & -5.90 & 0.000 & -2.15 & 0.36 & -2.91 & -1.39 \\
\hline Naso-labial furrow deepened * & 1.50 & 1.19 & 0.05 & 0.23 & -5.33 & 0.000 & -1.45 & 0.27 & -2.01 & -0.88 \\
\hline Frowning eyebrows, forehead * & 1.75 & 1.21 & 0.05 & 0.23 & -6.17 & 0.000 & -1.70 & 0.28 & -2.27 & -1.12 \\
\hline Facial restlessness * & 1.85 & 1.14 & 0.74 & 0.81 & -3.51 & 0.001 & -1.11 & 0.32 & -1.76 & -0.47 \\
\hline \multicolumn{11}{|l|}{ Movement } \\
\hline Moving hand \# & 2.20 & 1.20 & 2.26 & 1.45 & 0.15 & 0.882 & 0.06 & 0.42 & -0.80 & 0.92 \\
\hline Moving arm, no stretching \# & 2.00 & 1.03 & 1.84 & 1.26 & -0.43 & 0.669 & -0.16 & 0.37 & -0.90 & 0.59 \\
\hline Moving torso, no stretching \# & 0.85 & 1.14 & 0.84 & 1.26 & -0.02 & 0.984 & -0.01 & 0.38 & -0.79 & 0.77 \\
\hline Moving foot \# & 0.75 & 1.16 & 1.11 & 1.33 & 0.89 & 0.380 & 0.36 & 0.40 & -0.45 & 1.16 \\
\hline Moving leg \# & 1.20 & 1.15 & 1.16 & 1.43 & -0.10 & 0.919 & -0.04 & 0.41 & -0.88 & 0.80 \\
\hline Pulling up legs, knees \# & 0.60 & 0.88 & 0.58 & 1.07 & -0.07 & 0.947 & -0.02 & 0.31 & -0.66 & 0.61 \\
\hline Restless movements * & 1.70 & 1.34 & 0.47 & 0.77 & -3.52 & 0.001 & -1.23 & 0.35 & -1.94 & -0.52 \\
\hline Restless movements with head $\sim$ & 1.35 & 1.18 & 0.37 & 0.76 & -3.10 & 0.004 & -0.98 & 0.32 & -1.63 & -0.34 \\
\hline Protecting injured body part \# & 0.50 & 1.10 & 0.00 & 0.00 & -2.03 & 0.056 & -0.50 & 0.25 & -1.01 & 0.01 \\
\hline \multicolumn{11}{|l|}{ Social-Emotional } \\
\hline Restlessness * & 1.85 & 1.23 & 0.32 & 0.82 & -4.61 & 0.000 & -1.53 & 0.33 & -2.21 & -0.86 \\
\hline Panicky* & 1.00 & 0.97 & 0.00 & 0.00 & -4.59 & 0.000 & -1.00 & 0.22 & -1.46 & -0.54 \\
\hline Inconsolable & 1.20 & 1.80 & 0.00 & 0.00 & -2.99 & 0.008 & -1.20 & 0.40 & -2.04 & -0.36 \\
\hline Anger & 0.80 & 1.20 & 0.05 & 0.23 & -2.74 & 0.012 & -0.75 & 0.27 & -1.32 & -0.18 \\
\hline Agitation * & 1.40 & 1.14 & 0.11 & 0.32 & -4.88 & 0.000 & -1.29 & 0.27 & -1.85 & -0.74 \\
\hline Resistance, mutinious behaviour & 0.85 & 1.27 & 0.05 & 0.23 & -2.76 & 0.012 & -0.80 & 0.29 & -1.40 & -0.20 \\
\hline \multicolumn{11}{|l|}{ Vocal / Physiological } \\
\hline Crying softly* & 1.25 & 1.45 & 0.05 & 0.23 & -3.65 & 0.002 & -1.20 & 0.33 & -1.88 & -0.51 \\
\hline Moaning, groaning * & 2.20 & 1.32 & 0.11 & 0.32 & -6.88 & 0.000 & -2.09 & 0.30 & -2.73 & -1.46 \\
\hline Penetrating, restless sounds * & 1.80 & 1.51 & 0.37 & 0.83 & -3.64 & 0.001 & -1.43 & 0.39 & -2.23 & -0.64 \\
\hline Crying loudly, intensely & 0.85 & 1.18 & 0.00 & 0.00 & -3.22 & 0.005 & -0.85 & 0.26 & -1.40 & -0.30 \\
\hline Screaming & 0.55 & 0.89 & 0.00 & 0.00 & -2.77 & 0.012 & -0.55 & 0.20 & -0.97 & -0.13 \\
\hline Irregular, jerky resperation * & 2.15 & 1.39 & 0.47 & 0.96 & -4.40 & 0.000 & -1.68 & 0.38 & -2.45 & -0.90 \\
\hline Tears * & 1.00 & 1.21 & 0.00 & 0.00 & -3.68 & 0.002 & -1.00 & 0.27 & -1.57 & -0.43 \\
\hline \multicolumn{11}{|l|}{ Other measures } \\
\hline VAS for pain * & 47.20 & 24.23 & 0.63 & 2.01 & -8.56 & 0.000 & -46.57 & 0.54 & -5.79 & -3.52 \\
\hline VAS for stress * & 42.55 & 23.94 & 2.95 & 9.17 & -6.89 & 0.000 & -39.60 & 0.58 & -5.15 & -2.78 \\
\hline NCCPC-PV * & 17.95 & 8.05 & 6.37 & 3.29 & -5.94 & 0.000 & -11.58 & 1.95 & -15.60 & -7.57 \\
\hline \multicolumn{11}{|c|}{$\begin{array}{l}\text { (1) Bonferoni corrected } 0.002 \\
\text { * Significant difference pain and no-pain scenes based on Bonfferonl corrected } a \text {; items retained } \\
\sim \text { Significant difference pain and no-pain scenes based on } 95 \% \text { C.I.D.; items subjected to further testing } \\
\text { \# Items that can be removed based on lack of difference between pain and no pain scenes }\end{array}$} \\
\hline
\end{tabular}


The item Facial restlessness' was the item with the highest mean score in children of the no pain scenes (mean 0.74). Table 5 also presents another six items of the KIDPAINS that did not have a zero in the $95 \%$ confidence interval of the difference. These items, which had $p$-values ranging from 0.004 to 0.012 , were further tested. In all, seven items did not differentiate between pain scenes and nopain scenes, and were therefore removed from the item selection. All of these items were related to the Movement dimension. A comparison of the extreme groups for the other measures used showed that all measures significantly differentiated between pain scenes and no-pain scenes.

For the six items that differentiated between pain scenes and no-pain scenes based on $95 \%$ confidence interval of the difference, a comparison was made between pain scenes of children with moderate pain (mean VAS $\geq 30 \mathrm{~mm}$ and $<60 \mathrm{~mm}$ ) and those of children with severe pain (mean VAS $\geq 60 \mathrm{~mm}$ ). The results are shown in Table 6.

\begin{tabular}{lc}
$\begin{array}{l}\text { Table } 6 \\
\text { Difference between severe pain scenes }(\mathbf{N}=\mathbf{8}) \\
\text { and moderate pain scenes }(\mathbf{N}=\mathbf{9})\end{array}$ & $\begin{array}{c}\text { Mean } \\
\text { difference }\end{array}$ \\
\hline & 1.18 \\
Items in KIDPAINS & 0.67 \\
\hline Crying loudly, intensely * & 1.03 \\
Screaming & 1.06 \\
Resistance, mutinious behaviour * & 0.64 \\
Anger * & 3.00 \\
Restless movements with head & \\
Inconsolable * & \\
* Mean difference $\geq 1$ point; items retained & \\
\hline
\end{tabular}

For four of these six items, a mean difference of at least 1 point on a five-point scale was found between moderate and severe pain, with those children who seemed to suffer from severe pain scoring higher. These four items were retained, resulting in a total of 18 items in the final scale (see Table 7, page 127). Children on the pain scenes on average displayed 12 different items of KIDPAINS ranging from 5 to 18 items.

\subsubsection{Factor structure of KIDPAINS items}

We used Principal Components Analysis (PCA) to explore whether these 18 items in the KIDPAINS were uni-dimensional or not. The results show that all individual items had measure of sampling adequacy (MSA) values ranging from 0.674 to 0.952 . Apart from the item Facial restlessness', all items had communalities of over 0.500 . Figure 1 (page 127) shows that based on the scree plot two components were identified. Table 8 (page 127) shows that these components together explained over $75 \%$ of the variance; component one $60.62 \%$, component two an additional $15.93 \%$. 
Table 7

Reduced KIDPAINS

Grimacing

Looking sad

Naso-labial furrow deepened

Frowining eyebrows, forehead

Facial restiessness

Crying softly

Moaning, groaning

Crying loudly, intensely

Irregular, jerky resperation

Tears

Inconsolable

Penetrating, restless sounds

Anger

Restlessness

Panicky

Agitation

Resistance, mutinious behaviour

Restless movements

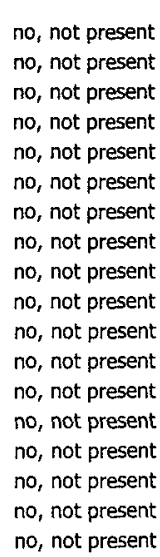

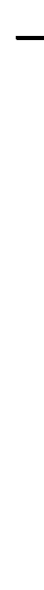

\begin{tabular}{lllll}
0 & 1 & 2 & 3 & 4 \\
\hline 0 & 0 & 0 & 0 & 0
\end{tabular}

o

0

0

o

o

0

0

0

0

0

0

0

0

0

0

0

(1)

o

0

$\begin{array}{ll}0 & 0 \\ 0 & 0\end{array}$

00

$\begin{array}{ll}0 & 0 \\ 0 & 0\end{array}$

00

00

00

00

$\begin{array}{ll}0 & 0 \\ 0 & 0\end{array}$

00

00

00

00

00

00

$\begin{array}{ll}0 & 0 \\ 0 & 0 \\ 0 & 0\end{array}$

00

$\begin{array}{ll}0 & 0 \\ 0 & 0\end{array}$

Table 8

\section{KIDPAINS: final item selection - Pattern Matrix}

Component ${ }^{1,2}$

One Two

\begin{tabular}{ll}
\hline Facial & \\
Grimacing & 0.99 \\
Looking sad & 0.91 \\
Naso-labial furrow deepened & 0.98 \\
Frowining eyebrows, forehead & 0.96 \\
Facial restlessness & 0.59 \\
Movement &
\end{tabular}

Restless movements

\section{Social-Emotional}

Inconsolable

0.70

0.31

1.03

0.81

0.79

0.87

0.99

Resistance, mutinious behaviour

Vocal / Physiological

Crying softly

Moaning, groaning

Penetrating, restless sounds

Crying loudly, intensely

$0.59 \quad 0.31$

Irregular, jerky resperation

$0.52 \quad 0.44$

Tears

0.78

Variance explained

$61 \% \quad 16 \%$

Eigenvalue

$10.91 \quad 2.87$

Correlation between components

0.47

0.78

Kaiser-Meyer-Olkin MSA

$\begin{array}{ll}\text { Kaiser-Meyer-Olkin MSA } & 0.78 \\ \text { Bartlett's Test of Sphericity Significance } & 0.00\end{array}$

(1) Extraction method: principal components analysis, Rotation method:

Oblimin with Kaiser Normalisation

(2) Factor loadings $>0.3$ are presented
Figure 1
Scree plot principal components analysis KIDPAINS

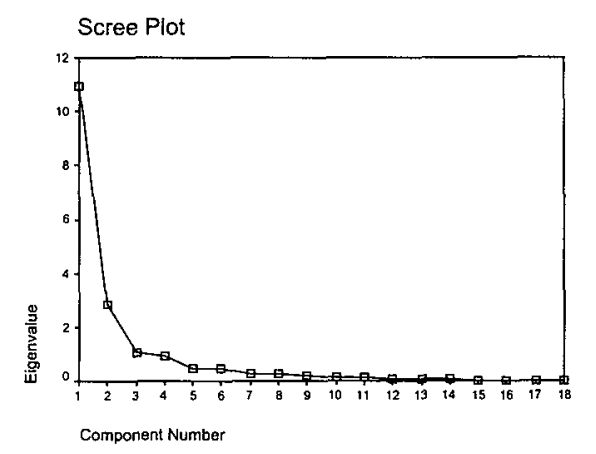

yes, continously present

yes, continously present

yes, continously present

yes, continously present

yes, continously present

yes, continously present

yes, continously present

yes, continously present

yes, continously present

yes, continously present

yes, continously present

yes, continously present

yes, continously present

yes, continously present

yes, continously present

yes, continously present

yes, continously present

yes, continously present 
The Kaiser-Meyer-Olkin measure was 0.78. Items loading on both components include 'Moaning, groaning', 'Crying loudly, intensely', 'Irregular, jerky respiration' and Inconsolable'. The lowest loading for these double-loading items was 0.31 .

\subsubsection{Reliability of the final item selection}

The reliability of the 18 items retained in the final version of KIDPAINS (see Table 7) was investigated as shown in Table 9, Cronbach's $\alpha$ values between different raters ranged from 0.90 to 0.93 using all 18 items. ICCs for inter-rater reliability ranged from 0.84 to 0.87 , while the ICC for intra-rater reliability was 0.90 . Standard Errors of Measurement (SEM) were approximately 5 points.

Table 9

Overview of reliability final item selection

\begin{tabular}{l|cccc}
\multirow{2}{*}{ KIDPAINS } & Intra-class & Standard error of & \multicolumn{2}{c}{ Cronbach's a } \\
& correlation $^{1}$ & measurement & Rater & Total \\
\hline Raters 1-2 - 3 & 0.87 & 4.90 & 1 & 0.92 \\
& & & 2 & 0.90 \\
Rater 3a-3b & 0.90 & 4.96 & $3 a$ & 0.93 \\
Raters 3b-7 & 0.84 & 5.41 & $3 b$ & 0.96 \\
& & & 7 & 0.91
\end{tabular}

(1) Two way random, absolute agreement intra-class correlation for sum-score 18 items KIDPAINS

\subsubsection{Relation with demographic characteristics}

The correlational analyses of the reduced KIDPAINS scores of raters 1, 2, 3, and 7 with demographic characteristics revealed that the total score seemed related to communication using eta correlations (gender $0.07-0.21$; communication 0.34 0.49 ; surgical versus intervention-specific episode $0.02-0.24$; behavioural and emotional disturbances $0.06-0.25$; spasticity $0.03-0.16$ ) and to the cause of the intellectual disability using Pearson correlations (chronological age -0.16-0.08; cause of intellectual disability $-0.10--0.48$ ). Further analyses of these findings, using independent samples $t$-tests, showed no significant differences in any of the five summed KIDPAINS scores between children who were able to babble and children who did not produce any language sounds $(\alpha 0.05)$. However, all raters tended to give higher ratings to children who were able to babble (maximum mean difference -12.23). Analysis of the differences between children with prenatal, perinatal and postnatal causes of intellectual disability, using ANOVA $(\alpha 0.05)$, revealed no significant differences. However, all raters tended to give higher ratings to children with a prenatal cause of the intellectual disability (maximum mean difference -14.69).

\subsubsection{Criterion validity}

Although VAS pain cannot be regarded as the gold standard, its reliability was satisfactory and nine different values on the VAS pain by eight different raters for each video recording were available, so it was decided that a mean VAS pain rating 
would be an acceptable 'silver' standard. Descriptive findings on the various VAS pain ratings are presented in Table 10.

Table 10

Descriptive information on pain ratings for cases (mean VAS rater 1-8 $\geq 30 \mathrm{~mm}$ ) versus non-cases (mean VAS rater $1-8<30 \mathrm{~mm}$ )

\begin{tabular}{|c|c|c|c|c|c|}
\hline \multicolumn{3}{|c|}{ VAS pain (on scale 0-100) } & \multirow{2}{*}{$\begin{array}{l}\text { Rater } 1 \\
3\end{array}$} & \multirow{2}{*}{$\frac{\text { Rater } 2}{3}$} & \multirow{2}{*}{$\frac{\text { Rater 3a }}{3}$} \\
\hline Non-cases & Mean VAS < $30 \mathrm{~mm}$ & $\mathrm{~N}$ & & & \\
\hline Non-cases & \multirow{3}{*}{ Mean VAS $\geq 30 \mathrm{~mm}$} & Mean (SD) & $10(4)$ & $15(12)$ & $15(1)$ \\
\hline \multirow{5}{*}{ Cases } & & $\mathrm{N}$ & 17 & 17 & \\
\hline & & Mean (SD) & $48(30)$ & $53(23)$ & $47(26)$ \\
\hline & \multirow{3}{*}{ Mean VAS $\geq 60 \mathrm{~mm}$} & $\mathrm{~N}$ & 8 & 8 & 8 \\
\hline & & Mean (SD) & $70(20)$ & $62(20)$ & $68(17)$ \\
\hline & & & Rater $3 b$ & Rater 4 & Rater 5 \\
\hline \multirow{2}{*}{ Non-cases } & \multirow{2}{*}{ Mean VAS < 30mm } & $\mathrm{N}$ & 22 & 3 & 22 \\
\hline & & Mean (SD) & $3(5)$ & $20(9)$ & $5(11)$ \\
\hline \multirow{5}{*}{ Cases } & \multirow{2}{*}{ Mean VAS $\geq 30 \mathrm{~mm}$} & $\mathrm{~N}$ & 17 & 17 & \\
\hline & & Mean (SD) & $53(21)$ & $56(18)$ & $59(17)$ \\
\hline & \multirow{3}{*}{ Mean VAS $\geq 60 \mathrm{~mm}$} & $\mathrm{~N}$ & 8 & 8 & \\
\hline & & Mean (SD) & $71(9)$ & $70(8)$ & $63(19)$ \\
\hline & & & Rater 6 & Rater 7 & Rater 8 \\
\hline \multirow{2}{*}{ Non-cases } & \multirow{2}{*}{ Mean VAS $<30 \mathrm{~mm}$} & N & 15 & 22 & 22 \\
\hline & & Mean (SD) & $9(15)$ & $4(11)$ & $6(18)$ \\
\hline \multirow{4}{*}{ Cases } & \multirow{2}{*}{ Mean VAS $\geq 30 \mathrm{~mm}$} & $\mathrm{~N}$ & 11 & 17 & 17 \\
\hline & & Mean (SD) & $54(18)$ & $50(17)$ & $52(16)$ \\
\hline & \multirow{2}{*}{ Mean VAS $\geq 60 \mathrm{~mm}$} & $\mathrm{~N}$ & 4 & 8 & 8 \\
\hline & & Mean (SD) & $58(23)$ & $58(18)$ & $62(12)$ \\
\hline \multicolumn{2}{|c|}{ KIDPAINS (on scale 0-72) } & & Rater 3b & Rater 7 & \\
\hline \multirow{2}{*}{ Non Cases } & \multirow{2}{*}{ Mean VAS $<30 \mathrm{~mm}$} & Mean (SD) & $4(4)$ & $3(3)$ & \\
\hline & & Range & $0-14$ & $0-13$ & \\
\hline \multirow{4}{*}{ Cases } & \multirow{2}{*}{ Mean VAS $\geq 30 \mathrm{~mm}$} & Mean (SD) & $30(15)$ & $24(9)$ & \\
\hline & & Range & $10-53$ & $8-42$ & \\
\hline & \multirow{2}{*}{ Mean VAS $\geq 60 \mathrm{~mm}$} & Mean (SD) & $43(10)$ & $30(7)$ & \\
\hline & & Range & $23-53$ & $22-42$ & \\
\hline \multicolumn{2}{|c|}{ NCCPC-PV (on scale 0-81) } & & Rater $3 b$ & Rater 4 & \\
\hline \multirow{2}{*}{ Non Cases } & \multirow{2}{*}{ Mean VAS $<30 \mathrm{~mm}$} & Mean (SD) & $7(4)$ & $11(3)$ & \\
\hline & & Range & $3-15$ & $9-15$ & \\
\hline \multirow{4}{*}{ Cases } & \multirow{2}{*}{ Mean VAS $\geq 30 \mathrm{~mm}$} & Mean (SD) & $19(8)$ & $16(7)$ & \\
\hline & & Range & $10-33$ & $8-30$ & \\
\hline & \multirow{2}{*}{ Mean VAS $\geq 60 \mathrm{~mm}$} & Mean (SD) & $25(7)$ & $23(6)$ & \\
\hline & & Range & $11-33$ & $16-30$ & \\
\hline
\end{tabular}

The mean VAS pain rating was dichotomised for the purpose of creating a receiver operating characteristic (ROC) curve. Mean VAS pain ratings $\geq 30 \mathrm{~mm}$ were considered to represent pain in the individual child. VAS pain ratings $<30 \mathrm{~mm}$ were considered to represent no pain. In all, 17 pain cases were identified and 22 non-pain cases. Of the 17 pain cases, 8 were given a mean VAS pain rating $\geq 60$ $\mathrm{mm}$, suggesting they suffered from severe pain according to the eight raters. 
As Table 10 shows, the mean VAS pain ratings for individual raters ranged from 47 to $59 \mathrm{~mm}$ on a $100 \mathrm{~mm}$ scale for the identified cases. Mean KIDPAINS ratings for cases ranged from 24 to 30 points on a scale from 0 to 72 . Mean NCCPC-PV ratings for cases ranged from 16 to 19 on a scale from 0 to 81 . Mean VAS pain ratings by individual raters for the cases that seemed to suffer from severe pain ranged from 58 to $71 \mathrm{~mm}$. Cases with severe pain were given mean scores of 30 to 43 points on the reduced KIDPAINS and mean scores of 23 to 25 on the NCCPC-PV.

Based on the identified cases and non-pain cases, sensitivity and specificity were calculated using data from one of the raters in the present study (rater 3) and one rater from the previous study (rater 7 ) since these two raters had provided ratings for all 39 children. As Table 11 shows, the reduced KIDPAINS showed high sensitivity and specificity with the above-mentioned VAS dichotomisation of cases versus non-cases.

Table 11

Criterion validity

\begin{tabular}{|c|c|c|c|c|c|c|c|c|}
\hline \multirow[b]{2}{*}{ KIDPAINS } & \multicolumn{4}{|c|}{$\begin{array}{l}\text { Cases Mean VAS } \geq 30 \mathrm{~mm}(\mathrm{~N}=17) \text { versus Mean } \\
\text { VAS }<30 \mathrm{~mm}(\mathrm{~N}=22)\end{array}$} & \multicolumn{4}{|c|}{$\begin{array}{l}\text { Cases Mean VAS } \geq 60 \mathrm{~mm}(\mathrm{~N}=8) \text { versus Mean VAS } \\
<60 \mathrm{~mm}(\mathrm{~N}=31)\end{array}$} \\
\hline & $\begin{array}{l}\text { Area under } \\
\text { ROC curve }\end{array}$ & Sensitivity & $\begin{array}{c}1- \\
\text { Specificity }\end{array}$ & Cut-off $^{1}$ & $\begin{array}{l}\text { Area under } \\
\text { ROC curve }\end{array}$ & Sensitivity & $\begin{array}{c}1- \\
\text { Specificity }\end{array}$ & Cut-off ${ }^{1}$ \\
\hline Rater 3b & 0.99 & 1.00 & 0.09 & $\geq 10$ & 0.99 & 1.00 & 0.07 & $\geq 23$ \\
\hline Rater 7 & 1.00 & 0.94 & 0.05 & $>10$ & 0.99 & 1.00 & 0.10 & $\geq 21$ \\
\hline Mean rater $3 b / 7$ & 1.00 & 1.00 & 0.05 & $\geq 10$ & 0.99 & 1.00 & 0.07 & $\geq 21$ \\
\hline
\end{tabular}

The table shows that sensitivity ranged from 1.00 to 0.94 , while specificity ranged from 0.95 to 0.91 . The cut-off point for the reduced KIDPAINS was found to be 10 , indicating that for a scoring range of 0 to 72 , a score of 10 points differentiated between children with and those without pain. The cut-off point was also explored for cases with severe pain. A score between 21 and 23 seemed to differentiate between children with severe pain and children with moderate or no pain. The sensitivity was 1.00 , while the specificity ranged from 0.93 to 0.90 for the cases with severe pain.

\subsubsection{Convergent validity KIDPAINS}

Results of our examination of correlations between the reduced KIDPAINS and the other measures used in this study are presented in Table 12 (page 131). As this table shows, the correlations between the 18-item version of KIDPAINS and VAS pain scores were highly significant in almost all cases. In those cases where a VAS stress score was provided, the correlations with VAS stress were also significant, except for the ratings by raters 2 and 4 . However, the correlations with the VAS pain ratings were mostly higher. 
Table 12

Convergent relations between KADPAINS and other measures

\begin{tabular}{|c|c|c|c|c|c|c|}
\hline \multirow{2}{*}{$\begin{array}{l}\text { current } \\
\text { raters }\end{array}$} & \multicolumn{2}{|c|}{ Rater 1} & \multicolumn{2}{|c|}{ Rater 2} & \multicolumn{2}{|c|}{ Rater 3a } \\
\hline & VAS pain & VAS stress & VAS pain & VAS stress & VAS pain & VAS stress \\
\hline Rater 3b & 0.814 & $0.81^{4}$ & $0.53^{1}$ & 0.43 & $0.81^{4}$ & 0.76 \\
\hline Rater 7 & 0.65 & $0.69^{3}$ & $0.74^{4}$ & $0.55^{1}$ & $0.72^{4}$ & 0.80 \\
\hline
\end{tabular}

\begin{tabular}{l|ccc|ccc}
$\begin{array}{l}\text { current } \\
\text { raters }\end{array}$ & VAS pain & $\begin{array}{c}\text { Rater 3b } \\
\text { VAS stress }\end{array}$ & NCCPC-PV & VAS pain & Ras stress & NCCPC-PV \\
\hline Rater 3b & $0.91^{4}$ & $0.86^{4}$ & $0.944^{4}$ & 0.854 & 0.41 & 0.824 \\
Rater 7 & 0.864 & $0.80^{4}$ & 0.834 & $0.843^{4}$ & 0.41 & 0.734
\end{tabular}

\begin{tabular}{l|cccc}
$\begin{array}{l}\text { previous } \\
\text { raters }\end{array}$ & $\begin{array}{c}\text { Rater } 5 \\
\text { VAS pain }\end{array}$ & $\begin{array}{c}\text { Rater } 6 \\
\text { VAS pain }\end{array}$ & $\begin{array}{c}\text { Rater 7 } \\
\text { VAS pain }\end{array}$ & $\begin{array}{c}\text { Rater } 8 \\
\text { VAS pain }\end{array}$ \\
\hline Rater 3b & 0.754 & $0.64^{4}$ & 0.784 & 0.814 \\
Rater 7 & 0.784 & $0.71^{4}$ & $0.833^{4}$ & 0.834
\end{tabular}

Correlating the two components of the the reduced KIDPAINS separately with VAS pain and VAS stress scores it was found that correlations of component one with VAS pain were higher than correlations with VAS stress for all raters. In addition correlations between component 2 and VAS stress were higher for all but one rater as Table 13 shows.

Table 13

Convergent relations between components KIDPAINS and VAS pain and VAS stress

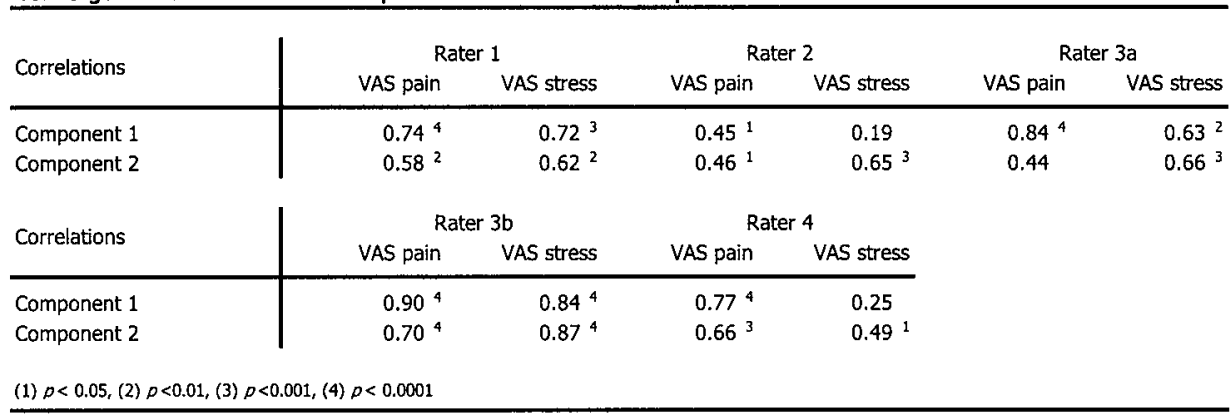

However, both components resulted in significant correlations with both VAS pain and VAS stress and absolute differences between correlation coefficients were not always high.

\subsection{Discussion}

The reduced version of the KIDPAINS comprising 18 items was found to be a valid as well as reliable scale for children with profound multiple disabilities. The instrument was found to be internally consistent, and high intra-class correlations 
were found both within and between observers, and between observers familiar with the research project as well as those unfamiliar with it. This implies that nurses who are unfamiliar with a child and his or her specific situation can reliably use the KIDPAINS. In addition, the item selection correlated highly with other measures used, showing convergent validity. Using the average VAS rating for eight different raters, we were able to dichotomise pain versus no pain at a cut-off point of VAS $\geq 30 \mathrm{~mm}$. This 'silver' standard led to a highly sensitive and specific scale. Our findings show that a cut-off point of 10 on the KIDPAINS currently seems the best diagnostic criterion. A cut-off point of 21 to 23 can be used to decide whether a child is in severe pain. However, like all psychometric properties, these findings need further confirmation.

We conclude that limiting the study population to children with profound multiple disabilities was useful since it allowed us to reduce the number of items in the KIDPAINS. To begin with, three items relating to motor abilities were removed based on frequencies of endorsement, viz., 'Shifting body away to avoid touch', Wild bitting movements' and Independent, frequent position cbange'. These items were not observed in over $75 \%$ of the children in pain. At a later stage, the item Protecting injured body part' was removed, indicating that motor abilities or disabilities influence expressive pain behaviour.

A comparison between the reduced KIDPAINS and the NCCPC-PV, a scale developed by Breau et al. (2002b) for use in a wider group of children with intellectual disabilities, shows the following. We identified a cut-off point for the NCCPC-PV of 11. Table 10 shows that, based on the results of rater 4, the mean score for the identified non-cases was 11 , whereas the average score by rater $3 \mathrm{~b}$ was only three points below this cut-off point. Furthermore, the scoring range for non-cases did not start at zero. This is remarkable especially for the ratings by rater $3 \mathrm{~b}$, since these also included the ratings for children who had not been subjected to painful procedures. These findings indicate that some of the items of the NCCPC-PV are found in children with profound multiple disabilities even when they are not actually in pain. Furthermore, although the range of possible scores on the NCCPC-PV is larger than that for KIDPAINS (0-81 versus $0-72)$, the average score was lower, and the mean difference between cases and non-cases was smaller. In addition, children with severe pain were given a maximum score of only 33 points on the NCCPC-PV. An explanation for these findings can be found in the following. If we apply the same criteria as those used to reduce the number of items in KIDPAINS on the basis of frequencies of endorsement, the results of both raters (3b and 4) show that ten items on the NCCPC-PV should have been removed. Six of these items were related to (intentional) motor abilities: 'Gestures, or touches part of the body that burts', Protects, favours or guards part of the body that burts', Flinches or moves away part of the body that burts', Moves body in a specific way to show pain', and 'Seeks comfort of physical closeness' and 'Jumping around, agitated, fidgety'. It could be 
concluded that, although a scale that is applicable to a wider group of children might be easier to introduce in practice, it seems not to be in the best interest of children with profound multiple disabilities to be included in the same population with other children, as this could lead to a higher false-positive rate and lower pain scores. We recommend that future studies should be cautious about including all children with severe intellectual disabilities in one research population.

Looking at the final item selection in the KIDPAINS it is remarkable that it includes no items relating to muscle tone. The one item left in the scale after internal consistency analysis, 'High muscle tone, cramping, spastic', was removed on the basis of the reliability analysis. This item was assessed as not reliable based on the ICC resulting from nurses. This finding may have been influenced by the use of videos, as direct observation might allow a more accurate assessment of the increases in muscle tone. However, the finding may also have been influenced by the fact that raters were not familiar with the children in any way and were not able to touch them. As Hunt (2003) pointed out, the ability to sense the child's state through kinaesthetic sensations is important if one wants to rely on tone as a pain cue in children with severe neurologic impairment. Subtle changes in a tense or stiff body could be difficult to observe visually, since increased muscle tone and spasms are common. Detecting a change in muscle tone by touch is probably more reliable than by sight.

Other unreliable items were mostly related to the facial dimension. Again, this finding might be related to the use of video recordings. It is also possible, however, that some of these items were just too detailed for a multidimensional scale. Another interesting finding in this respect was the unreliability of ratings for anxiety, both those on the VAS anxiety and those using items relating to the facial expression of anxiety. Obviously, it was hard for raters to reliably assess anxiety.

A comparison of pain scenes with no-pain scenes shows that all items that did not differentiate between the two were related to the Movement dimension.

Apparently, taters did not observe a difference between the global movements of the children's hands, arms, feet, legs and torsos in pain scenes and those in no-pain scenes, since the mean difference for these items was very small, except for the item 'Restless movements', and to a lesser extent, for the items Restless movements with bead' and Protecting injured body part'. The latter two wete removed from the item. selection based on their lack of power to differentiate between pain scenes and non-pain scenes, as well as on the mean difference of less than 1 point between moderate and severe pain.

The final item selection for the KIDPAINS allowed us to distinguish two components on the basis of Principal Components Analysis (PCA). Although the sample size was small for the number of items present in the scale, both the 
statistical and the logical interpretation of the data seem to make sense. For instance, both the overall MSA values and the MSA values of individual items were high. At first sight, the identification of these two components might seem to contradict the five dimensions that had been distinguished before the present study: Facial, Tonus, Movement, Social-Emotional and Vocal/ Physiological. These dimensions were defined mainly on a theoretical basis. The final items selection includes items relating to the Facial $(N=5)$, Movement $(N=1)$, SocialEmotional $(\mathrm{N}=6)$ and Vocal/ Physiological $(\mathrm{N}=6)$ dimensions. There are no items left from the Tonus dimension, and only one item from the Movement dimension, thus the remaining items mainly comprise the Facial, Social-Emotional and Vocal/ Physiological dimensions. These are the same dimensions that were found to be most 'powerful' in our earlier item reduction study among children with profound intellectual and communicative disabilities (Chapter 5).

However, the PCA did not distinguish between these three dimensions in the data. Table 6 shows that all Facial items loaded on the first component, while the second component comprised mainly items from the Social-Emotional dimension. Furthermore, the one Movement item that was left, relating to the concept of restlessness, also loaded on this second component, which seems to make sense conceptually. The items loading on both components originate mainly from the Vocal/ Physiological dimension. These are the items that seem to contribute most to the relatively high correlation between the two components. The three items from the Vocal/ Physiological dimension that load on only one component are 'Crying softly' (component one), Tears' (component one), and Penetrating, restless sounds' (component two).

Another comparison that can be made is with the eleven sub-clusters of items identified in our earlier item reduction studies for KIDPAINS (Chapter 5). Items relating to six of these eleven sub-clusters were removed based on the results of the present study: 'Facial features expressing anxiety or distress', 'Motor features expressing increased tone', 'Motor features relating to the injured body part', 'Motor features of the upper limbs and torso', 'Motor features of the lower limbs', and 'Motor features expressing unrest'. Eighteen of the 20 items relating to these six sub-clusters were removed, the two items not removed being Facial restlessness' and Restless movements'. The five sub-clusters that remained after implementation of the results of the present study relate to 'Facial features expressing pain', 'Socialemotional features expressing unrest', 'Social-emotional features expressing being upset', 'Soft vocalisations' and 'Loud vocalisations'. However, PCA did not yield a clear distinction between soft and loud vocalisations.

The finding that most clearly invites further research is the fact that we found a standard error of measurement (SEM) of five points, indicating that agreement on the total score was not always satisfactory. This finding was mainly caused by the 
higher ratings on the scale: the higher the ratings, the more difficult it was to agree on the exact total KIDPAINS score. Improving this agreement would be especially important if KIDPAINS is to be used to differentiate not only between pain and no pain, but also between moderate and severe pain.

The sensitivity and specificity of KIDPAINS should be evaluated while keeping in mind that the identification of cases and non-cases is always arbitrary when there is no gold standard available. However, the descriptive results presented in Table 10 clearly show that all mean VAS scores for individual raters are over $47 \mathrm{~mm}$, indicating that even based on scores given by the most conservative rater, the identified cases have, on average, significant pain. Furthermore, the scores given by one of the raters in the present study (3b), as well as those given by a previous rater (7) using all 18 relevant items, show that the reduced KIDPAINS is highly sensitive and specific. As such, KIDPAINS can differentiate between cases and non-cases with hardly any misclassifications.

Finally, it was found that convergent relations of the reduced KIDPAINS with other measures were high. All but two of the correlations with other pain measures (VAS pain and NCCPC-PV) for the KIDPAINS scores given by raters $3 \mathrm{~b}$ and 7 were significant at the 0.0001 level. And although correlations with VAS stress ratings tended to be slightly lower, most of these correlations were significant as well. Thus, for most raters, KIDPAINS seems to correlate with both the global impression raters have of children's pain and the impression they have of children's stress.

The present study had several limitations. The first was that the sample size was small for such a heterogeneous population as children with profound multiple disabilities. However, the highly significant results of most of the analyses would seem to be clinically significant. Nevertheless, as always, psychometric properties need to be replicated using new research samples, settings and raters. In this respect, another limitation of the present study is that of the limited number of nurses who rated the video scenes. Although these nurses evaluated KIDPAINS as a clinically useful pain assessment scale, further tesearch is needed to investigate the utility of KIDPAINS in everyday practice. Furthermore, it should be investigated whether KIDPAINS could be used directly at a child's bedside, since the use of videos can also be regarded as a limitation, as pointed out above. At the same time, however, the use of videos can also be regarded as an advantage of the present study, since it allowed repeated and detailed observations. The use of existing video-recordings (Chapter 5) can also be regarded as a limitation of the present study. Although new raters provided ratings, the video recordings were not derived from newly participating children. The use of previous material led to the ability to create extreme groups, at the same time one can question whether the creation of extreme groups succeeded in view of the overall moderate pain scores. 
On the other hand, of the 17 identified cases almost half of the children were given a mean VAS rating over $60 \mathrm{~mm}$ indicating that severe pain seemed to be present in a considerable number of children who, at the onset of the study, were selected for presumed pain. Overall it is our opinion that KIDPAINS can be used to assist clinical judgement of procedural/ postoperative pain in children with profound multiple disabilities in a hospital setting. 




\section{Chapter 7}

\section{General discussion}

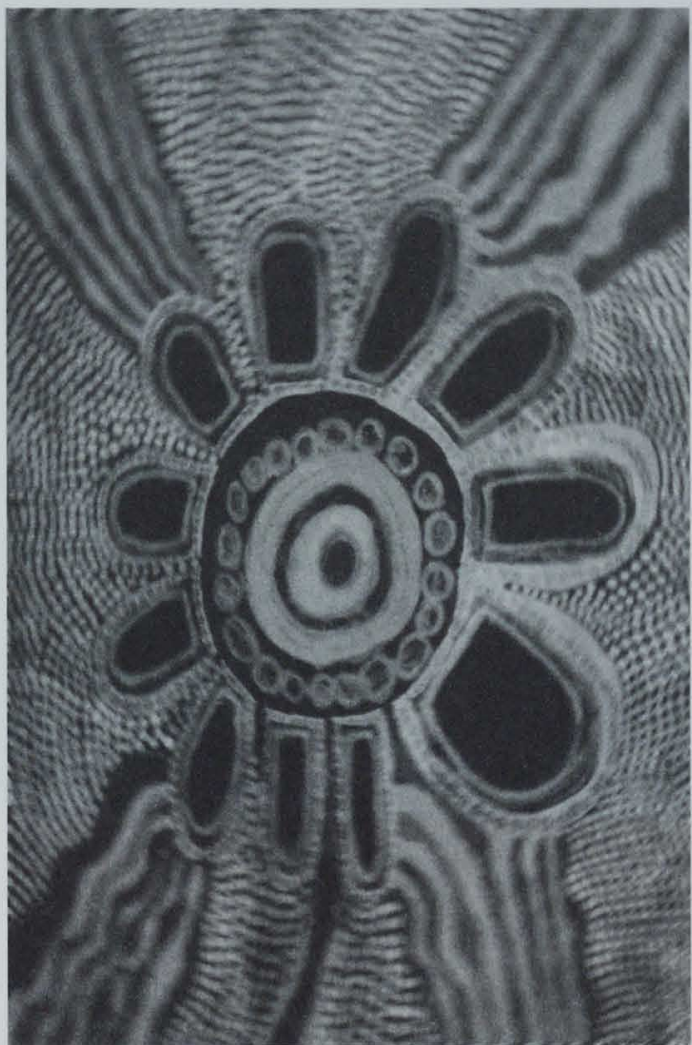

"Diagnosing pain in children with profound intellectual disabilities is like doing a jigsaw puzzle; you have to put all the pieces together before the picture becomes clear."

(Interview with a doctor specialising in the care of people with intellectual disabilities) 



\subsection{Introduction}

The research project described in this dissertation had three main purposes:

- examining non-verbal expressions of pain in children with severe to profound intellectual disabilities;

- developing a pain assessment scale based on the expressions identified;

- investigating the psychometric properties of this scale.

Piecing together the answers to the questions addressed in the studies reported on in the present dissertation, this chapter briefly summarises the main findings and presents some theoretical and methodological reflections. A distinction is made between the presentation of findings and reflections on expressive pain behaviour on the one hand and the pain assessment scale we developed, including its psychometric properties, on the other. The chapter ends with implications for practice and recommendations for further research.

\subsection{Expressive pain behaviour}

\section{Major findings}

Children with severe to profound intellectual disabilities display heterogeneous behavioural repertoires when in pain. This dissertation discusses a variety of pain expressions, the importance and occurrence of most of which were corroborated by parents and professional caregivers. Our examinations of expressive pain behaviour suggest that there are differences in behaviour between severely and profoundly intellectually disabled children and adults. The latter were more often reported to display behavioural expressions related to the Social-Emotional dimension and expressions relating to Activities of Daily Living, such as Eating little', whereas nurses caring for people with profound intellectual disability more often reported expressions relating to Physiology, such as Turning red in the face'. We found both differences and similarities compared to the literature on other nonverbal paediatric populations. The new items we added, based on the experiences of health care professionals caring for people with intellectual disabilities, were especially those belonging to the Social-Emotional dimension. The health care professionals also mentioned signs and symptoms of disease and diagnostic procedures as signals of pain. This finding underlines the difficulties health care professionals experience when diagnosing pain in people with severe intellectual disabilities in daily practice, when there is often no obvious relationship between a noxious stimulus and expressive pain behaviour.

The expressions that differed between sub-groups of children seemed to be related to the existence of additional disabilities such as motor impairments and behavioural and emotional disturbances. It was found, for instance, that for children with behavioural and emotional disturbances, 'Stereotypic repetitive behaviour' 
was among the 20 most frequently occurring items. Children with behavioural and emotional disturbances more often displayed items relating to aggressive behaviour towards themselves and others then children without these disturbances. In addition, parents of these children found it more difficult to observe pain in their child, as well as they feel that it is more difficult for other to observe pain. Nevertheless, parents of children with behavioural and emotional disturbances did not feel their children were indifferent to pain. Overall, $75 \%$ of all participating parents were of the opinion that their children had higher pain thresholds than normally developed children.

Children with severe multiple disabilities more often displayed expressive behaviours relating to muscle tone than children without additional disabilities. According to the parents, the expression 'High muscle tone, cramping' did frequently occur, and the same was reported for other items relating to muscle tone. As regards expressions relating to Injured Body Part, we found that children with severe multiple disabilities less often displayed items such as Withdrawing injured body part. Nevertheless, this item was included among the 20 most frequently occurring expressions for children with some verbal language. In addition, Using a word for pain' was among the five most important expressions for children with some verbal language. Thus it seems that both the intellectual ability to express oneself in language and the ability or inability to have motor control over limbs and body influence the behavioural expression of pain.

Although data obtained from the parents (Chapter 4) underline the heterogeneity of expressive pain behaviours, similarities were also reported. Based on the reports of parents and health care professionals of children with severe to profound intellectual disabilities, thirteen shared expressions were found to be prominent out of 145 different expressions. (Table 1, pages 143-146).

Table 1 shows that these overlapping items were reported in several studies presented in or related to the present dissertation. The thirteen expressions, which thus seem to occur frequently in all children with severe to profound intellectual disabilities according to parents and health care professionals, are: Restless movements'; Facial tension'; Looking sad'; Facial restlessness'; Looking anxious'; Restlessness'; 'Grimacing'; 'Irritable, cranky'; 'High muscle tone, cramping, spastic'; Restless movements with head'; Panicky'; 'Crying Loudly, intensely, vigorously'; and 'Tears'. Eight of those 13 items are part of the final item selection of KIDPAINS. The items that are not present in the KIDPAINS were discarded because they were not reliable (three items, Chapter 6), did not differentiate between extreme groups (one item, Chapter 6), or showed less consistency with other items (one item, Chapter 5). 
Table 1

Overview of the various datasets for comparison of frequency of occurrence

\begin{tabular}{|c|c|c|c|c|c|c|c|c|c|}
\hline \multirow{2}{*}{$\begin{array}{l}\text { Method } \\
\text { Number }\end{array}$} & \multirow{2}{*}{$\begin{array}{l}\text { Literature } \\
\qquad \mathrm{N}=16\end{array}$} & \multirow{2}{*}{$\begin{array}{c}\text { Open } \\
\text { obser- } \\
\text { vations } \\
\mathrm{N}=32\end{array}$} & \multirow{2}{*}{$\begin{array}{l}\text { Open } \\
\text { inter- } \\
\text { views } \\
N=26\end{array}$} & \multirow{2}{*}{$\begin{array}{l}\text { Question- } \\
\text { naire } \\
N=105\end{array}$} & \multicolumn{5}{|c|}{ Questionnaire } \\
\hline & & & & & $N=101$ & $\mathrm{~N}=82$ & $N=56$ & $N=50$ & $N=44$ \\
\hline Study popluation ${ }^{2}$ & Scales & Children & $\begin{array}{l}\text { Care- } \\
\text { givers }\end{array}$ & $\begin{array}{l}\text { Health } \\
\text { care } \\
\text { workers }\end{array}$ & $\begin{array}{c}\text { Parents } \\
\text { children } \\
\mathrm{NL}^{2}\end{array}$ & $\begin{array}{l}\text { Parents } \\
\text { children } \\
\text { SM }\end{array}$ & $\begin{array}{c}\text { Parents } \\
\text { children } \\
\text { NAD }\end{array}$ & $\begin{array}{c}\text { Parents } \\
\text { children } \\
\text { BAED }\end{array}$ & $\begin{array}{c}\text { Parents } \\
\text { children } \\
\text { SMD }\end{array}$ \\
\hline $\begin{array}{l}\text { Main focus regarding } \\
\text { intellectual disabiltiy }\end{array}$ & $\begin{array}{c}\text { Non- } \\
\text { disabled }\end{array}$ & $\begin{array}{l}\text { Severe } \\
\text { and } \\
\text { profound }\end{array}$ & $\begin{array}{l}\text { Severe } \\
\text { and } \\
\text { profound }\end{array}$ & $\begin{array}{c}\text { Severe } \\
\text { and } \\
\text { profound }\end{array}$ & Profound & Severe & Severe & $\begin{array}{l}\text { Severe } \\
\text { and } P \\
\text { profound }\end{array}$ & Profound \\
\hline Type of data in column & $\begin{array}{l}\text { Present } \\
\text { in scale }\end{array}$ & Observed & Reported & $\begin{array}{l}\text { Definitely } \\
\text { pain }\end{array}$ & Ranking & for highes & trequenc & $y$ (most imp & portant) \\
\hline \multicolumn{10}{|l|}{ FACIAL } \\
\hline Facial tension ${ }^{3}$ & $19 \%$ & & $27 \%$ & $>50 \%$ & 1 & $1(5)$ & 2 & 2 & 6 \\
\hline Facial restlessness ${ }^{3}$ & & & $23 \%$ & $>70 \%$ & 4 & 2 & 4 & 4 & \\
\hline Grimacing $^{3}$ & $50 \%$ & & $38 \%$ & $>50 \%$ & 9 & 10 & 8 & $15(3)$ & $10(5)$ \\
\hline Yawning $^{5}$ & & & & & & & & & \\
\hline Lips quivering & $6 \%$ & & $8 \%$ & & & & & & \\
\hline Jutting lower lip, pouting & $13 \%$ & $6 \%$ & $19 \%$ & & & 14 & 12 & & \\
\hline Pursing lips & $13 \%$ & & $4 \%$ & & & & & & \\
\hline Helding lips tightly & $6 \%$ & & $8 \%$ & $>70 \%$ & & & & & \\
\hline Biting lower lip & & & $4 \%$ & $>50 \%$ & & & & & \\
\hline Raising upper lip & & $9 \%$ & & & & & & & \\
\hline Pulling up nose & & $19 \%$ & & & & & & & \\
\hline Turning down mouth & $13 \%$ & $6 \%$ & $4 \%$ & & & & & & \\
\hline Pulling a wry mouth & & $3 \%$ & $4 \%$ & & & & & & \\
\hline $\begin{array}{l}\text { Stretching mouth vertically, } \mathrm{O} \text { - } \\
\text { shaped mouth }\end{array}$ & $19 \%$ & $9 \%$ & & & & & & & \\
\hline Taut tongue & $6 \%$ & $6 \%$ & $4 \%$ & & & & & & \\
\hline Tongue protrusion & $13 \%$ & & $4 \%$ & & & & & & \\
\hline Clenching jaws & $19 \%$ & & $4 \%$ & $>50 \%$ & & & & & \\
\hline Widened eyes & $13 \%$ & $9 \%$ & $8 \%$ & $>50 \%$ & & & 18 & & \\
\hline Eyes suddenly wide open & 114 & $"$ & $"$ & $>50 \%$ & & & 11 & & 16 \\
\hline Eyes in a slit & & $3 \%$ & $4 \%$ & & & & & & \\
\hline Squeezing eyes & $44 \%$ & $19 \%$ & $27 \%$ & & & & & & \\
\hline Blinking continously & & $6 \%$ & $8 \%$ & & & & & & \\
\hline Eyes whirling around & & $9 \%$ & $12 \%$ & & & & & & \\
\hline Looking sad ${ }^{3}$ & $13 \%$ & $6 \%$ & $42 \%$ & $>50 \%$ & 6 & 5 & 3 & 7 & 9 \\
\hline Looking serious, dejected & $"$ & $"$ & $"$ & & & 11 & 14 & 17 & 18 \\
\hline Looking anxious $^{3}$ & $13 \%$ & $3 \%$ & $8 \%$ & $>50 \%$ & 7 & 4 & 5 & 8 & 5 \\
\hline Looking angry ${ }^{6}$ & & & & & & & & & \\
\hline Naso-labial furrow deepened & $25 \%$ & & & & & & & & \\
\hline Nostrils flaring & $6 \%$ & & & & & & & & \\
\hline $\begin{array}{l}\text { Frowning } \text { chin }^{5} \\
\text { Quivering chin }\end{array}$ & $19 \%$ & & $8 \%$ & & & & & & \\
\hline $\begin{array}{l}\text { Raising eyebrows, forehead } \\
\text { furrowed }\end{array}$ & & & $8 \%$ & & & & & & \\
\hline Frowning eyebrows, forehead & $50 \%$ & $25 \%$ & $12 \%$ & & & & & & \\
\hline \multicolumn{10}{|l|}{ MOTOR } \\
\hline Involuntary movements & $6 \%$ & & $4 \%$ & & & & & & 17 \\
\hline Jerky movements & $13 \%$ & & $12 \%$ & & & & & & \\
\hline $\begin{array}{l}\text { High muscle tone, cramping } \\
\text { (spastic) }^{3}\end{array}$ & $44 \%$ & $50 \%$ & $65 \%$ & $>70 \%$ & $8(2)$ & 9 & 15 & 12 & $4(2)$ \\
\hline Stiffness, rigidity & $38 \%$ & & $19 \%$ & $>50 \%$ & 12 & & & & 8 \\
\hline Floppy & $13 \%$ & & $8 \%$ & & & & & & \\
\hline Tremor arm, hand & $6 \%$ & $3 \%$ & $8 \%$ & & & & & & \\
\hline
\end{tabular}


Table 1 continued

Overview various datasets for comparison frequency of occurrence

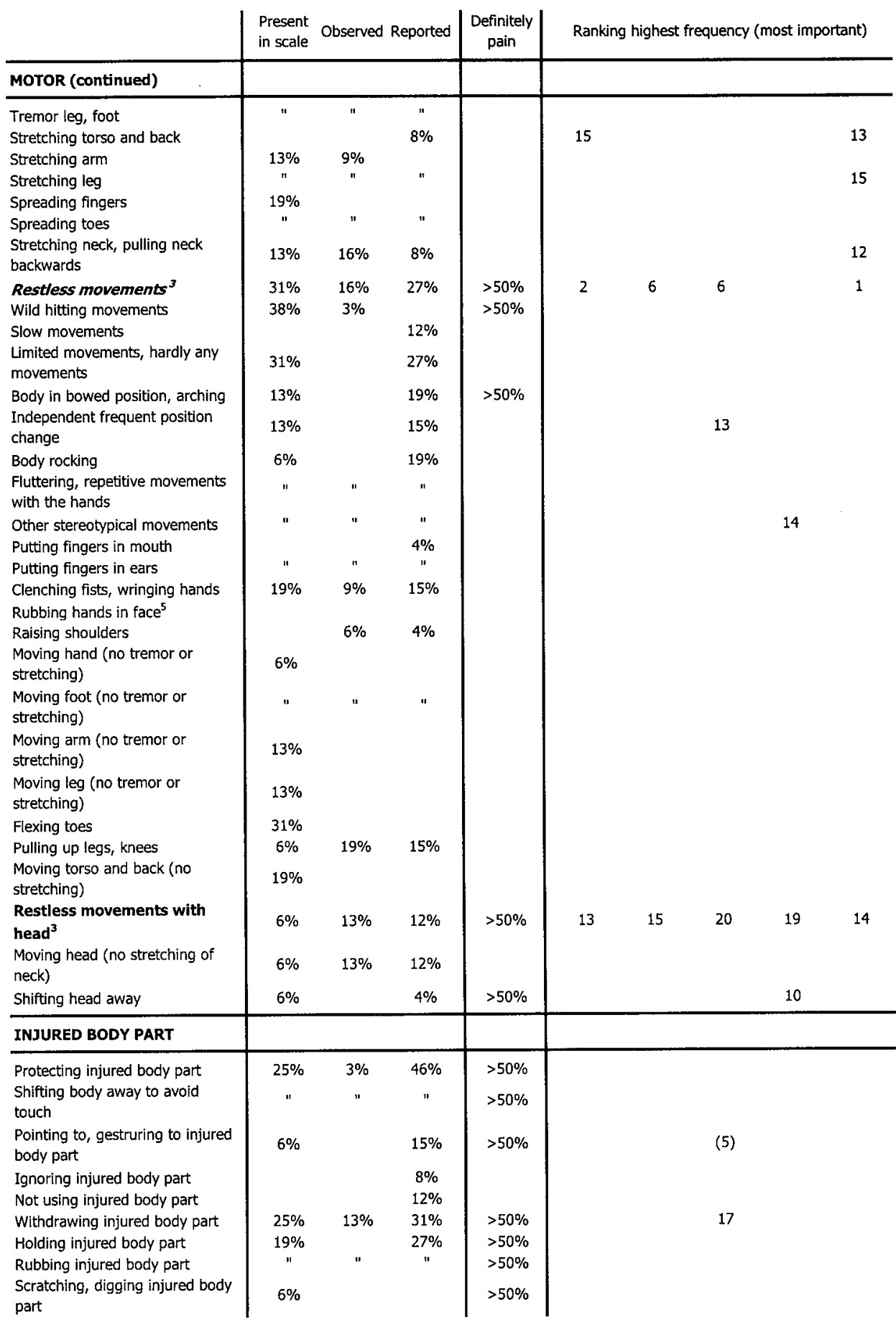


Table 1 continued

Overview various datasets for comparison frequency of occurrence

\begin{tabular}{|c|c|c|c|c|c|c|c|c|c|}
\hline \multirow[b]{2}{*}{$\begin{array}{l}\text { INJURED BODY PART } \\
\text { (continued) }\end{array}$} & \multirow[t]{2}{*}{$\begin{array}{l}\text { Present } \\
\text { in scale }\end{array}$} & \multicolumn{2}{|c|}{ Observed Reported } & \multirow[t]{2}{*}{$\begin{array}{c}\text { Definitely } \\
\text { pain }\end{array}$} & \multicolumn{5}{|c|}{ Ranking highest frequency (most important) } \\
\hline & & & & & & & & & \\
\hline $\begin{array}{l}\text { Hunching, pushing injured body } \\
\text { part } \\
\text { Pulling injured body part } \\
\text { Pulling clothes surrounding } \\
\text { injured body part } \\
\text { Taking off clothes, shoes }\end{array}$ & $\begin{array}{c}6 \% \\
n\end{array}$ & $"$ & $\begin{array}{c}19 \% \\
" \\
4 \%\end{array}$ & $>50 \%$ & & & & & \\
\hline SOCIAL EMOTIONAL & & & & & & & & & \\
\hline $\begin{array}{l}\text { Unrest, restlessness }{ }^{3} \\
\text { Agitation } \\
\text { Fussy, lively } \\
\text { Irritable, cranky }{ }^{3} \\
\text { Panicky } \\
\text { Not cooperating } \\
\text { Sleepy, drowsy } \\
\text { Dozing } \\
\text { Listless, insensible to stimuli } \\
\text { Very calm } \\
\text { Hardly interacting with } \\
\text { surrounding } \\
\text { Inconsolable } \\
\text { Refusing physical contact } \\
\text { Accepting comfort, consolable } \\
\text { Seeking comfort or physical } \\
\text { closeness } \\
\text { Resistance, mutinous behaviour } \\
\text { Anger, mad } \\
\text { Hitting, pinching, scratching and } \\
\text { other aggressive behaviours } \\
\text { (agression) } \\
\text { Destroying things, destructive } \\
\text { behaviour } \\
\text { Head banging } \\
\text { Self biting } \\
\text { Self slapping } \\
\text { Pulting own hair } \\
\text { Self injuring in other manner (self. } \\
\text { injury) } \\
\text { Hyperactive behaviour } \\
\text { Stereotypic, repetitive behaviour }\end{array}$ & $\begin{array}{c}31 \% \\
" \\
19 \% \\
25 \% \\
6 \% \\
6 \% \\
13 \% \\
" \\
19 \% \\
13 \% \\
31 \% \\
25 \% \\
\\
25 \% \\
13 \% \\
31 \% \\
\end{array}$ & $\begin{array}{c}1 " \\
3 \% \\
3 \% \\
25 \% \\
3 \%\end{array}$ & $\begin{array}{c}35 \% \\
27 \% \\
15 \% \\
\\
23 \% \\
35 \% \\
12 \% \\
31 \% \\
8 \% \\
12 \% \\
31 \% \\
8 \%\end{array}$ & $\begin{array}{l}>50 \% \\
>50 \% \\
\\
\\
>50 \% \\
>50 \% \\
>50 \%\end{array}$ & $\begin{array}{l}10 \\
11\end{array}$ & $\begin{array}{c}7 \\
\\
8 \\
13 \\
12\end{array}$ & $\begin{array}{c}7 \\
\\
9 \\
19 \\
10\end{array}$ & $\begin{array}{c}1 \\
16 \\
5(4) \\
11 \\
6\end{array}$ & 20 \\
\hline VOCAL & & & & & & & & & \\
\hline $\begin{array}{l}\text { Crying loud/y, intensely, } \\
\text { vigorous/y } \\
\text { Crying softly } \\
\text { Moaning, groaning } \\
\text { Screaming, yelling } \\
\text { Stereotypical, repetitive sounds } \\
\text { Angry shreeks } \\
\text { Grumbling } \\
\text { Grinding teeth } \\
\text { Spitting } \\
\text { Sucking } \\
\text { Smacking sounds, chewing }\end{array}$ & $\begin{array}{c}50 \% \\
31 \% \\
\\
" 1 \\
6 \% \\
6 \% \\
6 \%\end{array}$ & $\begin{array}{c}16 \% \\
6 \% \\
6 \% \\
" \\
6 \%\end{array}$ & $\begin{array}{c}27 \% \\
4 \% \\
50 \% \\
73 \% \\
4 \% \\
\\
" \\
15 \% \\
4 \% \\
4 \%\end{array}$ & $\begin{array}{l}>70 \% \\
>50 \% \\
>70 \% \\
>50 \%\end{array}$ & $\begin{array}{c}(1) \\
14(5)\end{array}$ & (1) & (1) & (5) & $11(3)$ \\
\hline
\end{tabular}


Table 1 continued

Overview various datasets for comparison frequency of occurrence

\begin{tabular}{|c|c|c|c|c|c|c|c|c|}
\hline \multirow[b]{2}{*}{ VOCAL (continued) } & \multirow[t]{2}{*}{$\begin{array}{l}\text { Present } \\
\text { in scale }\end{array}$} & \multicolumn{2}{|c|}{ Observed Reported } & \multirow[t]{2}{*}{$\begin{array}{c}\text { Definitely } \\
\text { pain }\end{array}$} & \multicolumn{4}{|c|}{ Ranking highest frequency (most important) } \\
\hline & & & & & & & & \\
\hline $\begin{array}{l}\text { Coughing } \\
\text { Paradoxical laughing } \\
\text { Quiet, not making any sounds } \\
\text { Making a special sound when in } \\
\text { pain } \\
\text { Guttural sounds } \\
\text { Penetrating, restless sounds } \\
\text { Using a specific word for pain } \\
\text { Babbling }\end{array}$ & $\begin{array}{c}13 \% \\
13 \% \\
6 \% \\
" \\
" \\
6 \%\end{array}$ & $\begin{array}{c}9 \% \\
25 \% \\
" \\
"\end{array}$ & $\begin{array}{c}4 \% \\
15 \% \\
31 \% \\
42 \% \\
" 1 \\
" \\
27 \%\end{array}$ & $>50 \%$ & & (2) & (3) & 19 \\
\hline PHYSIOLOGICAL & & & & & & & & \\
\hline $\begin{array}{l}\text { Holding or drawing in breath } \\
\text { Sharp intake of breath } \\
\text { Increased respiration rate } \\
\text { Irregular, jerky respiration } \\
\text { Gasping } \\
\text { Snorting respiration } \\
\text { Perspiring } \\
\text { Shivering } \\
\text { Grey pallor } \\
\text { Pallor } \\
\text { Looking flushed } \\
\text { Blue lips } \\
\text { Spotted body } \\
\text { Tears } \\
\text { Rumination } \\
\text { Absence of rumination } \\
\text { Epileptic insult }\end{array}$ & $\begin{array}{c}19 \% \\
13 \% \\
25 \% \\
25 \% \\
13 \% \\
\\
13 \% \\
6 \% \\
6 \% \\
13 \% \\
6 \%\end{array}$ & $\begin{array}{l}13 \% \\
6 \%\end{array}$ & $\begin{array}{c}8 \% \\
8 \% \\
15 \% \\
8 \% \\
4 \% \\
4 \% \\
35 \% \\
4 \% \\
4 \% \\
8 \%\end{array}$ & $\begin{array}{l}>50 \% \\
>50 \% \\
>50 \% \\
>50 \%\end{array}$ & (3) & (4) & (4) & (4) \\
\hline
\end{tabular}

(1) Data presented in Chapter 2; Koot et al., 2000; Chapter 4 respectively

(2) $\mathrm{NL}=$ no language, $\mathrm{SM}=$ some language, $\mathrm{NAD}=$ no additional disabilities, $\mathrm{BAED}=$ behavioural and emotional disturbances, $\mathrm{SMD}=$ severe multiple disabilities

(3) Italic items are included in the reduced LIDPAINS; bold items comprise frequently occuring items according to parents and health care professionals

(4) ${ }^{\prime \prime}=$ Items regrouped and regarded as being conceptually different (from the item mentioned in the line above) by experts during validation process

(5) Items resulting from pilot study (Appendix 1)

(6) Items resulting from study among nurses (Chapter 3 )

However, the reports by parents and professional caregivers were not consistent for all items. E.g., 'Seeking comfort' is often present according to the parents, while Inconsolable' is definitely a pain item according to professional caregivers. Nurses considered 'Seeking comfort' mote important for people with severe intellectual disability than for people with profound intellectual disability, whereas parents of children with severe multiple disabilities did not report 'Seeking comfort' to be less frequently present in their child. Professional caregivers might interpret 'Seeking comfort' more literally then parents do.

The research presented in this dissertation showed that all 145 items identified in the item-devising process and adopted in further research were either present or regarded as important in individual children according to their parents or caregivers. All caregivers who provided information in the questionnaires were consistent in this respect. Thus, although a core set of thirteen items was identified, 
expressive pain behaviours may also vary across sub-samples of children as well as across individual children.

\subsection{Theoretical reflections}

\section{Are the findings comparable with the international literature?}

A comparison with the findings of other studies on the expressive behaviour of children with severe intellectual disabilities reveals some similarities. Of the core items mentioned above, expressions relating to facial expression and vocalisations have been mentioned most often in the literature. In line with these findings, Donovan (2002) found that nurses caring for a mostly preverbal population of individuals with intellectual disabilities reported relying heavily on facial expression. Furthermore, nurses reported that crying was often the only indication of pain shown by their clients. This finding is supported by a study by Carter and colleagues (2002), who reported that vocalisations such as crying and moaning were often a key means of pain expression, although several children cried very rarely according to their parents. All parents in their study reported that the facial expression of their child changed when he or she was in pain, making it another strong pain indicator. Stallard and colleagues (2002b) recently identified six core cues used by parents to identify pain in their children with severe cognitive impairment. 'Screwed up or distressed looking face' was the strongest individual predictor of pain in their study (Stallard et al., 2002a), and both 'Crying with or without tears' and 'Screaming, yelling, groaning or moaning' were also core indicators. Recent work by Breau and colleagues on the validation of their scale for postoperative pain (Breau et al., 2002b) also indicated that facial expressions might be the most consistent cues shown by children with cognitive impairment. In addition, the item 'Moaning, whining, whimpering (fairly soft)' was the most frequently displayed item within their Vocal subscale according to caregivers, which is in line with the present dissertation. However, although interrater reliability was good for both the Vocal and Facial subscales, the authors reported that only $50 \%$ of the children displayed any vocal behaviour after surgery.

A comparison of specific expressions used shows that some authors refer to crying (McGrath et al., 1998; Hunt, 2000; Oberlander \& O’Donnel, 2001; Hadden \& Bayer von, 2002; Stallard et al., 2002a), while others refer to vocalisations (Carter et al., 2002) or facial expressions in general (Oberlander \& O'Donnel, 2001; Carter et al., 2002). 'Grimacing' (Hunt et al., 2000) and 'Distressed face' (Stallard et al., 2002a) are among the specific items with the highest ratings. In addition, items relating to muscle tone have been frequently reported; these include 'Stiffening and spasming' (Hunt et al., 2002), 'Changes in muscle tone' (Oberlander \& O'Donnel, 2001), 'Stiff' spasm' (Hadden \& Bayer von, 2002) and 'Tense body' (Stallard et al., 2002b). In 
addition, several studies also mention items relating to 'Moaning and groaning', 'Screaming', 'Moving body part away, flinching', and Inconsolability'.

Exact comparisons are difficult, however, since various authors interpret items differently. For instance, Stallard and colleagues (2002a) regard 'Screaming yelling, groaning, moaning' as one expression, whereas other authors refer to these expressions as two separate items (Hunt, 2000). Furthermore, the literature on pain in children with intellectual disabilities makes no distinction between 'Crying loudly' and 'Crying softly', whereas our own research regarded these two expressions as separate entities. Comparing behaviours is thus complicated by the fact that items are phrased in different ways. Some items, such as 'Changes in motor function' (Oberlander \& O'Donnel, 2001), are more global dimensions compared with the present dissertation. Also, some authors combine several detailed behaviours within one item, like the item Not moving, less active, quiet' (McGrath et al, 1998), again making comparisons between results less reliable. Another factor that sometimes makes comparing between authors difficult is the fact that it is not always clear what the abilities and disabilities were of the population from which the expressions were derived. Since these (dis-) abilities are likely to influence the behavioural expression of pain insight is needed into study populations.

Finally, one of the most remarkable differences between the results discussed in the present dissertation and the literature is the concept of restlessness. Although some studies mention items relating to agitation, items relating to restlessness are mostly not present among the highest scoring items reported by other authors. This contradicts our findings, as we found all items relating to restlessness to be part of the core set of items identified in our studies. The only other author that identified high ratings for restlessness is Hunt and colleagues (2004). It is not clear why this difference occurs.

Are the findings comparable with the communicative behaviour of children with intellectual disabilities?

Hadjistavropoulos \& Craig (2002) described the connection between pain and communication. They stated that observational measures of pain capture behaviour that is less subject to voluntary control and more automatic. They also stress the difficulty for observers to decode these messages. This might partially explain the fact that, although the facet design presented in the General introduction (Chapter 1) stresses the importance of items like mouth movement, eyes and glance in the communication of people with profound intellectual disabilities, these items do not seem to play a clear role in the results reported in the present dissertation. Although several interviewees referred to specific items relating to the eyes and the mouth (Chapter 2), these specific items were not mentioned as being frequently present by either professional caregivers or parents, nor did they play an important role in the construction of our KIDPAINS scale. 
This apparent discrepancy might be explained by the fact that these behaviours are either too idiosyncratic or they are not specific indications of pain as identified in the literature (Prkachin \& Craig, 1995). As Hadjistavropoulos \& Craig (2002) state, behaviour related to pain represents stereotyped reflexive patterns of response to actual or impending tissue damage that are outside immediate conscious awareness or involuntary control. Eye movement, for instance, might rather be an expression of an intentional communicative act.

Another explanation for the absence of these behaviours from our own item selection could be that observers tend to focus on the expressions they are familiar with in diagnosing pain. When examining 115 behaviours in young children, McGrew (1969) found that while body posture, head posture and glance seemed to be crucial in the expression of emotions, thoughts and needs, caregivers in general seemed to be focussed on vocalisations, gestures and facial expressions. In addition, Wills (1973) concluded that professional caregivers experience difficulties in achieving the necessary distance from usual interactive behaviours in their interpretation of communicative behaviour in people with severe intellectual disabilities. This may also have been the case with pain behaviour. Thus, the importance of the interpretation by the observer has to be kept in mind.

The Communications Model of Pain (Hadjistavropoulos \& Craig, 2002) shows that the internal experience of pain cannot be directly observed, but is encoded in nonverbal, behavioural expressions. Observers decode non-verbal cues with varying degrees of success, reflecting attention and response biases. As was found in our qualitative study (Chapter 2), caregivers find the decoding of non-verbal messages difficult, since the same behaviours are used for the expression of a variety of emotions such as stress, anxiety or frustration. In this context, Van der Maat (1992) reported that the interpretation of an expressive behaviour can vary across professional caregivers, making the identification of the behaviour even more difficult. In addition Hogg (2001) found that caregivers showed little agreement about the meaning of certain behaviours. Campbell \& Wilcox (1989) found that only in $52 \%$ of cases there was agreement between the judgements of professional caregivers about the meaning of communicative behaviour in their clients with profound multiple disabilities. Due to their limited behavioural repertoire, these people have to express needs, feelings and desires within a variety of communicative functions and discourse roles with a very limited number of expressions. For this reason, the communicative competence of persons with profound intellectual disability can be expected to show substantial variation, depending on context and the primary goal of interaction, and not to be as stable as the communicative competence of persons without disabilities (Granlund, 1993). Thus, it is not only the abilities of the individual but also the condition of the context that affects the communicative competence of the individual (Granlund, 1996). This finding stresses the importance of carefully examining the 
level of agreement on encoding individual items between various observers, as well as that of making items as simple and unambiguous as possible. As we found when we tried to derive pain expressions from the literature, pain researchers tend to combine various expressions into one item, while providing more detailed expressions only in the appendices to the scales.

The results of the research reported on in the present dissertation show that in encoding the behaviours distinguished in the above model of communication, it is important to take additional disabilities as well as the idiosyncratic nature of the behaviour into account. In expressive as well as responsive behaviour, people with profound intellectual disability are hampered by the additional impairments that coexist with the intellectual disability (Campbell \& Wilcox, 1989). Granlund (1993) states that motor disabilities primarily affect the production of messages, whereas in responding to others, people with profound intellectual disability are also hampered by visual and auditory disabilities.

Van der Maat (1992) discusses several studies that refer to the existence of behavioural and emotional disturbances as communicative behaviour. The results of our qualitative study and those of the questionnaire study among parents in the present dissertation both stress the importance of the existence of emotional and behavioural disturbances in the behavioural expression of pain. Furthermore, Velthausz (1987) refers to the influence of the individual intellectual abilities: although communication and intellectual development are two separate entities, there are overlaps between the two. Parents report different behaviours for children with and without the ability to use linguistic communication. According to the normal development of communication described in the General introduction (Chapter 1), children should be able to start using gestures in the proto-symbolic phase, a development which is expected to evolve further in the symbolic phase. This explains our finding that non-verbal children, according to parents, used items relating to the Injured Body Part dimension less commonly. Furthermore, in line with the level of pre-intentional communication, the idiosyncratic nature of communication in the reflexive phase is corroborated by the findings of our qualitative study (Chapter 2) as well as the questionnaire study among professional caregivers (Koot et al., 2000) and parents (Chapter 4). Van der Maat (1992) states that at the level of pre-intentional communication, every change in behaviour in comparison with a previous condition can have a signal function for the caregiver, a comment which was indeed often made in our interviews with professional caregivers (Chapter 2).

In the literature, the fact that some behavioural expressions are present only briefly is regarded as an indication of interaction and communication problems in intellectually disabled individuals (Velthausz, 1992). This means that the possible delay in response to a painful stimulus that was mentioned in the qualitative study 
(Chapter 2) reported on in the present dissertation poses an additional threat to adequate interaction and communication. In addition, almost half of the parents in our study indicated that their child at least sometimes seemed to show a slow response to a noxious stimulus. Together, these aspects indicate that studies among children with severe intellectual disabilities run a greater risk of attention and response bias. Sternberg et al. (1980) argued that even persons with the most profound multiple disabilities can display simple intentional communicative behaviours, provided that persons in their environment can interpret and respond to the behaviours displayed.

\subsection{Methodological reflections}

\section{Were the appropriate designs used?}

First of all, one should remember that the cross-sectional studies and the qualitative study discussed in the present thesis do not establish causal relationships. Although a large amount of information was gathered, we still do not know for sure what behaviours are indeed expressions of pain. The lack of a gold standard in pain measurement contributes to the difficulty establishing causal relationships. However, qualitative and cross-sectional studies are appropriate designs for research in such a new subject area. Furthermore, the range of studies done allows comparisons between results to be made. The strength of the designs used for the present dissertation is therefore that the studies reported on are complementary, as Table 1 shows. Using different samples and different designs allowed us to use triangulation. On the other hand, samples sizes in the crosssectional studies in particular were relatively small, especially in view of the heterogeneous nature of the population under investigation. Since the questionnaires included many detailed questions, this limited sample size makes it difficult to generalise our conclusions. It may also be questioned whether both parents and professional caregivers were indeed able to differentiate between all the detailed expressions presented to them. The various results presented in Table 1 suggest, however, that there was a fair degree of concordance between the various sources.

\section{What could have been done differently?}

As regards our qualitative study (Chapter 2), it would have been possible to devise items based on interviews and the literature, analyse these findings, and then make observations about the results. This would have enabled us to investigate the occurrence of items at an earlier stage. However, our aim was to collect, in an open manner, all possible expressions of pain. Although this open observational method led to various additional pain expressions, very little can be said about the behaviour that, according to the observer, was actually present. Furthermore, 
although it was a qualitative study, it would have been an option to use a VAS for the observations.

As for the study among nurses (Chapter 3), a different response scale could have been used. As it was, respondents had ten answering options, which probably automatically led to high ratings, as ten was a rather large number to choose from. It would also have been better to make the questionnaire and the draft observational scale as similar as possible, as was done with the questionnaire for parents. Although the fact that we copied items from Giusiano et al. (1995) verbatim led to some interesting findings on the value nurses place on items such as 'Crying during manipulation', it was difficult to compare the results from the questionnaire for nurses with that for parents and healthcare professionals in terms of individual expressions. Furthermore, it remains unclear whether or not participants of the various studies had the same understanding of the population under investigation. Although the terms severely and profoundly intellectually disabled are easily used, they are difficult to operationalise. Therefore the questionnaires could have included more questions about the functional abilities of the children and adults one was caring for.

\subsection{Development and psychometric testing of a pain assessment scale}

\section{Main findings}

Based on the various studies reported in the present dissertation, we developed the Kids with Intellectual Disabilities Pain Assessment Instrument for Non-verbal Signals (KIDPAINS). An overview of the developmental process of KIDPAINS is presented in Table 2 .

\section{Table 2}

\section{Developing KIDPAINS}

(1) Item devising ( $\mathrm{N}=209$ ) by qualitative research (Chapter 2 )

(2) Based on Chapter 3, two items were added to the item bank $(\mathrm{N}=211)$

(3) Item selection and modification based on interpretability and face validity check by experts (Appendix I)

(4) Item selection and modification based on videos pilot study using a draft scale (Appendix I)

(5) Item selection based on rechecking for interpretability and content validity among health care professionals using a draft scale (Appendix I)

(6) Item selection based on final check of draft scale using videos in pilot study (Appendix I); from 145 to 138 items

(7) Item selection based on questionnaire for parents of children with profound intellectual disabilities (Appendix II); from 138 to 114 items

(8) Item selection and preliminary psychometric evaluation based on clinical data of children with profound intellectual disabilities (Chapter 5); from 114 to 42 items

(9) Testing psychometric properties in children with profound multiple disabilities (Chapter 6); from 42 to 18 items 
KIDPAINS turned out to be a psychometrically sound scale for the assessment of pain in children with severe multiple disabilities. A careful, thorough item devising and item selection process was carried out, before psychometric properties were investigated. The items that were selected from the item bank we had constructed (Chapter 2 \& Chapter 3), on the basis of interpretability and applicability within a hospital setting (Appendix I), showed content validity when tested for their applicability as pain expressions in children with severe to profound intellectual disabilities by healthcare professionals (Koot et al., 2000; see Table 1). The findings of a study among parents of profoundly intellectually disabled children (Chapter 4) then allowed us to narrow down the item selection from 138 to 114 items (see Appendix ID).

Subsequently, we used observations among 52 children with profound intellectual disabilities during standardised episodes before and after a medical procedure under general anaesthesia in a children's hospital, and at an intervention-specific moment, to further reduce the item selection. Separate analyses were conducted for each dimension at each time episode, thus cross-validating the item selection process. Forty-two items were retained in the item selection for at least one time episode. The postoperative episodes resulted in similar item selections. Each dimension yielded adequate $(0.643)$ to good (0.893) Cronbach's $\alpha$ values, indicating homogeneity between items. Subtraction of the behaviour scored one day before and one month after the procedure from the behaviour during the pain-inducing episodes resulted in correlations with VAS that were particularly significant for the Facial, Social-Emotional and Vocal components identified by Principal Components Analysis (PCA). Clear convergent telationships with pain could not be established for all identified components. The 42 remaining items of KIDPAINS were tested for reliability, criterion validity and construct validity, using a known-groups design of children with profound multiple disabilities in identified painful and non-painful situations.

This further item selection yielded 18 items. A PCA identified two components, one more closely related to VAS pain, the other more closely related to VAS stress. Overall, the 18 remaining items showed good psychometric properties. Using a proxy silver standard based on nine VAS ratings, we found high internal consistency ratings (Cronbach's $\alpha 0.90-0.96$ ), high intra-class correlations for interrater $(0.90)$ and intrarater $(0.87)$ agreement, high sensitivity $(0.94-1.00)$ and specificity (0.91-0.95) and high convergent relations with VAS pain and the NCCPC-PV. However, significant correlations were also found with VAS stress. Finally, the reduced KIDPAINS showed construct validity differentiating significantly between pain and no pain. We therefore conclude that all steps taken have led to a scale that seems to be both valid and reliable. 


\subsection{Theoretical reflections}

What are the psychometric properties of other recently developed scales for assessing pain in children with intellectual disabilities?

In recent years, a great deal of work has led to the development of several observational scales for the assessment of pain behaviour in non-verbal children with intellectual disabilities. Tables 3 and 4 (pages 155-157) present an overview of these scales and their current psychometric properties.

So far, the Non-Communicating Children Pain Checklist (NCCPC), developed by the Canadian research group of Breau and McGrath and colleagues has been subjected to the most tigorous psychometric testing, both in home settings (NCCPC-R) and in the assessment of postoperative pain (NCCPC-PV) (Breau et al., 2002a; Breau et al., 2002b). Overall, the NCCPC shows good psychometric properties. Hence, the postoperative version of this scale was used to investigate convergent validity in our Chapter 6 .

Another scale that has gone through thorough psychometric testing is the Paediatric Pain Profile (PPP) by Hunt and colleagues (2004). Both the NCCPC and the PPP initially focused on pain assessment by parents in the child's everyday living situation. A comparison of the various scales that have been developed shows that all these behavioural rating scales focus on non-verbal children, although most focus on children with severe as well as those with profound intellectual disability. The Checklist Pain Behaviour (CPB)(Terstegen et al., 2003) is, apart from KIDPAINS, the only scale limiting the population to children with profound cognitive impairment. Up to 138 items, the same item development and item selection process presented in the present thesis (Dongen van et al, 2002b) also served as the basis for the development of the $\mathrm{CPB}$, although the further construction of the CPB was based on different reduction techniques (Terstegen, 2004).

Giusiano \& Collignon specifically investigated children with severe cerebral palsy. Their primary aim was to assess pain during medical examination. Stallard and colleagues (2002a) are the only scale developers who specifically focused on chronic rather than acute pain. Besides the differences in the populations that were investigated, a major difference between the scales presented in Table 3 seems to be the way in which items were developed and selected, as well as the number of items that were present in the item selection at one point. Breau and colleagues only removed one item from their initial selection, whereas Stallard and colleagues reduced their number of items from 203 to 6 in one step. Also, Hunt and colleagues took several steps in developing the items of the PPP, using different sources and different data collection methods, whereas Breau and colleagues devised their items in one step, using interviews only. 


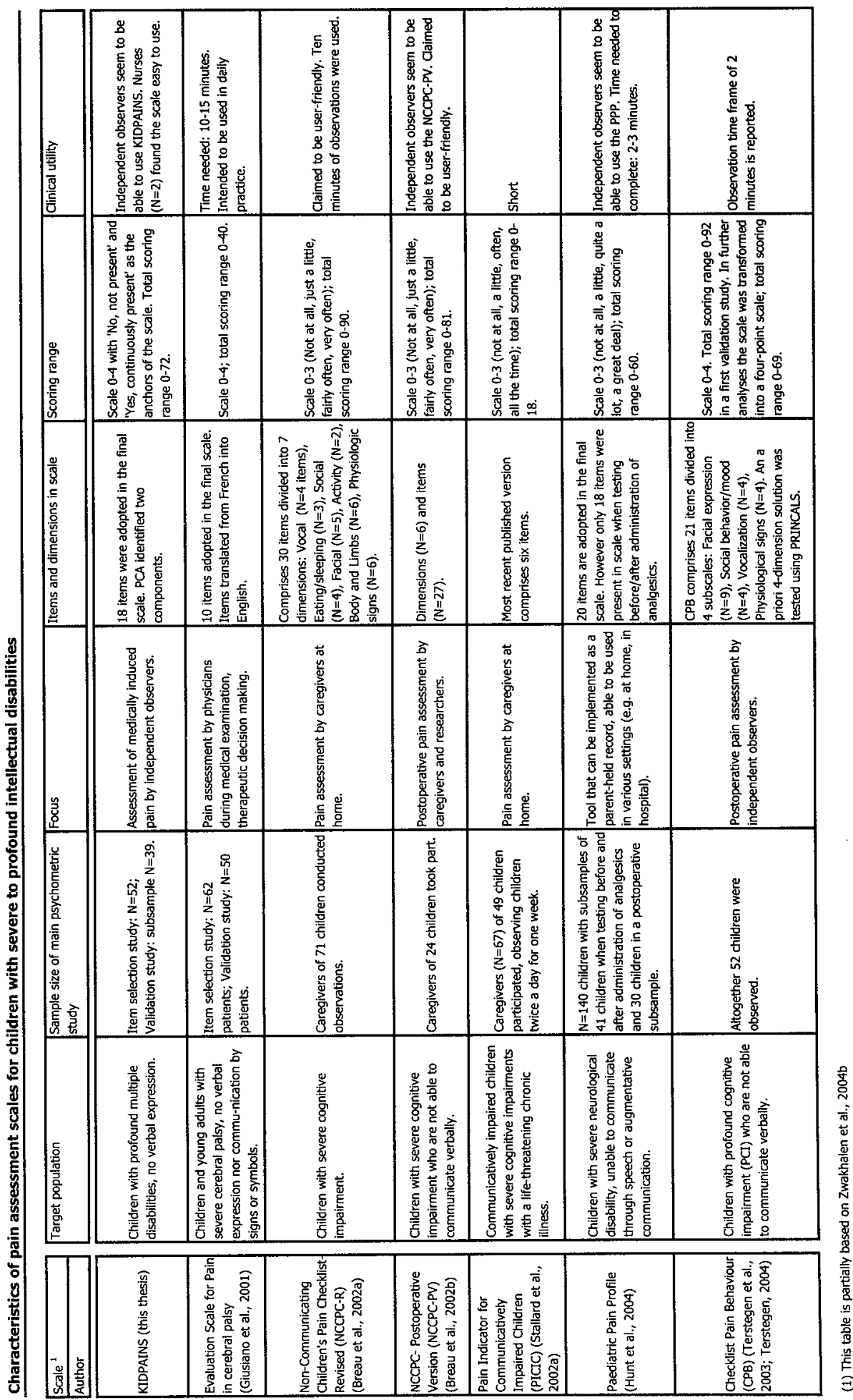




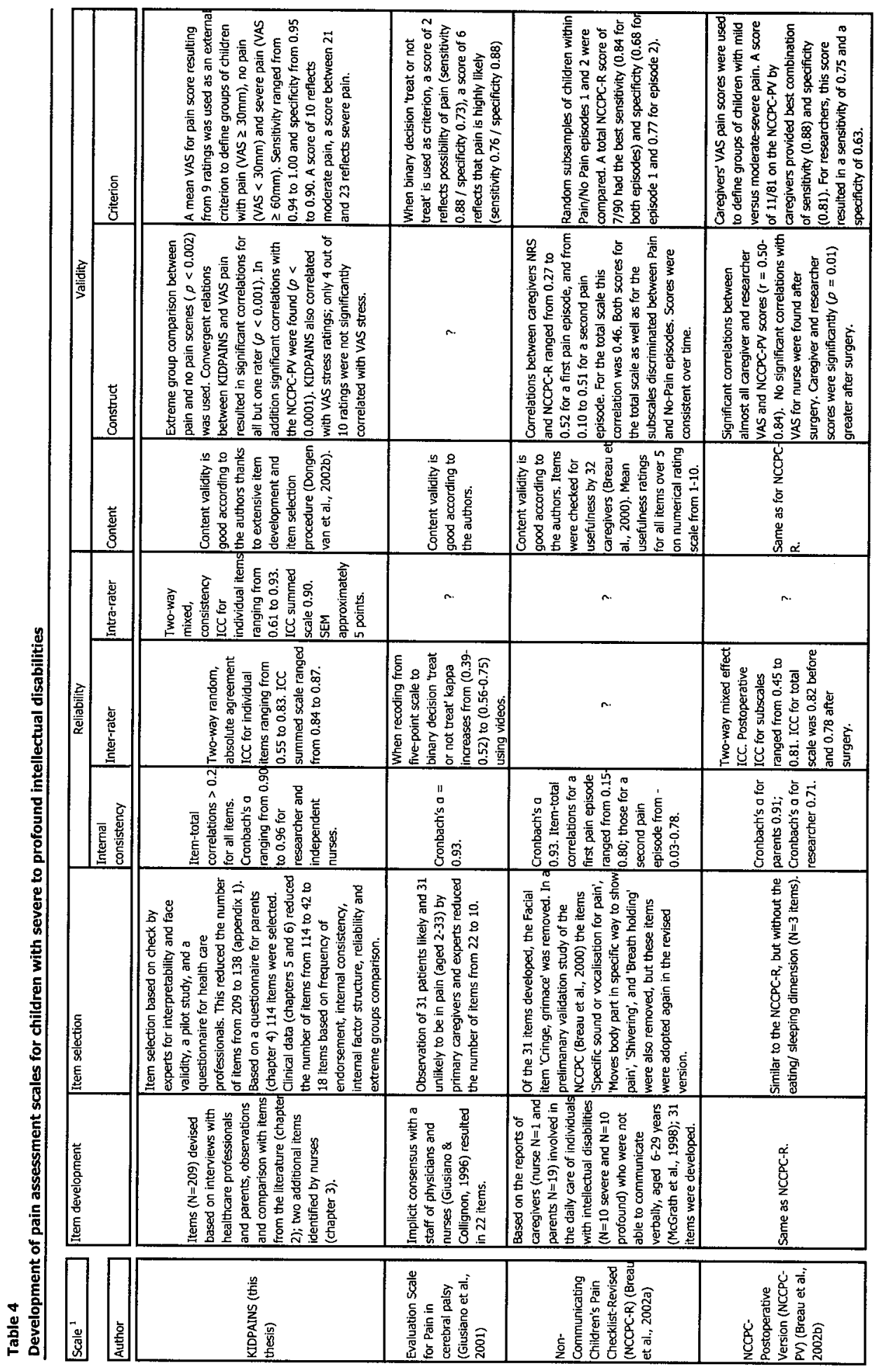




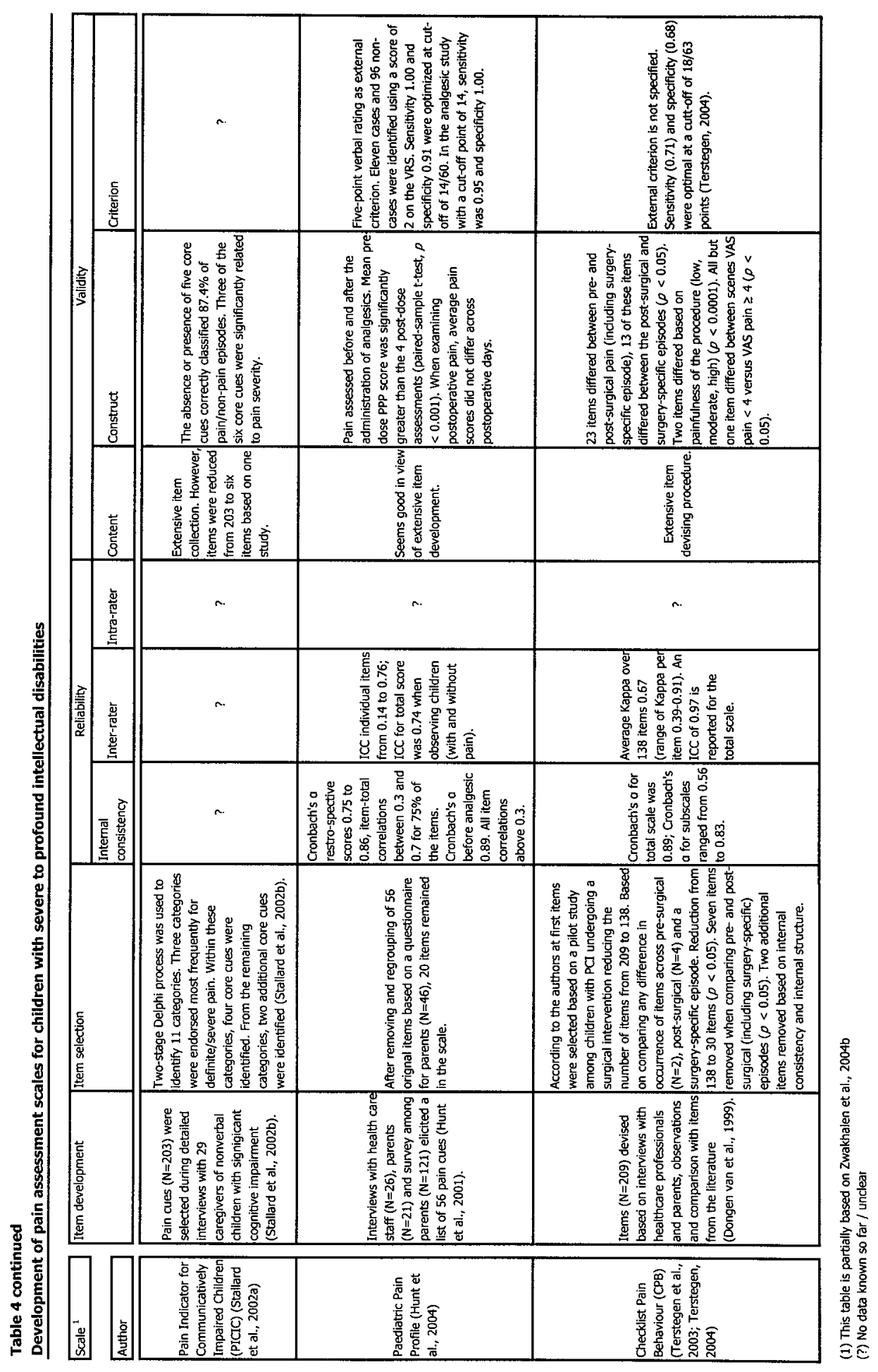


Since most recently developed scales show good psychometric properties, are their item selections also comparable?

Interestingly, when comparing the items adopted in the final version of the scales described in Tables 3 and 4, there are major differences between the item selections, as Table 5 (pages 159-162) shows. Items that are present in most item selections relate, for instance, to grimacing, crying, moaning and increased muscle tone. However, some authors regard moaning and screaming as one item (Hunt et al., 2004; Stallard et al., 2002a), whereas others make a distinction between moaning and screaming (Breau et al., 2002).

As described in the present dissertation, the item 'High muscle tone, cramping' was removed from the KIDPAINS item selection based on low inter-rater reliability (Chapter 6). Other authors did not discard this item from their item selection. A comparison of item selections indicates that there is more overlap between scales that were initially developed for use by parents at home, such as the NCCPC-R and the PPP. These selections include, for instance, items relating to eating and sleeping. In addition, the number of items relating to the injured body part included in the scales by Giusiano et al. (2001), Breau et al. (2002) and Hunt et al. (2004) may be related to the motor abilities of their populations. Items such as Floppy' (Breau et al., 2004) and 'Bit self or banged bead' (Hunt et al., 2004) were only part of the final item selection of a single scale.

\section{Are the items in KIDPAINS greatly different from those in other non-verbal paediatric populations like neonates?}

The short answer to this question is no, they are not. A look at the 18 items ultimately included in KIDPAINS shows that 13 items had also been adopted from the literature on other non-verbal paediatric populations like neonates, as presented in the General introduction to this dissertation (Chapter 1). These 13 items are: 'Grimacing' (Pokela, 1994; Mills, 1996; Ambuel et al., 1992; Lawrence et al, 1993; Lin \& Sentivany, 1994; Krechel \& Bildner, 1995; Bell, 1996), Looking sad' (Mills, 1996), Frowning eyebrows, forebead' (Grunau \& Craig, 1987, 1990; Horgan \& Choonarah, 1996; Mills, 1996; Lawrence et al., 1993; Krechel \& Bildner, 1995; Stevens et al., 1996; Bell, 1996), 'Naso-labial furrow deepened' (Grunau \& Craig, 1987, 1990); Krechel \& Bildner, 1995; Stevens et al., 1996; Bell, 1996), Restless movements' (Barrier et al., 1989; Pokela, 1994; Horgan \& Choonarah, 1996; Ambuel et al., 1992; Bell, 1996), 'Agitation'; Restlessness' (Horgan \& Choonarah, 1996; Ambuel et al., 1992; Lawrence et al., 1993; Bell, 1996), Inconsolable' (Pokela, 1994; Mills, 1996; Krechel \& Bildner, 1995; Bell, 1996), 'Panicky' (Ambuel et al., 1992), Resistance, mutinous behaviour' (Craig et al., 1993; Pokela, 1994; Mills, 1996; Wielenga, 1994; Bell, 1996), 'Crying loudly, intensely' (Lawrence et al., 1993; Wielenga, 1994; Bell, 1996), 'Moaning, groaning' (Mills, 1996; Lawrence et al., 1993; Lin \& Sentivany, 1994; Krechel \& Bildner, 1995; Bell, 1996; Chambers et al., 1996), Irregular, jerky respiration' (Lawrence et al., 1993; Wielenga, 1994; Bell, 1996). 


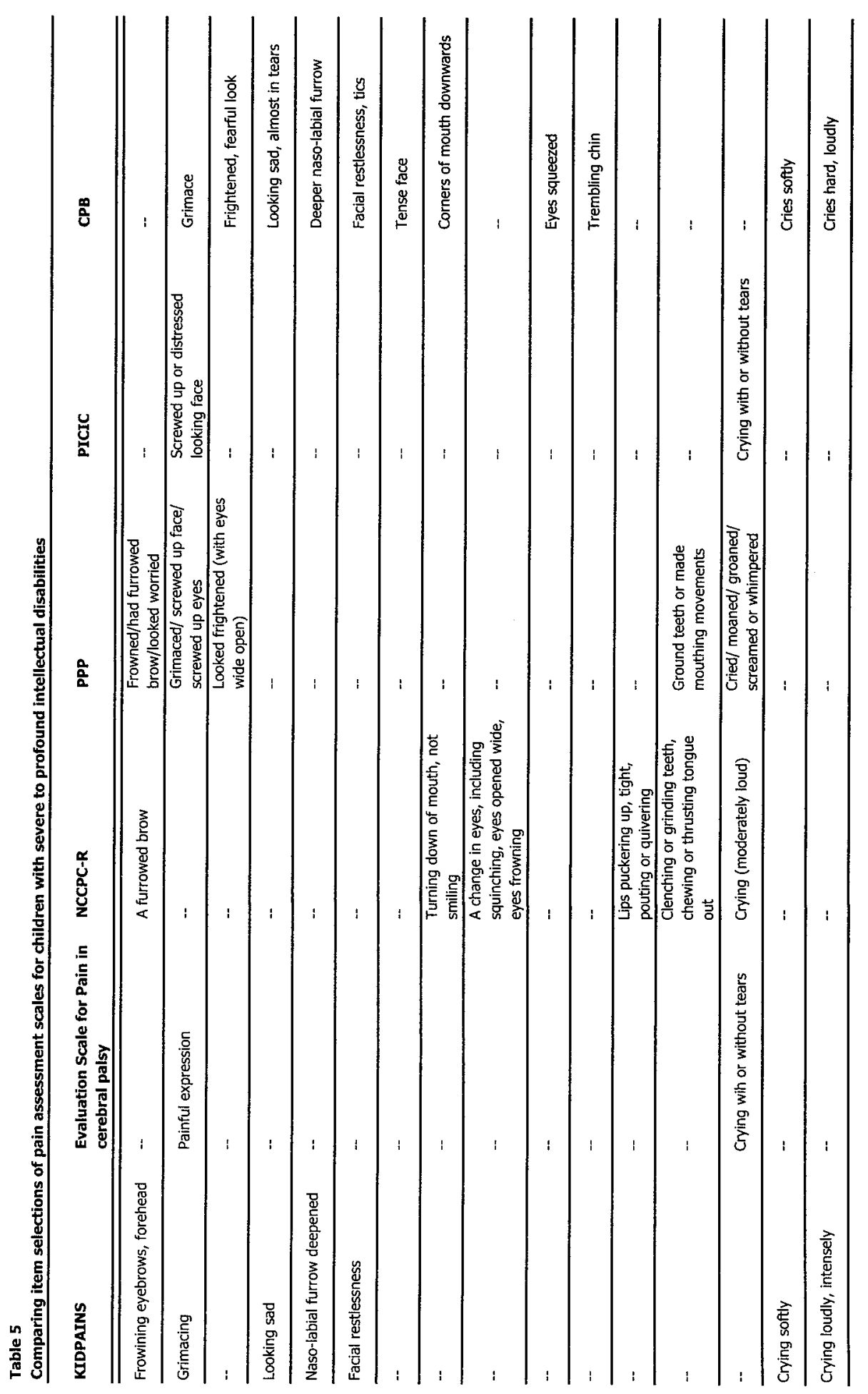




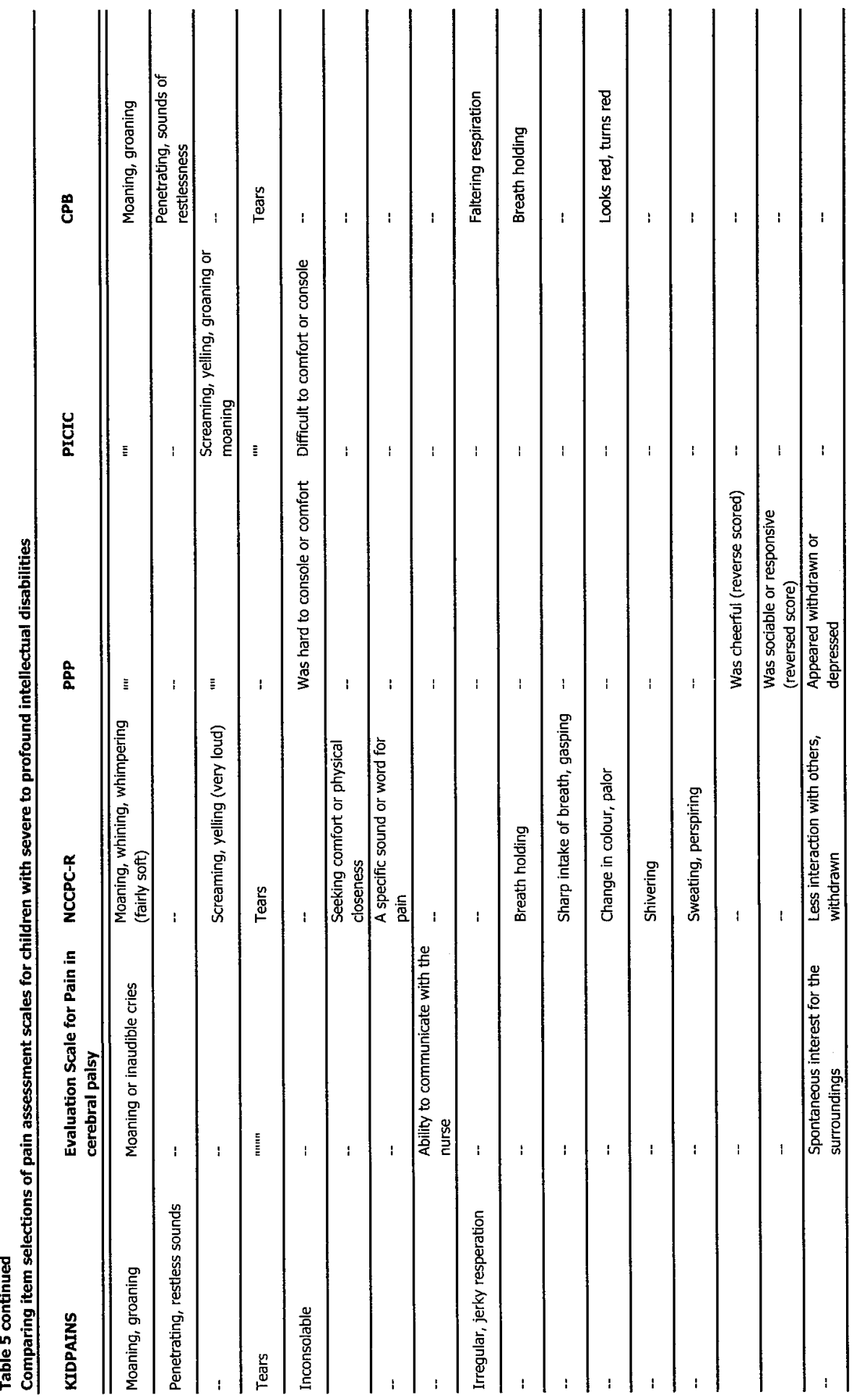




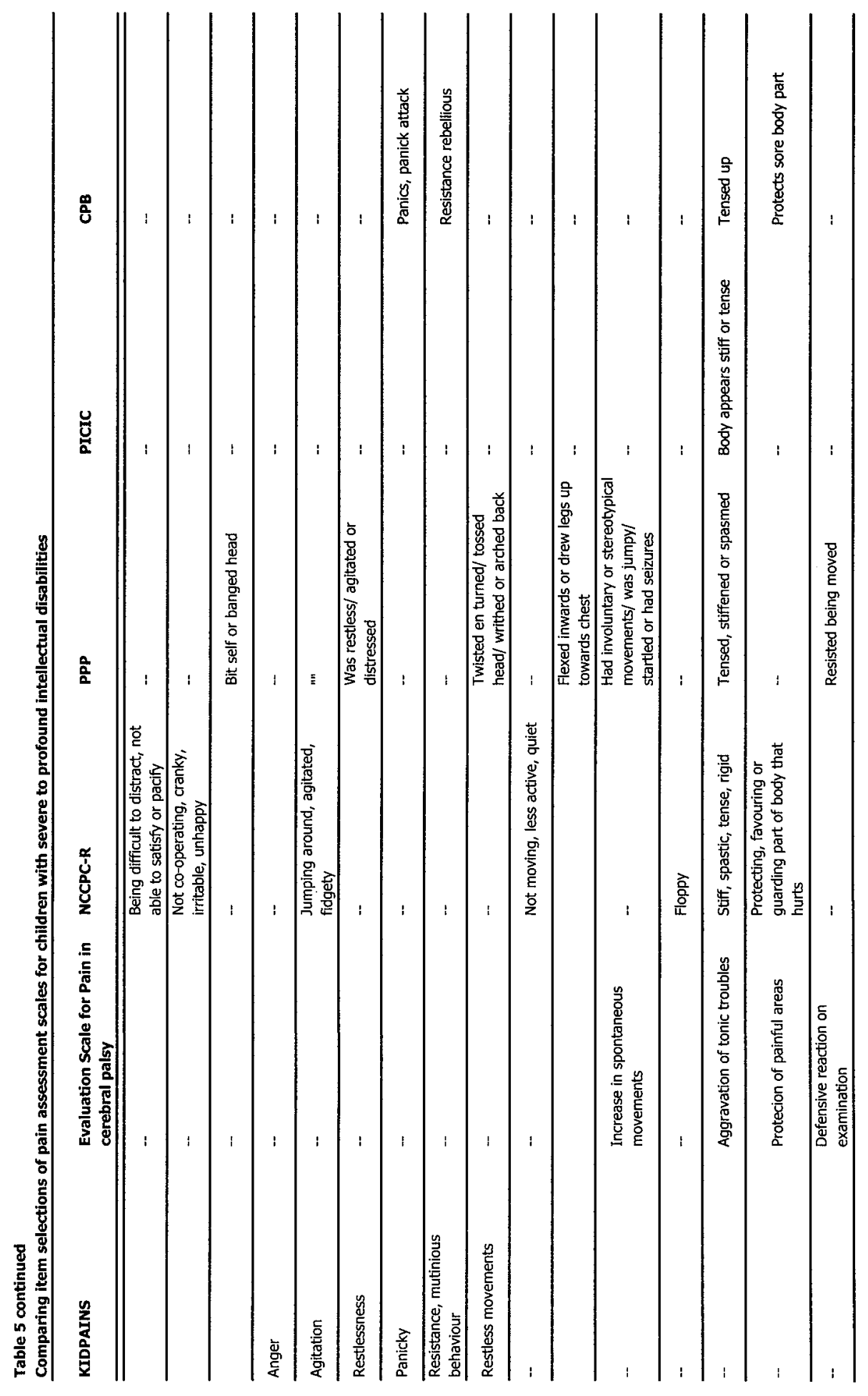




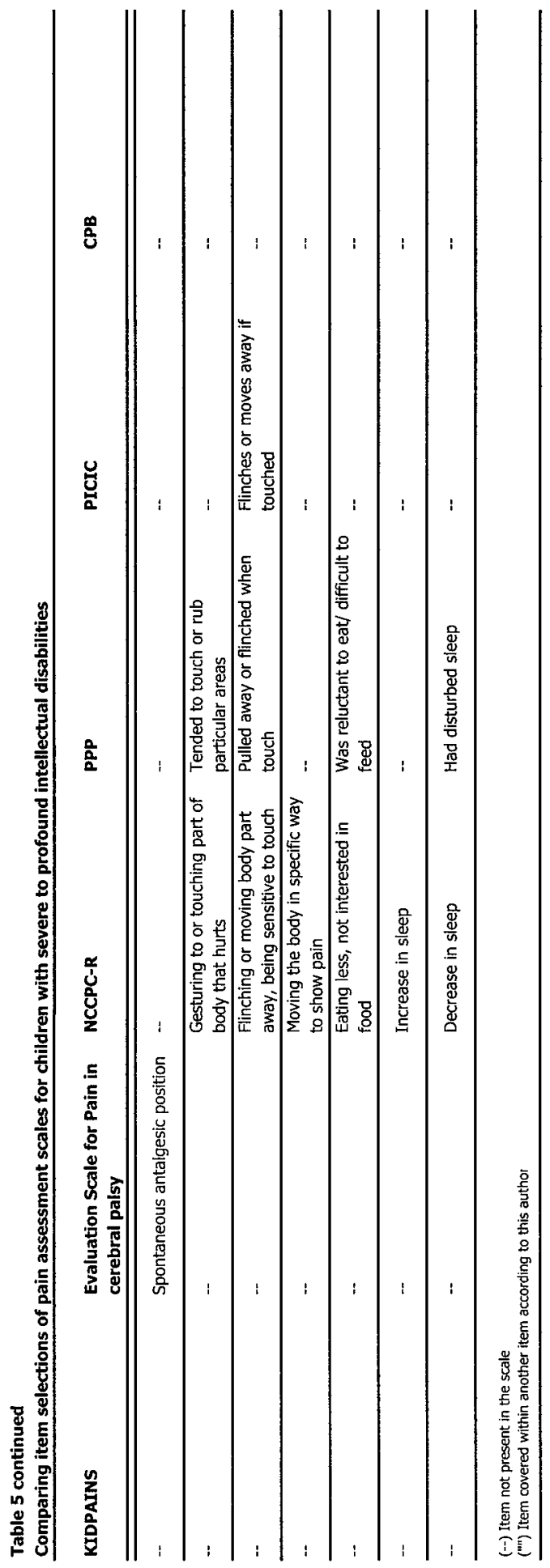


Although the item 'Tears' was also adopted from the literature, this item was only found in the item selection for the Non Communicating Children's Pain Checklist for children with cognitive impairment (McGrath et al., 1998). Appendices 1 and 2 show that the final item selection for KIDPAINS comprises four items that had not been adopted from the literature: Penetrating, restless sounds', Facial restlessness', 'Anger' and 'Crying softly'. However, common sense suggests that at least the items 'Crying softly', 'Anger' and 'Tears' could also be observed in children without intellectual disability. A study by Terstegen et al. (2004) found that the expressions 'Crying softly', 'Penetrating, restless sounds' and Facial restlessness' differed post-surgically between children with and those without intellectual disability. The final two of these items were not present at all in children without intellectual disability, indicating that they might be specific to people with intellectual disabilities. Other items in the study by Terstegen (2004) that did not explain any of the variance in normally developed children were 'Chin quivering' and Looking anxious'. Both items, however, were derived from scales for children without intellectual disability (see Table 1 on pages 18-19 in the General introduction to the present dissertation). Thus, a comparison of some of the items in KIDPAINS for children with and without intellectual disability does show differences. According to the author (Terstegen, 2004) results need replication in light of the small sample size.

What is the added value of KIDPAINS, since the final item selection comprises so many 'common' expressions?

Firstly, 'common' expressions mentioned in the previous question were selected from a long and diverse list. We examined all the newly devised expressions we had initially collected, and asked both healthcare professionals and parents to identify relevant items. The results indicate that the children we studied displayed idiosyncratic expressive pain behaviours as well. Thus uncommon expressions of pain are both present in, and important for individual children. As Velthausz (1992) stated, the social and communicative behaviour of individuals with profound intellectual disability is both fundamentally different from and, in other aspects, comparable to the social and communicative behaviour of non-disabled individuals. Van der Maat (1992) also indicated that communicative behaviours used by individuals with profound intellectual disabilities are both unusual and expected. This is exactly what we found for expressive pain behaviour in the research discussed in the present dissertation. However, only by carefully collecting and investigating the whole variety of items we were able to identify the shared expressions. This knowledge is the added value of KIDPAINS. Moreover, we know that for the individual child the items present in KIDPAINS do not necessarily fully cover the behavioural repertoire of the individual child. We therefore strongly recommend investigating the possibilities for developing an Individual Pain Profile tailored to the individual child (Dongen van et al., 2000) and thus allowing for idiosyncratic behavioural expressions of pain. The item bank 
created in our research provides a good starting point for the development of such a scale.

\section{Is crying an expression of pain or distress?}

Although parents describe vocalisations of their intellectually disabled children in pain as being qualitatively different from cries associated with distress (Carter et al., 2002), the role of vocal expressions, especially crying and moaning or groaning, still seems ambiguous. Based on the results of our questionnaire for parents (Chapter 4), the items 'Crying softly', 'Crying loudly' and, Tears' were discarded because of low item-total correlations $(<0.02)$ with other vocal expressions. The results of our PCA (Chapter 6) clearly show that both 'Moaning, groaning' and 'Crying loudly' load on both components we identified. It seems clear therefore that crying is somehow a problematic expression. Stallard and colleagues (2002a) showed that 'Crying with or without tears' was not related to pain severity and concluded that it might be a general indicator of distress in a population of non-verbal children with cognitive impairment. Other authors have generally reported crying to be a warning signal (Craig \& Gruneau, 1994). In our research we found that, although the first of the two facial components in Chapter 5 correlated more closely with VAS-Video, both facial components correlated significantly with the vocal component(s). This finding might support the conclusion by Stallard and colleagues (2002a) that vocal expressions are also present in distressing situations. Similarly, Hamers and colleagues (1996) found that paediatric nurses in a paediatric postoperative pain context allocated higher pain intensity ratings to children who expressed their pain vocally.

\section{Can pain be differentiated from anxiety and stress?}

This question is difficult to answer. Our Chapter 5 identified the possible existence of a component relating to 'Facial features expressing anxiety or distress'. In line with these findings, Kappesser \& Williams (2002) found a fear-face and a pain-face to be two extremes on the same axis, which might be explained by vertical versus centrifugal changes in the face. The existence of such an anxiety or stress face in children with profound intellectual disabilities could have been a possibility. To further explore the difference between pain, anxiety and stress, we included VAS ratings for these three constructs in Chapter 6 . The analysis, however, resulted in all but one of the items relating to the second facial component being removed. Furthermore, Chapter 6 found that a global VAS rating to measure anxiety was not reliable, whereas a global VAS rating to measure stress did result in satisfactory agreement between observers. Correlating both of the components identified in Chapter 6 with VAS stress and VAS pain shows that the Facial and Vocal items correlate more strongly with VAS pain, while the second component, comprising items relating to unrest and emotional disturbance, showed slightly higher correlations with VAS stress. This finding did, however, vary between observers. This means that one observer might base his judgement about pain or stress on the 
existence of other behaviours than another observer. Overall, both VAS pain and VAS stress ratings significantly correlated with KIDPAINS, indicating that the distinction between pain and stress is not straightforward and needs further investigation.

\subsection{Methodological reflections}

Was it appropriate to limit the original research population to non-verbal children with profound multiple disabilities?

Initially, the focus of the research on which the present dissertation is based was on children with severe as well as those with profound intellectual disabilities. This is also the reason why we originally set out to collect all expressive pain behaviours possible for this group. Later, it was decided to shift to medically induced procedural/ postoperative pain in a hospital setting. At that stage, it became evident that it was mostly non-verbal children with profound intellectual disabilities who were admitted to hospital. Even more importantly, the results of the questionnaire for parents showed that there seemed to be a difference in pain behaviour between children with and those without the ability to express themselves verbally. For this reason, it was decided to limit the study population to non-verbal children with profound intellectual disabilities. Even though this meant that the total number of children who could be included in the analyses was smaller, these children made up a more homogenous population, which meant that non-relevant items that only contribute noise could be eliminated. Thus the research process took the shape of a funnel. After the first clinical item selection study (Chapter 5) it was decided to further limit the research population for the psychometric evaluation of KIDPAINS to children with profound multiple disabilities. Hence, only children with profound intellectual and motor disabilities were included in Chapter 6 . Since children in our clinical study suffered little pain according to the various VAS ratings (Chapter 5), children with equivocal diagnoses had to be eliminated from the analysis comparing cases with non-cases. Otherwise it would remain unclear whether the differences found were based on the pain or were caused by other factors (Streiner \& Norman, 1998). However this further limited the sample size of this study population.

The question thus remains whether we were right to restrict the population under investigation in this way. When applying the post-operative version of the NonCommunicating Children's Pain Checklist in Chapter 6 to children with profound multiple disabilities, it was found that the average score for children assumed to have no pain on the NCCPC-PV was 7 on a scale of $0-81$, whereas the two raters found maximum scores of 33 and 30 for children with presumed pain, and average scores of 19 and 16. In view of the cut-off point that was identified (11) and the scoring range of the NCCPC-PV, it seems that the identified non-cases received 
relatively high ratings on the NCCPC-PV, whereas children with presumed pain received relatively low ratings. When comparing this result with the maximum scores for KIDPAINS, which were 53 and 42 for children with presumed pain and 4 and 3 for children without pain, it seems that there might be a risk of falsely labelling children with profound multiple disabilities when using a scale that was developed for a broader group of children. This poses an important question. Although most scales that have been developed focus on both children with severe and those with profound intellectual disability, the assumption that all these children's pain should be assessed with a tool comprising items that are either not relevant or that are continuously relevant for some part of the population is open to doubt and needs further investigation.

\section{Why did we collect new items when there were so many expressions available in} the literature?

When the research for the present dissertation started, very little was known about pain in children with intellectual disabilities. At that stage only the paper describing the initial scale construction of Giusiano and colleagues (1996) had been published. Since the 'normal' behaviour of children with an intellectual disability is different from the 'normal' behaviour of children without an intellectual disability, items that were to be found in the literature on non-verbal paediatric populations were not sufficient. It was necessary to ensure that all possible behavioural expressions of pain would be detected, in order to decide if the item selection of Giusiano and colleagues was comprehensive enough. Thus, great emphasis was placed on devising the items. As Van Dijk (2001) states, it is useless to develop new pain instruments unless new indicators for pain are added. Since this was indeed the case after Chapter 2, we continued to develop our scale.

Why did we develop a pain assessment scale when other authors had already made attempts to do so?

At the onset of the research that forms the basis of the present dissertation, one study was identified that presented a list with 22 items indicative of pain in people with cerebral palsy (Giusiano \& Collignon, 1996). Somewhat later, the checklist of $\mathrm{McGrath}$ et al. (1998) was published, the first version of the NCCPC. Both were preliminary attempts to develop a scale, with, at that stage, only limited identified psychometric properties. The authors either focused on only some of the children with intellectual disabilities (i.e., those with cerebral palsy), or collected the items for their scale on the basis of 20 individual children only. This number of children seemed insufficient in view of the heterogeneous nature of the population under investigation. Furthermore, the communication literature indicated that more behavioural expressions could be present. We therefore felt it necessary to proceed with devising items and to compare those identified in a qualitative study with items used in the literature. Because of the nature of the measurement scales being developed in this area, it seemed important to invest in a solid foundation. In view 
of the number of additional items collected, we continued developing our scale. A look at the differences in design and focus of the various scales developed over the past years (see Tables 3 and 4) indicates that each scale has provided its own contribution to the body of knowledge. In view of the new research domain of children with intellectual disabilities, and the differences between the scales, it is our opinion that one scale would not have been enough; all the developed scales are valuable. Now that we know so much more about pain assessment in children with severe intellectual disabilities, however, it seems unnecessary to undertake new attempts to develop pain items and pain assessment scales for this specific paediatric population. The emphasis should rather be on further psychometric evaluation of the existing generic scales in various sub-samples of children.

Item devising, testing for interpretability, face and content validity, initial item selections; why did the developmental process involve so many steps? A major challenge in the field of pain assessment is the discovery of the necessary and sufficient indices of pain (Hadjistavropoulos \& Craig, 2002). Our goal was to invest in item devising and basic testing of the items in order to create a solid foundation for the KIDPAINS instrument. As Velthausz (1987) points out, the content of the behavioural checklists used to observe behaviour to a large extent determines what is actually being observed. How the elements of a pain measure are selected is rarely reported, particularly with pain measurements for children Johnston, 1998). Item devising however, is a far from trivial task and "no amount of statistical manipulation after the fact can compensate for poorly chosen questions; those that are badly worded, ambiguous, irrelevant, or - even worse - not present" (Streiner \& Norman, 1998). Item devising as well as testing for basic psychometric properties was therefore an essential part in the developmental process of KIDPAINS. Key informant interviews, clinical observations and indicators derived from the literature were used to develop the items in the scale underlying KIDPAINS. We wanted to run as little risk as possible of missing expressive behaviours that could be of importance.

Overall, many different steps were taken to ensure the quality of the draft scale, which even meant making observations with all of the 138 selected items. We believe this careful process was especially important since children are at high risk of undergoing painful procedures throughout their lives. The consequence of this approach, however, was the creation of a large number of detailed descriptions. When obsetving at a detailed, molecular level, the variability of behaviour becomes larger. This is, however, a fundamental characteristic of behaviour (Altman, 1965). Although it was ultimately proven that the children in the population under investigation do show important similarities in behavioural repertoires, it was also found that the assessment of pain in these children should not be limited to the similarities identified at the onset of the research. We would not have known this if we had not taken all these steps. Furthermore, although the final psychometric 
testing took place in only a limited part of the original target population, a sound body of knowledge has now been provided for further scale development in different groups of children as well as individual children. We believe that the studies presented in the present dissertation can serve as a starting point for other scales to be psychometrically tested in children with severe to profound intellectual disabilities.

\section{Why did we not reduce the number of items at an earlier stage?}

A comparison of the results of the various studies discussed in the present dissertation shows that several behavioural expressions were found to occur frequently, or were found to be relevant or important in all studies. Now that the final item selection for KIDPAINS has been established, it could be said with hindsight that the number of expressions could have been reduced for instance on the basis of what parents reported to be the most frequently occurring items. However, although parents turned out to be good predictors of their child's behaviour, little was known about parents' predictions of their intellectually disabled children's pain behaviour at the start of our research. In addition, the literature on paediatric pain research shows that parents do not always have the reputation of being good proxies of their child's pain (Goodenough et al., 2000; Chambers et al., 1998; Kelly et al., 2002). Finally, even if parents and caregivers report that a behavioural expression of pain is often present when a child is in pain, this does not necessarily mean that this type of behaviour will actually be present, or observed, in a clinical situation. Comparable findings, however, do validate the item selection for KIDPAINS.

\section{Is the intervention-specific episode comparable with other episodes?}

The item selection process using videos of children undergoing medically induced pain was carried out for different time episodes (Chapter 5). Whereas it was found that item selections for the procedural/ postoperative measurements $(N=3)$ were comparable, the acute pain episode seemed to result to some extent in different expressions. At that stage it was unclear whether this finding was caused by the intervention-specific episode being a more pain-inducing moment, or by the intervention-specific episode being conceptually different. In Chapter 6 it was found that there was no relation between scores on KIDPAINS and the origin of an observation (eta correlation 0.02-0.24). Some items, however, which seemed to differ between the two types of episodes in Chapter 5, were removed in Chapter 6 .

\section{What other variables should have been measured?}

With hindsight, the most important element that was missing from our studies is that we should have used different ways to investigate muscle tone. Although muscle tone seems important for diagnosing pain in children with severe multiple disabilities, the item 'High muscle tone, cramping, spastic' was not selected because of the low intra-class correlation (0.26) between researcher and nurses (Chapter 6). 
Since other authors have also reported on difficulties in observing muscle tone (Hunt et al., 2003), it seems important for future studies to use other methods than just observation to investigate the role of muscle tone.

Since both the literature (Breau et al., 2002a,b; Stallard et al., 2002a; Terstegen et al., 2003) and the data presented in the present dissertation show that facial expression is important for diagnosing pain in children with severe intellectual disabilities, future studies might use scales focussing on facial expression only, such as the Child Facial Coding System (Chambers et al., 1996b).

Finally, scales to evaluate functional abilities of children with profound multiple disabilities, such as the Gedrags'TaxatieInstrument (Vlaskamp et al., 2002), could be used to gain more insight into the normal behaviour of the children.

Is VAS pain an adequate tool for establishing criterion validity, since there is no gold standard available?

Although no gold standard is available for pain measurement, 'silver standards' are often used Johnston, 1998). Van Dijk (2001) found that an observational VAS score could serve as an indication of a child's pain. However, studies of children with intellectual disability have not yet yielded a great deal of information about the psychometric properties of the observational VAS. The research discussed in the present dissertation used a mean VAS rating by nine different observers as a silver standard. We feel that such an average VAS rating might at least approximate the impression 'others' have of a child's pain. It seems insufficient, however, to use a VAS pain rating by only one researcher as a silver standard. Chapter 5 showed that the use of a VAS does not always result in a satisfactory level of agreement about children's pain. Chapter 6 found acceptable agreement (ICC 0.63) for VAS pain when comparing ratings of raters familiar with the research process and those unfamiliar with a child. However, agreement on VAS was lower than the agreement on KIDPAINS itself. This might be explained by the fact that observers provide a VAS rating based on their own judgment, rather than being 'forced' to provide ratings for a set of objective items. Thus, further research is needed to determine the appropriateness of VAS as a criterion.

\section{Did we use the correct statistical methods?}

The first statistical method used that could be called into question is the Principal Components Analysis, especially in view of the small sample size and the large number of items in the scale. However, PCA was used merely as a means of exploring the data (Chapter 5) as well as to provide more in-depth information regarding the underlying factor structure (Chapter 5 and 6). No items were removed on the basis of PCA alone. Furthermore, stringent PCA criteria were used for MSA values, factor loading etc. Most importantly, the results of PCA 
made sense. We therefore feel that its use was adequate. Especially since its use resulted in similar item selections for different episodes (Chapter 5).

Another question that must be addressed as regards item selection is whether the removal of a large number of items based on internal consistency analyses (Chapter 5) was appropriate, in view of the risk of losing content validity (Streiner \& Norman, 1996). First of all, this procedure was not applied to the total scale including all items in the analysis, but to the items of the various individual dimensions (Chapter 5). Hence, we removed only items with low item-total correlations within a dimension, or items that led to a significant improvement in $\alpha$. Furthermore, we feel that the heterogeneity of items is partly related to the variety of sub-samples within the population under investigation, rather than to the trait (pain behaviour) itself. Hence, those items that were not related to pain for the majority of children had to be removed. Rather strict Bonferroni corrections were used for all statistical tests, which was necessary because of the large numbers of tests employed. Finally, besides $p$-values we also report confidence intervals in order to provide observed differences between groups.

\section{What could have been done differently?}

In future studies it would be important to investigate children on the basis of a clearer distinction between painful and non-painful conditions. Fortunately, pain in children is currently being more actively treated, especially in children's hospitals. Although the standardised episodes selected for the present study did induce pain, 'only' 55 of the 233 presumed pain episodes, relating to 33 children, yielded observations with a VAS-video score $\geq 30 \mathrm{~mm}$ (Chapter 5). Thirty-six percent of these observations were made during the intervention-specific episode. The direct VAS-video scores yielded a slightly larger number of 'pain scenes', namely 73 , relating to 39 children. The relatively small number of children that seemed to be in pain made it difficult to test the construct validity for standardised time episodes. In our clinical study (Chapter 5) of a large number of children it was of course questionable whether they suffered from pain. Instead of observing at standardised time episodes, observations could have been made before and after the administration of analgesics. Thus, it is debatable whether the appropriate time episodes were selected. In addition, it would have been more informative to include at least two intervention-specific episodes, since this seemed to be by far the most pain-inducing moment.

When investigating pain in a group of children that makes up only a small percentage of the general population, it is questionable whether a children's hospital should serve as the only place to recruit subjects. Altogether, it took us three years of data collection to investigate 76 children, 52 of which were profoundly intellectually disabled. The item selection based on clinical data (Chapter 5) however could only take place when the data collection had been 
completed. In addition when developing scales for future subgroups of children, we now know that we can use parents and health care professionals as a source for earlier item selection. As it turned out, the final item selection for KIDPAINS was highly comparable with data provided by these two groups (see Table 1, pages 143146).

A limitation of the present research was that no direct observations were made using KIDPAINS. This may, for instance, have influenced observations of physiological items like those relating to skin colour, muscle tone or breathing. At the same time, however, video-recordings are a good starting point for investigating basic psychometric properties, capturing data that would otherwise have been lost. It is particularly in a group of children as unique as those with profound multiple disabilities that it is important to be able to consult the raw data again.

\subsection{Recommendations for further research and implications for practice}

Psychometric evaluations are never complete. Validating a scale is a process whereby we determine the degree of confidence we can place on inferences we make about people based on their scores on that scale (Streiner \& Norman, 1996). Although we have come a long way, a great deal of work still needs to be done. If a scale measures a hypothetical construct, such as pain, the validation task is an ongoing one (Streiner \& Norman, 1996). Further testing for reliability, construct and criterion validity in different (larger) samples in different settings and in different groups of children should be undertaken. Harsher methods, such as Bland and Altman's limits of agreement, should be used to investigate reliability (Bland \& Altman, 1986). This is important in view of the relatively large measurement errot (approximately 5 points) we found. In addition, live observations will have to be made instead of using videos only.

Although most scales that have been developed focus on both children with severe and those with profound intellectual disability, the assumption that all these children's pain should be assessed with a tool comprising items that are either not relevant or that are continuously relevant for some part of the population is open to doubt. In general, we feel future research should focus on the expressions shared between all children with severe to profound intellectual disabilities. We feel that most of the 18 expressions included in KIDPAINS might be relevant to children other than those with profound multiple disabilities only (see Table 1). However, this hypothesis awaits confirmation. Our scale, which was developed in a bottom-up approach, reducing the research population as well as the items as in a funnel, can now be investigated using a top-down approach, since information relating to the various sub-samples of the present research indicates that shared 
expressions seem to be present for all children with severe to profound intellectual disabilities. It remains unclear whether these items are also applicable to children with mild and moderate intellectual disability. This would therefore also be an important subject of further research.

The possibility of adding subscales relating to, for instance, children with behavioural and emotional disturbances, including e.g. items relating to selfinjurious behaviour, might be worthwhile investigating. The overview of data presented in this dissertation provides an extensive database of expressive pain behaviours for such additional subscales. For children with profound multiple disabilities it is recommended to further investigate the role of muscle tone and the way muscle tone can be judged. Increasing tone seems an important indication that a child with severe multiple disabilities is in pain. However, muscle tone is difficult to reliably assess by observation only. Other paediatric pain assessment scales such as the COMFORT (Ambuel et al., 1992) assess muscle tone by touching, stretching or lifting an arm or leg of a child during the observation period (Dijk van, 2001). Although such a procedure requires baseline knowledge about 'normal' tone, it seems worthwhile investigating other options.

As mentioned earlier, we recommend the psychometric testing of a child-specific pain measure (the Individual Pain Profile), in addition to KIDPAINS. Such a scale would be tailored to the individual child, thus limiting opportunities for psychometric evaluation and generalisability. It would seem useful to make a selection of relevant pain items from our total list of 145 items for each child using the same scaling response used for KIDPAINS. As such, both individual and general expressive pain behaviours can be studied by those who have to evaluate a child's pain. This would be especially important for children with limited behavioural repertoires. Our data suggest that children with the least abilities to express themselves received the lowest scores on KIDPAINS (Chapter 6). For these children any additional information is valuable. In addition our data (Chapter 6) suggest that most items are absent, or nearly absent, when children do not seem to be in pain, it is recommended to record a child's behaviour at baseline, when he or she is not in pain. If these baseline measurements come close to the identified cut-off point for KIDPAINS, one has to be cautious with the measurement.

Another important research topic is the feasibility of using KIDPAINS in everyday practice. Although the nurses in Chapter 6 found the scale feasible for use in their routine work environment, it would be important to scientifically examine the feasibility of KIDPAINS in an every day setting where the scale might be further tested or used.

Finally, in the present dissertation we focussed on pain assessment in a situation where it is likely that a child is experiencing pain. Although this is an important and 
logical first step in the development of pain assessment methods, in everyday practice it is mostly not very clear whether a child with profound multiple disabilities has been exposed to a noxious stimulus. As Brinker \& Golbart (1981) state: "The problem is not a confusion in assigning behavioural codes once you know what has bappened. The problem seems to be generating the script for what bappened". When generating such a script, it is important to focus not only on possible behavioural expressions of pain, but also on the context in which this behaviour occurs. The situational context is a determining factor in giving meaning to behaviour. In everyday practice, caregivers must be continuously aware of the individual child's pain behaviour in order to be aware of the possibility that a child is in pain, especially since everyday pain is common in this group of children. As Turk \& Melzack (2001) stated: "The development of pain assessment instruments and procedures that have appropriate psychometric properties is necessary but not sufficient. Given the complexities inherent in the construct of subjective pain, there is a need to obtain a diversity of assessment information that must then be integrated to understand the patient's pain and to contribute to treatment decision-making". In the case of children with severe intellectual disabilities, it is important that the child's personal record provides information about pain behaviour, and that this is regularly updated. An individual pain record for each child seems valuable in everyday practice. Thus when testing KIDPAINS in a child's normal living situation, the tool has to be adapted and supplemented with such a record. Such a 'pain detection record' should however include a valid and reliable pain assessment scale such as KIDPAINS.

Evidence-based nursing practice is becoming increasingly important, and psychometrically sound, robust scales play an important part in this process (Rycroft et al., 2002). Finding ways to deliver care based on the best possible evidence remains however an ongoing challenge. Successful implementation of research into practice is influenced by the context into which the research is to be placed, and the method in which this process is facilitated (Cox \& Titchen, 2003). Thus, as the mother in the quotation in the opening of this dissertation stated, children are still very much dependent on their caregivers to observe, interpret and, most importantly, act to prevent, diagnose and manage pain. The present dissertation however has provided professional caregivers with a robust tool to act on pain: KIDPAINS. 



\section{Appendix I}

Items for KIDPAINS were devised based on interviews among health care professionals and parents, observations and a comparison with items from the literature. A back-translation procedure was used for items derived from English scales (Chapter 2). This resulted in an item bank comprising 209 expressions. Based on a study among nurses (Chapter 3), two items were added to the item bank. Four experts then checked the items for interpretability, judging aspects like reading level, ambiguity, use of jargon and possible overlap. When all four experts commented unfavourably on an item, it was removed (Appendix I; code 1a). This represented an initial item selection. Modified items (Appendix I, code $1 \mathrm{~b}$ ) as well as other remaining items were used in a pilot study to test their applicability in a hospital environment, using a draft scale developed for this purpose. Based on the results, further adjustment of the items took place (Appendix I, code 2b) and several items were removed from the selection of the draft scale (Appendix I, code 2a). This led to all items relating to the Activities of Daily Living dimension being removed, and to five new items being added to the draft scale. Items were further tested for content validity and interpretability among health care professionals attending a symposium on people with intellectual disabilities (Koot et al., 2000). They were asked to describe to what extent an item was useful (not, a little, definitely) as an expression of pain (Chapter 7). Based on the opinion of the health care professionals several items from the draft scale were removed (Appendix I, code 3a) or modified (Appendix I, code 3b). Based on the results at that stage, a draft of the scale was transformed into a questionnaire for parents, including 145 questions (Chapter 4). A final check of the draft scale using videos from the pilot study led to the removal of another seven items (Appendix I, code 4a). 
Appendix I

Item selection and modification

\section{Facial}

Facial expression

Contorted face, cringing, flinching; Facial restlessness

\section{Grimacing}

Facial tension, tight facial muscles

Change in eyes (eyes)

Eyes tightly shut, eye squeeze

Eyes wide open; Eyes suddenly wide open

Little eye movement, no blinking

Looking sad; Looking serious, dejected

Fear, looking anxious, fright reaction face

Open lips

Stretch mouth vertically, ' $O$ ' mouth

Stretch mouth horizontaliy

Lips tightly held, lips tightly shut

Turning down of mouth/ not smiling

Lips pouting, jutting lower lip

Lip pursing

Lips quivering

Tongue protrusion

Taut tongue

Chin quivering

Clenched jaw, clenches teeth

Brow bulge (furrowed), frowning, frowning forehead

Naso-labial furrow (deepened)

Nostrils flaring

Blinking continiously

Eyes slit

Eyes whirling around

Eyes not whirling around

Movement of the eyes

Staring

Mouth

Mouth wry

Contorted mouth

Biting lips

Brow bulge raised

Raising upper lip

Raising cheeks

Contorted skin between nose/ mouth

Wrinkle above nose, raising nose

Stop smiling

Looking angry

Frowning chin

Yawning
Literature ${ }^{1}$ Observations Interviews

Other Code Modification

\begin{tabular}{|c|c|c|c|c|}
\hline $3^{2}$ & -- & 22 & $1 a^{4}$ & \\
\hline $5^{3}$ & -- & 6 & 1b & Split \\
\hline $8^{3}$ & -- & 10 & & \\
\hline 3 & -- & 7 & & \\
\hline $1^{3}$ & -- & 15 & 1a & \\
\hline $7^{3}$ & 6 & 7 & & \\
\hline $2^{3}$ & 3 & 2 & $2 b$ & Split \\
\hline 1 & - & - & $1 \mathrm{a}$ & \\
\hline $2^{3}$ & 2 & 11 & $2 b$ & Split \\
\hline 2 & 1 & 2 & & \\
\hline 2 & - & -- & $2 a$ & \\
\hline 3 & 3 & -- & & \\
\hline $2^{3}$ & .. & 1 & $1 a$ & \\
\hline
\end{tabular}

$1 \mathrm{a}$

$1 \mathrm{a}$

$1 \mathrm{a}$

$1 a$

$1 \mathrm{a}$

$2 a$

$2 a$

ia

-. 2

$\begin{array}{lllll}- & - & - & & \\ & - & - & \text { Nurses }\end{array}$

$\begin{array}{lllll}- & - & - & & \\ - & - & \text { Pilot }\end{array}$

$\begin{array}{lllll}- & - & - & - & \text { Pilot }\end{array}$

\section{Motor}

Literature Observations Interviews

Other Code Modification

Moving body in specific way to show pain, way of movement

Spontaneous motor activity, incessant gros motor movement; Increased involuntary movements

Complex agitation, excitable, jittery, vigorous;

Restlessness; Restless movements, unrest motion

13

-. 4

$$
4
$$

$1 a$

Mild kicking and wiggling

Flailing and thrashing, wild hitting movements,

floundering

Wriggling body movements, writhing, log rolling

Spontaneous excitability

Jerking/starting, jerky movements, hitch in movement pattern

\section{3}

\section{5}

1

6

3

2

2 


\begin{tabular}{|c|c|c|c|c|c|c|}
\hline Motor (continued) & Literature & Observations & Interviews & Other & Code & Modification \\
\hline $\begin{array}{l}\text { Increased involuntary movements; Spontaneous motor } \\
\text { activity }\end{array}$ & $1^{2}$ & -- & 1 & & $2 b^{4}$ & Merged \\
\hline $\begin{array}{l}\text { Repetitive movements, stereotypical movements; Body } \\
\text { roching; Fluttering }\end{array}$ & 1 & -- & 5 & & $2 b$ & Split \\
\hline Decreased movement, limited movement (hardly any) & $5^{3}$ & -- & 7 & & & \\
\hline Arm extended; Legs extended & 2 & 3 & -- & & $2 b$ & Split \\
\hline Arms/ legs rapid extension/ flexion & 1 & -- & -- & & $1 a$ & \\
\hline Arms/ legs (tightly) flexed & 2 & 3 & -- & & $1 a$ & \\
\hline Fingers and toes in rapid extension/ flexion & 1 & -- & -- & & $1 \mathrm{a}$ & \\
\hline Flexion of fingers/ toes, flaring toes, grasping fingers & 5 & -- & -- & & & \\
\hline Spreading fingers; 5preading toes & 3 & -- & -- & & $2 b$ & Split \\
\hline Twitching of fingers and toes & 1 & -- & -- & & $1 a$ & \\
\hline Wringing hands, making fists & 3 & 3 & 4 & & & \\
\hline Arm movements & 2 & -- & -- & & & \\
\hline $\begin{array}{l}\text { Hand movements; Foot movements; rotation of wrist, } \\
\text { flexion, extension }\end{array}$ & 1 & -- & -- & & $2 b$ & Split \\
\hline Feet pointed downward and held stifly (extending) & 1 & 1 & -- & & $1 b$ & Transformed \\
\hline Feet turned upwards at sharp angle to leg & 1 & -- & - & & $1 b$ & Transformed \\
\hline Leg movements & 2 & -- & - & & & \\
\hline Knees drawn up, pull up legs & 1 & 6 & 4 & & & \\
\hline Head movements; Restless movement with head & 1 & 4 & 3 & & $2 b$ & Split \\
\hline Neck flexion/ extension, chin down onto chest & 2 & 5 & 2 & & & \\
\hline Head turn, turn away face & 1 & - & 1 & & & \\
\hline Torso movements & 3 & -- & -- & & & \\
\hline Evaluation of muscle tone & $5^{2}$ & -- & 8 & & $1 a$ & \\
\hline Strong hypertonicity; Spastic & 5 & 11 & 14 & & $2 b$ & Merged \\
\hline Spastic; Strong hypertonicity & $2^{2,3}$ & 5 & 3 & & $2 b$ & Merged \\
\hline Tremors in hands/limbs & 1 & 1 & 2 & & & \\
\hline Floppy & $2^{3}$ & -- & 2 & & & \\
\hline Rigid/tense, rigidity of the limbs and body & $6^{3}$ & -- & 5 & & & \\
\hline Frequent position change & $2^{2}$ & -- & 4 & & & \\
\hline Body in bowed position, arching & 2 & -- & 5 & & & \\
\hline Raising shoulders & -- & 2 & 1 & & & \\
\hline Putting fingers in mouth; Putting fingers in ears & -- & -- & 1 & & $2 b$ & Split \\
\hline Body extending & -- & -- & 2 & & $2 b$ & Transformed \\
\hline Toes wiggling & -- & 1 & -- & & 1a & \\
\hline Feet wiggling & -- & 4 & - & & $1 a$ & \\
\hline Slow movements, getting slower & - & -- & 3 & & & \\
\hline Rubbing hands in face & -- & -- & -- & Pilot & & \\
\hline Injured Body Part & Literature & Observations & Interviews & Other & Code & Modification \\
\hline $\begin{array}{l}\text { Restricted movement, splinting ; Hitch in movement } \\
\text { pattern }\end{array}$ & 2 & - & 3 & & $\begin{array}{l}1 b \\
3 a\end{array}$ & Split and Moved \\
\hline Position body part for comfort, favour & $3^{2,3}$ & - & 1 & & $2 a$ & \\
\hline Withdrawing affected body part, flinching & $4^{3}$ & 4 & 8 & & & \\
\hline $\begin{array}{l}\text { Protecting/ guarding painful body part, avoiding of touch } \\
\text { or treatment; Shifting body away }\end{array}$ & $4^{2,3}$ & 1 & 12 & & $2 b$ & Split \\
\hline $\begin{array}{l}\text { Grabbing, holding painful body part, touching; Rubbing } \\
\text { over }\end{array}$ & $3^{3}$ & -- & 7 & & $2 b$ & Split \\
\hline Gesturing to painful body part, showing, pointing at & $1^{3}$ & -- & 4 & & & \\
\hline Scratching/digging painful part & 1 & -- & -- & & & \\
\hline $\begin{array}{l}\text { Hunching body part, pushing; Pulling; Pulling clothes } \\
\text { surrounding injured body part }\end{array}$ & 1 & -- & 5 & & $2 b$ & Split \\
\hline Indifference & 12 & -- & -- & & Oa & \\
\hline Not wanting to use body part & -- & -- & 3 & & $4 a$ & \\
\hline Ignore, repel, body part & -- & -- & 2 & & $4 a$ & \\
\hline Let feel body part & -- & -- & 2 & & $2 \mathrm{a}$ & \\
\hline Taking of clothes, shoes & -- & -- & -- & Nurses & & \\
\hline
\end{tabular}




\section{Appendix I (continued)}

State of arousal (sleeping/ awake versus fussy)

Hardly interaction with surrounding, sociability (eye

contact), failing to pay attention; Apathic

1

Attempting to withdraw, closing in on themselves

Interest in surroundings

Not do the things $s /$ he normally does, listless, insensible

to stimuli; Decreased play

Decreased play; Listless insensible to stimuli

Less energy, no activity, being very calm

Self-injuring, increase in, development of self-injuring

Self-biting

Self-pinching; Other self-injurious behaviour

Aggression

Fussy, jittery

Agitation, fidgety; Restless, unrest

Not able to be satisfied or pacified

Not co-operating

Irritability, cranky

Consolability

Inconsolable, no consolability

Seeking comfort or physical closeness

Panicky

Anxious, fright reaction

Whining, complaining

Difficult to distract

Acting more worried

Self-consolation

Resistance, resisting movement and handling

Calm autistic manifestations; Stereotypic behaviour

Destructive behaviour

Throwing things; Destructive behaviour

Tearing clothes apart; Destructive behaviour

Kicking at something; Destructive behaviour

Slamming the doors; Destructive behaviour

Stamp at the ground; Destructive behaviour

Self hit

Head banging

Pulling hair

Ear rap; Other self-injurious behaviour

Self scratch; Other self-injurious behaviour

Anger, mad

Hitting someone, aggressive behaviour

Pushing someone, aggressive behaviour

Kicking someone, aggressive behaviour

Scratching someone, aggressive behaviour

Biting someone, aggressive behaviour

Pinching, aggressive behaviour

Making oneself upset, outburst

Hyperactive behaviour

Stereotypic behaviour

Compulsive behaviour

Self-restrained behaviour, self-consolation

Enjoying

Not wanting to be comforted, refusing physical contact Unhappy, depressed
52

2

12

1

$2^{3}$

12

1

1

3

53 
Appendix I (continued)

Item selection and modification

\begin{tabular}{|c|c|c|c|c|c|c|}
\hline Vocal & Literature & Observations & Interviews & Other & Code & Modification \\
\hline Crying & 42,3 & 4 & 24 & & $1 a^{4}$ & \\
\hline $\begin{array}{l}\text { Quality of cry (piercing, shrill, pitiable, siren like cry, high } \\
\text { pitched), way of crying }\end{array}$ & $6^{3}$ & - & 9 & & $3 a$ & \\
\hline Crying intensely, vigorously, loudly & 3 & -- & 7 & & & \\
\hline Crying quantity, crying more easily & 5 & -- & 4 & & $1 \mathrm{a}$ & \\
\hline Spontaneous crying, suddenly & $3^{2}$ & -- & 1 & & $2 a$ & \\
\hline Screaming, yelling & $5^{3}$ & 2 & 19 & & & \\
\hline Moans/groans, whimpering, grunting & $8^{2,3}$ & 5 & 13 & & & \\
\hline Pain talk (ouch, verbalisation) & 1 & -- & 7 & & $4 a$ & \\
\hline $\begin{array}{l}\text { Specific sound or vocalisation for pain; Guttural sounds; } \\
\text { Penetrating restless sounds }\end{array}$ & $1^{3}$ & 8 & 11 & & $\begin{array}{l}1 b \\
4 a\end{array}$ & Split \\
\hline Quiet, stop making noises & $2^{3}$ & 1 & 8 & & & \\
\hline Chewing & $1^{3}$ & -- & 1 & & & \\
\hline Grinding teeth & $1^{3}$ & 2 & 4 & & & \\
\hline Paradoxial laughter & $2^{2,3}$ & -- & 4 & & & \\
\hline Sucking (disorganised) & 1 & - & - & & & \\
\hline Crying softly & -- & -- & 1 & & & \\
\hline Way of screaming & -- & -- & 1 & & $1 \mathrm{a}$ & \\
\hline Screaming loud & -- & - & 1 & & $1 \mathrm{a}$ & \\
\hline Quantity of screaming & -- & - & 1 & & $1 \mathrm{a}$ & \\
\hline Whining, complaining noises & - & - & 3 & & $1 \mathrm{a}$ & \\
\hline Spitting & -- & - & 1 & & & \\
\hline Coughing & - & - & 1 & & & \\
\hline Humming, self-conjuring noises, stereotypic noises & - & -- & 1 & & $2 b$ & Transformed \\
\hline Grumbling; Angry shrieks & - & 2 & -- & & $2 \mathrm{~b}$ & Split \\
\hline Babbling & -- & -- & -- & Pillot & & \\
\hline Physiological & Literature & Observations & Interviews & Other & Code & Modification \\
\hline Tears & 13 & -- & 9 & & & \\
\hline Diaphoresis, perspiring & $2^{3}$ & - & 2 & & & \\
\hline Gagging & 1 & -- & $\cdots$ & & $2 a$ & \\
\hline Requires $\mathrm{O} 2$ for Sat $>95$ (oxygenation) & 3 & - & - & & 1a & \\
\hline Blood pressure (increase systolic), increased MAP/ DBP & 5 & - & -- & & $2 a$ & \\
\hline Heart rate & 5 & - & 3 & & $2 a$ & \\
\hline Tachycardia & 1 & - & -- & & $2 a$ & \\
\hline $\begin{array}{l}\text { Breathing patterns irregular (apnea/ tachypnea), irregular, } \\
\text { jerky repsiration; Restless respiration }\end{array}$ & $4^{3}$ & 2 & 4 & & $\begin{array}{l}2 b \\
3 a\end{array}$ & Split \\
\hline Increased respiration rate & 4 & -- & -- & & & \\
\hline Respiratory response & 1 & -- & -- & & $2 a$ & \\
\hline Gasps; Sharp intake of breath & $2^{3}$ & -- & -- & & $2 b$ & Split \\
\hline Breath holding, indrawing & $3^{3}$ & 4 & -- & & & \\
\hline Decreased TCP $/ \mathrm{O}_{2}$ SAT $10 \%$ TC; $5 \%$ SAT & 1 & - & -- & & $1 a$ & \\
\hline Pallor/ cyanosis & $2^{3}$ & 1 & 4 & & & \\
\hline Looking flushed & 1 & - & 2 & & & \\
\hline Grey pallor & 1 & - & 2 & & & \\
\hline Shivering & $1^{3}$ & - & -- & & & \\
\hline Ruminating & -- & -- & 1 & & & \\
\hline Not ruminating & -- & - & 1 & & $4 a$ & \\
\hline Incontinent & -- & - & 3 & & $2 a$ & \\
\hline Shortness of breath & -- & - & 1 & & $1 \mathrm{a}$ & \\
\hline Lips looking blue & -- & -- & 1 & & & \\
\hline Red spots, spotted body & - & -- & 1 & & & \\
\hline Epileptic insult & - & 1 & 3 & & $4 a$ & \\
\hline Snorting respiration & -- & -- & - & Pilot & & \\
\hline
\end{tabular}


Appendix I (continued)

Item selection and modification

Activities of daily living

Refusing to eat

Altered appetite

Increase in sleep, drowsy, naps, being tired; Dozing

Sleeping (pattern, amount)

Decrease in sleep, sleepless, constantly awake

Sleeping during preceding hour

Difficulty falling asleep

Nocturnal awakenings

Take medication when s/he normally refuses

Change in eating pattern

Refuse to drink

Altered thirst

Drink a lot

Falling back in development

Literature Observations Interviews Other Code Modification

$1 \quad--\quad 13 \quad 2 a^{4}$

33

$-$

$2 a$

$2 \mathrm{~b}$ Split and moved

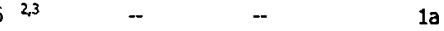

$\begin{array}{lllll}2 & 3 & - & 2 & 1 a\end{array}$

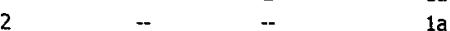

$\begin{array}{lllll}12 & - & 1 & 2 a\end{array}$

$\begin{array}{lllll}12 & -- & 2 & 2 a\end{array}$

$\begin{array}{llll}1 & -- & 2 & 2 a\end{array}$

--

- $\quad-\infty \quad 1$ 1a

$\begin{array}{llll}- & - & 5 & 2 a\end{array}$

$\begin{array}{llll}- & - & 3 & 2 a\end{array}$

$\begin{array}{llll}- & - & 1 & 2 a\end{array}$

$-\quad+-\quad 3 \quad 1 a$

(1) Source of items

(2) Items proposed by physicians to assess pain in cerebral palsy (Giusiano et al., 1995)

(3) Items caregivers use to determine pain in non-verbal, cognitively impaired individuals (McGrath et al., 1998)

(4) Code: $0 \mathrm{a}=$ removed in qualitative study; $1 \mathrm{a}=$ removed by experts, $1 \mathrm{~b}=$ modified by experts; $2 \mathrm{a}=$ removed after pilot, $2 \mathrm{~b}=$ modified after pilot; $3 \mathrm{a}=$ removed by health care professionals, $3 b=$ modified by health care professionals; $4 a=$ removed in final stage 


\section{Appendix II}

Based on the results of the questionnaire for parents of children with profound intellectual disability (Chapter 4) the 138 items that were in concardence with the draft scale were narrowed down from 138 to 114 (Appendix ID). These 114 items were used to rate video recordings derived from the observations of 52 children with profound intellectual disabilities at standardised episodes before and after a medical procedure under general anaesthesia (Chapter 5). Two episodes were selected for presumed absence of pain, while three episodes were selected for presumed presence of procedural/ postoperative pain. One additional episode was selected as an intervention-specific moment presumed to reflect acute pain. Item selection took place for each episode separately in order to cross-validate the item selection process. Items were discarded based on frequencies of endorsement, internal consistency and Principal Components Analysis per dimension (Streiner \& Norman, 1998). Five additional items were discarded based on a negative coherence between components, resulting in 42 items that were present in the item selection for at least one episode. During the item selection process, the Vocal and Physiological dimensions were merged and a dimension relating to muscle tone was distinguished from other motor behaviours. This meant that the facet design was partially abandoned. The 42 remaining items of KIDPAINS were tested for reliability, criterion and construct validity, using a known-groups design of children with profound multiple disabilities in identified painful and non-painful situations (Chapter 6). The results led to three items being removed based on frequencies of endorsement, whereas five items were removed based on low item-total correlations $(<0.2)$ (Appendix II). Assessment of inter-rater agreement showed that seven items of KIDPAINS did not result in adequate intra-class correlations between raters who were familiar and those (i.e. nurses) who were unfamiliar with the children. Another 13 items did not significantly differentiate between pain scenes and no-pain scenes, four of these items were retained based on their ability to differentiate between moderate and severe pain. The PCA did not cause additional items to be removed. Thus in total 18 items were selected for the reduced KIDPAINS. 


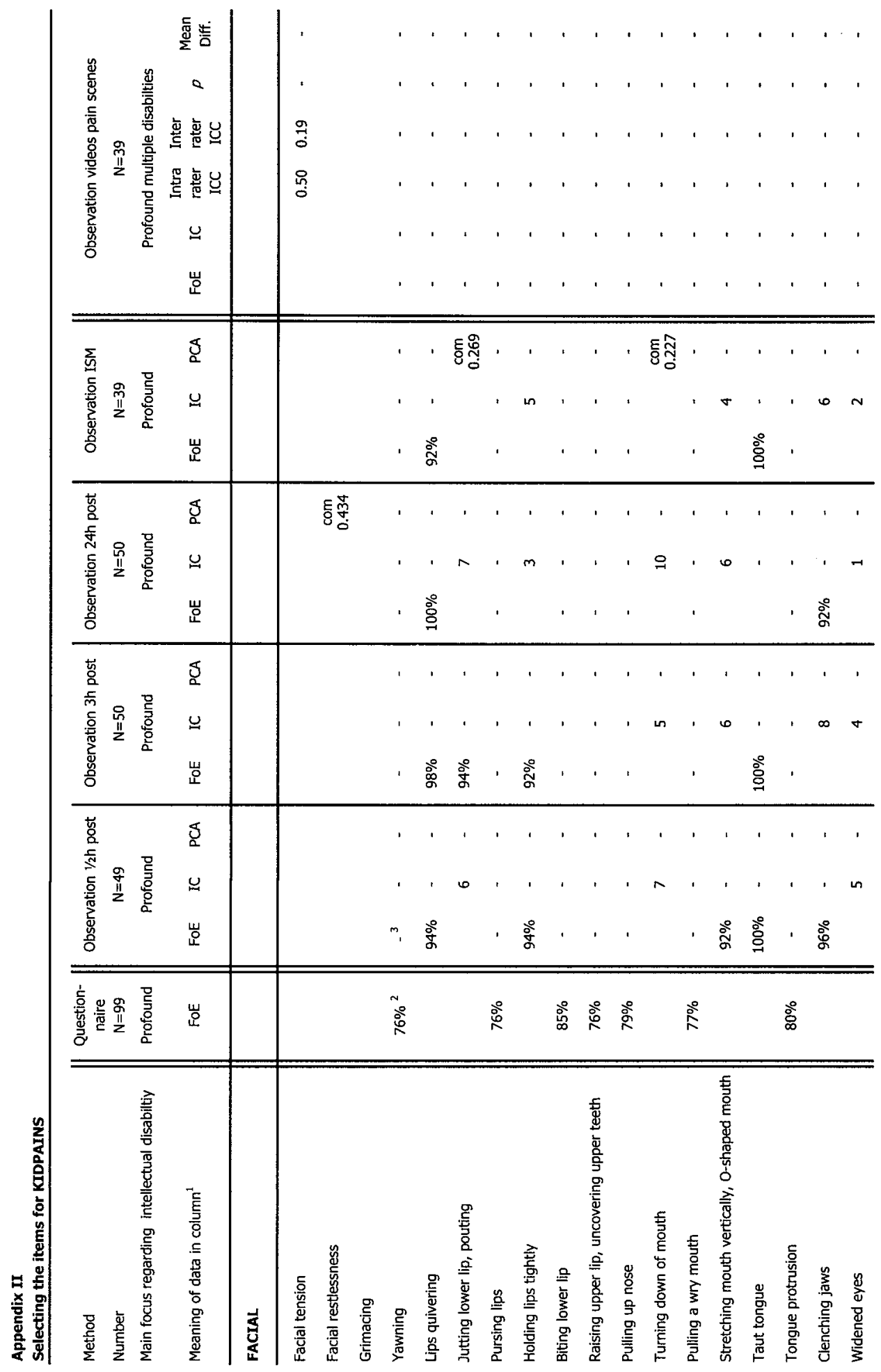




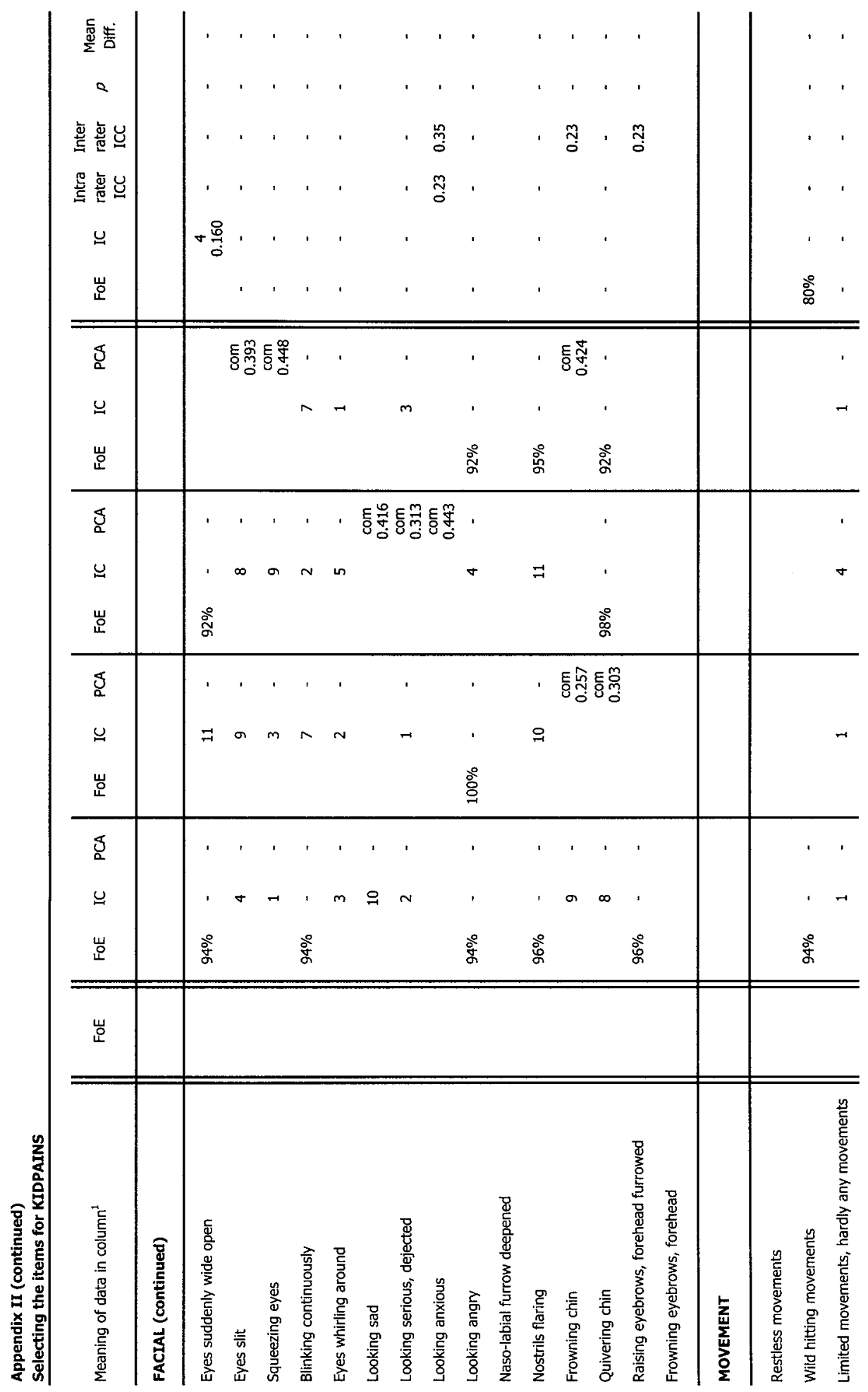




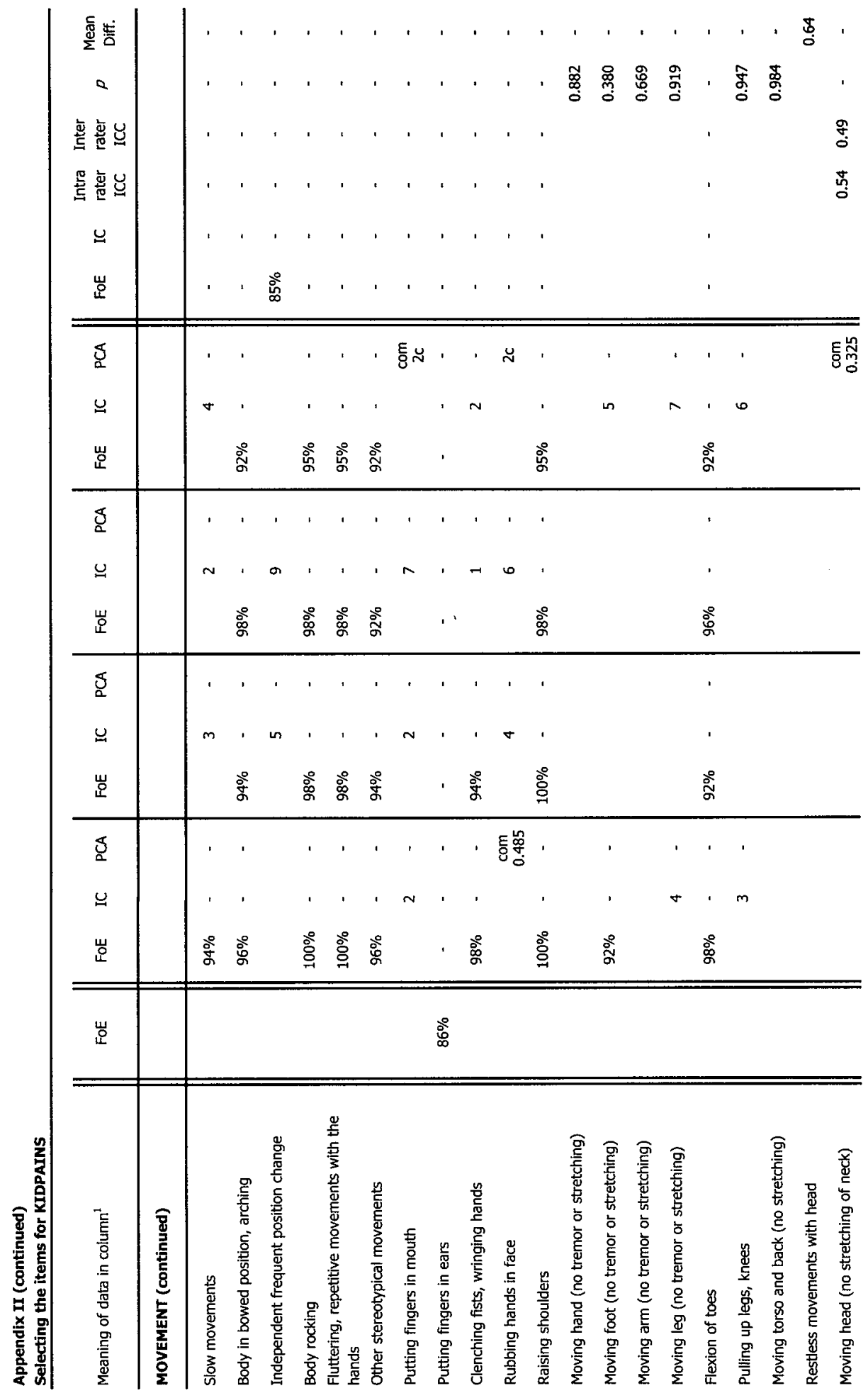




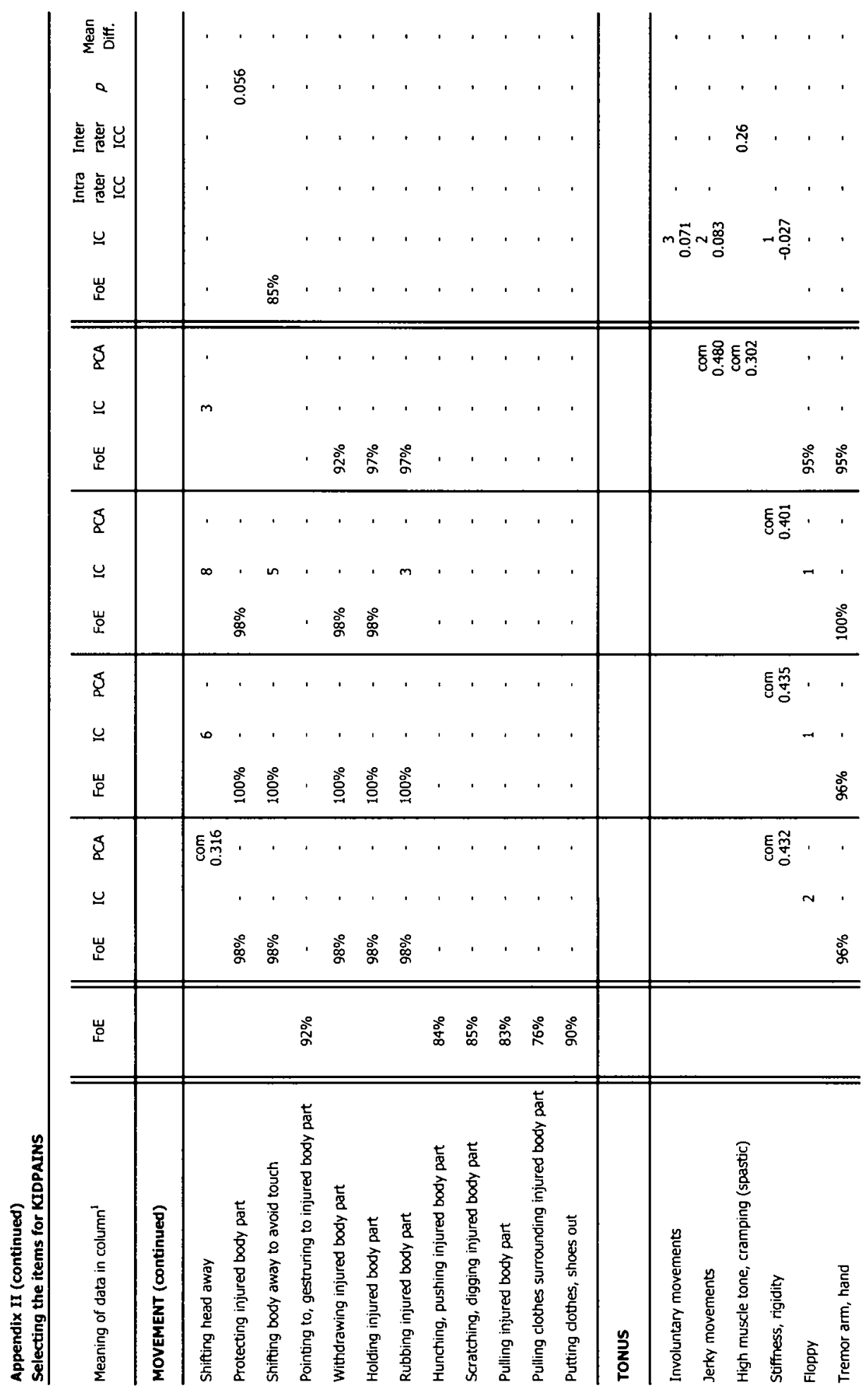




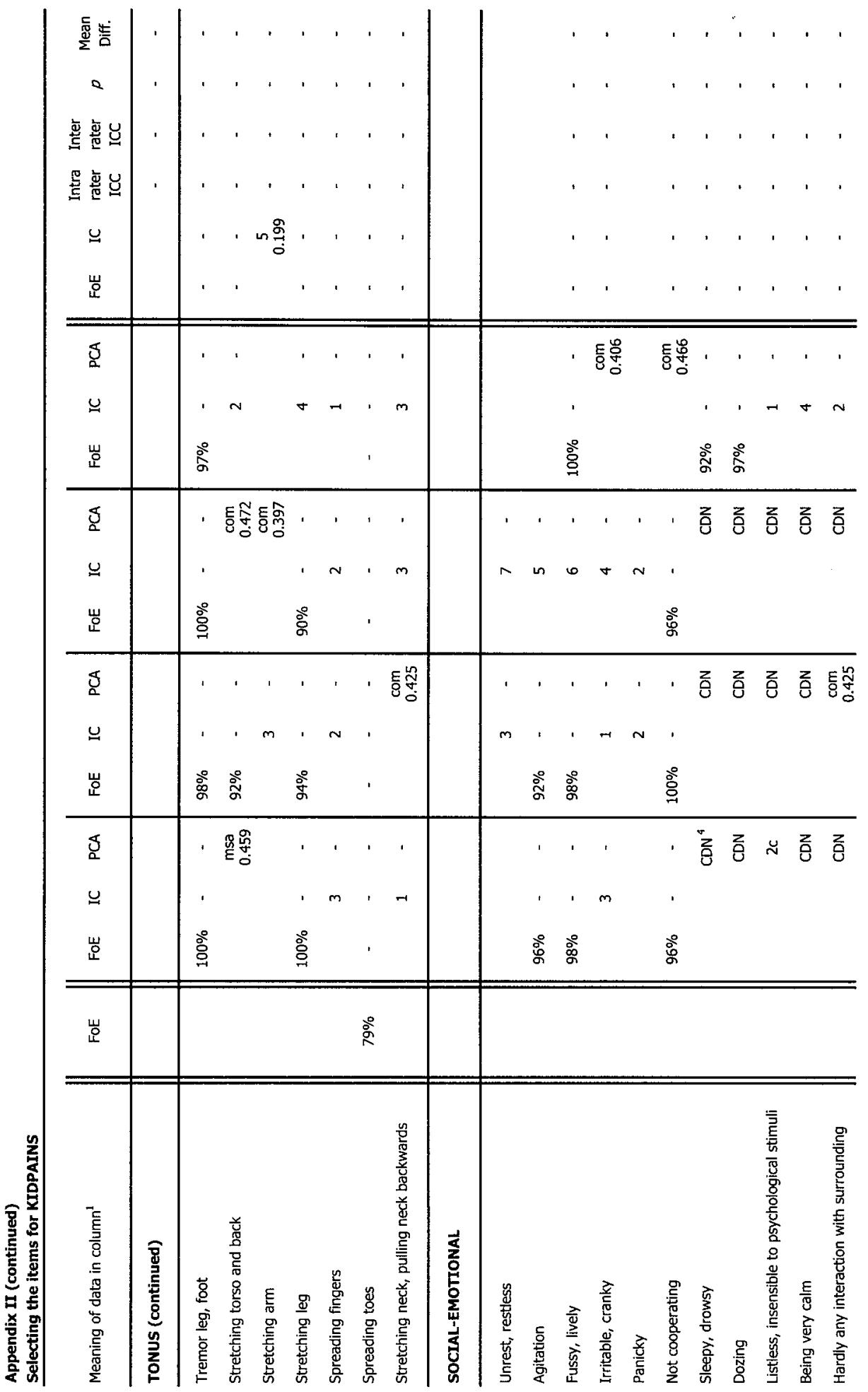




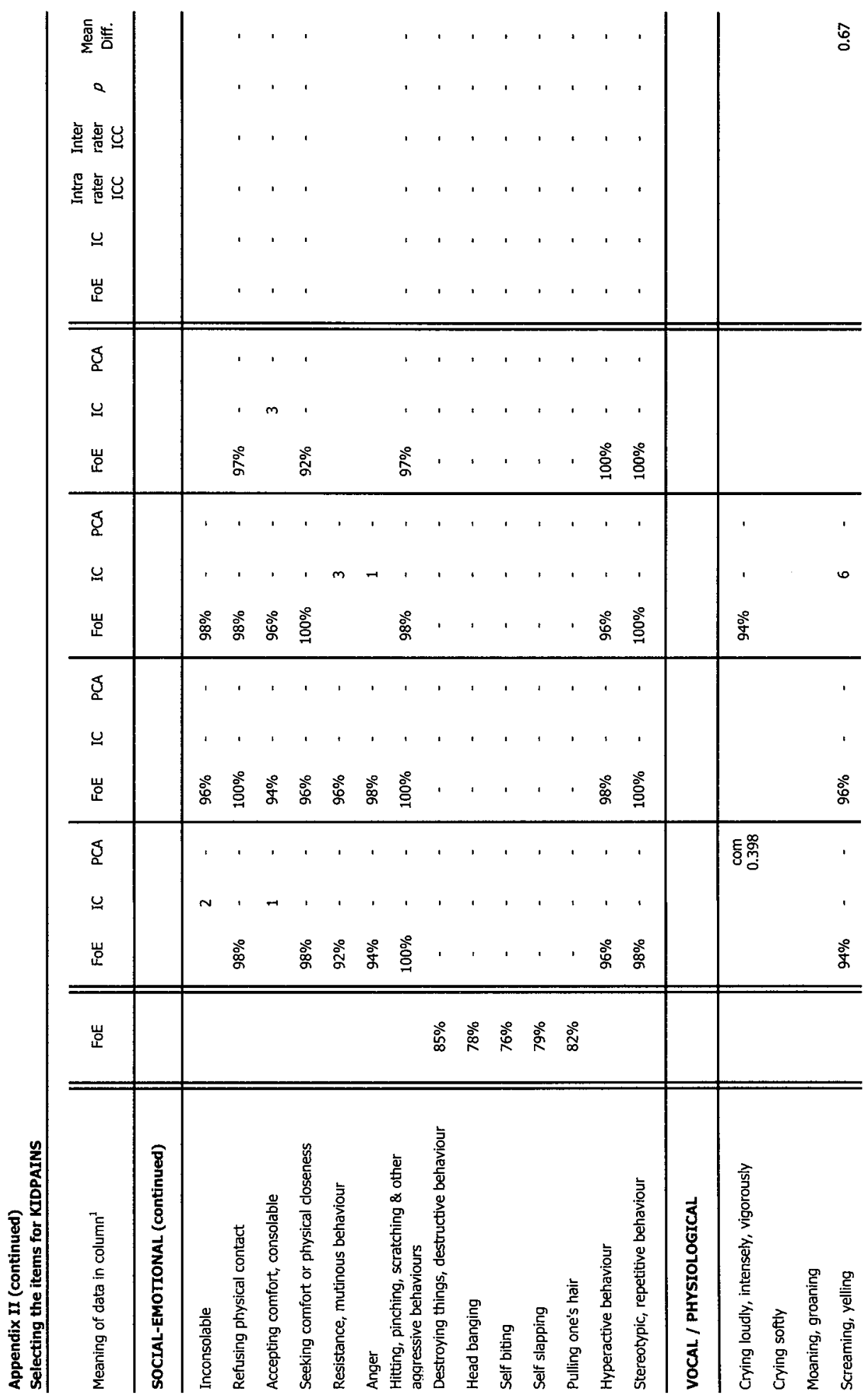




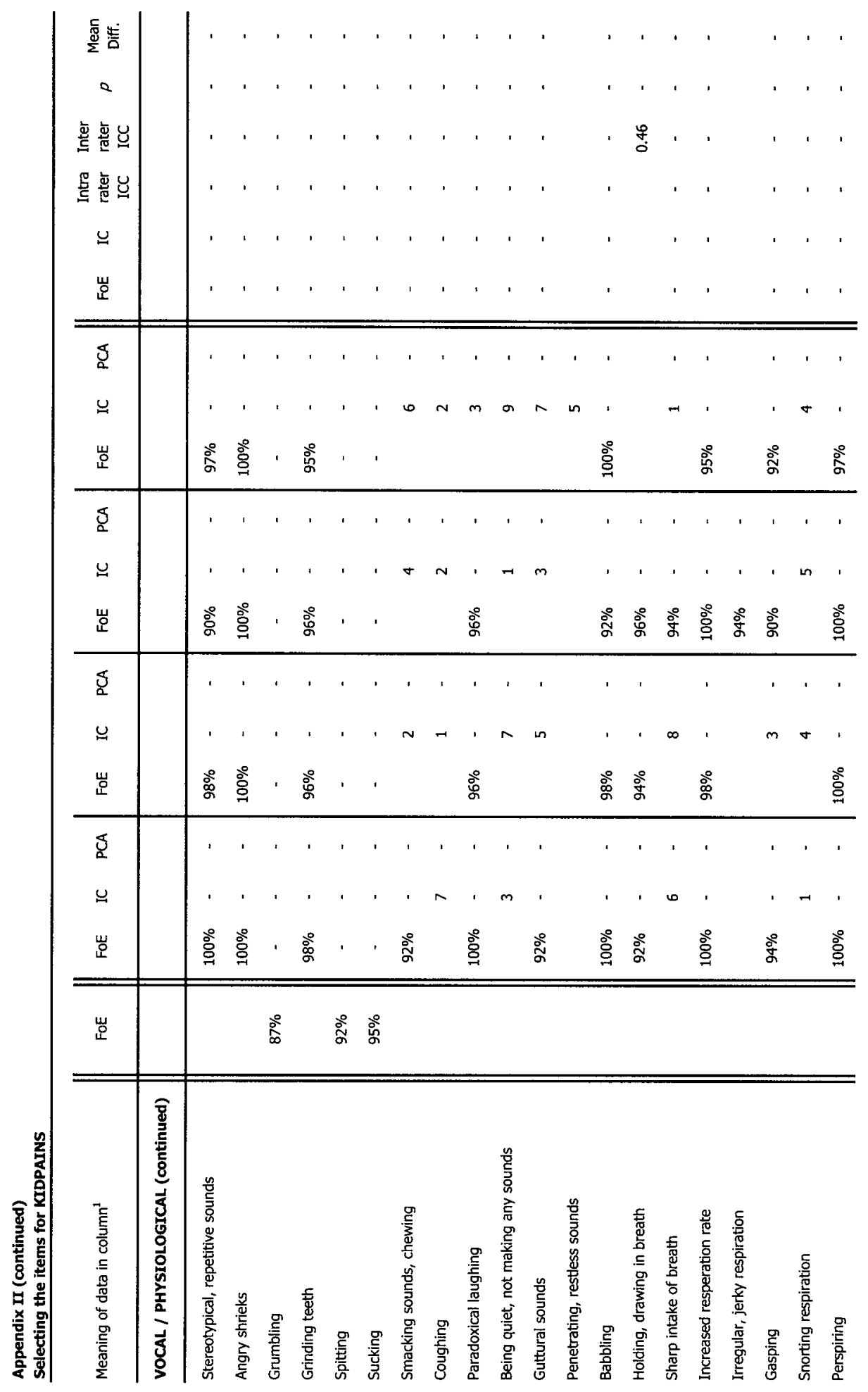




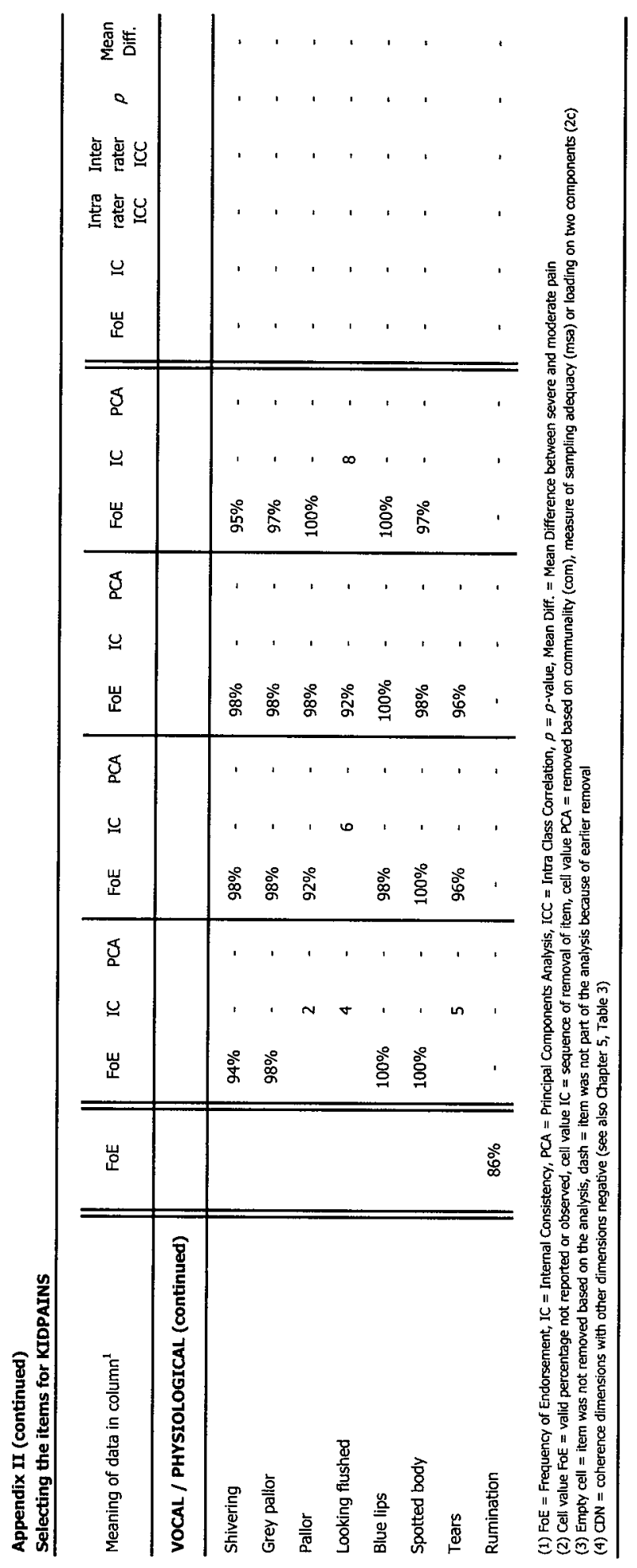





\section{References}

Abrahamsen, A. A., Romski, M. A., \& Sevcik, R. A. (1989). Concomitants of success in acquiring an augmentative communication system: changes in attention, communication and sociability. American Joumal on Mental Retardation, 93(5), 475-496.

Abu-Saad, H. (1984). Assessing children's responses to pain. Pain, 19, 163-171.

Abu-Saad, H., Kroonen, E., \& Halfens, R. (1990). On the development of a multidimensional Dutch pain assessment tool for children. Pain, 43, 249-256.

Algra, H., Berg van den-Willemsen, A. M. J. M., Loen van, W. W. H., Pekelharing, J. G., \& Velthausz, F. J. M. (1992). Lokale ervaringskennis met betrekking tot kommunikatie bij diepzwakzinnigen: Provinciaal overleg van ortho-pedagogen en psychologen van de Noordhollandse zwakzinnigeninstellingen.

Allen Finley, G., Chambers, C. T., McGrath, P. J., \& Walsh, T. M. (2003). Construct validity of the parents' postoperative pain measure. The Clinical Joumal of Pain, 19(5), 329-334.

Altman, S. (1965). Sociobiology of rhesus monkeys II: stochastics of social communication. Journal of Theoretical Biology, 8, 490-522.

Aman, M. G. (1991). Review and evaluation of instruments for assessing emotional and behavioural disorders. Australia and New Zealand Joumal of Developmental Disabilities, 17(2), 127-145.

Ambuel, B., Hamlett, K. W., Marx, C. M., \& Blumer, J. L. (1992). Assessing distress in pediatric intensive care environments: the COMFORT scale. Joumal of Pediatric Psychology, 17(1), $95-$ 109.

American Association on Mental Retardation. (2002a). Changing the name of the association. Retrieved June 14, 2002, from http://www.aamr.org/Membership/new name.shtml

American Association on Mental Retardation. (2002b). Mental retardation: definition, classification, and systems of support (10 ed.). Washington: American Association on Mental Retardation.

American Psychiatric Association. (1994). Diagnostic and statistical manual of mental disorders (Vol. Fourth edition DSM-IV). Washington: APA.

Anand, K. J. S., \& Craig, K. D. (1996). New perspectives on the definition of pain. Pain, 67, 3-6.

Anand, K. J. S., \& McGrath, P. J. (1993). Pain in neonates (Vol. 5). Amsterdam: Elsevier.

Anderson, H., \& West, C. K. (1995). Commentary: An analysis of a qualitative investigation: A matter of whether to believe. Reading Research Quarterly, 30(3), 562-569.

Assema van, P., Mesters, I., \& Kok, G. (1992). Het focusgroep-interview: een stappenplan. Tijdschrift Sociale Gezondbeidszorg, 70, 431-437.

Astor, R. (2001). Detecting pain in people with profound learning disabilities. Nursing Times, 97(40), 38-40.

Barrier, G., Attia, J., Mayer, M. N., Amiel-Tison, C., \& Shider, S. M. (1989). Measurement of postoperative pain and narcotic administration in infants using a new clinical scoring system. Intensive Care Medicine, 15, s37-s39.

Battaglia, M., Russo, E., Bolla, A., Chiusso, A., Bertelli, S., Pellegri, A., et al. (2004). International classification of functioning, disability and health in a cohort with cognitive, motor, and complex disabilities. Developmental Medicine \& Child Neurology, 46, 98-106.

Beitchmann, J. H., \& Peterson, M. (1986). Disorders of language, communication, and behavior in mentally retarded children: some ideas on their co-occurence. Psycbiatric Clinics of North America, 9(4), 689-698.

Bell. (1996). Neonatal Pain Assessement Scale. Not published.

Berde, C. B., Lehn, B. M., Yee, J. D., Sethna, N. F., \& Russo, D. (1991). Patient-controlled analgesia in children and adolescents: a randomized, prospective comparison with intramuscular administration of morphine for postoperative analgesia. The Journal of Pediatrics, $118,460-$ 466. 
Beyer, J. E., \& Wells, N. (1989). The assessment of pain in children. In Pediatric clinics of North America (pp. 837-854). Philadelphia: Saunders.

Biasini, F. J., \& Bray, N. W. (1986). Comparison and message-formulation skills in the referential communication of severly mentally retarded children. American Joumal on Mental Retardation, 90(6), 686-693.

Bieri, D., Reeve, R. A., Champion, G. D., Addicoat, L., \& Ziegler, J. B. (1990). The Faces Pain Scale for the self-assessment of the severity of pain experienced by children: development, initial validation and preliminary investigation for ratio scale properties. Pain, 41, 139-150.

Biersdorff, K. K. (1994). Incidence of significantly altered pain experience among individuals with developmental disabilities. American Joumal of Mental Retardation, 98(5), 619-631.

Bland, J. M., \& Altman, D. G. (1986). Statistical methods for assessing agreement between two methods of clinical measurement. The Lancet, 8(February), 307-310.

Bosch, C. F. M. (1990). De Grounded Theory benadering in een onderzoek op psycho-geriatrische verpleegafdelingen. In A. L. Francke (Ed.), Kwalitatief onderzoek in de verpleegkunde. Amsterdam: Swets \& Zeitlinger.

Bosch, J. (2002). Use of directed history and behavioral indicators in the assessment of the child with a developmental disability. Joumal of Pediatric Health Care, July / August, 170-179.

Bosch, J., Dyke Van, D. C., Smith, S. M., \& Poulon, S. (1997). Role of medical conditions in the exacerbation of self-injurious behavior: an exploratory study. Mental Retardation, 35(2), 124130.

Bours, J. J. W., Huijer Abu-Saad, H., Hamers, J. P. H., \& Dongen van, R. T. M. (1996). Pain assessment in neonates: state of the art study (State of the art study). Maastricht: Universiteit Maastricht.

Bowler, D. M. (1987). Spatial and temporal sequencing of signs and words by severly mentally retarded children. American Joumal on Mental Retardation, 92(1), 112-115.

Breau, L. M., Camfield, C., McGrath, P. J., Rosmus, C., \& Finley, G. A. (2001). Measuring pain accurately in children with cognitive impairments: refinement of a caregiver scale. The Journal of Pediatrics, May, 721-727.

Breau, L. M., Camfield, C. S., McGrath, P. J., \& Allen Finley, G. (2003). The incidence of pain in children with severe cognitive impairments. Arch Pediatr Adolesc Med, 157, 1219-1226.

Breau, L. M., Camfield, C. S., Symons, F. J., Bodfish, J. W., MacKay, A., Allen Finley, G., et al. (2003). Relation between pain and self-injurious behavior in nonverbal children with severe cognitive impairments. The Joumal of Pediatrics, 142(5), 498-503.

Breau, L. M., Finley, G. A., McGrath, P. J., \& Camfield, C. S. (2002b). Validation of the NonCommunicating Children's Pain Checklist-Postoperative version. Anesthesiology, 96, 528-535.

Breau, L. M., MacLaren, J., McGrath, P. J., Camfield, C. S., \& Allen Finley, G. (2003). Caregivers' beliefs regarding pain in children with cognitive impairment: relation between pain sensation and reaction increases with severity of impairment. The Clinical Joumal of Pain, 19, 335-344.

Breau, L. M., McGrath, P. J., Camfield, C., Rosmus, C., \& Finley, G. A. (2000). Preliminary validation of an observational pain checklist for persons with cognitive impairments and inability to communicate verbally. Developmental Medicine \& Child Neurology, 42, 609-616.

Breau, L. M., McGrath, P. J., Camfield, C. S., \& Finley, G. A. (2002a). Psychometric properties of the Non-Communicating Children's Pain Checklist-revised. Pain, 99, 349-357.

Breukelen van, G. (2000). Factoranalyse. In M. P. F. Berger, T. Imbos \& M. P. E. Janssen (Eds.), Methodologie en Statistiek. Maastricht: Universitaire Pers Maastricht.

Breukelen van, G., \& Candel, M. (2000). Betrouwbaarheid, validiteit en overeenstemming. In M. P. F. Berger, T. Imbos \& M. P. E. Janssen (Eds.), Methodologie en statistiek. Maastricht: Universitaire Pers Maastricht.

Brodin, J. (1991). To interpret childrens signals. Stockholm, Stockholm. 
Bromley, J., Emerson, E., \& Caine, A. (1998). The development of a self-report measure to assess the location and intensity of pain in people with intellectual disabilities. Joumal of Intellectual Disability Research, 42(Part 1), 72-80.

Buntinx, W. H. E., \& Bernard, S. (1996). 'Verstandelijke handicap': kritische beschouwing van de definitie volgens de American Association on Mental Retardation (AAMR). NTZ, 5(1), 3 17.

Campbell, P. H., \& Wilcox, M. J. (1989). Communication programming from birth to three. San Diego: College Hill Press.

Carbo, C. (2002). Deskundige handen aan het bed. Markant, maart, 24-27.

Carter, B., McArthur, E., \& Cunliffe, M. (2002). Dealing with uncertainty: parental assessment of pain in their children with profound special needs. Journal of Advanced Nursing, 38(5), 437-448.

Chadwick, O., Piroth, N., Walker, S., Bernard, S., \& E., T. (2000). Factors affecting the risk of behaviour problems in children with severe intellectual disability. Joumal of intellctual disabilitiy research, 44(part. 2), 108-123.

Chambers, C. T. (2000). The application of measurement tool to the assessment of pain in children with cognitive impairments: What bas been accomplished and what more is there to do? Paper presented at the Conference on pain with significant neurological impairment, Toronto.

Chambers, C. T., Cassidy, K. L., McGrath, P. J., Gilbert, C. A., \& Craig, K. D. (1996b). Child facial coding system: a manual. Nova Scotia and Vancouver: Dalhousie University and University of British Colombia.

Chambers, C. T., Allen Finley, G., McGrath, P. J., \& Walsh, T. M. (2003). The parents' postoperative pain measure: replication and extension to 2-6-year-old children. Pain, 105, 437-443.

Chambers, C. T., Reid, G. J., McGrath, P. J., \& Finley, A. (1996a). Development and preliminary validation of a postoperative pain measure for parents. Pain, 68, 307-313.

Chenitz, W. C., \& Swanson, J. M. (1986). From Practice to Grounded Theory: qualitative research in nursing. Menlo Park: Addison-Wesley Publishing Company, Inc.

Cleland, C. (1979). The profoundly mentally retarded. Englewood Cliffs.

Cox, K., \& Titchen, A. (2003). Doen en weten dichter bij elkaar brengen voor evidence-based practice. Verpleegleunde, 18(4), 232-241.

Coggins, T. E., \& Carpenter, R. L. (1981). The communicative intention inventory: a system for observing and coding children's early intentional communication. Applied Psycholinguistics, 2, 235-251.

Collignon, P., \& Giusiano, B. (2000). Pain evaluation scale for patients with severe cerebral palsy. Paper presented at the Conference on pain with significant neurological impairment, Toronto.

Collignon, P., \& Giusiano, B. (2001). Validation of a pain evaluation scale for patients with severe cerebral palsy. European Jourmal of Pain, 5, 433-442.

Collignon, P., Giusiano, B., Boutin, A. M., \& Combes, J. C. (1997). Utilisation d'une échelle d'hétéroévaluation de la douleur chez le sujet sévérement polyhandicapé. Douleur et Analgésique, 1, 27-32.

Collignon, P., Giusiano, B., Porsmoguer, E., Jimeno, M. T., \& Combe, J. C. (1995). Difficultés du diagnostic de la douleur chez l'enfant polyhandicapé. Annales De Pédiatrie, 42(2), 123-126.

Collins, S. L., Moore, R. A., \& McQuay, H. J. (1997). The visual analogue pain intensity scale: what is moderate pain in millimetres? Pain, 72, 95-97.

Cook, A. S. R., Niven, C. A., \& Downs, M. G. (1999). Assessing the pain of people with cognitive impairment. Intermational Joumal of Geriatric Psychiatry, 14, 421-425.

Cools, A. T. M., \& Hermanns, J. M. A. (1979). DOS-bandleiding. Amsterdam: Swets \& Zeitlinger.

Craig, D. C., \& Grunau, R. V. E. (1993). Neonatal pain perception and behavioral measurement. In K. J. S. Anand \& P. J. McGrath (Eds.), Pain in neonates. Amsterdam: Elsevier.

Craig, K. D. (1998). The facial display of pain. In G. A. Finley \& P. J. McGrath (Eds.), Measurement of pain in infants and children, Progress in pain research and management (Vol. 10). Seattle: IASP Press. 
Craig, K. D., \& Grunau, R. V. E. (1994). Infant pain bebaviors and clinical decision-making: judging pain in newborms. Paper presented at the Third international symposium on pediatric pain, Philadelphia.

Craig, K. D., Hadjistavropoulos, T., McGrath, P. J., \& Horgas, A. L. (1999). Pain measurement in aging persons with intellectual disability or cognitive impaiment, Geneve.

Craig, K. D., McMahan, R. J., Morison, J. D., \& Zaskow, C. (1984). Developmental changes in infant pain expression during immunization injections. Sor Sci Med, 19, 1331-1337.

Craig, K. D., Whitfield, M. F., Grunau, R. V. E., Linton, J., \& Hadjistavropoulos, H. D. (1993). Pain in the preterm neonate: behavioral and psychological indices. Pain, 52, 287-299.

Denzin, N. K. (1978). The research act: a theoretical introduction to sociological methods. New-York: McGrawHill.

Denzin, N. K. (1994). Handbook of Qualitative Research. Thousand Oaks: SAGE Publications, Inc.

Dews, T. E., Schubert, A., Fried, A., Ebrahim, Z., Oswalt, K., \& Paranandi, L. (1996). Intrathecal morphine for analgesia in children undergoing selective dorsal rhizotomy. Joumal of Pain and Symptom Management, 11(3), 188-194.

Dijk van, M. (2001). Pain unbeard? Postoperative pain assessment in neonates and infants. Erasmus Universiteit Rotterdam, Rotterdam.

Dijk van, M., Koot, H. M., Huijer Abu-Saad, H., Tibboel, D., \& Passchier, J. (2002). The observational Visual Analogue Scale in pediatric pain assessment: useful tool or good riddance. Clinical Joumal of Pain, 18, 310-316.

Dingemans, W. A., Groenman, N. H., Kleef van, M., \& Krijgsman, M. J. (1993). Pijn en pijnbebandeling: een basaal ondernijscurriculum. Maastricht: Universitaire Pers.

Dongen van, K. A. J. (2001). Waar doet het pijn? In V. M. de (Ed.), Bijzondere qorg voor bijzondere kinderen (pp. 97-112).

Dongen van, K. A. J., Abu-Saad, H., \& Hamers, J. P. H. (2000). Pain assessment in children with profound cognitive impairment. Journal of Intellectual Disabilitiy Research, 44(303).

Dongen van, K. A. J., Huijer Abu-Saad, H., \& Hamers, J. P. H. (1999). On the development of an observational scale to measure pain in non-verbal children with severe or profound cognitive impaiment; collecting the indicators. Paper presented at the 9th World Congress on Pain, Vienna.

Dongen van, K. A. J., Huijer Abu-Saad, H., Hamers, J. P. H., \& Terstegen, C. M. (2000). Developing an individual pain profile for pain assessment in children with profound cognitive impairment. Joumal of Intellectual Disabilitiy Research, 44, 303.

Dongen van, K. A. J., Huijer Abu-Saad, H., Hamers, J. P. H., \& Zwakhalen, S. M. G. (2002b). Pain assessment in the intellectually disabled child: the challenges of tool development. The Suffering Child, 1(1), 21-26.

Dongen van, K. A. J., Terstegen, C. M., Huijer Abu-Saad, H., Hamers, J. P. H., \& Zwakhalen, S. (2002a). Selecting the indicators of an observational scale to measure pain in non-verbal cbildren with profound cognitive impairment. Paper presented at the 10th World Congress on Pain, San Diego.

Donovan, J. (1997). Pain signals. Nursing Times, 45(93), 60-62.

Donovan, J. (2002). Learning disability nurses' experience of being with clients who may be in pain. Joumal of Advanced Nursing, 38(5), 458-466.

Dosen, A. (1990). Psychische en gedragsstoornissen bij zuvakinnigen. Meppel: Boom.

Downing, J. E., \& Siegel-Causey, E. (1988). Enhancing the Nonsymbolic Communicative Behavior of Children with Multiple Impairments. Language, Speech, and Hearing Services in Schools, 19, 338-348.

Eekhof, J. A. H., Mol, S. S. L., \& Pielage, J. C. (1992). Is doorgaans vaker dan dikwijls; of hoe vaak is soms? Nederlands Tijdscbrift der Geneeskunde, 136(1), 41.

Einfeld, S. L., \& Tonge, B. J. (1991). Psychometric and clinical assessment of psychopathology in developmentally disabled children. Australia and New Zealand Joumal of Developmental Disabilities, $17(2), 147-154$. 
Einfeld, S. L., \& Tonge, B. J. (1995). The Developmental Behavior Checklist: the development and validation of an instrument to assess behavioral and emotional disturbance in children and adolescents with mental retardation. Joumal of Autism and Developmental Disorders, 25(2), 81 104.

Ellis, J. A., Virley O'Conner, B., Cappelli, M., Goodman, J. T., Blouin, R., \& Reid, C. W. (2002). Pain in hospitalized pediatric patients: How are we doing? The Clinical Journal of Pain, 18, 262269.

Engel, J. M., Schwartz, L., Jensen, M. P., \& Johnson, D. R. (2000). Pain in cerebral palsy; the relation of coping strategies to adjustment. Pain, 88, 225-230.

Fanurik, D. (2000). Pain assessment and treatment in children with cognitive impaiment. Paper presented at the Conferende on pain with significant neurological impairment, Toronto.

Fanurik, D., Koh, J. L., Schmitz, M. L., Harrison, R. D., \& Conrad, T. M. (1999b). Children with cognitive impairment: parent report of pain and coping. Developmental and Bebavioral Pediatrics, 20(4), 228-234.

Fanurik, D., Koh, J. L. K., Harrison, R. D., Conrad, T. M., \& Tomerlin, C. (1998). Pain assessment in children with cognitive impairment: an exploration of self-report skills. Clinical Nursing Research, 7(2), 103-124.

Fanurik, D., Koh, L., Smitz, M. L., Harrison, D., Roberson, P. K., \& Killebrew, P. (1999a). Pain assessment and treatment in children with cognitive impairment; a survey of nurses' and and physicians' beliefs. The Clinical Journal of Pain, 15, 304-312.

Ferguson, A., McKinlay, I. A., \& Hunt, A. (2002). Care of adolescents with severe learning disability from tuberous sclerosis. Developmental Medicine of Child Neurology, 44, 256-262.

Finley, G. A., \& McGrath, P. J. (Eds.). (1998). Measurement of pain in infants and cbildren (Vol. 10). Seattle: IASP Press.

Francke, A. L. (1990). Kwalitatief onderzoek in de verpleegkunde. Amsterdam: Swets \& Zeitlinger.

Frankenmolen, F. W. A., \& Berensen, W. J. H. (1996). Lokale anesthesie bij kinderen en verstandelijk gehandicapten. Nederlands Tijdscbrift voor Tandbeelkunde, 103, 109-194.

Fuchs-Lacelle, S., \& Hadjistavropoulos, T. (2004). Development and preliminary validation of the Pain Assessment Checklist for Seniors with Limited Ability to Communicate (PACSLAC). Pain Management Nursing, 5(1), 37-49.

Geiduschek, J. M., Haberkern, C. M., McLaughlin, J. F., Jacobson, L. E., Hays, R. M., \& Roberts, T. S. (1994). Pain mangement for children following selective dorsal thizotomy. Canadian Joumal of Anaesthesia, 41(6), 492-496.

Gelb, S. A. (1998). One number fits all? Why typology is poor science. Mental Retardation, 36(6), 496498.

Gemert van, G. H., \& Noorda, W. K. (1988). Leerboek zwakezinnigenzorg (Vol. 2). Assen: Van Gorcum.

Gilbert-MacLeod, C. A., Craig, K. D., Rocha, E. M., \& Mathias, M. D. (2000). Everyday pain responses in children with and without developmental delays. Joumal of Pediatric Psychology, 25(5), 301-308.

Giusiano, B., Jimeno, M. T., Collignon, P., \& Chau, Y. (1995). Utilization of a neural network: the elaboration of an evaluation scale for pain in cerebral palsy. Methods of Information in Medicine, 34, 498-502.

Glaser, B. G., \& Strauss, A. L. (1967). The discovery of grounded theory: strategies for qualitative research. Chicago: Aldine.

Golden, J., \& Reese, M. (1996). Focus on communication: improving interaction between staff and residents who have severe or profound mental retardation. Research in Developmental Disabilities, 17(5), 363-382.

Golianu, B., Krane, E. J., Galloway, K. S., \& Yaster, M. (2000). Pediatric acute pain management. Pediatr Clin North Am, 47(3), 559-587. 
Goodenough, T. B., Perrott, D. A., Champion, G. D., \& Thomas, W. (2000). Painful pricks and prickle pains: is there a relation between children's ratings venipuncture pain and parental assessments of usual reaction to other pains? Clinical Joumal of Pain, 16(2), 135-143.

Goorhuis, S. M., \& Schaerlaekens, A. M. (1994). Handboek taalontwikkeling, taalpathologie en taaltherapie bij Nederlands sprekende kinderen. Leusden: De Tijdstroom.

Goorhuis, S. M., \& Schaerlaekens, A. M. (2000). Handboek taalontwikkeling, taalpathologie en taaltherapie bij Nederlands sprekende kinderen. Leusden: De Tijdstroom.

Granlund, M. (1993). Communicative competence in persons with profound mental retardation. Acta Universitatis Upsaliensis, Uppsala.

Granlund, M. (1996). Preparing professionals for family centered intervention with children with profound multiple disabilities and their families. In C. Jong de \& H. Neugenbauer (Eds.), Timely intervention. Wurzburg: Edition Bentheim.

Granlund, M., \& Olsson, C. (1997). Eerst observeren, dan communiceren. Utrecht: Elsevier / De Tijdstroom.

Green, C. W., \& Reid, D. H. (1996). Defining, validating, and increasing indices of happiness among people the profound multiple disabilities. Journal of Applied Bebavior Analysis, 29(1), 67-78.

Green, C. W., \& Reid, D. H. (1999a). A behavioral approach to identifying sources of happiness and unhappiness among individuals with profound multiple disabilities. Bebavior Modification, 23(2), 280-293.

Green, C. W., \& Reid, D. H. (1999b). Reducing indices of unhappiness among individuals with profound multiple disabilities during therapeutic exercise routines. Joumal of Applied Bebavior Analysis, 32(2), 137-147.

Greenberg, R. B., Billett, C., Zahurak, M., \& Yaster, M. (1999). Videotapes increase parental knowledge about pediatric pain managment. Pediatric Anastbesia, 89, 899-9023.

Grunau, R. V. E., \& Craig, K. D. (1987). Pain expression in neonates: facial action and cry. Pain, 28, 395-410.

Grunau, R. V. E., \& Craig, K. D. (1990). Facial activity as a measure of neonatal pain expression. In D. C. Tyler \& E. J. Krane (Eds.), Advances in pain research therapy (pp. 147-155). New York: Raven Press.

Gunsett, R. G., Mulick, J. A., Fernal, W. B., \& Martin, J. L. (1989). Brief report: indicators for medical screeening prior to behavioral programming for severely and proundly mentally retarded clients. Journal of Autism and Developmental Disorders, 19(1), 167-172.

Hadden, K. L., \& Bayer von, C. L. (2002). Pain in children with cerebral palsy: common triggers and expressive behaviors. Pain, 99, 281-288.

Hadjistavropoulos, H. D., Craig, K. D., Eckstein Grunau, R., \& Whitfield, M. (1997). Judging pain in infants: behavioural, contextual, and developmental determinants. Pain, 73, 319-324.

Hadjistavropoulos, T., Baeyer von, C., \& Craig, K. D. (2001). Pain assessment in persons with limited ability to communicate. In Turk D.C. \& Melzack R. (Eds.), Handbook of pain assessment (Vol. second edition, pp. 134-150).

Hadjistavropoulos, T., \& Craig, K. D. (2002). A theoretical framework for understanding self-report and observational measures of pain: a communications model. Pain, 40, 551-570.

Hadjistavropoulos, T., LaChapelle, D., MacLeod, F., Hale, C., O'Rourke, N., \& Craig, K. D. (1998). Cognitive functioning and pain reactions in hospatilized elders. Pain Research and Management, 3, 145-151.

Hadjistavropoulos, T., LaChapelle, D. L., MacLeod, F. K., Snider, B., \& Craig, K. D. (2000). Measuring movement-excerbated pain in cognitively impaired frail elders. The Clinical Joumal of Pain, 16(1), 54-63.

Hair, J. F. J. (1998). Multivariate data analysis. New York: Prentice Hall.

Hamers, J. (1995). Postoperative pain in children. Maastricht, Maastricht.

Hamers, J. P. H., H., H. A.-S., Van den Hout, M. A., Halfens, R. J. G., \& Kester, A. D. M. (1996). The influence of children's vocal expressions, age, medical diagnosis and information 
obtained from parents on nurses' pain assessments and decisions regarding interventions. Pain, 65, 413-421.

Harwood, N. K., Hall, L. J., \& Shinkfield, A. J. (1999). Recognition of facial emotional expression from moving and static displays by individuals with mental retardation. American Joumal of Mental Retardation, 104(3), 270-278.

Hastings, R. P. (1994). On "good" terms: labeling people with mental retardation. Mental Retardation, 32(5), 363-365.

Hennequin, M., Morin, C., \& Feine, J. S. (2000). Pain expression and stimulus localisation in individuals with Down syndrome. The Lancet, 356(9245), 1882-1887.

Hogg, J., Reeves, D., Roberts, J., \& Mudford, O. C. (2001). Consistency, context and confidence in judgements of affective communication in adults with profound intellectual and multiple disabilities. Joumal of Intellectual Disability Research, 45(1), 18-29.

Horgan, M. F., \& Choonarah, I. (1996). Measuring pain in neonates: an objective score. Paediatric Nursing 8(10), 24-27.

Horgan, M. F., Glenn, S., \& I., C. (2002). Further development of the Liverpool Infant Distress Scale. Joumal of Child Health Care, 6(2), 96-106.

Houlihan, C. M., O'Donnel, M., Conaway, M., \& Stevenson, R. D. (2004). Bodily pain and healthrelated quality of life in children with celebral palsy. Developmental Medicine of Child Neurology, $46,305-310$.

Huijer Abu-Saad, H. (1998). Pijn en verstandelijke handicap. Een verkenning. In G. H. M. M. Horn ten, W. H. E. Buntinx, E. T. Klapwijk, P. A. H. Lieshout van, A. Vos-Olyslagers \& B. Zijderveld van (Eds.), Handboek mogelijkheden: vraaggerichte zorg voor mensen met een verstandelijke bandicap. Maarssen: Elsevier / De Tijdstroom.

Huijer Abu-Saad, H. (2000a). Challenge of pain in the cognitively impaired. The Lancet, 356(9245), 1867-1868.

Huijer Abu-Saad, H. (2000b). Pain assessment in the cognitively impaired: a challenge. Paper presented at the Conference on pain with significant neurological impairment, Toronto.

Hunt. (2000). Pain sources and pain cues of children with severe neurological impairment. Paper presented at the Conference on pain with significant neurological impairment, Toronto.

Hunt, A., \& Burne, R. (1995). Medical and nursing problems of children with neurogenerative disease. Palliative Medicine, 9, 19-26.

Hunt, A., Goldman, A., Seers, K., Crichton, N., Mastroyannopoulou, K., Moffat, V., et al. (2004). Clinical validation of the paediatric pain profile. Developmental Medicine \& Child Neurology, 46, 9-18.

Hunt, A., Goldman, A., Seers, K., Mastroyannopoulou, K., Moffat, V., Oulton, K., et al. (2002). $V$ alidation of the paediatric pain profile, a behavioural rating scale to assess pain in children with severe neurological impaiment. Paper presented at the 10th World Congtess on Pain, San Diego.

Hunt, A., Mastroyannopoulou, K., Goldman, A., \& Seers, K. (2003). Not knowing - the problem of pain in children with severe neurological impairment. International Joumal of Nursing Studies, 40, 171-183.

IASP. (1979). Pain terms: a list with definitions and notes on usage. Pain, 6, 249-252.

International Association for the Scientific Study of Intellectual Disabilities. (2001). Special Interest

Research Group 'Individuals with Profound Multiple Disabilities. Retrieved June 10, 2004, from http://www.iassid.org/pdf/p-mdisablitiesnewsletter.pdf

Jancar, J., \& Speller, C. J. (1994). Fatal intestinal obstruction in the mentally handicapped. Joumal of Intellectual Disabilitiy Research, 38, 413-422.

Janssens, J. M. A. M. (1991). Ogen doen onderzoek. Amsterdam: Swets \& Zeitlinger.

Jensen, M. P. (2003). Questionnaire validation: a brief guide for readers of the research literature. The Clinical Joumal of Pain, 19, 345-352. 
Johnston, C. C. (1998). Psychometric issues in the measurement of pain. In G. A. Finley \& P. J. McGrath (Eds.), Measurement of pain in infants and children, Progress in pain research and management.

Kalkman, C. J., Visser, K., Moen, J., Bonsel, G. J., Grobbee, D. E., \& Moons, K. G. M. (2003). Preoperative prediction of severe postoperative pain. Pain, 105, 415-423.

Kappesser, J., \& Williams, A. C. d. C. (2002). Pain and negative emotions in the face: judgements by health care professionals. Pain, 99, 197-206.

Kearney, P. M., \& Griffin, T. (2002). Between joy and sorrow; being a parent of a child with developmental disability. Joumal of Advanced Nursing, 34(5), 582-592.

Kelly, A. M., Powell, C. V., \& Williams, A. (2002). Parental visual analogue scale ratings of children's pain do not reliably reflect pain reported by child. Pediatric Emengengy Care, 18(3), 159-162.

Kiernan, C. C., Reid, B. D., \& Jones, L. M. (1982). Signs and symbols: a review of literature and survey of use of nonvocal communication systems (Vol. 11). London: University of London Institute of Educational Studies in Education.

Koot, H. M., Terstegen, C. M., \& Dongen van, K. A. J. (1999). Vaststelling van pijn bij mensen met een verstandelijke handicap. In Evenhuis H.M. \& Nagtzaam L. (Eds.), Medisch wetenschappelijk onderzoek bij verstandelijk gehandicapten.

Koot, H. M., Terstegen, C. M., Dongen van, K. A. J., \& Koudijs, S. M. (2000). Pain assessment in cognitively impaired children: attitudes of bealth care professionals and cortisol measurements. Paper presented at the Millcroft Inn Symposium, Toronto.

Kraijer, D. W. (1988). Psychosociale diagnostiek. In G. H. Gemert van \& W. K. Noorda (Eds.), Leerboek zuakzinnigenzorg (pp. 237-246). Assen: Van Gorcum.

Kraijer, D. W., \& Kema, G. N. (1994). SRZ, Sociale Redzaambeidsschaal voor Zwakqinnigen. Handleiding. Lisse: Swets \& Zeitlinger.

Kraijer, D. W., \& Plas, J. J. (1997). Psychodiagnostiek in de zorg voor verstandelijk gehandicapte mensen. Lisse: Swets \& Zeitlinger.

Krechel, S. W., \& Bildner, J. (1995). Cries: a new neonatal postoperative pain measurement core. Initial testing of validity and reliability. Paediatric Anaesthesia, 5, 53-61.

Kuo, R. S., \& Macnicol, M. F. (1996). Congenital insensitivity to pain: orthopaedic implications. Journal of Pediatric Orthopeadics part B, 5, 292-295.

LaChapelle, D. L., Hadjistavropoulos, T., \& Craig, K. D. (1999). Pain measurement in persons with intellectual disabilities. The Clinical Joumal of Pain, 15, 13-23.

Lawrence, J., Alcock, D., McGrath, P. J., Kay, J., Macmurray, S. B., \& Dulberg, C. (1993). The development of a tool to assess neonatal pain. Neonatal Network, 12, 59-66.

Leifer, J. S., \& Lewis, M. (1984). Acquisition of conversational response skills by young Down children and nonretarded young children. American Joumal of Mental Deficiency, 88(6), 610618.

Leong, F. T. L., \& Austin, J. T. (1996). The psychology research handbook: a guide for graduate students and research assistants. Thousand Oaks: SAGE Publications, Inc.

Lewis, J. N., Tonge, B. J., Mowat, D. R., Einfeld, S. L., Siddons, H. M., \& Rees, V. W. (2000). Epilepsy and associated psychopathology in young people with intellectual disability. Journal of Paediatrics and Cbild Health: Official Journal of the Australian College of Paediatrics, 36(2), 172175.

Lin, Y. C., \& Sentivany, S. K. (1994). Consistency in parameters of pain scores in a cbildren's bospital. Paper presented at the Third International Symposium on Pediatric Pain, Philadelphia.

Lincoln, Y. S., \& Guba, E. G. (1985). Naturalistic inquiry. London: SAGE.

Linfoot, K. (1988). Functions of communicative behaviour in children with severe developmental delay. Paper presented at the I.A.A.M.D., Dublin.

Liptak, G. S., O'Donnel, M., Conaway, M., Clumlea, W. C., Worley, G., Henderaon, R. C., et al. (2001). Health status of children with moderate to severe cerebral palsy. Developmental Medicine ef Child Neurology, 43, 364-370. 
Lloyd, L. L. (1989). Augmentative and alternative communication. American Joumal on Mental Retardation, 93(5), 500-502.

Loeser, J. D. (1980). Perspectives on pain. In Proceedings of first world conferences on clinical pharmacology and therapeutics (pp. 313-316). London: MacMillan Publishers.

Longley, S., \& Collins, G. J. (1994). The development of a non-verbal satisfaction measure for use with people who have severe of profound learning disabilities. The British Joumal of Developmental Disabilities, 40-2(79), 143-149.

Lower, T. A. (1999). Intellectual disabilities: Have we lost our sences? Mental Retardation, 37(6), 498503.

Luckasson, R. (2001). Request for comments of proposed new edition of mental retardation: definition, classification, and systems of supports

Luckasson, R., Coulter, D. L., \& Polloway, E. A. (1992). Mental retardation: definition, classification and systems of supports. Washington DC: AAMR.

Luckasson, R., \& Reeve, A. (2001). Naming, defining, and classifying in mental retardation. Mental Retardation, 39(1), 47-52.

Luckasson, R. J. D., Borthwick-Duffy, S., Butinx, W. H. E., VCoulter, d. L., Craig, E. M., Reeve, A., et al. (2002). Mental retardation; definition, classification, and systems of supports (10 ed.).

Maat van der, S. (1992). Communicatie tussen personen met een diep mentale bandicap en bun opvoed(st)ers. Leuven: Garant.

MacMillan, D. L., \& Gresham, F. M. (1993). Conceptual and psychometric concerns about the 1992 AAMR definition of mental retardation. American Journal on Mental Retardation, 98(3), 325335.

Malviya, S., Pandit, U. A., Merkel, S., Voepel-Lewis, T., Zang, L., Siewert, M., et al. (1999). A comparison of continuous epidural infusion and intermittent intravenous bolus doses of morphine in children undergoing selective dorsal rhizotomy. Regional Anestbesia and Pain Medicine, 24(5), 438-443.

Malviya, S., Voepel-Lewis, T., Trait, A. R., Merkel, S., Lauer, A., Munro, H., et al. (2001). Pain managment in children with and without cognitive impairment following spine fusion surgery. Pediatric Anasthesia, 11, 453-458.

Maso, I. (1994). Kwalitatief onderzoek (3 ed.). Amsterdam: Boom.

McGaffery, M. (1979). Nursing managment of the patient with pain. New York: Lippinkot.

McGaffery, M., \& Beebe, A. (1994). Pain: Clinical manual for nursing practice. St. Louis: Mosby Company.

McGaffery, M., \& Pasero, C. (2001). Assessment and treatment of patients with mental illness. AJN, 101(7), 69-70.

McGrath, P. A. (1990). Pain in children: nature, assessment \& treatment. New York: The Guilford Press.

McGrath, P. J. (1998). Behavioral measures of pain. In G. A. Finley \& P. J. McGrath (Eds.), Measurement of pain in infants and children, Progress in pain and research management (Vol. 10). Seattle: IASP Press.

McGrath, P. J. (2000). "But be doensn't feel pain mucb"; Five steps in the pain patbway in individuals with significant cognitive impairment. Paper presented at the Conference on pain with significant neurological impairment, Toronto.

McGrath, P. J., Johnston, G., Goodman, J. T., Schillinger, J., Dunn, J., \& Chapman, J. A. (1985). CHEOPS: a behavioral scale for rating post-operative pain in children. In H. L. Fields, R. Dubner \& F. Cervero (Eds.), Advances in pain research and therapy (Vol. 9, pp. 395-402). New York: Raven Press.

McGrath, P. J., Rosmus, C., Canfield, C., Campbell, M. A., \& Hennigar, A. (1998). Behaviours caregivers use to determine pain in non-verbal cognitively impaired individuals.

Developmental Medicine of Child Neurology, 40, 340-343.

McGrath, P. J., \& Unruh, A. M. (1987). Pain in children and adolescents. Amsterdam: Elsevier.

McGrath, P. J., \& Unruh, A. M. (1994). Measurement and assessment of pediatric pain. In R. Melzack \& P. D. Wall (Eds.), Textbook of pain (pp. 303-313). Edinburgh: Churchill Livingstone. 
McGrew, W. (1969). An ethological study of agonistic behavious in preschool children. Paper presented at the Second International Congress of Primatology, Basel.

McLaughlin, P. J., \& Wehman, P. (1996). Mental retardation and developmental disabbilities. Austin: PRO$\mathrm{ED}$, Inc.

McLean, J., \& Snyder-McLean, L. (1987). Form and function of communicative behaviour among persons with severe developmental disabilities. Australia and New Zealand Joumal of Developmental Disabilities, 13(2), 83-98.

McLean, L. K., Brady, N. C., \& McLean, J. E. (1996). Reported communication abilities of individuals with severe mental retardation. American Joumal on Mental Retardation, 100(6), 580-591.

Merskey, H. (1991). The definition of pain. European Joumal of Psychiatry, 6, 153-159.

Merskey, H. (2003, May 16). LASP pain terminology. Retrieved June 20, 2004, from http://wwww.iasppain.org/terms-p.html

Merskey, H., \& Bogduk, N. (1994). Classification of chronic pain: descriptions of chronic pain syndromes and definitions of pain terms (2nd ed.). Seattle: IASP Press.

Mette, F., Abittan, J., \& L'équipe de reeducation. (1988). Essais d' evaluation de la douleur chez le polyhandicape. Annales de Kinestherapy, 15(3), 101-104.

Miles, M. B., \& Huberman, A. M. (1994). Qualitative data analyses: an expanded sourcebook (2 ed.). Thousand Oaks: SAGE Publications.

Miller, A. C., Johann-Murphy, M., \& Pit-ten Cate, I. M. (1997). Pain, anxiety, and cooperativeness in children with cerebral palsy after thizotomy: changes throughout rehabilitation. Joumal of Pediatric Psychology, 22(5), 689-705.

Miller, J. F., \& Chapman, R. S. (1984). Disorder of communication: Investigating the development of language of mentally retarded children. American Joumal of Mental Deficiency, 88(5), 536-545.

Mills, N. M. (1989). Pain behavior in infants and toddlers. Joumal of Pain and Symptom Management, 4, 184-190.

Mills, N. M. (1996). Mills Infant/Toddler Pain Index. Not published.

Morgan, J., Peden, V., Bhaskar, K., Vater, M., \& Choonara, I. (2001). Assessment of pain by parents in young children following surgery. Paediatric Nursing, 11, 449-452.

Munhall, P. L., \& Oiler Boyd, C. (1993). Nursing research: a qualitative perspective (2 ed.). New York: National League for Nursing Press.

Murray, L. (2003). Self-harm among adolescents with developmental disabilities. Joumal of Psychosocial Nursing, 41(11), 37-45.

Nihira, K., Foster, R., Schelhaas, M., \& Leland, H. (1975). Manual for AAMD adaptive bebavior scale. Washington DC: AAMD.

No author listed. (1979). Pain control for the mentally disabled. The Joumal of the American Dental Assaciation, 98(1), 18-19.

No author listed. (1998). Pain control for the mentally disabled. The Joumal of the American Dental Association, 98(1), 18-19.

Nolan, J., Chalkiadis, G. A., Olesch, C. A., \& Brown, T. C. K. (2000). Anaesthesia and pain management in cerebral palsy. Anaestbesia, 55, 23-41.

Norman, G. R., \& Streiner, D. L. (2000). Biostatistics; the bare essentials. Hamilton: B.C. Decker.

Noterdeame, M., Sitter, S., Mildenberger, K., \& Amorosa, H. (2000). Diagnostic assessment of communicative and interactive behaviours in children with autism and receptive language disorder. European Cbild and Adolecent Psycbiatry, 9, 295-300.

Nowicki, S., \& Duke, M. P. (1994). Individual differences in the nonverbal communication of affect: the diagnostic analysis of nonverbal accuracy scale. Joumal of Nonverbal Behavior, 18(1), 9-35.

Oberlander, T. F. (2001). Pain assessment and management in infants and young children with developmental disabilities. Inf Young Children, 14(2), 33-47. 
Oberlander, T. F., Gilbert, C. A., Chambers, C. T., O'Donnel, M., \& Craig, K. D. (1999b). Biobehavioral resonses to acute pain in adolescent with a significant neurological impairment. The Clinical Joumal of Pain, 15, 201-209.

Oberlander, T. F., \& O'Donnel, M. (2001). Beliefs about pain among professionals working with children with significant neurological impairment. Developmental Medicine \& Child Neurology, 43, 136-140.

Oberlander, T. F., O'Donnel, M., \& Montgommery, C. J. (1999a). Pain in children with significant neurologic impairment. Developmental and Behavioral Pediatrics, 20(4), 235-242.

Oberlander, T. F., Symons, F. J., Dongen van, K. A. J., \& Huijer Abu-Saad, H. (2003). Pain in individuals with developmental disabilities. In J. O. Dostrovsky, D. B. Carr \& M. Koltzenberg (Eds.), Proceedings of the 10th world congress on pain. Progress in pain research and management (Vol. 24). Seattle: IASP Press.

O'Donnel, M., \& Armstrong, R. (1997). Pharmacologic interventions for management of spasticity in cerebral palsy. Menr Retard Dev Disabl Res Rev, 3, 204-211.

Ogletree, B. T., Wetherby, A. M., \& Westling, D. L. (1992). Profile of the prelinguistic intentional communicative behaviors of children with profound mental retardation. American Joumal on Mental Retardation, 97(2), 186-196.

Patja, K., Livanainen, M., Vesala, H., Oksanen, H., \& Ruoppila, I. (2000). Life expectancy of people with intellectual disability: a 35-year follow-up study. Joumal of Intellctual Disabilitiy Research, 44(part 5), 591-599.

Peters, J. W. B., Koot, H. M., Grunau, R. V. E., Boer de, J., Druenen van, M. J., Tibboel, D., et al. (2003). Neonatal facial coding system for assessing postoperative pain in infants: item reduction is valid and feasible. The Clinical Joumal of Pain, 19, 353-363.

Philipsen, H. (1990). Kwalitatief onderzoek: een plaatsbepaling. In A. L. Francke (Ed.), Kwalitatief onderzoek in de verpleegkunde. Amsterdam: Swets \& Zeitlinger.

Piaget, J., \& Inhelder, B. (1969). The psychology of the cbild. New York: Basic Books.

Pigeon, H. M., McGrath, P. J., Lawrence, J., \& Macmurray, S. B. (1989). Nurses' perceptions of pain in the neonatal intensive care unit. Joumal of Pain and Symptom Management, 4(4), 179-183.

Pokela, M. J. (1994). Pain relief can reduce hypoxemia in distressed neonates during routine treatment procedures. Pediatrics, 93, 379-383.

Poppes, P., \& Vlaskamp, C. (2001). Gedeeld en opgeteld. Rotterdam: Lemniscaat.

Porter, F. (1993). Pain assessment in children: infants. In Schechter N.L., Berde C.B. \& Yaster M. (Eds.), Pain in infants, children and adolescents. Baltimore: Williams \& Wilkins.

Price, D.D., Bush, F.M., Long, S. \& Harkins, S.W. (1994). A comparison of pain measurement characteristics of mechanical visual analogue and simple numerical tating scales. Pain, 56, 217-226.

Prkachin, K. M., \& Craig, K. D. (1985). Influencing non-verbal expressions of pain: signal detection analyses. Pain, 21, 399-409.

Ptkachin, K. M., \& Craig, K. D. (1995). Expressing pain: the communication and interpretation of facial pain signals. Joumal of Nonverbal Bebavior, 19, 191-205.

Quint, E., Elkins, T., Sorg, C., \& Kope, S. (1999). The treatment of cyclical behavioral changes in women with mental disabilities. Joumal of Pediatric \& Adolescent Gynecology, 12, 139-142.

Radbruch, L., Sabatowski, R., Loick, G., Jonen-Thielemann, I., Kasper, M., Gondek, B., et al. (2000). Cognitive impairment and its influence on pain and symptom assessment in a palliative care unit: development of a Minimal Documentation System. Palliative Medicine, 14, 266276.

Reid, G. J., Hebb, J. P. O., McGrath, P. J., Finley, G. A., \& Forward, S. P. (1995). Cues parents use to assess postoperative pain in their children. The Clinical Joumal of Pain, 11, 229-235.

Reimer, M. (2000). How well do proxies represent the views of cognitively impaired patients. AXON, June, 78.

Reiss, S. (1994). Issues in defining mental retardation. American Journal on Mental Retardation, 99(1), 1-7. 
Rincover, A. (1986). Behavioral research in self-injury and self-stimulation. Psychiatric Clinics of North America, 9, 755-766.

Romsing, J., Moller-Sonnergaard, J., Hertel, S., \& Rasmussen, M. (1996). Postoperative pain in children: comparison between ratings of children and nurses. Joumal of Pain and Symptom Management, 11(2), 42-46.

Romski, M. A., Sevcik, R. A., \& Adamson, L. B. (1997). Framework for studying how children with developmental disabilities develop language through augmented means. Augmentative and Alternative Communication, 13, 172-178.

Romski, M. A., Sevcik, R. A., \& Adamson, L. B. (1999). Communication patterns of youth with mental retardation with and without their speech-output communication devices. American Journal of Mental Retardation, 104(3), 249-259.

Rondal, J. A., \& Edwards, S. (1997). Language in mental retardation. London: Wurr Publishers Ltd.

Ross, D. M., \& Ross, S. A. (1988). Childhood pain: current issues, research and management. Baltimore: Urban \& Schwarzenberg.

Rüster, K., Argenton, K., Sievers, R., Kischkel, W., \& Berry, P. (1994). A multi-dimentional communication programme for a residential group of severely mentally handicapped women. International Joumal of Rebabitation Research, 17, 364-367.

Rycroft-Malone, J., Harvey, G., Kitson, A., McGormack, B., Seers, K., \& Titchen, A. (2002). Getting evidence into practice: ingredients for change. Nursing Standard, 16(37), 38-43.

Sappington, J., Reedy, S., Welch, R., \& Hamilton, J. (1989). Validity of messages from quadriplegic persons with celebral palsy. American Journal on Mental Retardation, 94(1), 49-52.

Schade, J. G., Joyce, B. A., Gerkensmeyer, J., \& Keck, J. F. (1996). Comparison of three preverbal scales for postoperative pain assessment in a diverse pediatric sample. Joumal of Pain and Symptom Management, 12(6), 348-359.

Schechter, N. L. (1993). Pain in infants, cbildren and adolescents. Baltimore: Williams \& Wilkins.

Scheers, T. F. H., \& Minderaa, R. B. (1995). Zwakzinnigheid. In J. A. R. Sanders-Woudstra, F. C. Verhulst \& H. F. J. Witte de (Eds.), Kinder-en Jeugdpsychiatrie. Assen: Van Gorcum.

Schofield, P., \& Davis, B. (2000). Sensory stimulation versus relaxation: a potential strategy for the management of chronic pain. Disability and Rebabilitation, 22(15), 675-682.

Schott, G. D. (2004). Communicating the experience of pain: the role of analogy. Pain, 108, 209-212.

Schrojenstein Lantman van - Valk de, H. M. J., Akker van den, M., Maaskant, M. A., Haveman, M. J., Urlings, H. F. J., Kessels, A. G. H., et al. (1997). Prevalence and incidence of health problems in people with intellectual disability. Joumal of intellctual disabilitiy research, 41(1), 4251.

Schrojenstein Lantman van - Valk de, H. M. J., Heurn van - Nijsten, E. W. A., \& Wullink, M. (2002). Prevalentie-onderzoek mensen met een verstandelijke beperking in Nederland. Maastricht: Universiteit Maastricht, capaciteitsgroep huisartsgeneeskunde.

Schrojenstein Lantman van - Valk de, H. M. J., Metsemakers J.F.M., Haveman M.J., \& Crebolder H.F.J.M. (2000). Health problems in people with intellectual disability in general practice: a comparative study. Family Practice, 17(5), 405-407.

Schwartz, L., Engel, J. M., \& Jensen, M. P. (1999). Pain in persons with cerebral palsy. Arch Pbys Med Rebabil, 80, 1243-1246.

Seibert, J., \& Hogan, A. (1982). Procedures manual for the early social-communication scales. Miami: University of Miami.

Shapiro, E. S., \& Browder, D. M. (1990). Behavioral assessment. In J. L. Matson (Ed.), Handbook of behaviour modifications with the mentally retarded. New York: Plenum Press.

Sherrard, J., Tonge, B. J., \& Ozanne- Smith, J. (2001). Injury in young people with intellectual disability: descriptive epidemiology. Injury prevention, 7, 56-61.

Shye, S. (1978). Theory construction and data analysis in the behavioral sciences. San Francisco: Jossey-Bass.

Silverman, D. (1993). Interpreting qualitative data. London: SAGE Publications, Inc. 
Simons, J., Franck, L., \& Roberson, E. (2001). Parent involvement in children's pain care: views of parents and nurses. Joumal of Advanced Nursing, 36(4), 591-599.

Smaling, A. (1987). Methodologische objectiviteit en kwalitatief onderzoek. Lisse: Swets \& Zeitlinger.

Smaling, A. (1996). De methodologische kwaliteit van kwalitatief onderzoek. Verpleegkunde, 11(4), 240-254.

Smaling, A., \& Zuuren van, F. (1992). De praktijk van kwalitatief onderzoek: voorbeelden en reflecties. Amsterdam: Boom.

Stallard, P., Williams, L., Lenton, S., \& Velleman, R. (2001). Pain in cognitively impaired, noncommunicating children. Arch Dis Cbild, 85, 460-462.

Stallard, P., Williams, L., Velleman, R., Lenton, S., \& McGrath, P. J. (2002b). Brief report: behaviors identified by caregivers to detect pain in noncommunicating children. Journal of Pediatric Psychology, 27(2), 209-214.

Stallard, P., Williams, L., Velleman, R., Lenton, S., McGrath, P. J., \& Taylor, G. (2002a). The development and evaluation of the Pain Indicator for Communicatively Impaired Children (PICIC). Pain, 98(1-2), 145-149.

Sternberg, L., Battle, C., \& Hill, J. (1980). Prelanguage communication programming severely and profoundly handicapped. Joumal of the Association for Persons with Handicaps, 5, 224-233.

Stevens, B. (1998). Composite measures of pain. In G. A. Finley \& P. J. McGrath (Eds.), Measurement of pain in infants and children, Progress in pain research and management (Vol. 10, pp. 161-178). Seattle: IASP Press.

Stevens, B., Johnston, C., Petryshen, P., \& Taddio, A. (1996). Premature Infant Pain Profile: development and initial validation. Clinical Joumal of Pain, 12, 13-22.

Strang, J. D. (1990). Cognitive deficits in children: adaptive behavior and treatment techniques. Epilepsia, 31 (suppl 4), 54-58.

Strauss, A., \& Corbin, J. (1990). Basics of qualitative research: Grounded Theory procedures and tecbniques. Newbury Park: SAGE Publications, Inc.

Streiner, D. L., \& Norman, G. R. (1998). Health measurement scales; a practical guide to their development and use. Oxford: Oxford University Press.

Suraseranivongse, S., Santawat, U., Kraiprasit, K., Petcharatana, S., Prakkamodom, S., \& Muntraporn, N. (2001). Cross-validation of a composite pain scale for preschool children within 24 hours of surgery. British Journal of Anaesthesia, 87(3), 400-405.

Swanborn, P. G. (1987). Metboden van sociaal-2vetenschappelijk onderzoek. Meppel: Boom.

Symons, F. J., Butler, M. G., Sanders, M. D., Feurer, I. D., \& Thompson, T. (1999). Self-injurious behavior and Prader-Willi syndrome: behavioral forms and body locations. American Joumal of Mental Retardation, 104, 260-269.

Symons, F. J., Koppekin, A., \& Wehby, J. H. (1999). Treatment of self-injurious behavior and quality of life for persons with mental retardation. Mental Retardation, 37(4), 297-307.

Symons, F. J., \& Thompson, T. (1997). Self-injurious behaviour and body site preference. Journal of Intellctual Disabilitiy Research, 41(Pt 6), 456-468.

Taylor, D. V., Rush, D., Hetrick, W. P., \& Sandman, C. A. (1993). Self-injurious behavior within the menstrual cycle of women with mental retardation. American Journal on Mental Retardation, 97(6), 659-664.

Terstegen, C. M. (2004). Assessing pain in cbildren with profound cognitive impaiment: the development of the Checklist Pain Behavior. Erasmus, Rotterdam.

Terstegen, C. M., \& Dongen van, K. A. J. (2002). De ontwikkeling van een meetinstrument voor pijnbeoordeling bij kinderen met een (zeer) ernstige verstandelijke handicap. Tijdscbrift Kindergeneeskunde, 70(1), 20-24.

Terstegen, C. M., Koot, H. M., Boer de, J., \& Tibboel, D. (2003). Measuring pain in children with cognitive impairment: pain response to surgical procedures. Pain, 103, 187-198. 
Tordjman, S., Antoine, C., Cohen D.J., Gauvain- Piqaurd, A., Carlier, M., Roubertoux, P., et al. (1999). Etude des conduites auto-aggresives, de la reactivite al la douleur et de leurs enterralations chez les enfants autistes. L'Encephale, 15, 122-134.

Tracy, J. M., \& Wallace, R. (2001). Presentation of physical illness in people with developmental disability; the example of gastro-oesophageal reflux. $M J A, 175,109-111$.

Turk, D. C., \& Flor, H. (1987). Pain behaviors: the utility and limitations of the pain behavior construct. Pain, 31, 277-295.

Turk, D. C., \& Melzack, R. (2001). Handbook of pain assessment. New York: The Guilford Press.

Turk, M. A., Geremski, C. A., Rosenbaum, P. F., \& Weber, R. J. (1997). The health status of women with cerebral palsy. Arch Pbys Med Rebabil, 78(suppl), 10-17.

Twycross, A. (1999). Pain management for children with special needs: a neglected area? Paediatric Nursing, 11(6), 43-45.

Twycross, A. (2000). Education about pain: a neglected area. Nurse Education Today, 220, 244-253.

Tyson, M. E., \& Favell, J. E. (1988). Mental retardation in children. In V. B. Van Hasselt, P. S. Strair \& M. Hersen (Eds.), Handbook of developmental and pbysical disabilities. London: Pergamon Press.

Ulvund, S. E., \& Smith, L. (1996). The predictive validity of nonverbal communicative skills in infants with perinatal hazards. Infant Behavior and Development, 19, 441-449.

United Nations High Commissioner for Human Rights (1989). Conventions on the rights of the child. Retrieved September 17, 2004, from

http://www.unhchr.ch/html/menu2/6/crc/treaties/crc.htm

Velthausz, F. J. M. (1987). Sociaal gedrag, sociale interaktie en kommunikatie bij diepravakginnigen. Utrecht: Proefschrift.

Verhofstadt-Denève, L., Geert van, P., \& Vyt, A. (1995). Handboek onturikkelings psychologie: grondslagen en theoriën. Houten: Bohn Stafleu van Loghum.

Verpoorten, R. A. W. (1996). Communicatie met verstandelijk gehandicapte autisten: een multidimensionaal communicatiemodel. Nederlands Tijdscbrift voor Zwakzinnigenzong, 2, 106-120.

Verstraete, J. (1997). Tandverzorging van mentaal gehandicapten: persoonlijke ervaringen. Dental Medicine, Belgisch Tijdscbrift voor Tandbeelkunde, 52(2), 56-68.

Villarreal, P., \& Johnson, C. P. (1995). Nursing care of children with developmental disabilities having surgery. Seminars in Perioperative Nursing, 4(2), 96-111.

Vlaskamp, C. (1993). Een kwestie van perspectief: methodiekontwikkeling in de zory voor emstig meervoudig gebandicapten. Groningen: Proefschrift.

Vlaskamp, C. (1997). Afgesproken werk: het belang van regels in de omgang met personen met ernstige meervoudige beperkingen. Tijdscbrift voor Ortbopedagogiek, Kinderpsycbiatrie en Klinische Kinderpsychologie, 22, 168-176.

Vlaskamp, C. (1999). Een eigen perspectief; een programma voor mensen met emstige meervoudige beperkingen. Assen: Van Gorcum.

Vlaskamp, C., Blokhuis, A., \& Ploemen, M. (1996). Gewoon bijzonder: opvoeden van kinderen met een ernstige meervoudige bandicap. Assen: Van Gorcum.

Vlaskamp, C., Meulen van der, B. F., \& Smrkovsky, M. (1999). GedragsTaxatieInstrument voor personen met emstige meervoudige beperkingen. Groningen: Stichting Kindstudies.

Vlaskamp, C., Meulen van der, B. F., \& Zijlstra, H. P. (2002). De instrumentele realisering van het GedragsTaxatieInstrument; normen, validiteit en betrouwbaarheid. Nederlands Tijdscbrift voor Orthopedagogiek, 1, 22-31.

Vlaskamp, C., \& Nakken, H. (1999). Missing in execution - therapies and activities for individuals with profound multiple disabilities. British Joumal of Development Disabilities, 45, Part 2(89), 99-109.

Vlaskamp, C., \& Oxener, G. (2002). Communicatie bij mensen met ernstige meervoudige beperkingen: een overzicht van assessment en interventie methoden. Nederlands Tijdschrift voor de Zorg aan verstandelijk gehandicapten, 28(4), 226-237. 
Vos de, M. (2001). Wat kan er nog meer? In De Vos M. (Ed.), Bijzondere zorg voor bijzondere kinderen (pp. 125-145)

Waldman, H. B., Swerdloff, M., \& Perlman, S. P. (2000). Children with mental retardation and epilepsy: Demographics and general concerns. Journal of Dentistry for Children, 67(4), 268-274, 231.

Watt-Watson, J. H. (1987). Nurses' knowledge of pain issues: A survey. Joumal of Pain and Symptom Management, 2, 207-211.

Werff van de, D. (2001). Strijd tegen pijn. In Vos M. de (Ed.), Bijzondere zorg voor bijzondere kinderen (pp. 115-123).

Wester, F. (1995). Strategieën voor kwalitatief onderzoek (3 ed.). Bussum: Dick Coutinho.

Wielenga, J. (1994). Observatie van gedragsmatige responsen en fysiologische responsen van neonaten met pijn: de ontwikkeling van een meetinstrument.Unpublished manuscript, Maastricht.

Wilcox, R. R. (2001). Fundamentals of modem statistical methods: substantially improving power and accuracy. New York: Springer.

Willems, A. B. C. (1997). Het dagcentrum voor kinderen met een verstandelijke of meervoudige handicap. In G. H. Gemert van \& R. B. Minderaa (Eds.), Zorg voor mensen met een verstandelijke bandicap. Assen: Van Gorcum.

Willems, J. B. H. G. (1996). Kijk op communicatie; constructie van een meetinstrument voor communicatie van mensen met een verstandelijke handicap. Unpublished manuscript, Tilburg. Wibro, Helmond.

World Health Organisation. (1992). Intermational statistical classification of diseases and related bealth problems (10th ed.). Geneva: WHO.

World Health Organisation. (2001). International classification of functioning, disability and health; classification by World Health Organisation. Retrieved June 14, 2002, from http://www3.who.int/icf/icftemplate.cfm?myurl=checklist.html\&mytitle=ICF\%20Checkli st

World Health Organisation. (2002). International classification of functioning, disability and bealtb; classification by World Health Organisation. Retrieved June 14, 2002, from http://www3.who.int/icf/onlinebrowser/icf.cfm?parentlevel=3\&childlevel=4\&itemslevel

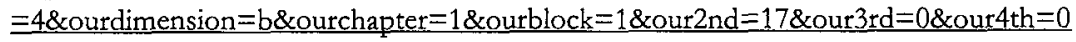

Yirmiya, N., Kasari, C., Sigman, M., \& Mundy, P. (1989). Facial expression of affect in autistic mentally retarded and normal children. Joumal of Child Psychology / Psychiatry, 30(5), 725-735.

Yoder, P. J., \& Feagans, L. (1988). Mothers' attributions of communication to prelinguistic behavior of developmentally delayed and mentally retarded infants. American Joumal on Mental Retardation, 93(1), 36-43.

Zhan S., \& Ottenbacher K.J. (2001). Single subject research design for disability research. Disability and Rebabilitation, 23(1), 1-8.

Zwakhalen, S. M. G., Dongen van, K. A. J., Hamers, J. P. H., \& Huijer Abu-Saad, H. (2004). Pain assessment in cognitively impaired individuals: non-verbal indicators nurses use. Journal of Advanced Nursing.

Zwakhalen, S. M. G., Dongen van, K. A. J., \& Huijer Abu-Saad, H. (2004). Pijnbeoordeling bij mensen met verstandelijke beperkingen. Nederlands Tijdschrift voor de Zorg aan mensen met verstandelijke beperkingen, 30(1), 3-21. 



\section{Summary}

This dissertation reports on the assessment of expressive pain behaviour in children with severe to profound intellectual disabilities, a topic in the area of paediatric pain that had rarely been investigated at the start of the research project. Over the years, valuable insight was gained into non-verbal expressions of pain in this specific population. In addition, this dissertation describes the development and psychometric evaluation of the instrument called Kids with Intellectual Disabilities Pain Assessment Instrument for Non-verbal Signals (KIDPAINS).

Chapter 1, the introduction to this dissertation, describes the rationale for the research project, and provides an overview of non-verbal expressions of pain derived from the literature on pain assessment in non-verbal paediatric populations at the start of the research project. The chapter also presents the facet design used to enable the comparison with the literature, based on seven dimensions of pain behaviour. Finally, the objectives and research questions underlying this dissertation are addressed.

Chapter 2 describes the development of an item bank using qualitative research methods. Possible expressions of pain were collected by conducting unstructured interviews with health care professionals and parents of non-verbal children and young adults with severe to profound intellectual disabilities, and by observing these children and young adults during possibly painful situations. A comparison was made with the items derived from the literature described in Chapter 1. In all, 209 expressive pain behaviours were included in the item bank, some of which were consistent with those found in the literature, although a large number of additional expressions were identified as well. The findings indicated that expressive pain behaviour by children with severe to profound intellectual disabilities is only partially comparable with that of normally developing children. It was hypothesised that functional abilities and behavioural repertoires might influence the expression of pain in this population.

Chapter 3 presents a cross-sectional study among nurses, investigating whether nurses caring for people with severe to profound intellectual disabilities regarded the items identified from the literature on pain assessment in this field as important. The study also included the newly identified items in Chapter 2, as well as signs of nociception. Data provided by nurses caring for people with severe intellectual disabilities were compared with those of nurses caring for people with profound intellectual disabilities. Results show that functional abilities and level of disability seem to influence the indicators nurses regard as important when diagnosing pain. In addition, nurses seemed to value all indicators as being important in diagnosing pain. Indicators referring to the context of behaviour as well as those referring to nociception were regarded as the most important ones. 
The data of this study could not be used to reduce the number of items in the item bank developed in Chapter 2. In fact, the study identified two additional items for the item bank, raising the total number of expressions in the item bank to 211 .

Chapter 4 describes the prevalence of the remaining six dimensions and 145 expressions of pain retained in the item bank after it had been tested for content as well as face validity and interpretability (Chapters 2, 3, Appendix I), in various groups of children with severe to profound intellectual disabilities. Information about the frequency of occurrence of the expressions was collected by means of a questionnaire for parents. The study investigated whether the ability to express pain in language, as well as additional disabilities such as severe motor impairments and the presence of behavioural and emotional disturbances, influence the expression of pain. Results showed that children with severe multiple disabilities more often displayed items related to the Motor dimension (e.g. High muscle tone, cramping) and were less likely to express themselves by using behaviours related to the Injured Body Part dimension (e.g. Rubbing injured body part). Children with behavioural and emotional disturbances, by contrast, more often displayed changes in Social-Emotional and Vocal behaviour (e.g. 'Self-biting' and 'Stereotypical, repetitive sounds). This study also showed that, although there are differences in the most frequently occurring items, the various groups of children also displayed similarities in terms of common expressions of pain. Items such as Restless movements' and Looking sad' frequently occurred in all children. In addition, 'Crying loudly, intensely' was seen as the most important behavioural expression of pain by all parents. Based on the above findings, it was decided to limit the population for the development of the KIDPAINS instrument to non-verbal children with profound intellectual disabilities. Results of the questionnaire for parents were used to achieve an initial item selection for KIDPAINS.

Chapter 5 describes the item selection process for KIDPAINS. The 114 items retained after reduction based on parents' reports (Appendix II) and a final check of the draft scale (Appendix I) were used to rate video recordings derived from observations of 52 children with profound intellectual disabilities at standardised episodes before and after a medical procedure under general anaesthesia. Two episodes were selected for presumed absence of pain (one day before the procedure within the hospital and one month after the procedure at home), while three episodes were selected for presumed presence of pain (30 minutes, 3 hours, 24 hours after extubation). One episode was selected as an intervention-specific moment presumed to reflect acute pain. The item selection process was applied separately for each time episode in order to cross-validate the selection process. Items were discarded based on frequencies of endorsement, internal consistency and Principal Components Analysis per dimension for each different time episode, as well as based on a negative coherence between components. This resulted in 42 items that were present in the item selections for at least one time episode. The facet design presented in Chapter 1 was partially abandoned based on these analyses. After subtraction of the 'normal' behaviour, as scored one day before and 
one month after the procedure, from the behaviour at the moments of presumed pain, correlations with VAS were especially significant for the Facial, Vocal and Social-Emotional components identified by PCA. A comparison of the results for different time episodes identified a total of 11 of these possible components. Since clear convergent relationships with pain could not be identified for all components/ dimensions, further investigation of psychometric properties was needed.

Chapter 6 describes the further psychometric evaluation of KIDPAINS for children with profound multiple disabilities. To this end, known groups were created based on previous VAS pain ratings in order to investigate construct validity. Four observers, including two nurses not familiar with the participating children, observed children who had previously been judged to be in pain, as well as those who had been judged to be pain free. The results of this study led to a final 18-item version of KIDPAINS, which was internally consistent and both between and within observers agreement was good. In addition, the reduced KIDPAINS instrument was found to be sensitive and specific both in differentiating between no-pain and pain situations and in differentiating between moderate and severe pain. A diagnostic cut-off point was established for moderate and severe pain. KIDPAINS showed strong convergent relations with other pain measures. However significant correlations with VAS stress were identified as well. This study also found that a scale developed for a broader population of children with severe to profound intellectual disabilities might lead to underestimation of pain in children with profound multiple disabilities.

Chapter 7 presents a general discussion of the main findings of all studies presented in the dissertation. A distinction is made between the investigation of expressive pain behaviour as such and the development and psychometric evaluation of the pain assessment scale. Theoretical and methodological reflections on both topics are provided in the form of answers to critical questions. In addition, an update is provided of the literature available by the end of the present research project.

\section{Appendix I}

After an overall inventory of items had been made (Chapters 2 and 3), the resulting 211 items were further developed and an initial item selection process took place. This process is described in Appendix I. Four experts checked the items for interpretability, judging aspects like reading level, ambiguity, use of jargon and possible overlap. The remaining, adjusted items were used in a pilot study to test their applicability in a hospital environment, using a draft scale developed for this purpose. Based on the results, further adjustment of the items took place and several items were removed from the selection. Items were then further tested for content validity among health care professionals attending a symposium on people with intellectual disabilities. They were invited to describe to what extent an item was useful as an expression of pain (not, a little, definitely) and to provide additional comments on the items. Based on the remaining items, a questionnaire 
for parents was developed including 145 questions (Chapter 4) relating to the 145 expressions included in the draft scale at that point. A final check of the draft scale led to the removal of another seven items, leaving 138 items in the scale.

Appendix II provides the statistical background information for the item selection process presented in Chapters 5 and 6. In this process, the item selection was narrowed down from 138 to 114 items, based on parents' reports. In addition, clinical data were used to reduce the number of items for KIDPAINS from 114 to 42 items. Finally, the study reported on in Chapter 6 selected 18 items for the final version of KIDPAINS. 


\section{Samenvatting}

Deze dissertatie gaat in op het beoordelen van pijngedrag bij kinderen met een (zeer) ernstige verstandelijke beperking. Een onderwerp dat, toen het in dit proefschrift beschreven onderzoek van start ging, nog nauwelijks enige aandacht had gekregen. In de loop der jaren is inzicht verkregen in non-verbale uitingen van pijn bij deze bijzondere groep kinderen. Bovendien werd de Kids with Intellectual Disabilities Pain Assessment Instrument for Non-verbal Signals (KIDPAINS) ontwikkeld en psychometrisch getest. Een instrument waarmee pijn bij kinderen met zeer ernstige meervoudige beperkingen op valide en betrouwbare wijze beoordeeld kan worden.

Hoofdstuk 1, de introductie van dit proefschrift, beschrijft de achtergrond en relevantie van het onderzoek. Bovendien geeft het een overzicht van non-verbale uitingen van pijn die op basis van de literatuur op het gebied van pijnbeoordeling bij kleine kinderen onderscheiden kon worden bij de aanvang van het onderzoek. Tevens wordt in dit hoofdstuk een facet design gepresenteerd waarin zeven dimensies van pijn beschreven zijn. Dit design werd ontwikkeld om het hele scala aan pijnuitingen te dekken en om uitingen van pijn met elkaar te kunnen vergelijken. Tenslotte wordt ingegaan op de doelstellingen en onderzoeksvragen die aan dit proefschrift ten grondslag liggen.

Hoofdstuk 2 beschrijft de ontwikkeling van een database met pijnuitingen die op basis van kwalitatieve onderzoeksmethoden werd opgezet. Mogelijk pijngedrag werd verzameld door middel van (1) ongestructureerde interviews met professionele hulpverleners uit de zorg voor mensen met een verstandelijke beperking, (2) ongestructureerde interviews met ouders van kinderen en jong volwassenen met een ernstige tot zeer ernstige verstandelijke beperking, en (3) het observeren van deze groep kinderen en jong volwassenen tijdens mogelijk pijnlijke situaties. In totaal werden 209 uitingen van pijn in de database opgenomen. Deze uitingen kwamen gedeeltelijk overeen met de uitingen uit het literatuuronderzoek, beschreven in Hoofdstuk 1. Daarnaast is echter een groot aantal nieuwe uitingen geïdentificeerd. De bevindingen geven aan dat expressief pijngedrag van kinderen met een (zeer) ernstige verstandelijke beperking slechts gedeeltelijk is te vergelijken met het pijngedrag van normaal ontwikkelde kinderen. Hieruit volgt de veronderstelling dat functionele mogelijkheden en gangbare gedragspatronen mogelijk invloed hebben op het uiten van pijn binnen de populatie. Tevens werd vastgesteld dat men in de dagelijkse praktijk veel gebruik lijkt te maken van symptomen die wijzen op een weefselbeschadiging als indicator van pijn.

Hoofdstuk 3 beschrijft een cross-sectioneel onderzoek uitgevoerd onder verpleegkundigen. Er is onderzocht in welke mate verpleegkundigen die in de praktijk zorg verlenen aan mensen met een ernstige of zeer ernstige verstandelijke 
beperking de uitingen afkomstig uit de literatuur op het gebied van pijnbeoordeling in deze groep belangrijk vinden. Hierbij werden ook de nieuw geïdentificeerde items uit Hoofdstuk 2 meegenomen, alsmede signalen die wijzen op een weefselbeschadiging. Vervolgens zijn de gegevens van verpleegkundigen die zorg verlenen aan mensen met een ernstige verstandelijke beperking vergeleken met de gegevens van verpleegkundigen die zorg verlenen aan mensen met een diep verstandelijke beperking. De resultaten hiervan geven aan dat de functionele mogelijkheden en de mate van de verstandelijke beperking invloed lijken te hebben op de indicatoren die verpleegkundigen belangrijk vinden bij het vaststellen van pijn. De verpleegkundigen vinden overigens alle indicatoren belangrijk als het gaat om het vaststellen van pijn. Aan indicatoren die meer informatie verschaffen over de context van het pijngedrag en vragen die te maken hebben met tekenen van nociceptie wordt de meeste waarde gehecht. De gegevens uit dit onderzoek kunnen niet gebruikt worden om de database met indicatoren uit Hoofdstuk 2 te reduceren. Het onderzoek brengt echter wel twee nieuwe indicatoren aan het licht, waardoor het totaal aan uitingen in de database uitkomt op 211.

Hoofdstuk 4 beschrijft de prevalentie van de zes dimensies van pijn in verschillende onderscheiden groepen kinderen met (zeer) ernstige verstandelijke beperkingen. Daarnaast wordt de mate waarin 145 uitingen van pijn voorkomen beschreven. Deze uitingen werden op het eerste gezicht valide bevonden door experts alsmede getest op inhoudsvaliditeit en interpreteerbaarheid (Hoofdstukken 2 en 3 en Appendix I). Informatie over de frequentie van het voorkomen van deze uitingen bij kinderen wordt verkregen door middel van een vragenlijst voor de ouders. Er is onderzocht of de mogelijkheden die kinderen hebben om pijn te kunnen uiten middels taal alsmede of het hebben van ernstige motorische beperkingen of gedragsproblemen pijngedrag beïnvloeden.

De resultaten van dit onderzoek geven onder andere aan dat kinderen met ernstige meervoudige beperkingen vaker pijn uiten middels uitingen die tot de dimensie Motoriek behoren. Hierbij valt bijvoorbeeld te denken aan In spanning komen, verkrampen, spasticiteit'. Daarentegen uiten deze kinderen pijn minder vaak middels gedrag behorend tot de dimensie Aangedaan Lichaamsdeel. Zo zullen zij minder vaak 'Wrijuen over het aangedaan lichaamsdeel'. Kinderen met gedragsproblemen laten vaker een gedragsverandering zien op het gebied van de Sociaal-Emotionele of de Vocale dimensie (zoals 'Zichzelf bijten' en 'Stereotiep, steeds berbalend geluid'). Het onderzoek laat verder zien dat, hoewel er verschillen zijn in de mate waarin de 145 uitingen van pijn voorkomen, de verschillende groepen kinderen ook overeenkomsten hebben in hun pijngedrag. Items zoals 'Bewegingsonrust' en 'Droevig kijken' komen bij alle kinderen veelvuldig voor, ongeacht mogelijkheden en beperkingen. Volgens alle ouders is 'Hard, intens, doordringend builen' het meest belangrijke signaal dat een kind pijn heeft. 
Gebaseerd op bovenstaande bevindingen is besloten om voor de verdere ontwikkeling van de KIDPAINS de populatie te beperken tot kinderen met een zeer ernstige verstandelijke beperking. Deze kinderen worden niet in staat geacht om pijn te uiten middels woorden. De resultaten van de vragenlijst voor de ouders werden mede gebruikt om indicatoren voor KIDPAINS te selecteren.

Hoofdstuk 5 beschrijft het proces van selecteren van indicatoren voor KIDPAINS. $\mathrm{Na}$ reductie gebaseerd op een laatste controle van de ontwerpschaal $(\mathrm{N}=138)$ en de vragenlijsten voor ouders resteerden 114 uitingen van pijn. Deze zijn gebruikt voor het beoordelen van video-opnamen van 52 kinderen met een zeer ernstige verstandelijke beperking op vastgestelde tijdstippen voorafgaand aan en na een medische ingreep onder algehele narcose. Er zijn twee tijdstippen gekozen in een verondersteld pijnloze situatie (een dag voor de ingreep en een maand na de ingreep terug in de thuissituatie) en drie tijdstippen waarop verondersteld mag worden dat de kinderen onderhevig zijn aan pijn (dertig minuten, drie uur en 24 uur na de ingreep). Tot slot is een moment gekozen als interventie-specifiek moment, waarbij acute pijn verondersteld is. Het selecteren van indicatoren vond voor ieder tijdsinterval separaat plaats om het selectieproces te kunnen crossvalideren. Indicatoren zijn verwijderd op basis van (1) de mate waatin ze gescoord werden, (2) interne consistentie analyses en (3) Principale Componenten Analyse (PCA) per dimensie, voor ieder afzonderlijk tijdsstip. Daarnaast zijn indicatoren verwijderd op basis van een negatieve samenhang tussen componenten. Uiteindelijk resulteerde deze analyses in 42 pijnuitingen die gedurende minimaal één tijdsinterval werden geobserveerd. Het facet design uit Hoofdstuk 1 werd op basis van deze analyses gedeeltelijk losgelaten. Na subtractie van het 'normale' gedrag (één dag voor en één maand na de ingreep) van het gedrag op momenten van veronderstelde pijn bleek dat correlaties met de Visueel Analoge Schaal (VAS) met name significant waren voor de Gelaats-, Vocale en Sociaal-Emotionele componenten die middels PCA werden geïdentificeerd. Een vergelijking van de resultaten op verschillende tijdsstippen bracht in totaal elf mogelijke componenten naar voren. Aangezien een duidelijke convergente relatie met VAS pijn niet voor alle componenten/dimensies aangetoond kon worden is verder onderzoek van de psychometrische kenmerken vereist.

Hoofdstuk 6 beschrijft het verder psychometrisch testen van KIDPAINS bij kinderen met zeer ernstige meervoudige beperkingen. Constructvaliditeit werd onderzocht door het vormen van twee extreme groepen. Hiervoor werden VAS pijnscores gebruikt uit eerder onderzoek (Hoofdstuk 5) Vier beoordelaars, waaronder twee verpleegkundigen die niet bekend waren met de deelnemende kinderen en het onderzoek, observeerden video-opnamen van kinderen waarvan eerder verondersteld was dat ze pijn ondervonden, alsmede opnamen van kinderen die geen pijn leken te hebben. De resultaten van dit onderzoek leidden tot een verdere reductie en een uiteindelijk selectie van 18 indicatoren voor KIDPAINS. 
Het ontwikkelde instrument bleek zowel intern consistent te zijn alsmede te leiden tot een goede overeenstemming tussen beoordelaars en binnen dezelfde beoordelaar. Op basis van Principale Componenten Analyse werden twee componenten geïdentificeerd. Daarnaast bleek dat de KIDPAINS sensitief en specifiek was, zowel in het differentiëren tussen pijn en geen pijn als in het differentiëren tussen gematigde en ernstige pijn. Op basis van deze resultaten werd een diagnostisch criterium vastgesteld voor zowel de aanwezigheid van pijn als de aanwezigheid van ernstige pijn. Bovendien vertoont KIDPAINS sterke convergente relaties met andere pijnbeoordelingsinstrumenten. Er werden echter ook correlaties vastgesteld met het construct Stress. Uit dit onderzoek kwam verder naar voren dat een schaal die ontwikkeld is voor de bredere groep van kinderen met een ernstige tot zeer ernstige verstandelijke beperking mogelijk leidt tot een onderschatting van de pijn van kinderen met zeer ernstige meervoudige beperkingen.

Hoofdstuk 7 behelst de algemene discussie van de voornaamste bevindingen van alle onderzoeken die gepresenteerd worden in deze dissertatie. Hierbij wordt een verschil aangebracht tussen het bediscussiëren van het onderzoeken van expressief pijngedrag enerzijds en het ontwikkelen en psychometrisch testen van een pijnbeoordelingsschaal anderzijds. Zelfkritische vragen worden gesteld in het licht van de theoretische en methodologische overwegingen met betrekking tot beide onderwerpen. Tot slot wordt een update van de huidige stand van zaken in de literatuur weergegeven.

Appendix I beschrijft het proces van het opzetten van de database van 211 indicatoren (Hoofdstuk 2 en Hoofdstuk 3) en het verder ontwikkelen en reduceren van die database. $\mathrm{Na}$ het verzamelen van indicatoren hebben vier experts de indicatoren onderzocht op interpreteerbaarheid, met inbegrip van aspecten als begrijpelijkheid, dubbelzinnigheid, gebruik van jargon en mogelijke overlap tussen indicatoren. De overblijvende en eventueel aangepaste indicatoren werden gebruikt in een pilotstudy om hun toepasbaarheid te testen in een ziekenhuisomgeving. Hiervoor is een ontwerpschaal ontwikkeld. Gebaseerd op de resultaten van deze schaal vond verder aanpassing van de indicatoren plaats en werd een aantal uitingen verwijderd uit de selectie. De indicatoren zijn vervolgens verder getoetst op inhoudsvaliditeit door professionele hulpverleners in de zorg aan mensen met een verstandelijke beperking die een symposium bijwoonden over pijn in deze populatie. Hen werd gevraagd te beschrijven in hoeverre een pijnuiting voor hen bruikbaar was (niet, een beetje, zeer) en of zij nog aanvullende commentaren op de indicator hadden. Op basis van deze gegevens werden indicatoren aangepast of alsnog verwijderd. Gebaseerd op de overblijvende uitingen is een vragenlijst voor ouders samengesteld bestaande uit 145 vragen (Hoofdstuk 4) relaterend aan de 145 uitingen uit de ontwerpschaal op dat moment. 
Een laatste check van deze schaal leidde tot het verwijderen van nog eens zeven uitingen, waardoor een schaal ontstond van 138 indicatoren.

Appendix II voorziet in de statistische achtergrondinformatie betreffende de reductie van indicatoren in Hoofdstuk 5 en Hoofdstuk 6. In deze hoofdstukken werd de selectie in eerste instantie teruggebracht van 138 naar 114 door gebruik te maken van de vtagenlijsten van ouders van kinderen met zeer ernstige verstandelijke beperkingen die niet verbaal konden communiceren. Vervolgens is de selectie voor KIDPAINS op basis van klinische data verder teruggebracht van 114 naar 42 indicatoren. Tot slot zijn in Hoofdstuk 6 uiteindelijk 18 indicatoren geselecteerd voor de gereduceerde en definitieve versie van KIDPAINS die psychometrisch getest werd bij kinderen met een zeer ernstige meervoudige beperking. 



\section{Dankwoord}

Hoera, dit proefschrift is klaar!

Als een naïeve enthousiasteling met een hart voor onderzoek en mensen met een verstandelijke beperking ben ik zes jaar geleden aan dit project begonnen. Gaandeweg het proces werd steeds duidelijker dat er bij een promotieonderzoek meer komt kijken. Het gaat in de wetenschap niet altijd om het belang van het onderzoek en het belang van de doelgroep. Andere belangen spelen een rol. Belangen waar je geen invloed op hebt. Het leren onder ogen zien van die realiteit was een moeizaam proces. Het proefschrift werd een beproevingsschrift. Maar juist dat proces heeft gemaakt dat ik onderweg zoveel bagage heb kunnen meenemen. Na veel klimmen, stilstaan, periodes aan de zuurstof, afdalen en opnieuw beginnen eindelijk de top van de berg in zicht. Met een rugzak vol persoonlijke en psychometrische ervaringen. Gesterkt door al die bagage is één ding zeker: de supporters in het basecamp maken de reis pas echt de moeite waard.

Op de eerste plaats wil ik daarom Paul bedanken. One love. Jouw onvoorwaardelijke steun in zes tropenjaren heeft ervoor gezorgd dat dit proefschrift hier nu ligt. Dank je wel voor alles wat je me hebt gegeven. Ik verheug me enorm op de rest van ons leven samen. We gaan heerlijk genieten; van elkaar en van ons kindje! Lief klein ukkie in mijn buik, wat een geluk dat wij jou verwachten. Jouw komst is mooier dan welk proefschrift ook!

In het bijzonder wil ik ook bedanken alle kinderen en hun ouders die aan het tot stand komen van dit proefschrift hebben bijgedragen. Ik hoop dat ik jullie pijn heb weten te vertalen naar een methode waarmee anderen begrijpen wat jullie zonder woorden over pijn vertellen. Dat is het enige wat telt.

In het begeleidingskamp wil ik me als eerste richten tot Huda Huijer Abu-Saad, mijn promotor. Beste Huda, ik heb jou leren kennen tijdens het schrijven van het jaarwerkstuk. Mijn eerste kennismaking met het onderwerp pijn bij kinderen. Dankzij jouw hulp kon ik kort daarop samen met Nanda mijn koffers pakken om Down Under te gaan voor ons afstudeeronderzoek. Onder toeziend oog van jouw collega David Champion kwamen we in het Paediatric Pain Laboratory van Sydney's Childrens Hospital terecht bij Belinda Goodenough. We hadden het niet beter kunnen treffen. $\mathrm{Bij}$ terugkomst in Nederland wist je me te interesseren voor een aio-plaats. Jij werd mijn promotor. Wat ik de afgelopen jaren het meest in jou heb gewaardeerd is je passie en enthousiasme voor het onderzoek. Ik wil je vooral bedanken voor het vertrouwen wat ik door de jaren heen van jou heb gekregen. Vertrouwen in mijn kwaliteiten als onderzoeker, en als persoon. Ook op momenten dat het niet zo vanzelfsprekend was. 
Naast Huda was daar voortdurend mijn copromotor Jan Hamers. Beste Jan, als copromotor ben je door weer en wind bij mij en het onderzoek betrokken geweest. Dat was vast niet altijd makkelijk. Steeds bleef je echter optimistisch over een goede afloop. Je hebt gelijk gekregen. Dank voor het trouw lezen van mijn stukken en je kritische feedback daarop. Dat heb ik erg gewaardeerd. Dank ook voor de Kleenex die je hebt uitgedeeld tijdens onze vele bijeenkomsten en je altijd hartelijke ontvangst.

Mijn tweede promotor Martijn Berger nam 'het stokje over' van Huda toen zij naar Libanon verhuisde. Beste Martijn, van adviserend statisticus werd je mijn promotor. Jij hebt mij ertoe bewogen de 'vaart' in mijn promotie te krijgen toen het einde van mijn aanstelling in zicht kwam. Daarvoor dank, alsmede voor je adviezen op het gebied van statistiek en het maken van stellingen...

Onlosmakelijk met Maastricht verbonden is ook mijn paranimf Sandra Zwakhalen. Lieve San. Elk nadeel heb z'n voordeel. In de periode dat ik zelf mijn werk niet kon doen kwam jij 'op' het project. Ik had me geen betere vervanger kunnen wensen en wat een geluk dat je bent gebleven toen ik weer terugkwam. Bedankt voor al het werk dat je hebt verzet voor het project (vragenlijsten invoeren, video's scoren, het opschonen van databestanden, het controleren van dossiers, etc., etc.). Dank ook voor je luisterend oor, het meedenken, het meelezen en al je goede zorgen. Het is niet meer dan logisch dat jij mijn nimf bent!

Het onderzoek beschreven in dit proefschrift werd niet alleen vanuit Maastricht georganiseerd. Op de eerste plaats wil ik Chantal Terstegen bedanken voor de Rotterdamse bijdrage aan het project. Als co's begonnen wij in 1998 aan het onderzoek. We hebben samen veel plezier gehad. Op stap met een veel te grote videocamera, rennend met een infuusstandaard door het ziekenhuis. Jammer genoeg bleek onze vriendschappelijke samenwerking niet voldoende basis te zijn om tot een gezamenlijk eindresultaat te komen. Ik wens je veel geluk met Maarten en jullie meisjes.

Beste professor Tibboel en professor Koot. Ik heb veel van jullie geleerd, waarvoor dank. Professor Passchier wil ik bedanken voor zijn rol als mediator en voor het lezen en beoordelen van mijn proefschrift. Josien de Boer voor haar stimulerende inbreng in de projectgroepvergaderingen.

Tevens wil ik alle verpleegkundigen, artsen, tandartsen, mondhygiënistes, fysiotherapeuten, (neuro-) psychologen, orthopedagogen en andere hulpverleners die deelgenomen hebben aan de interviews, vragenlijsten hebben ingevuld of op een andere wijze hebben bijgedragen aan het project heel hartelijk bedanken. Fijn dat jullie je kennis en ervaringen hebben willen delen. Jullie inbreng was onmisbaar. In het bijzonder wil ik bedanken alle medewerkers van Sint Anna in Heel, Op de Bies in Landgraaf, Maasveld in Maastricht en de Stichting Bijter in Rotterdam. Daarnaast natuurlijk ook alle verpleegkundigen, artsen, anesthesisten, en secretariële ondersteuners van het Sophia Kinderziekenhuis in Rotterdam. 
Dank ook aan alle studenten die een bijdrage hebben geleverd aan de dataverzameling van dit proefschrift. In het bijzonder wil ik noemen Alineke van Nieuwenhuize, Martijn van Lobenstein, Clemens Ketels en Suzanne Koudijs.

Verder wil ik me in Maastricht tot een aantal mensen richten. Op de eerste plaats Jan Klerkx. Beste Jan, jouw kritische blik beperkte zich niet alleen tot mijn Engelse teksten. Dank voor al je goede vragen, opmerkingen en je snelle, betrouwbare service. Lieve Brenda, ongeveer tegelijkertijd begonnen we aan ons aio-schap, ongeveer tegelijkertijd zijn we klaar. Jouw promotie was mijn generale repetitie. Het was fijn om een bondgenoot te hebben, zeker omdat jij je evenzeer als ik met 'onze' doelgroep verbonden voelt. Dank je wel voor je hulp door de jaren heen. Daamaast dank aan alle collega's van Verplegingswetenschap en het voormalig Centre for Nursing Research die bij mij en mijn onderzoek betrokken zijn geweest. Ik wil Nienke bedanken voor het aanschouwen van mijn dansjes, Inez, Anja, en Mirjam voor alle gezellige onderonsjes, Karen voor haar betrokkenheid bij mij en mijn werk en Arnold voor het geduldige beantwoorden van mijn logische en minder logische computervraagstukken. Mijnheer Buntinx wil ik bedanken voor zijn altijd enthousiaste uitleg over het AAMR classificatiesysteem alsmede voor zijn hulp bij de kwalitatieve dataverzameling. Marian Maaskant dank ik voor haar humoristische reflectie.

Ton Schmidt en Ton van Attekum stonden mij bij tijdens een moeilijke periode in het project. Ook zou ik via deze weg Cindy Vijn willen bedanken. Beste Cindy, jij was de begeleidster van mijn andere promotietraject. Ik ben je erg dankbaar voor het inzicht wat je mij hebt weten te geven.

Beste Tineke, ik heb op jou gepast toen je nog een klein meisje was. Wat een verrassing toen bleek dat jij zo'n goede kunstenares bent geworden. Je mag trots zijn op jezelf. Jouw bloem straalt vrolijkheid en kracht uit en ik vind hem heel erg mooi!

Lieve papa en mama. Van jullie heb ik altijd de kans gekregen om te studeren. Mijn doorzettingsvermogen heb ik aan jullie te danken. Een onmisbaar ingrediënt om een proefschrift af te kunnen ronden. Dank je wel voor jullie steun. Vanaf nu gaan we de vruchten plukken van al die jaren hard werken.

Lief zusje, zussen bij toeval, vriendinnen bij keuze. Ik ben trots op wie je bent en wat je hebt bereikt. Dank je wel voor al je wijze woorden.

Lieve Ankie en Leo. Het is boffen om zulke schoonouders te hebben. Of het nou om zelfgemaakte appelmoes of om vervoer naar Schiphol gaat, jullie staan altijd voor ons klaar! Dank je wel voor jullie support. 


\section{"Life is notbing without friendship"}

Lieve Stans, "Dat groeit toch uit elkaar", zei Anja op het einde van ons Esprittijdperk. Ze had er niet meer naast kunnen zitten. Van collega's naar snotvriendinnen. Dank je wel voor je betrokkenheid bij alle goede en minder goede tijden die we in de loop der jaren samen hebben gedeeld. Het was niet altijd leuk om een promoverende vriendin te hebben. $\mathrm{Nu}$ is de tijd aangebroken om 'de schade' in te halen. Lekker met z'n tweetjes of samen met Yorick en jullie meisje; mijn petekindje Britte. Ik verheug me daar ontzettend op!

Hele lieve Mascha, Joyce, Saskia, Inge, Leontien en Ursula, oftewel lieve meisjes, of beter gezegd onverbeterlijke U.F.'s. Nooit gedacht dat ons midweekje Terschelling zou leiden tot Rozengeur en Wodkalime. $\mathrm{Na}$ een avondje lachen (en janken) met jullie is de batterij altijd weer opgeladen. Dank jullie wel voor jullie vriendschap. Ook in alle subclubjes... Dat er nog veel weekeindjes, uitstapjes en etentjes mogen volgen. Ik wil er geen meer missen!!! Lieve David, Raymond, Peter, Eldon, Gery, Gijs, Pleun, Lot, Jet, Job en Suus bedankt voor het lenen van jullie partners en mama's!

Lieve Frank en Eef. Het is altijd feest om samen met jullie en Maetje te zijn. Bedankt voor de goede gesprekken op momenten dat het nodig was.

Alle familieleden, vrienden en kennissen die door de jaren heen met belangstelling mijn vorderingen hebben gevolgd wil ik bedanken voor hun interesse. Denise \& Willem, Mariken \& Eric, Ted \& Lenneke, Astrid \& Remco, Barbara \& Patrick, Femke \& Rob, de jongens van de jaarclub met partners, vrienden uit Liempt, Femke, Lucienne Hoogwerf en alle andere collega's van Fontys Hogeschool Verpleegkunde, Mam 2 en Theo, buren uit de Sophia van Wurtemberglaan, DE buren uit Boxtel, ....en al die andere lieve mensen.

Lieve Nanda. Samen met jou is mijn onderzoeksavontuur begonnen. In Australië hebben we de tijd van ons leven gehad. Al gauw in goed gezelschap van Arno. In het lab van Belinda liggen onze onderzoekswortels, in O'Malleys die van onze vriendschap. Bedankt voor je steun op beide fronten. Ik weet zeker dat we samen ooit oud en grijs achter de geraniums belanden. Ik ben er trots dat je 10 november als paranimf achter me staat. De cirkel is rond.

It's a beautiful day. 




\section{Curriculum Vitae}

Katinka van Dongen was born on April 3, 1972 in Rotterdam, The Netherlands. After graduating high school (VWO) at the Jacob Roelandslyceum in Boxtel in 1990, she began studying at Fontys Hogeschool Verpleegkunde in Eindhoven. In 1994 she obtained her bachelor degree in nursing (cum laude). Shortly hereafter, she enrolled as a student at Maastricht University to study Health Sciences with the specialisation Nursing Science. She also followed several additional epidemiological courses. Her masters' research project was completed with the Paediatric Research Group at Sydney Children's Hospital, Randwick, Australia. Together with Nanda Herrijgers - Brouwer she investigated factors that influence the pain intensity and pain unpleasantness dimension of the needle pain experience in children. In 1997 she obtained her Master's Degree in Health Sciences and hereafter worked as a community health nurse. In 1998 she was employed as a PhD student at the department of Nursing Science and started the studies described in this dissertation. In 2002 she got married to Paul van Hastenberg. She started to work for Fontys Hogeschool Verpleegkunde in Eindhoven in 2003. Currently she still works there as a teacher and is involved in various research projects. 